\title{
MONZOGRANITO DE LA CORCOVA
}

\Cordillera Oriental Departamento de Santander

Gabriel Rodríguez, Ana María Correa Martínez, Gilberto Zapata y María Isabel Arango

Catálogo de las unidades litoestratigráficas de Colombia / Triásico-Jurásico

Citación: Rodríguez, G., Correa Martínez, A. M., Zapata, G. y Arango, M. I. (2020). Monzogranito de La Corcova. En Catálogos de las unidades litoestratigráficas de Colombia: Macizo de Santander. Vol. 1. Servicio Geológico Colombiano. https://doi.org/10.32685/9789585279445.4 
La actividad magmática triásico-jurásica está evidenciada por el emplazamiento de cuerpos intrusivos graníticos, hipoabisales y vulcanismo riolítico-riodacítico en el basamento metamórfico del Macizo de Santander.

Los cuerpos intrusivos alargados se presentan orientados en dirección preferencial norte-noroeste, los cuales concuerdan con el rumbo de las fallas regionales que delimitan las diferentes unidades del macizo, principalmente la falla de Bucaramanga.

Uno de estos cuerpos, producto del magmatismo de arco continental triásico-jurásico, corresponde al Monzogranito de La Corcova. En el presente catálogo, como aporte al desarrollo del conocimiento geológico del país, se incluyen análisis petrográficos, químicos y edades radiométricas U-Pb de este plutón.

\section{Origen del nombre, distribución geográfica y reseña histórica}

La denominación Monzogranito de La Corcova atiende a su composición modal predominante y a su localización geográfica cerca del corregimiento de La Corcova (Santander), sobre la vía Bucaramanga-Pamplona.

\subsection{Distribución geográfica}

El Monzogranito de La Corcova aflora en las vecindades de la localidad de La Corcova, sobre la carretera Bucaramanga-Pamplona. Es un plutón de forma tabular alargada en sentido $\mathrm{N}-\mathrm{S}$, con una extensión en el eje mayor de aproximadamente $15 \mathrm{~km}$ y un ancho variable promedio de $3 \mathrm{~km}$, con un área aproximada de 103,4 km². La localización de sus afloramientos se puede observar en las planchas geológicas 109 Río Negro (Ward et al., 1977a), 110 Pamplona (Ward et al., 1970), 120 Bucaramanga (Ward et al., 1977b) y 121 Cerrito (Ward et al., 1977c) (figura 1).

\subsection{Reseña histórica}

Goldsmith et al., (1971) propusieron el término cuarzomonzonita de La Corcova en el trabajo sobre dataciones radiométricas del Macizo de Santander, sin hacer una descripción litológica de la unidad. Posteriormente Ward et al., (1973) describen las rocas de la Cuarzomonzonita de La Corcova, que afloran en las vecindades de la localidad de La Corcova, sobre la carretera Bucaramanga-Pamplona. Dichos autores correlacionaron algunos cuerpos con el Monzogranito de La Corcova, tales como los que afloran al noreste del plutón principal en los cuadrángulos H-12 y H-13, plutones pequeños en el Neis de Bucaramanga al este de Chitagá y cuerpos intrusivos cerca de Vetas y Morro Nevado (cuadrángulo H-13). En la Plancha 136 Málaga rocas de esta unidad, probablemente, aparecen cartografiadas como cuarzomonzonita de Santa Bárbara. Dada la falta de certeza geológica de que correspondan a un mismo pulso magmático, en el presente estudio no se incluyen estas rocas como parte del Monzogranito de La Corcova. 


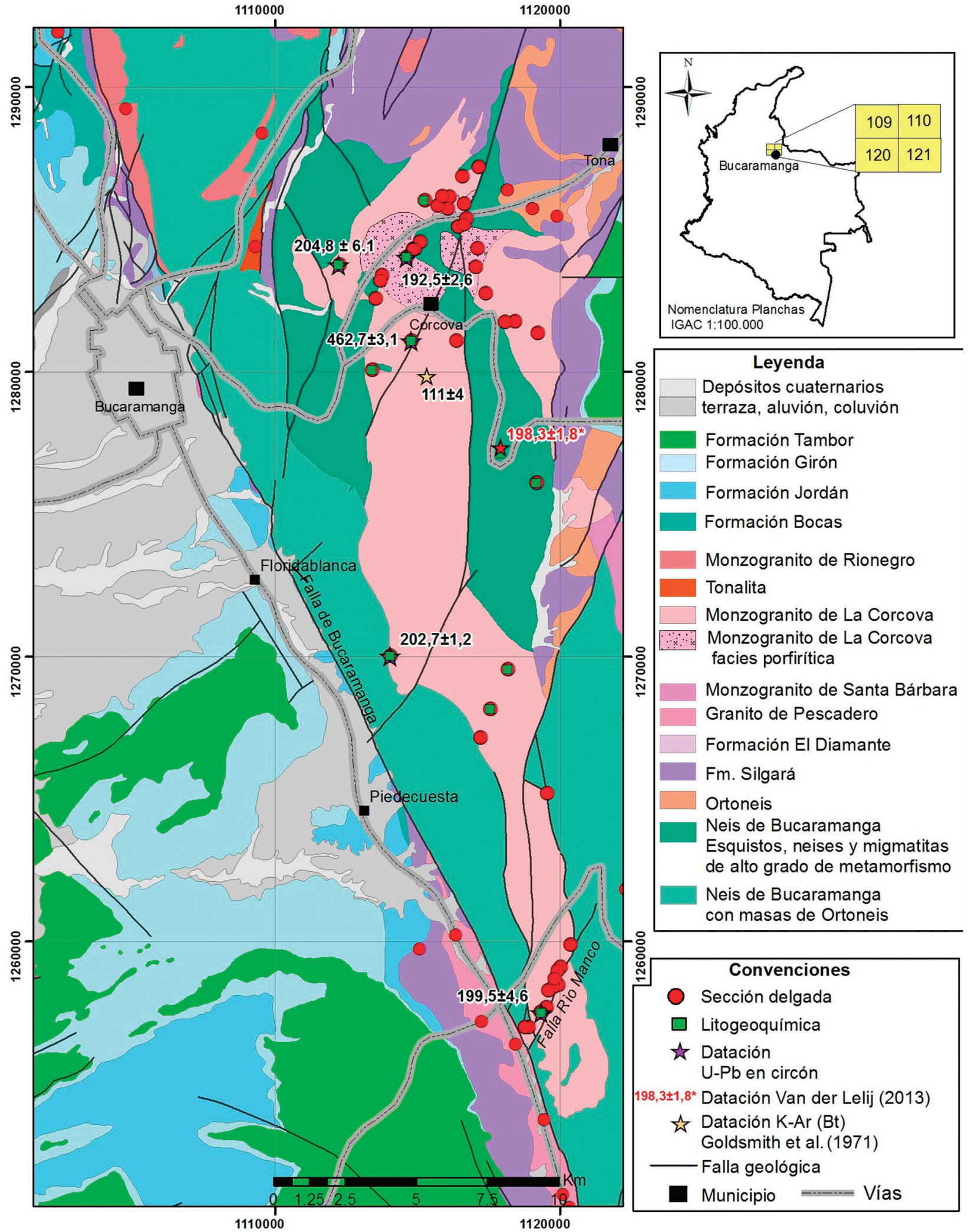

Figura 1. Localización del Monzogranito de La Corcova y distribución del muestreo

Fuente: Ward et al. (1970, 1977 a, b, c) y este trabajo 


\section{Descripción geológica}

\subsection{Marco geológico}

El Macizo de Santander es parte de un bloque de forma triangular limitado por las fallas de Santa Marta-Bucaramanga en el lado occidental, la falla de Oca-Ancón en el lado norte y la falla de Boconó en el lado oriental.

Las rocas más antiguas del Macizo de Santander comprenden unidades metamorficas como el Neis de Bucaramanga (Ward et al., 1973), denominado también Complejo Bucaramanga (Clavijo, 1994). El Neis de Bucaramanga está constituido por paragneises migmatíticos de edad Proterozoico (Goldsmith et al., 1971; Restrepo Pace et al., 1997; García y Ríos, 1999; Cordani et al., 2005; Ordóñez et al., 2006) a los cuales se les ha determinado un pico de metamorfismo de edad $1057 \pm 28$ Ma mediante el método U/Pb-SHRIMP en circón, relacionándolos con la orogenia Grenvilliana (Ordóñez et al., 2006).

Las edades de las unidades cartografiadas como Neis de Bucaramanga y Ortoneis, publicadas por Van der Lelij et al., (2016), y las obtenidas en el presente estudio por el método U/Pb-ICP-MS en circones, indican que el metamorfismo y la cristalización de estas dos unidades ocurrieron en el Ordovícico.

El Neis de Bucaramanga está cubierto por la formación Silgará, constituida por esquistos, filitas, metalodolitas, metaareniscas y escasos mármoles, rocas que hacen parte del basamento del Macizo de Santander (Ward et al., 1973; García y Ríos, 1999; Ríos et al., 2003; Mantilla et al., 2013; Mantilla et al., 2016). La formación Silgará presenta edades de metamorfismo del Ordovícico relacionadas con la orogenia caledoniana (Ríos et al., 2003; Ordóñez Cardona et al., 2006; Clavijo et al., 2008; Mantilla et al., 2013).

Datos geocronológicos obtenidos en este proyecto muestran magmatismo posterior y anterior al metamorfismo, representado por metavulcanitas y plutones que intruyen el basamento metamórfico, con edades $\mathrm{U} / \mathrm{Pb}$ en circón del Silúrico, Devónico Inferior, Carbonífero y limite Triásico-Jurásico.

Se considera que los plutones triásico-jurásicos del Macizo de Santander fueron emplazados en rocas metamorfas del terreno Chibcha, en el sentido de Restrepo y Toussaint (1988) y Restrepo et al., (2011), o del Terreno Santander de Etayo et al. (1983). Estos plutones están emplazados en rocas metamorficas Ordovícicas relacionadas con la orogenia famatiniana, y probablemente no tienen relación con el arco continental más joven, del Jurásico temprano a Medio, del valle superior del Magdalena, la serranía de San Lucas y la Sierra Nevada de Santa Marta, emplazado en el basamento metamórfico grenvilliano, del cual no se han reportado rocas metamorficas relacionadas con la orogenia famatiniana.

Durante el límite Triásico-Jurásico se desarrolló un importante magmatismo de arco continental, con el emplazamiento de grandes batolitos, stocks graníticos y cuerpos riolíticos subvolcánicos localizados hacía la margen occidental del Macizo de Santander, dentro del basamento metamórfico paleozoico.

Unidades sedimentarias cretácicas reposan discordantes sobre el basamento metamórfico y sobre los plutones. Con posterioridad a la sedimentación cretácica tuvo lugar un escaso magmatismo, durante el Mioceno, que emplazó pequeños cuerpos de pórfidos con mineralizaciones de oro (Leal, 201 1; Mantilla et al., 2013).

\subsection{Características macroscópicas de las rocas} del Monzogranito de La Corcova

Ward et al. (1973) afirman que el Monzogranito de La Corcova presenta una facies típica en la mayor parte del cuerpo intrusivo de composición granítica, una segunda facies porfirítica bien expuesta al oeste de La Corcova y en la carretera que conduce a Tona (cuadrángulo H-12), cerca del río del mismo nombre. Adicionalmente, reconocen facies menores ricas en biotita de grano fino con algo de hornblenda, expuestas localmente en la carretera Bucaramanga-Pamplona, al este de La Corcova, en la carretera de Los Curos a Guaca y al este del río Manco.

Diques y pequeños cuerpos de composición cuarzomonzonita, se encuentran intruyendo el Monzogranito de La Corcova, siendo más abundantes al norte del plutón, al este de Bucaramanga.

Las rocas del Monzogranito de La Corcova son de color blanco moteadas de negro a gris, cuando están frescas. Sus productos de alteración son de color amarillo claro moteados de gris y negro.

Dichas rocas son faneríticas de grano fino a medio, principalmente equigranulares, con textura sacaroide, $\mathrm{y}$ presentan biotita uniformemente diseminada (figura 2). Localmente presentan una débil estructura fluidal por orientación de todos los minerales, y tiende a meteorizar esferoidalmente.

La facies porfirítica contiene fenocristales rosados de feldespato alcalino en una matriz de grano fino a medio 
granular sacaroidea, aunque de grano ligeramente más fino que el monzogranito normal de La Corcova (figura 2). La facies rica en biotita también exhibe textura sacaroide de grano fino. Localmente, las rocas se tornan ligeramente porfiríticas, con fenocristales de plagioclasa blanca. Hacia los bordes del plutón se presentan facies más básicas, de cuarzodioritas a cuarzomonzonitas, equigranulares, de grano fino, de color blanco moteadas de negro, compuestas por cristales de plagioclasa subhedrales, y en menor proporción, cristales de cuarzo con contenidos mayores de biotita y hornblenda (figura 2).
El Monzogranito de La Corcova intruye al Neis de Bucaramanga, presenta xenolitos y techos colgantes de neises (figura 3), e igualmente intruye rocas de la formación Silgará en el sector norte del cuerpo. La "cuarzomonzonita” rosada de la facies porfirítica del Monzogranito de La Corcova corta la "cuarzomonzonita" gris típica (Ward et al., 1973). Localmente se presentan diques aplíticos de monzogranitos, riolitas porfídicas y venas de cuarzo.
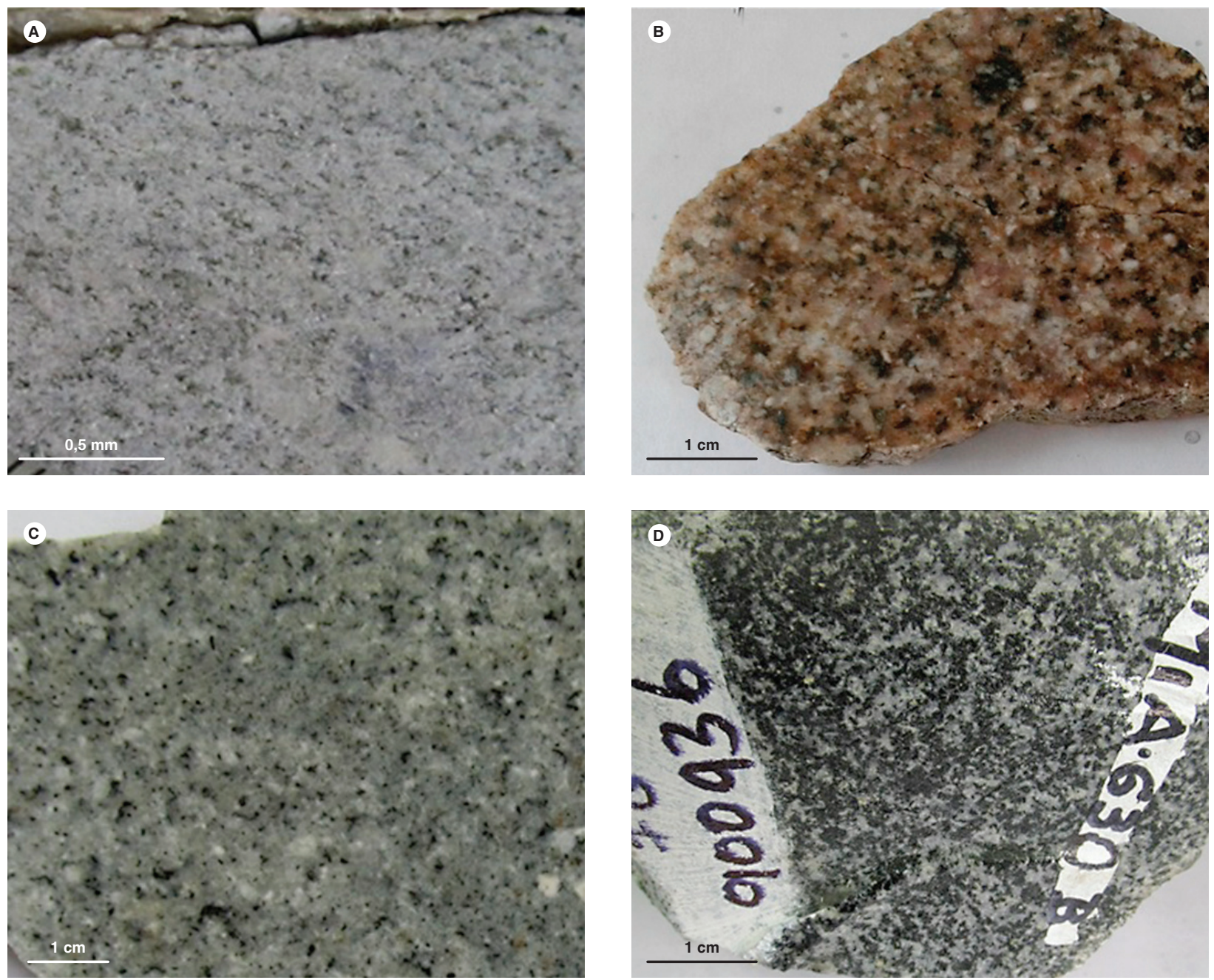

Figura 2. Aspecto macroscópico del Monzogranito de La Corcova. A) Muestra AMC-0129, monzogranito. B) Muestra LMC-078, ligeramente alterada. Facies porfídica. C) Muestra AMC-0131. D) Muestra MIA-630B, cuarzodiorita de borde 

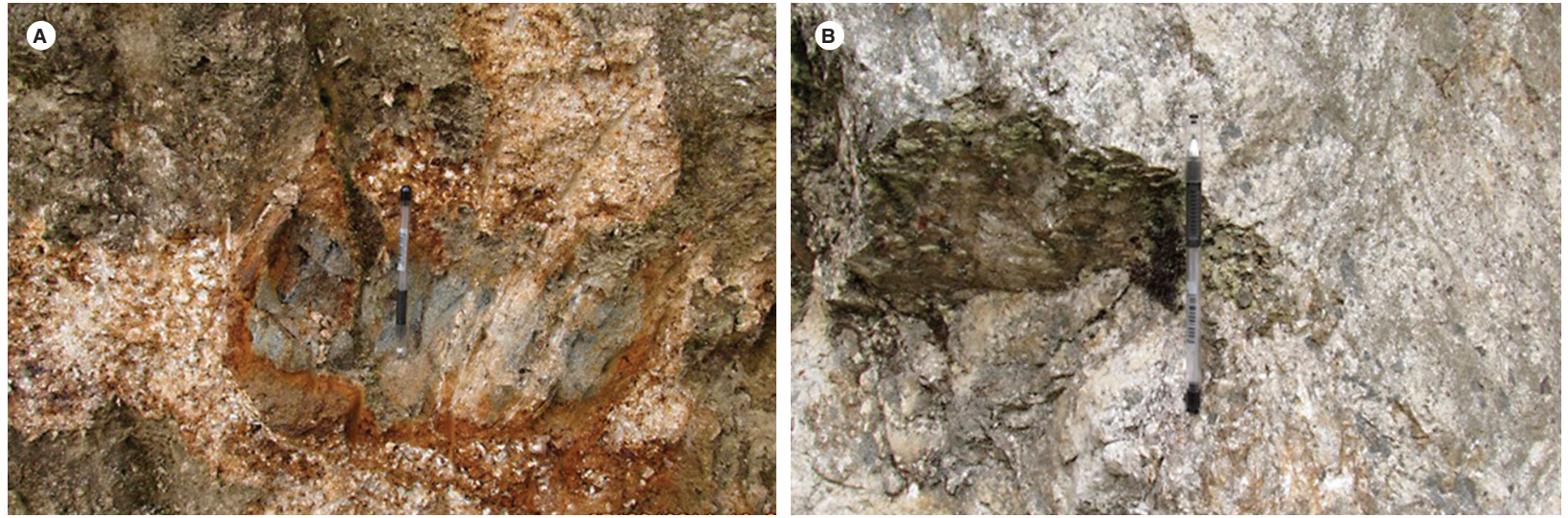

Figura 3. Xenolitos de la Formación Silgará dentro del Monzogranito de La Corcova, Estación GR-6721. Coordenadas: N: 1119073 , W: 1276559

\subsection{Características microscópicas de las rocas del Monzogranito de La Corcova}

Se analizaron 39 secciones delgadas del Monzogranito de La Corcova, dos muestras de diques que se clasificaron como riolita porfídica y microsienogranito, y trece secciones de rocas metamorficas presentes como xenolitos, techos colgantes y rocas de caja, once de las cuales se clasificaron como granofelsas y neises cuarzo-feldespáticos, una como esquisto de cuarzo, biotita y sillimanita, y otra como anfibolita.

En el presente trabajo se conserva la nomenclatura de facies propuesta por Ward et al. (1973), quienes separan tres tipos de "cuarzomonzonitas" del Monzogranito de La Corcova: la típica, la porfirítica y la rica en biotita (tabla 1).
El plutón está constituido principalmente por monzogranitos que pueden variar localmente a sienogranitos y granodioritas, y hacia los bordes del cuerpo intrusivo, a cuarzodioritas, cuarzomonzonitas y tonalitas (figura 4, tabla 1). En general, las rocas son faneríticas de grano fino a medio, de color blanco a gris moteado de negro, equi e inequigranulares, localmente bimodales y ligeramente porfídicas. Están constituidas por cristales de feldespato alcalino de color blanco, cuarzo blanco translúcido y plagioclasa blanca lechosa. Como minerales máficos se presentan biotita y, en menor proporción, hornblenda; como accesorios menores se reconocieron apatito, circón, opacos y, en algunas rocas, allanita y titanita.
1 Sienita de feldespato alcalino 2 Monzodiorita monzogabro 3 Diorita, gabro

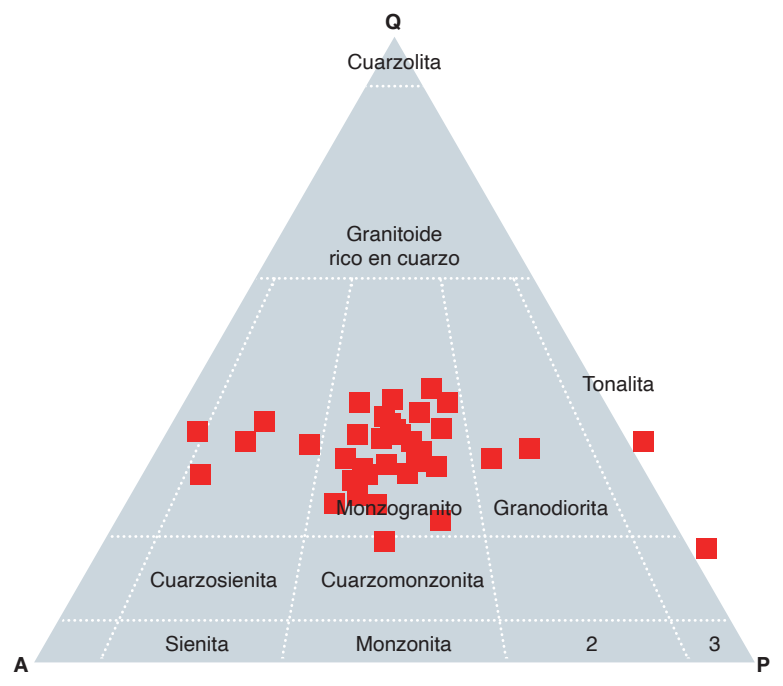

Figura 4. Clasificación modal de rocas del Monzogranito de La Corcova Fuente: Streckeisen (1974) y este trabajo 
Tabla 1. Composición modal de rocas del Monzogranito de La Corcova

\begin{tabular}{|c|c|c|c|c|c|c|c|c|c|c|c|c|c|c|c|c|}
\hline IGM & N. campo & $\mathbf{x}$ & $\mathbf{Y}$ & Qtz & PI & Fsp & $\mathrm{Hbl}$ & $\mathrm{Bt}$ & Ms & Op & Ap & Zrn & Ttn & Ep & Otros & Clasificación petrográfica \\
\hline \multicolumn{17}{|c|}{ Facies típica } \\
\hline 74895 & HM 1568 & 1123200 & 1298360 & 36 & 6 & 58 & & $x$ & & & & $\mathrm{x}$ & & & & Granito de feldespato alk. \\
\hline 74627 & $\mathrm{HM}-1443$ & 1137080 & 1305320 & 28 & 43 & 13 & & 7,5 & 7,5 & $\mathrm{x}$ & $\mathrm{x}$ & $\mathrm{x}$ & & $\operatorname{Tr}$ & 1 & Granodiorita \\
\hline $37971-1$ & GIR-1345 & 1117220 & 1267140 & 25 & 45 & 21 & & 4 & & $\operatorname{Tr}$ & & & $\operatorname{Tr}$ & 5 & & Milonita (granodiorita) \\
\hline 37175 & GIR-213 & 1118900 & 1256980 & 28 & 28 & 37 & & 5,7 & & $\operatorname{Tr}$ & $\operatorname{Tr}$ & & $\operatorname{Tr}$ & & 1,5 & Protomilonita (monzogranito) \\
\hline 37982 & GIR-1382 & 1118780 & 1256980 & 36 & 31 & 31 & & & 1 & & $\operatorname{Tr}$ & $\operatorname{Tr}$ & & 1,5 & & Protomilonita (monzogranito) \\
\hline 37425 & GIR-696B & 1115880 & 1286160 & 26 & 33 & 25 & & 16 & & $\mathrm{x}$ & & $x$ & & $\operatorname{Tr}$ & & Monzogranito \\
\hline 37429 & GIR-712 & 1116580 & 1286860 & 33 & 26 & 35 & & 5 & & 1 & $x$ & $\mathrm{x}$ & & $\operatorname{Tr}$ & & Monzogranito \\
\hline 11036 & FM 91 & 1113760 & 1283380 & 37 & 28 & 31 & & 2 & 1 & & & & & 1 & & Monzogranito \\
\hline 11284 & FM 178 & 1116430 & 1285080 & 24 & 34 & 39 & & 2,1 & $\operatorname{Tr}$ & 1,1 & & $\operatorname{Tr}$ & & & & Monzogranito \\
\hline 11287 & FM 161 & 1115720 & 1285830 & 28 & 30 & 38 & & 3 & & 1 & & $\operatorname{Tr}$ & & $\operatorname{Tr}$ & & Monzogranito \\
\hline 11490 & FM 407 & 1119220 & 1281350 & 34 & 32 & 30 & & 3,5 & $\mathrm{x}$ & 0,5 & & $\operatorname{Tr}$ & & $\mathrm{Tr}$ & & Monzogranito \\
\hline 11492 & FM 409 & 1118420 & 1281760 & 30 & 28 & 39 & & 3 & $?$ & 0,5 & $\operatorname{Tr}$ & $\operatorname{Tr}$ & & $\operatorname{Tr}$ & & Monzogranito \\
\hline 11493 & FM 410 & 1118080 & 1281750 & 37 & 24 & 32 & & 5 & $\mathrm{Tr}$ & $\operatorname{Tr}$ & $\mathrm{Tr}$ & $\operatorname{Tr}$ & & 2 & & Monzogranito \\
\hline 11533 & FM 383 & 1114910 & 1284310 & 36 & 31 & 26 & & 5 & 1,5 & $\operatorname{Tr}$ & & $\operatorname{Tr}$ & & 0,5 & & Monzogranito \\
\hline 37427 & GIR-705 & 1113530 & 1282560 & 20 & 41 & 30 & & 8 & & 1 & TR & TR & & $\operatorname{Tr}$ & $\mathrm{Ru}, \mathrm{All}$ & Monzogranito \\
\hline 37999 & GIR-1406B & 1119550 & 1265200 & 33 & 28 & 32 & & 6 & & 0,3 & $\operatorname{Tr}$ & 0,4 & & 0,3 & & Monzogranito \\
\hline 900862 & AMC-0129 & 1113420 & 1280055 & 38 & 28 & 29 & & 4,5 & 1,5 & 0,5 & $\mathrm{Tr}$ & $\mathrm{Tr}$ & & $\mathrm{Tr}$ & & Monzogranito \\
\hline 900929 & LMC-077 & 1112260 & 1283759 & 32 & 29 & 28 & & 8 & 2 & 1 & $\operatorname{Tr}$ & $\operatorname{Tr}$ & & $\operatorname{Tr}$ & & Monzogranito \\
\hline 900930 & LMC-078 & 1115257 & 1286012 & 29 & 34 & 30 & & 6 & $\mathrm{Tr}$ & 1 & $\operatorname{Tr}$ & $\operatorname{Tr}$ & & $\operatorname{Tr}$ & & Monzogranito \\
\hline 900921 & LMC-065 & 1119186 & 1276101 & 30 & 36 & 33 & & 1 & & $\operatorname{Tr}$ & & $\operatorname{Tr}$ & & $\operatorname{Tr}$ & & Monzogranito \\
\hline 900931 & MIA-627A & 1119356 & 1257497 & 34 & 26 & 30 & & 1,1 & 6,7 & 0,7 & 1 & TR & 0,5 & TR & & Protomilonita \\
\hline 37997 & GIR-1401 & 1119530 & 1257680 & 31 & 25 & 18 & & 3 & 10 & $\operatorname{Tr}$ & & & & 3 & 13 & Protomilonita (monzogranito) \\
\hline 37989 & GIR-1393 & 1120380 & 1259880 & 27 & 9,3 & 57 & & 2,3 & 2,3 & & & & & 0,2 & 1,6 & Sienogranito \\
\hline 900861 & AMC-0128A & 1114798 & 1281084 & 33 & 21 & 43 & & 3,3 & & 0,5 & $\operatorname{Tr}$ & $\operatorname{Tr}$ & & $\operatorname{Tr}$ & & Sienogranito \\
\hline 900909 & JGB-460A & 1117564 & 1268142 & 33 & 13 & 51 & TR & 2 & TR & TR & TR & & & 1 & & Sienogranito \\
\hline 10935 & $\mathrm{HCH}-47$ & 1119790 & 1258400 & 33 & 28 & 29 & & $\operatorname{Tr}$ & 7 & $\operatorname{Tr}$ & & & & 3 & & Protomilonita \\
\hline \multicolumn{17}{|c|}{ Facies porfídica } \\
\hline 37421 & GIR-691B & 1116730 & 1285370 & 31 & 46 & 21 & & 2 & & $x$ & $\mathrm{x}$ & $x$ & & $\operatorname{Tr}$ & & Granodiorita \\
\hline 37746 & GIR-702 & 1113700 & 1283200 & 27 & 29 & 39 & & $\operatorname{Tr}$ & & 2,6 & 2 & & & 0,4 & & Monzogranito \\
\hline 37424 & GIR-694B & 1116650 & 1285170 & 24 & 29 & 44 & & 3 & & $\mathrm{x}$ & $\mathrm{x}$ & $x$ & & $\operatorname{Tr}$ & & Monzogranito \\
\hline 37426 & GIR-698 & 1114850 & 1284280 & 30 & 34 & 28 & & 7 & $x$ & $x$ & $\mathrm{x}$ & $x$ & & $\operatorname{Tr}$ & 1 & Monzogranito \\
\hline 11008 & $\mathrm{HCH} 120$ & 1114860 & 1284300 & 33 & 34 & 23 & & 8 & & 1,5 & $\operatorname{Tr}$ & $\operatorname{Tr}$ & 0,5 & $\operatorname{Tr}$ & & Monzogranito \\
\hline 11038 & FM 93B & 1114911 & 1284311 & 28 & 30 & 31 & & 9 & & 1,3 & $\operatorname{Tr}$ & $\operatorname{Tr}$ & 0,7 & $\operatorname{Tr}$ & & Monzogranito \\
\hline 11039 & FM 94 & 1115100 & 1284560 & 35 & 32 & 20 & & 9 & 1 & 3 & $\operatorname{Tr}$ & $\operatorname{Tr}$ & & $\operatorname{Tr}$ & & Monzogranito \\
\hline 11283 & FM 177A & 1116635 & 1285880 & 24 & 30 & 39 & & 7 & $\mathrm{x}$ & 0,5 & $\operatorname{Tr}$ & & & $\operatorname{Tr}$ & & Monzogranito \\
\hline 11245 & FM 140A & 1117060 & 1283670 & 33 & 35 & 30 & & 2,5 & & $\operatorname{Tr}$ & $\operatorname{Tr}$ & Tr? & & & & Monzogranito \\
\hline 900863 & AMC-0131 & 1114638 & 1284010 & 34 & 13 & 45 & & 7 & 0,5 & 0,8 & $\operatorname{Tr}$ & 0,2 & & $\operatorname{Tr}$ & & Sienogranito \\
\hline \multicolumn{17}{|c|}{ Facies intermedia de borde } \\
\hline 900936 & MIA-630B & 1114060 & 1270011 & 9,5 & 44 & & 26 & 17 & & 1,2 & 0,8 & 1,1 & 1 & $\operatorname{Tr}$ & $\operatorname{Tr}$ & Cuarzodiorita \\
\hline 11229 & FM 125 & 1117151 & 1287191 & 18 & 38 & 41 & & 0,5 & $x$ & $\operatorname{Tr}$ & $\operatorname{Tr}$ & $\operatorname{Tr}$ & & & 2 & Cuarzomonzonita \\
\hline 37992 & GIR-1395 & 1120020 & 1259100 & 14 & 26 & & 29 & 15 & & 2,5 & $\mathrm{Tr}$ & & 1 & 9 & 4,5 & Tonalita \\
\hline
\end{tabular}

Las rocas de la facies típica del Monzogranito de La Corcova están compuestas por cuarzo (24 a 37\%), plagioclasa (entre 6 y $45 \%$ ) con contenidos predominantes entre 24 y $34 \%$; feldespato alcalino, principalmente microclina, que varía entre 13 y $58 \%$, y con porcentajes por lo regular de 30 a $45 \%$; la biotita varía de trazas a un $16 \%$, pero generalmente es menor del $3 \%$, y moscovita aparece en trazas hasta 7\%. Los accesorios son apatito, opacos y circón; rara vez allanita y titanita. Los minerales de alteración son clorita, epidota y sericita.

La plagioclasa es de tipo oligoclasa a andesina $\left(\mathrm{An}_{27}\right.$ $\mathrm{a} \mathrm{An}_{30}$ ), y se presenta en cristales anhedrales a subhedrales, de formas irregulares a tabulares cortos, incoloros, con tamaños que varían entre 0,5 y $1,5 \mathrm{~mm}$, y tienen maclas de tipo albita, albita-Carlsbad y Carlsbad. En algunas rocas los cristales presentan desmezclas con microclina 
en forma de parches, para conformar una textura antipertítica. Pueden aparecer texturas mirmequíticas en el contacto con el feldespato alcalino. La plagioclasa generalmente está alterada a saussurita y sericita en agregados microcristalinos, y presenta inclusiones de cuarzo y circón (figura 5).

El feldespato alcalino es ortosa pasando a microclina. Se encuentra en cristales anhedrales de forma irregular, incoloros, cuyo tamaño oscila entre 0,5 y 1,5 mm; en algunas rocas inequigranulares bimodales, hasta de $2 \mathrm{~mm}$, generalmente con macla de periclina y albita en enrejado. Esta última se presenta en algunos sectores del cristal o en su totalidad; la birrefringencia es gris clara de primer orden. Se observa textura pertítica por desmezcla de plagioclasa en forma de "flamas"; puede ser poiquilítica con inclusiones de cuarzo redondeado, plagioclasa, biotita y moscovita en menor proporción. Algunas rocas presentan textura micrográfica con desarrollo de cuarzo en forma cuneiforme dentro de los feldespatos.

Los cristales de cuarzo son anhedrales con bordes irregulares, incoloros, con caminillos de polvo. Su tamaño oscila entre 0,7 y 1,5 mm. En ellos se advierte birrefringencia débil de primer orden y extinción ondulatoria. Presentan inclusiones de plagioclasa, circón y opacos.
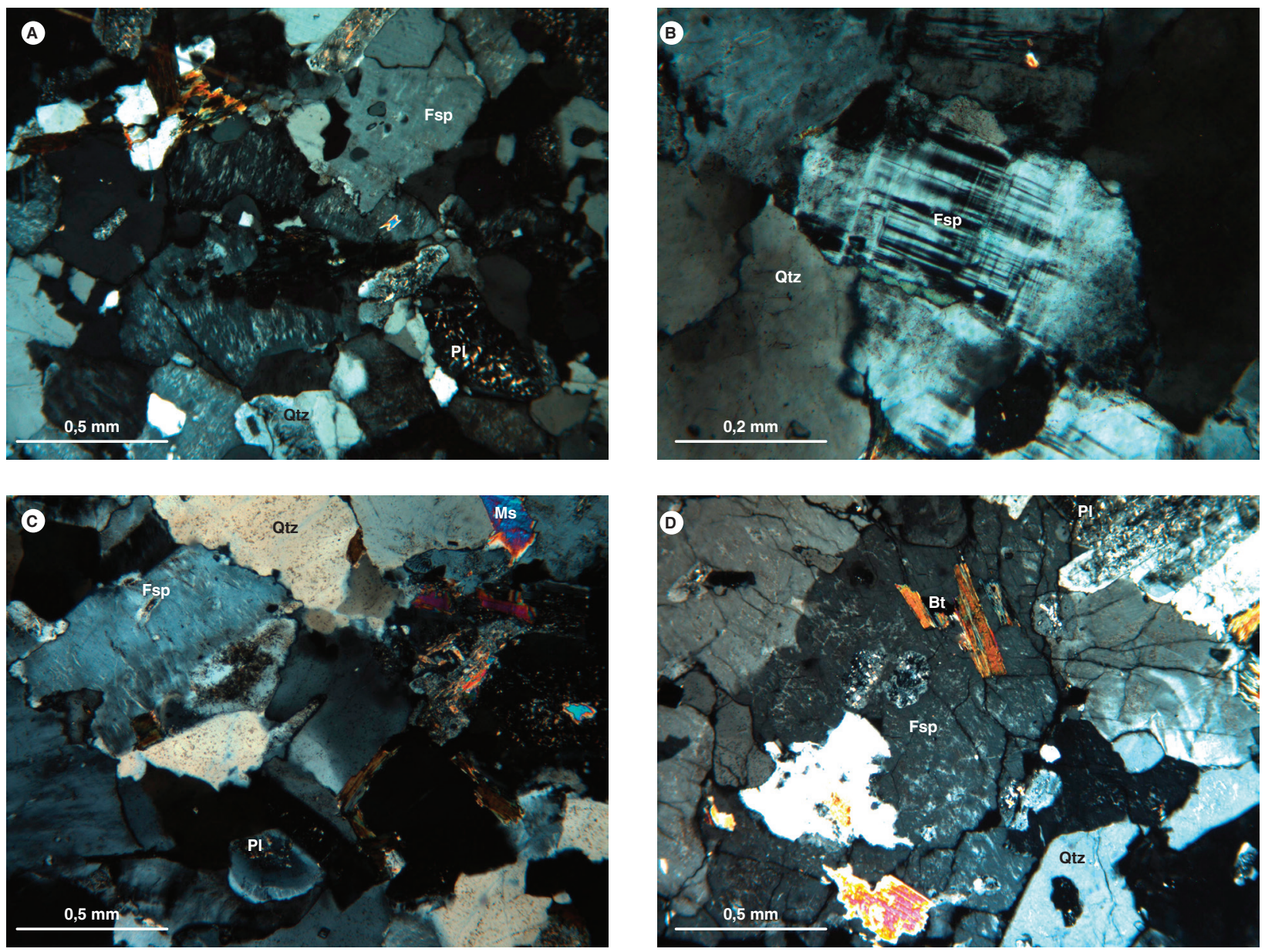

Figura 5. Aspecto microscópico de rocas monzograníticas del Monzogranito de La Corcova. XPL. A) IMN-11490, cristales de feldespato potásico (Fsp) con micropertitas, con inclusiones de cuarzo (Qtz). B) IGM-900862, feldespato potásico (microclina) (Fsp) y cuarzo (Qtz). C) IGM- 900929, cuarzo (Qtz), plagioclasa ( $\mathrm{PI}$ ) y feldespato ( $\mathrm{Fsp}$ ) con textura pertítica y moscovita (Ms) como mineral accesorio. D) IMN-11492, feldespato potásico poiquilítico (Fsp) con inclusiones de plagioclasa (PI), biotita (Bt) y moscovita (Ms) 
La biotita es escasa en la mayoría de las rocas. Se presenta en láminas subhedrales a euhedrales, de habito tabular, con pleocroísmo de marrón oscuro a claro, y su tamaño promedio es de $0,5 \mathrm{~mm}$. Algunos cristales presentan alteración a clorita (parcial o total) con birrefringencia anómala azul Berlín. Puede aparecer epidota secundaria en agregados.

Algunas rocas presentan moscovita en láminas tabulares subhedrales, de tamaño $<0,3 \mathrm{~mm}$, con birrefringencia fuerte de segundo orden (fucsia-verde encendido), y extinción en ojo de pájaro. Generalmente aparecen como inclusiones en feldespato alcalino o intersticial, entre los minerales principales.

Los minerales opacos pueden presentarse como cristales subhedrales a anhedrales, diseminados en la roca. Localmente, los opacos muestran epidota-clinozoisita en sus bordes, y son menores de $0,2 \mathrm{~mm}$.

Se presentan cristales prismáticos finos (entre 0,05 y $0,15 \mathrm{~mm}$ ) de circón, generalmente junto a $-\mathrm{o}$ como inclusiones dentro de - la biotita, algunos formando halos pleocroicos.

Rocas de la facies porfirítica. Exhiben una textura semejante a la de la facies normal, si bien varía de inequigranular bimodal seriada a equigranular. Corresponden principalmente a monzogranitos y, en menor proporción, a sienogranitos y granodioritas. El feldespato alcalino generalmente es de mayor tamaño que los otros minerales. Poiquilítico, puede tener desmezclas pertíticas y, en algunos cristales, zonación concéntrica; corresponde a ortosa, y en algunas muestras pasa a microclina. La plagioclasa es ligeramente más abundante que la microclina, de composición $\mathrm{An}_{29}$ a $\mathrm{An}_{31}$, y puede desarrollar intercrecimientos mirmequíticos. El cuarzo se presenta como cristales anhedrales y como inclusiones irregulares en feldespatos. Los contenidos de feldespato alcalino varían entre 20 y $41 \%$; el cuarzo, entre 24 y $35 \%$; la plagioclasa, entre 13 y $46 \%$; la biotita, en proporciones menores del 9\%; la moscovita está presente en trazas.
Los minerales accesorios son circón, apatito y opacos; esporádicamente se reconocieron allanita y titanita (figura 6).

Facies de borde. Está representada por rocas de composición cuarzodiorita-cuarzomonzonita (con feldespato alcalino entre 35 y $65 \%$ ), tonalita (con más del $20 \%$ de cuarzo), con textura granular a inequigranular, con mayores contenidos de minerales máficos, como biotita, que puede llegar hasta un $17 \%$, y por hornblenda, que puede alcanzar el $27 \%$. La moscovita está ausente. Como minerales accesorios se encuentran opacos, apatito, circón, allanita y titanita (figura 6).

El cuarzo se encuentra en cristales xenomorfos incoloros de tamaños que varían entre 0,8 y $1,4 \mathrm{~mm}$. La plagioclasa corresponde a andesina y se presenta en cristales subidiomorfos tabulares incoloros con alteración principalmente en los núcleos a sericita, presentan inclusiones de apatito, opacos y biotita.

La hornblenda es de color verde, con pleocroísmo X: verde claro, Y: verde, y Z: verde oscuro, con inclusiones de biotita, apatito y opacos. Se encuentra junto a titanita y se altera moderadamente a epidota.

La biotita aparece en láminas de tamaños entre 0,6 y $0,8 \mathrm{~mm}$; es subidiomorfa, de color verde, que indica bajo contenido de $\mathrm{Ti} \mathrm{y} \mathrm{Fe}^{+3}$ y alto $\mathrm{Fe}^{+2}$. Es pleocroica de verde oscuro a verde pálido, con extinción moteada. Presenta inclusiones de apatito, opacos, titanita y circón (figura 7).

Los minerales accesorios son apatito en cristales euhedrales con cortes basales hexagonales y longitudinales prismáticos, de tamaños menores de $0,5 \mathrm{~mm}$; titanita en cristales xenomorfos de color pardo formando agregados con hornblenda y opacos; circones en cristales subidiomorfos prismáticos tetragonales, incoloros, de alto relieve, se encuentran como inclusiones en cuarzo y en los agregados de biotita y hornblenda, con tamaños entre 0,05 y $0,1 \mathrm{~mm}$; opacos xenomorfos, algunos de formas equidimensionales, también presentes como inclusiones en minerales máficos como hornblenda y biotita. La allanita aparece en cristales anhedrales de color rojizo fuerte, pleocroico, con extinción recta. Se encuentra junto a hornblenda, biotita y epidota. 

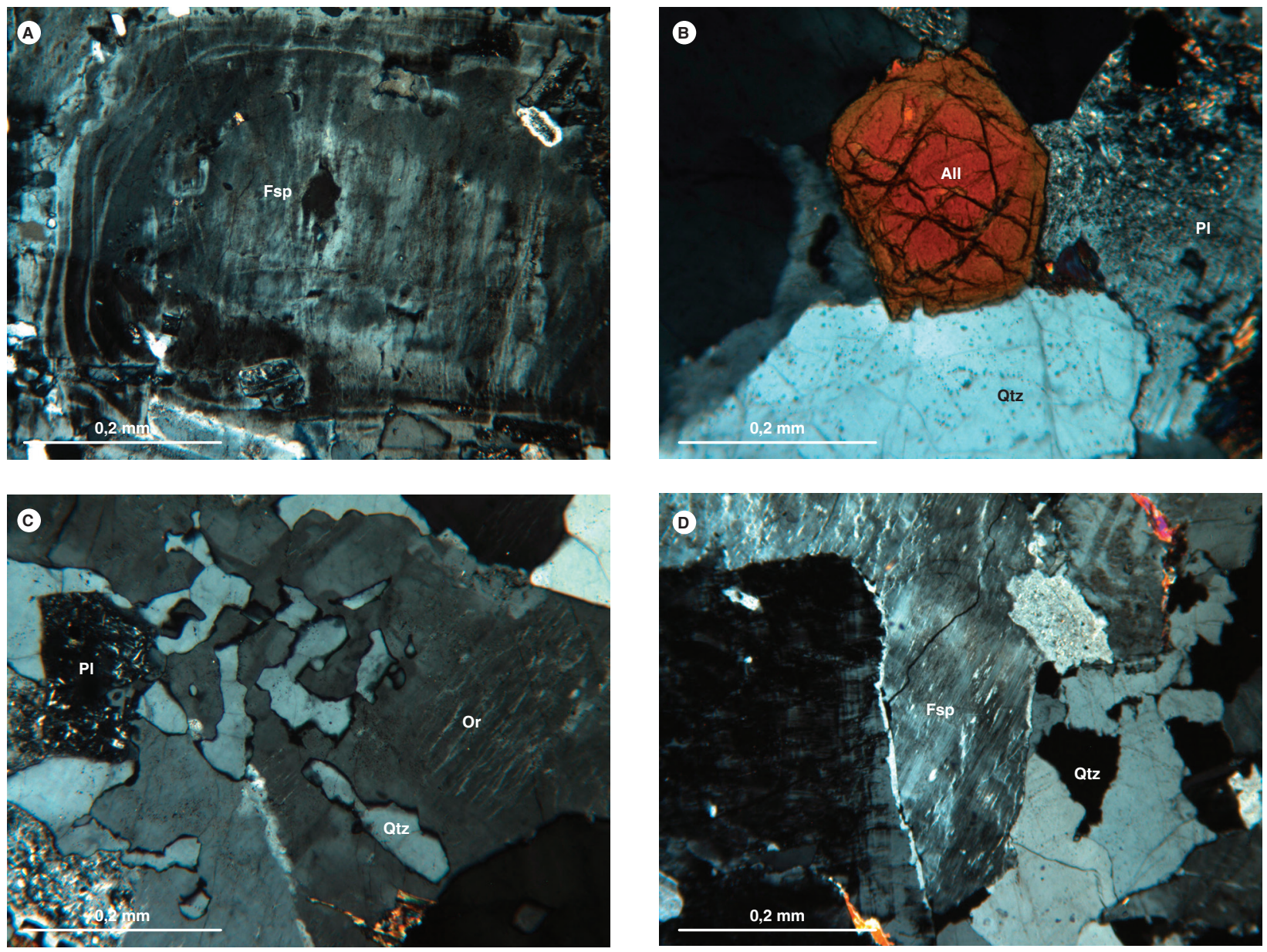

Figura 6. Aspecto microscópico de rocas de las facies porfirítica. A) IGM-900863, sienogranito. Textura inequigranular, feldespato potásico (Fsp) con zonación concéntrica, y pertitización. B) Monzogranito. IMN-11008, cristal de allanita (All) junto a plagioclasa (PI) y cuarzo (Qtz). C) Monzogranito IMN-11038. Textura micrográfica en un cristal de ortoclasa (Or) con textura pertítica; plagioclasa alterada a sericita (PI). D) Monzogranito IMN-11283. Feldespato potásico pertitizado (Fsp). Bordes de reacción entre cristales
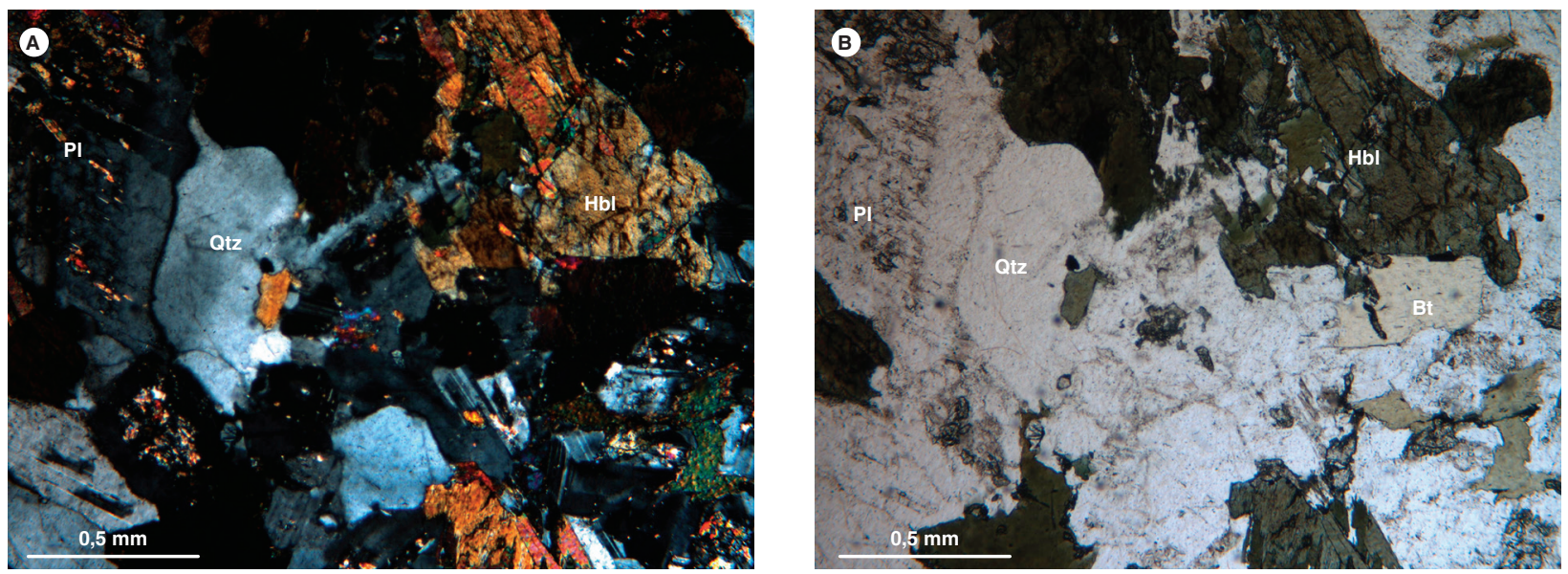

Figura 7. Aspecto microscópico de rocas de la facies de borde. IGM-900936, cuarzodiorita XPL y PPL. Aumento: 4X. La roca muestra una textura holocristalina subidiomorfa, y está compuesta por cuarzo $(\mathrm{Qtz})$, hornblenda $(\mathrm{Hbl})$, plagioclasa $(\mathrm{Pl})$ y láminas de biotita $(\mathrm{Bt})$ 
Xenolitos. Corresponden a bloques del Neis de Bucaramanga, y ocasionalmente a esquistos de la Formación Silgará embebidos en la roca granitoide del Monzogranito de La Corcova, o techos colgantes sobre este. Aparecen dispersos dentro del plutón o hacia los bordes de contacto, tanto en la margen occidental como en la oriental del cuerpo intrusivo.

Se analizaron trece secciones delgadas de dichas rocas metamorficas (tabla 2). Las rocas se clasificaron como granofelsas cuarzo-feldespáticas (ocho); neises de cuarzo, feldespato con moscovita y/o biotita-epidota (tres); esquistos de biotita, silimanita con cuarzo y cordierita (una), anfibolita (una) y un monzogranito. Las rocas metamorficas tienen textura granoblástica, son inequigranoblásticas, granolepidoblásticas y lepidoblásticas. Los neises y granofelsas presentan texturas de intercrecimientos simplectíticos de biotita y epidota, mirmequitas y desmezclas pertíticas.

Tabla 2. Muestras de xenolitos y cuerpos metamorfos incluidos en el Monzogranito de La Corcova

\begin{tabular}{|c|c|c|c|c|c|c|c|c|c|c|c|c|c|c|c|c|c|}
\hline IGM & N. campo & $\mathbf{x}$ & $\mathbf{Y}$ & Qtz & PI & Fsp & $\mathrm{Hbl}$ & $\mathrm{Bt}$ & Ms & Op & Ap & Zrn & Ttn & Ep/All & Sil & Crd & Clasificación petrográfica \\
\hline 37981 & GIR-1376A & 1119330 & 1257520 & 20 & 46 & 22 & & 9 & & 0,5 & 0,5 & $\operatorname{Tr}$ & & 2 & & & Neis de Qtz-Fsp con Bt y Ep \\
\hline 37981 & GIR-1376B & 1119330 & 1257520 & 43,8 & 21,6 & 26,6 & & 0,5 & 5,2 & $\operatorname{Tr}$ & & & & 2,3 & & & Neis de Qtz, Fsp con Ms y Bt \\
\hline 900932 & MIA-627B & 1119356 & 1257497 & 21,4 & 37,6 & & 35,4 & 4,2 & & 1,4 & $\operatorname{Tr}$ & $\operatorname{Tr}$ & $\operatorname{Tr}$ & $\operatorname{Tr}$ & & & Anfibolita \\
\hline 37428 & GIR-711 & 1117410 & 1282740 & 14 & 6 & & & 39 & 4 & $\operatorname{Tr}$ & $\operatorname{Tr}$ & $\operatorname{Tr}$ & & & 28 & 9 & Esquisto de Bt-Sill con Qtz y Crd \\
\hline 11503 & FM 443 & 1116370 & 1281090 & 28 & 38 & 17 & & 14 & 1,5 & $\operatorname{Tr}$ & & $\operatorname{Tr}$ & & & & & Granofels de Qtz, fsp y Bt \\
\hline 10934 & $\mathrm{HCH}-46$ & 1119940 & 1258450 & 42 & 22 & 23 & & 5 & 2 & $\operatorname{Tr}$ & & $\operatorname{Tr}$ & & 6 & & & Granofels de Qtz, fsp y Bt \\
\hline 37996 & GIR-1398 & 1119600 & 1258280 & 31 & 27 & 26 & & 8 & 1 & $\operatorname{Tr}$ & $\operatorname{Tr}$ & $\operatorname{Tr}$ & 3 & 4 & & & Granofels de Qtz, fsp y Bt \\
\hline 37993 & GIR-1396 & 1119930 & 1258960 & 36 & 20 & 26 & & 15 & & & $\operatorname{Tr}$ & $\operatorname{Tr}$ & $\operatorname{Tr}$ & 3 & & & Granofels de Qtz, fsp y Bt \\
\hline 37994 & GIR-1397A & 1119830 & 1258680 & 35 & 25 & 21 & & 6 & 4 & 1 & $\operatorname{Tr}$ & $\operatorname{Tr}$ & 1 & 7 & & & Granofels de Qtz-Fsp-Ep-Bt \\
\hline 37990 & GIR-1393B & 1120380 & 1259880 & 32 & 20 & 16 & & 7 & 11 & $\operatorname{Tr}$ & & $\operatorname{Tr}$ & $\operatorname{Tr}$ & 14 & & & Granofels de Qtz-Fsp-mica-Ep \\
\hline 900937 & MIA-631 & 1118186 & 1269536 & 26 & 34,3 & 17,2 & & 14,6 & TR & 0,5 & TR & 1,1 & 6,3 & TR & & & Granofels de $\mathrm{Pl}+\mathrm{Qtz}+\mathrm{Kfs}+\mathrm{Bt}$ \\
\hline 11255 & FM 147 & 1116130 & 1286140 & 41 & 12 & 34 & & 13 & & $\operatorname{Tr}$ & $\operatorname{Tr}$ & $\operatorname{Tr}$ & & & & & Granofelsa de Qtz-Fsp-PI-Bt \\
\hline 11228 & FM 124 & 1117150 & 1287190 & 30,3 & 30,3 & 36,1 & & 0,9 & 0,9 & & & & & & & 1,5 & Granofelsa de Fsp-Qtz-PI \\
\hline
\end{tabular}

Qtz: cuarzo, PI: plagioclasa; Fsp: feldespato de potasio; Hbl: hornblenda; Bt: biotita; Ms: moscovita; Op: opacos; Zrn: circón; Ttn: titanita; Ep: epidota; Sil: silimanita; Cdr: cordierita; All: allanita

Las granofelsas y neises están constituidos por cuarzo en proporciones que oscilan entre el 20 y el 44\% (figura 8), en cristales xenomorfos con extinción ondulatoria, algunas veces con bordes irregulares, suturados, formando mosaicos orientados o como inclusiones en plagioclasa y feldespato alcalino, a manera de gotas subredondeadas. La plagioclasa es de tipo andesina $\left(\mathrm{An}_{33}\right.$ $\mathrm{a} \mathrm{An}_{36}$ ), y su proporción varía entre 12 y $46 \%$; se presenta como cristales subidioblásticos con maclas de albita y albita-Carlsbad, algunas con macla de la periclina.

El feldespato alcalino corresponde a ortosa u ortosa invirtiéndose a microclina. Presenta maclas de Carlsbad y localmente el maclado típico de la microclina, normal- mente con desmezclas pertíticas en forma de flamas y parches. La biotita se presenta en láminas orientadas, entre los cristales de cuarzo, plagioclasa y ortoclasa; es subidioblástica de color castaño, pleocroica de verde claro a castaño o verde oscuro, con extinción paralela, en ojo de pájaro, y aparece generalmente junto a epidota, titanita y sericita. La epidota se encuentra en agregados xenoblásticos de relieve alto, incoloros a verde amarillentos, con pleocroísmo y colores de interferencia del primer y segundo orden, junto a biotita y sericita. Como minerales accesorios se presentan apatito, opacos, moscovita, titanita, circón de formas prismáticas cortas subredondeadas y algunos cristales de allanita. 

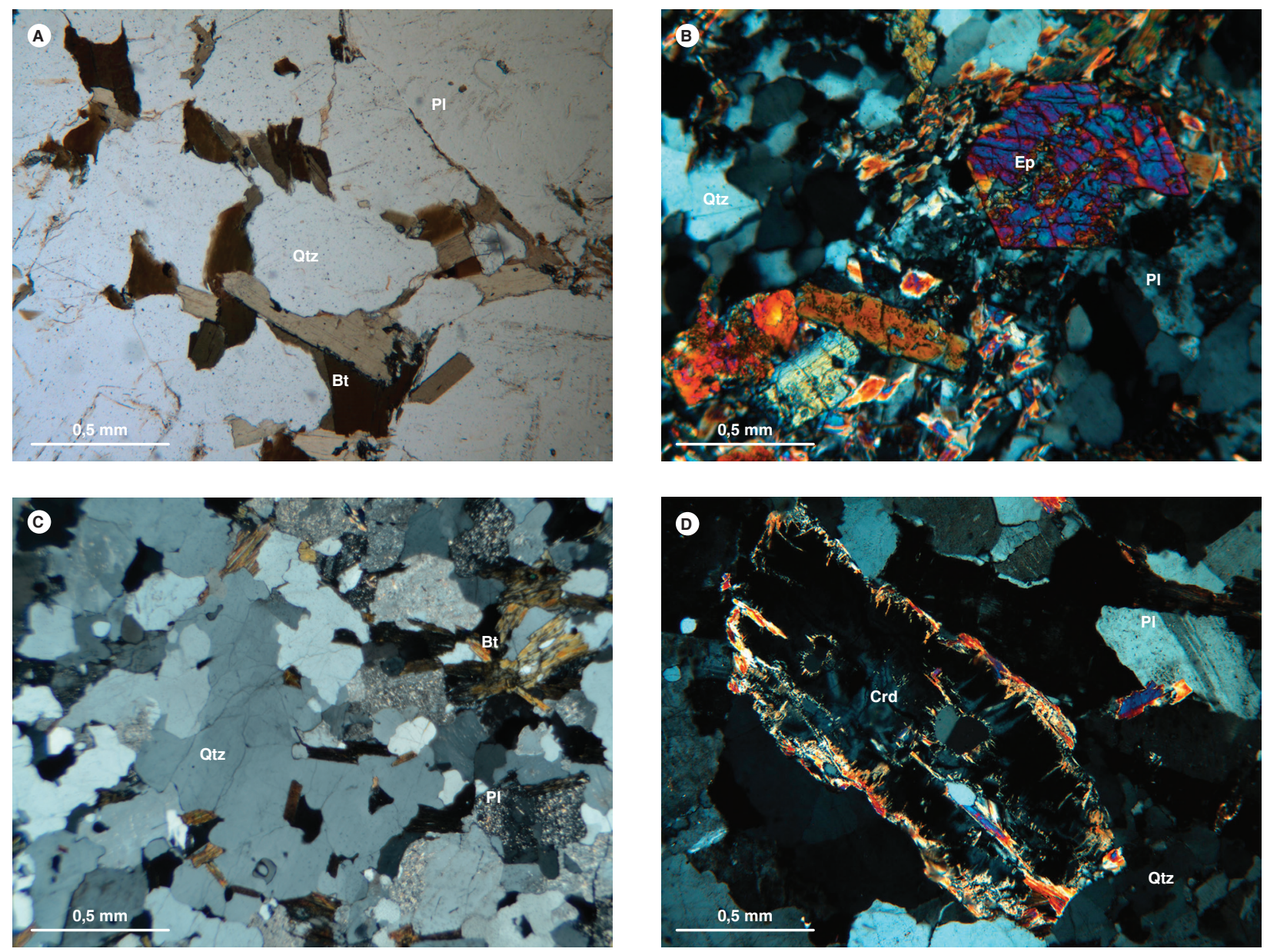

Figura 8. Aspecto microscópico de xenolitos metamorficos. A) Granofelsa de Qtz, Fsp y Bt-INM-37993. Cristales de cuarzo (Qtz), plagioclasa (PI), ortoclasa (Or) y biotita (Bt). B) Granofelsa de Qtz-Fsp-mica-Ep-INM-37990, cristales de epidota (Ep)-clinozoicita y cuarzo (Qtz) en mosaicos. C) Granofelsa de Qtz-Fsp-PI-Bt-INM-11255. La roca presenta textura granoblástica con biotitas definiendo foliación discontinua. D) Granofelsa de Fsp-Qtz-PIINM-11228. Cristal de cordierita completamente alterada, junto a plagioclasa (PI) y cuarzo (Qtz)

Rocas de dique. Se analizaron dos muestras de diques que atraviesan el Monzogranito de La Corcova (tabla 3).

Una muestra de riolita (INM-11241) presenta textura porfídica y microtexturas gráfica y mirmequítica.
Los fenocristales son de cuarzo, plagioclasa, feldespato alcalino y algunos de biotita, diseminados en una matriz felsítica microgranular. Como minerales accesorios se presentan opacos, circón, titanita y moscovita.

Tabla 3. Composición petrográfica de rocas de dique que cortan el Monzogranito de La Corcova

\begin{tabular}{ccccccccccccccc}
\hline IGM & N. campo & $\mathbf{X}$ & $\mathbf{Y}$ & Qtz & PI & Fsp & Bt & Ms & Op & Zrn & Ttn & Ep & Matriz & Clasificación petrográfica \\
\hline 11241 & FM 137 & 1117115 & 1284330 & 33 & 30 & 21 & 3 & 1 & 2 & $\operatorname{Tr}$ & 2 & $\operatorname{Tr}$ & 8 & Riolita porfirítica \\
\hline 11281 & FM 175 & 1116060 & 1285720 & 35 & 11 & 40 & 14 & 1,2 & & & Tr & Microsienogranito \\
\hline
\end{tabular}



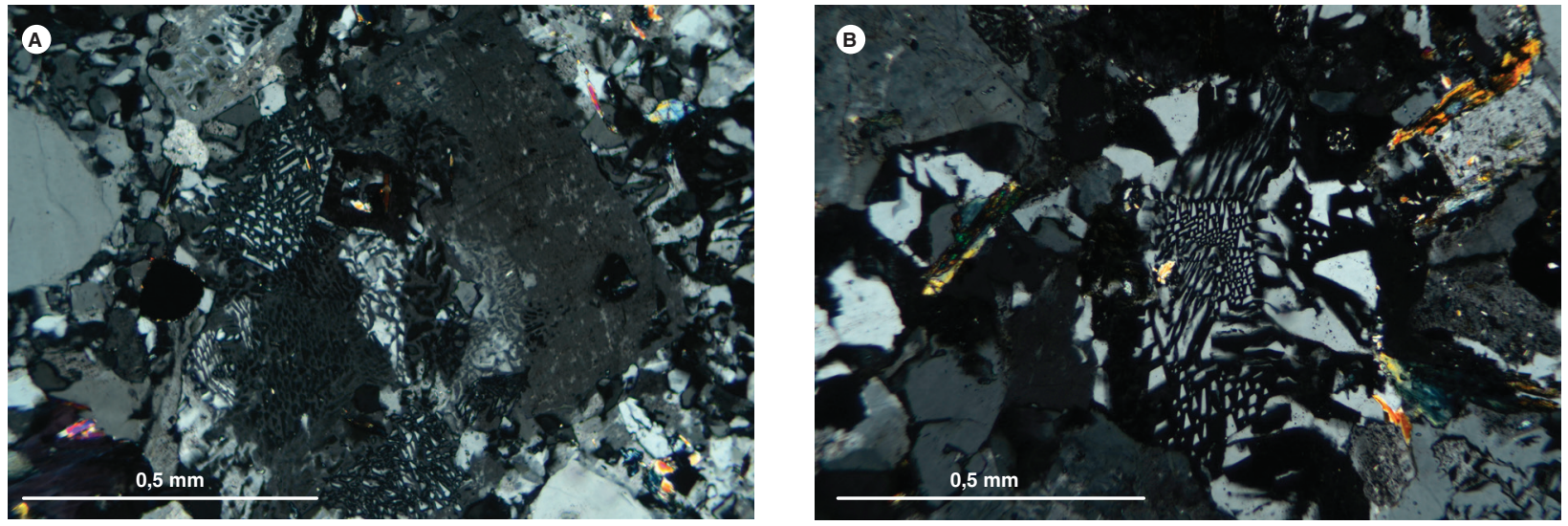

Figura 9. Aspecto microscópico de los diques de riolita (INM-11241) y sienogranito de grano fino (INM -12281) con textura gráfica

Los fenocristales de cuarzo son subredondeados, con tamaños que fluctúan entre 0,1 y 0,5 mm, si bien pueden llegar a los $2 \mathrm{~mm}$; presentan bahías de corrosión y bordes redondeados. La plagioclasa se encuentra como fenocristales y microcristales subhedrales, con hábito tabular, con tamaños que varían entre 0,5 y $2 \mathrm{~mm}$; presenta alteración a sericita y saussurita, y desarrolla en los bordes textura mirmequítica con cuarzo. El feldespato alcalino aparece como fenocristales y microcristales subhedrales, algunos de formas rectangulares y otros irregulares, con tamaños que oscilan entre 0,3 y $2 \mathrm{~mm}$; ocasionalmente presenta macla de Carlsbad, textura pertítica en forma de cordones y textura micrográfica con cuarzo. La biotita se presenta en baja proporción, en cristales de hábito tabular alterados a clorita y, en menor proporción, a epidota-clinozoisita. La moscovita se encuentra en láminas tabulares, incoloras, y su tamaño promedio es de 0,4 mm.

Como accesorios se reconocieron titanita en microcristales subhedrales y anhedrales, con bordes rectos a irregulares, de color pardo y con tamaño promedio de 0,3 mm. Circón en microcristales euhedrales, de formas prismáticas alargadas y cortas, de tamaño $<0,1 \mathrm{~mm}$. Apatito como cristales euhedrales de hábito prismático hexagonal, incoloros, de tamaño $<0,2 \mathrm{~mm}$. Dispersos en la muestra, minerales opacos de forma irregular y tamaño $<0,2 \mathrm{~mm}$.

El dique de sienogranito de grano fino (IGM-12281) presenta una textura inequigranular y una textura particular granofídica. Se encuentra constituido por cuarzo, plagioclasa, feldespato alcalino, biotita y moscovita, y como minerales de alteración se presentan sericita, clorita y epidota.
Los cristales de feldespato alcalino son anhedrales. Su tamaño varía entre 0,5 y 0,75 mm, y presentan relieve bajo ( $\mathrm{n}$ < bálsamo), algo sucio. Son de textura gráfica y mirmequítica en contactos con plagioclasa (figura 9). La plagioclasa es subhedral con tamaños de hasta 1,25 $\mathrm{mm}$. Tiene maclas polisintéticas enmascaradas por la alteración a saussurita. El cuarzo se presenta en cristales anhedrales finos, limpios e intercrecidos con cristales de feldespato potásico formando texturas gráficas; los cristales más grandes pueden alcanzar 1,25 mm. La biotita se presenta en láminas subhedrales, con coloración verde pálido a amarillento (fuertemente pleocroica), con extinción ojo de pájaro, con tamaños de hasta $1 \mathrm{~mm}$, alterada a clorita. La moscovita es un accesorio y se halla en láminas euhedrales de tamaños de hasta 0,1 mm.

\section{Química mineral}

Los análisis de química mineral se llevaron a cabo en la microsonda electrónica de la Universidad Nacional de Colombia, sede Bogotá. El equipo usado es una microsonda JEOL JXA 8230, cuyas condiciones de operación fueron: 1 a $10 \mu \mathrm{m}$ de diámetro del haz, tiempo en el pico de $20 \mathrm{~ms}$, intensidad 20 nA y voltaje de aceleración de $15 \mathrm{kV}$. Los conteos del instrumento son convertidos a porcentajes de óxidos mediante comparaciones con conteos de estándares naturales y sintéticos. Los datos se han tratado mediante la corrección ZAF (Z: número atómico; A: absorción de masas; F: fluorescencia) utilizando el programa de JEOL. La adquisición de los datos consistió en obtener imágenes de electrones retrodispersados de los cristales seleccionados para el análisis y en realizar los análisis puntuales. 
Para este análisis se seleccionaron las muestras AMC-0131, MIA-627A y LMC-078, clasificadas petrográficamente como sienogranito de la facies porfídica y protomilonitas a partir de monzogranito y monzogranito de la facies normal, respectivamente. Además, se analizó la muestra MIA-631, que corresponde a un xenolito del Neis de Bucaramanga clasificado como granofelsa de $\mathrm{Pl}+\mathrm{Qtz}+\mathrm{Kf}+\mathrm{Bt}$. Para el análisis de microsonda, en la muestra AMC-0131 se escogieron plagioclasa, feldespato alcalino, biotita y opacos; para la muestra MIA-627A, plagioclasa, feldespato alcalino, moscovita e ilmenita; para la muestra LMC-078, plagioclasa, feldespato alcalino, biotita, moscovita, magnetita e ilmenita, y para la muestra MIA-631, feldespato alcalino.

\subsection{Feldespato alcalino}

Los resultados de la química mineral en feldespato alcalino correspondientes a las muestras AMC-0131, MIA-627A, LMC-078 y MIA-631 se muestran en las tablas 4, 5, 6 y 7.

Se analizaron dos cristales de feldespato alcalino de la muestra AMC-0131 (figura 10), cuyos resultados se resu- men en la figura 11. El feldespato potásico en la muestra AMC-0131 exhibe micropertitas en filoncillo y parches que se pueden apreciar en las imágenes de los dos cristales analizados (figura 10), correspondientes a ortosa o microclina pertítica para el campo C9 (Or $\left.{ }_{94,8}-\mathrm{Or}_{96,1}, \mathrm{Ab}_{3,9}-\mathrm{Ab}_{5,2}\right)$ y C3 $\left(\mathrm{Or}_{89,9}-\mathrm{Or}_{95,5}, \mathrm{Ab}_{9,9}-\mathrm{Ab}_{4,2}\right)$ y a pertita en el campo C3 $\left(\mathrm{Or}_{75} \mathrm{Ab}_{24,6}\right)$ (un punto) (tabla 4, figura 11). Los resultados de la mayoría de análisis se alinean en el campo de la ortosa pertítica.

En los casos de las muestras MIA-627A y MIA-631 se analizaron cuatro y dos cristales de feldespato, respectivamente (figura 12). En la muestra MIA-627A el feldespato potásico exhibe micropertitas en parches que se aprecian en las imágenes retrodispersadas (figura 12), correspondientes a ortosa o microclina pertítica $\left(\mathrm{Or}_{92,5-96,7} \mathrm{Ab}_{2,9-7,4}\right)$, y en la muestra MIA-631 el feldespato alcalino presenta algunos parches de plagioclasa; los dos cristales corresponden a ortosa o microclina pertítica $\left(\mathrm{Or}_{89,4-95,6} \mathrm{Ab}_{4,4-10,3}\right)$. Los resultados se resumen en la figura 11 .

Tabla 4. Análisis de cristales de feldespato alcalino de la muestra AMC-0131

\begin{tabular}{|c|c|c|c|c|c|c|c|c|c|}
\hline & $\begin{array}{c}\text { AMC-0131-C9- } \\
\text { Kfs-2 }\end{array}$ & $\begin{array}{c}\text { AMC-0131-C9- } \\
\text { Kfs-3 }\end{array}$ & $\begin{array}{c}\text { AMC-0131-C9- } \\
\text { Kfs-4 }\end{array}$ & $\begin{array}{c}\text { AMC-0131-C3- } \\
\text { Kfs-1 }\end{array}$ & $\begin{array}{c}\text { AMC-0131-C3- } \\
\text { Kfs-2 }\end{array}$ & $\begin{array}{c}\text { AMC-0131-C3- } \\
\text { Kfs-3 }\end{array}$ & $\begin{array}{c}\text { AMC-0131-C3- } \\
\text { Kfs-4 }\end{array}$ & $\begin{array}{c}\text { AMC-0131-C3- } \\
\text { Kfs-5 }\end{array}$ & $\begin{array}{c}\text { AMC-0131-C3- } \\
\text { Kfs-6 }\end{array}$ \\
\hline $\mathrm{SiO} 2$ & 65,541 & 65,389 & 65,286 & 64,776 & 64,69 & 64,167 & 64,124 & 64,121 & 64,889 \\
\hline $\mathrm{TiO} 2$ & 0,005 & 0,016 & 0,011 & 0,025 & 0,005 & 0,001 & 0,005 & 0,038 & 0,019 \\
\hline $\mathrm{Al} 2 \mathrm{O} 3$ & 18,542 & 18,518 & 18,624 & 18,347 & 18,611 & 18,174 & 18,375 & 18,019 & 18,33 \\
\hline $\mathrm{FeO}$ & 0,03 & 0 & 0,026 & 0,041 & 0,026 & 0,042 & 0,049 & 0,045 & 0,044 \\
\hline $\mathrm{MgO}$ & 0 & 0 & 0 & 0 & 0,014 & 0 & 0 & 0 & 0 \\
\hline $\mathrm{CaO}$ & 0,017 & 0 & 0 & 0,05 & 0,089 & 0,024 & 0,056 & 0,026 & 0,002 \\
\hline $\mathrm{Na} 2 \mathrm{O}$ & 0,478 & 0,435 & 0,582 & 1,102 & 2,745 & 0,485 & 0,685 & 0,464 & 0,975 \\
\hline K2O & 16,091 & 16,274 & 16,084 & 15,222 & 12,75 & 15,97 & 15,71 & 15,919 & 15,368 \\
\hline Total & 100,704 & 100,632 & 100,613 & 99,563 & 98,93 & 98,863 & 99,004 & 98,632 & 99,627 \\
\hline $\mathrm{Si}$ & 12,009 & 12,002 & 11,982 & 11,989 & 11,950 & 11,995 & 11,963 & 12,012 & 12,003 \\
\hline $\mathrm{Al}$ & 4,004 & 4,006 & 4,028 & 4,002 & 4,052 & 4,004 & 4,040 & 3,978 & 3,996 \\
\hline $\mathrm{Ti}$ & 0,001 & 0,002 & 0,002 & 0,003 & 0,001 & 0,000 & 0,001 & 0,005 & 0,003 \\
\hline $\mathrm{Fe} 2+$ & 0,003 & 0,000 & 0,003 & 0,004 & 0,003 & 0,004 & 0,005 & 0,005 & 0,005 \\
\hline $\mathrm{Mg}$ & 0 & 0 & 0 & 0 & 0,003856 & 0 & 0 & 0 & 0 \\
\hline $\mathrm{Na}$ & 0,170 & 0,155 & 0,207 & 0,395 & 0,983 & 0,176 & 0,248 & 0,169 & 0,350 \\
\hline $\mathrm{Ca}$ & 0,003 & 0,000 & 0,000 & 0,010 & 0,018 & 0,005 & 0,011 & 0,005 & 0,000 \\
\hline K & 3,761 & 3,811 & 3,766 & 3,594 & 3,005 & 3,809 & 3,739 & 3,804 & 3,627 \\
\hline Total & 19,9519 & 19,976 & 19,987 & 19,999 & 20,015 & 19,993 & 20,007 & 19,978 & 19,982 \\
\hline Z & 16,01 & 16,01 & 16,01 & 15,99 & 16,00 & 16,00 & 16,00 & 16,00 & 16,00 \\
\hline$x$ & 3,94 & 3,97 & 3,98 & 4,00 & 4,01 & 3,99 & 4,00 & 3,98 & 3,98 \\
\hline Or & 95,60 & 96,10 & 94,79 & 89,86 & 75,01 & 95,47 & 93,52 & 95,63 & 91,20 \\
\hline $\mathrm{Ab}$ & 4,32 & 3,90 & 5,21 & 9,89 & 24,55 & 4,41 & 6,20 & 4,24 & 8,79 \\
\hline An & 0,08 & 0,00 & 0,00 & 0,25 & 0,44 & 0,12 & 0,28 & 0,13 & 0,01 \\
\hline Total & 100,00 & 100,00 & 100,00 & 100,00 & 100,00 & 100,00 & 100,00 & 100,00 & 100,00 \\
\hline
\end{tabular}



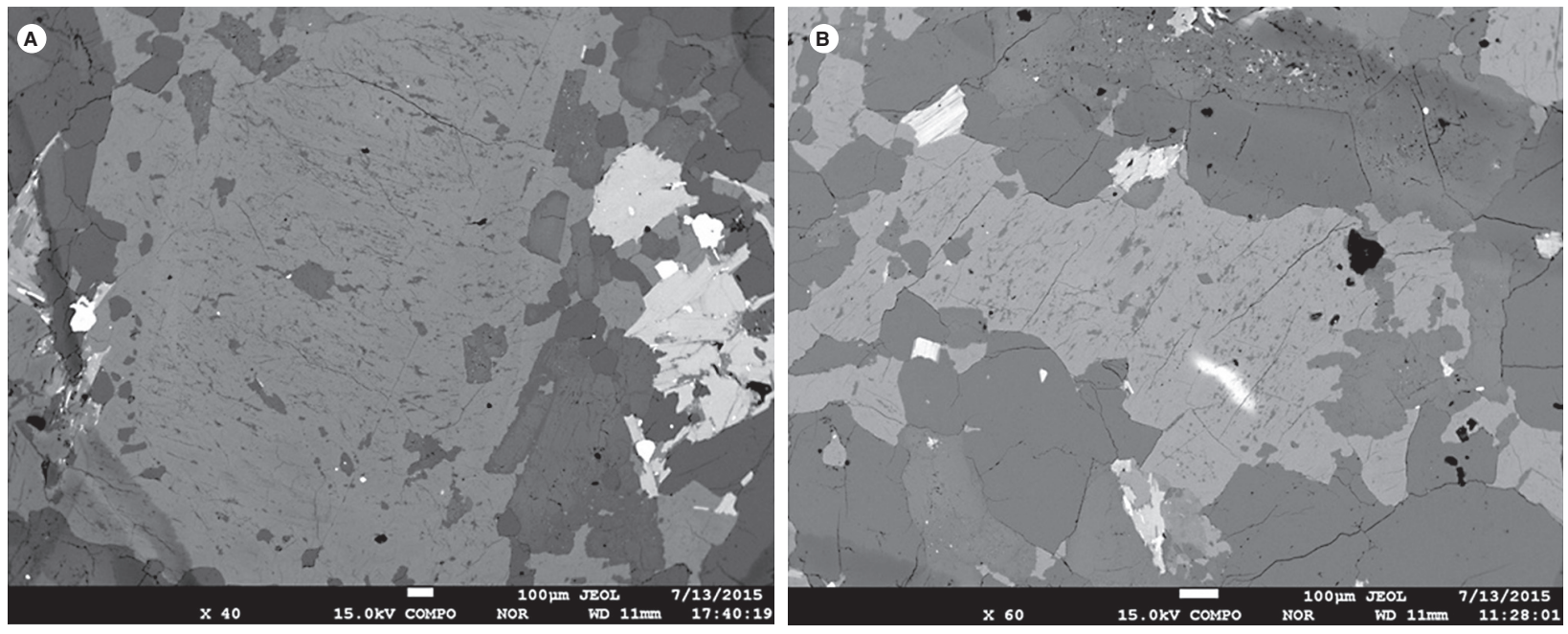

Figura 10. Imágenes de electrones retrodispersados de cristales de feldespato potásico en las que se observan las micropertitas en filoncillos y parches (muestra AMC-131)

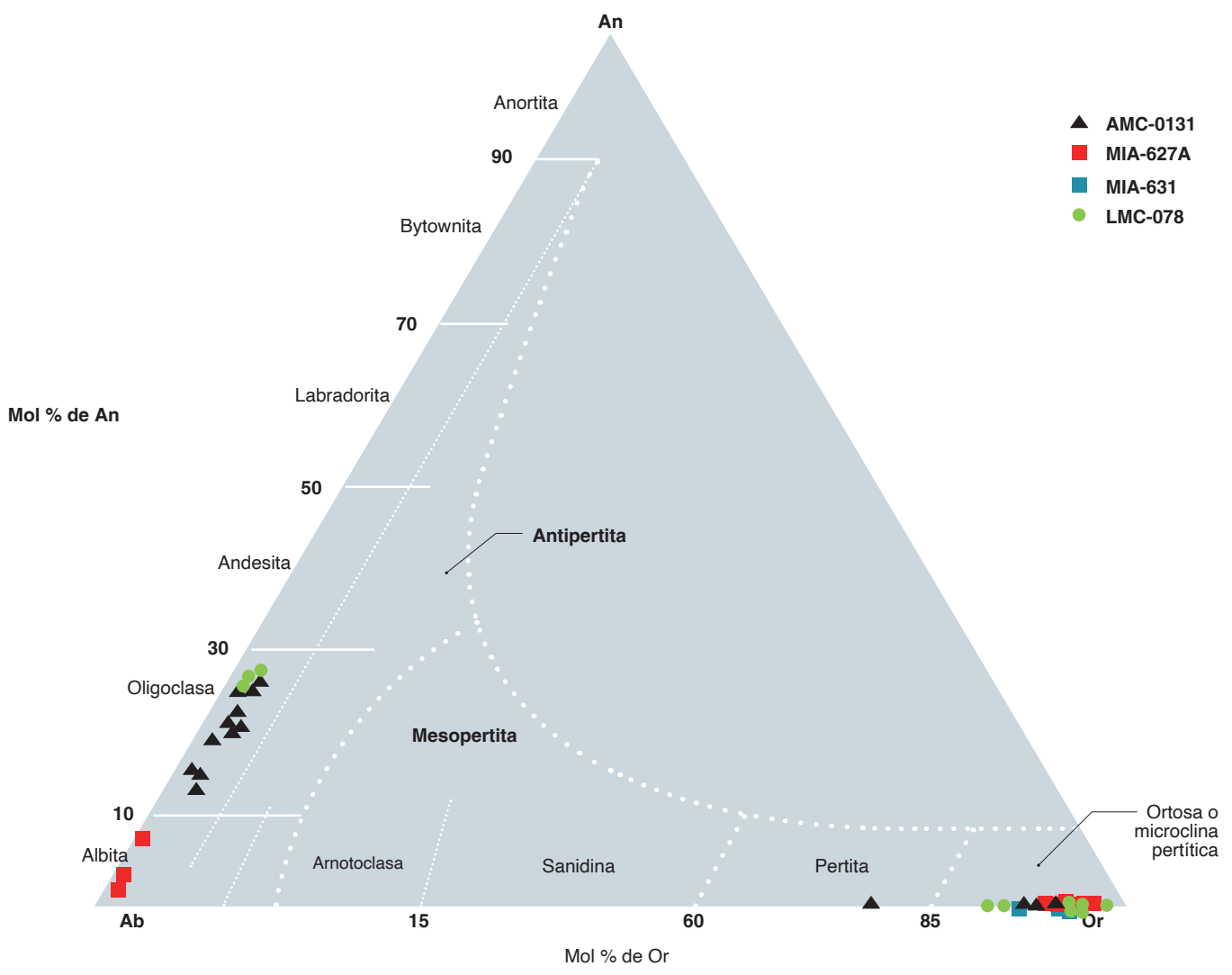

Figura 11. Composición de los feldespatos potásicos y las plagioclasas en rocas del Monzogranito de La Corcova

Fuente: diagrama de Smith-Brown (1988) y este trabajo 

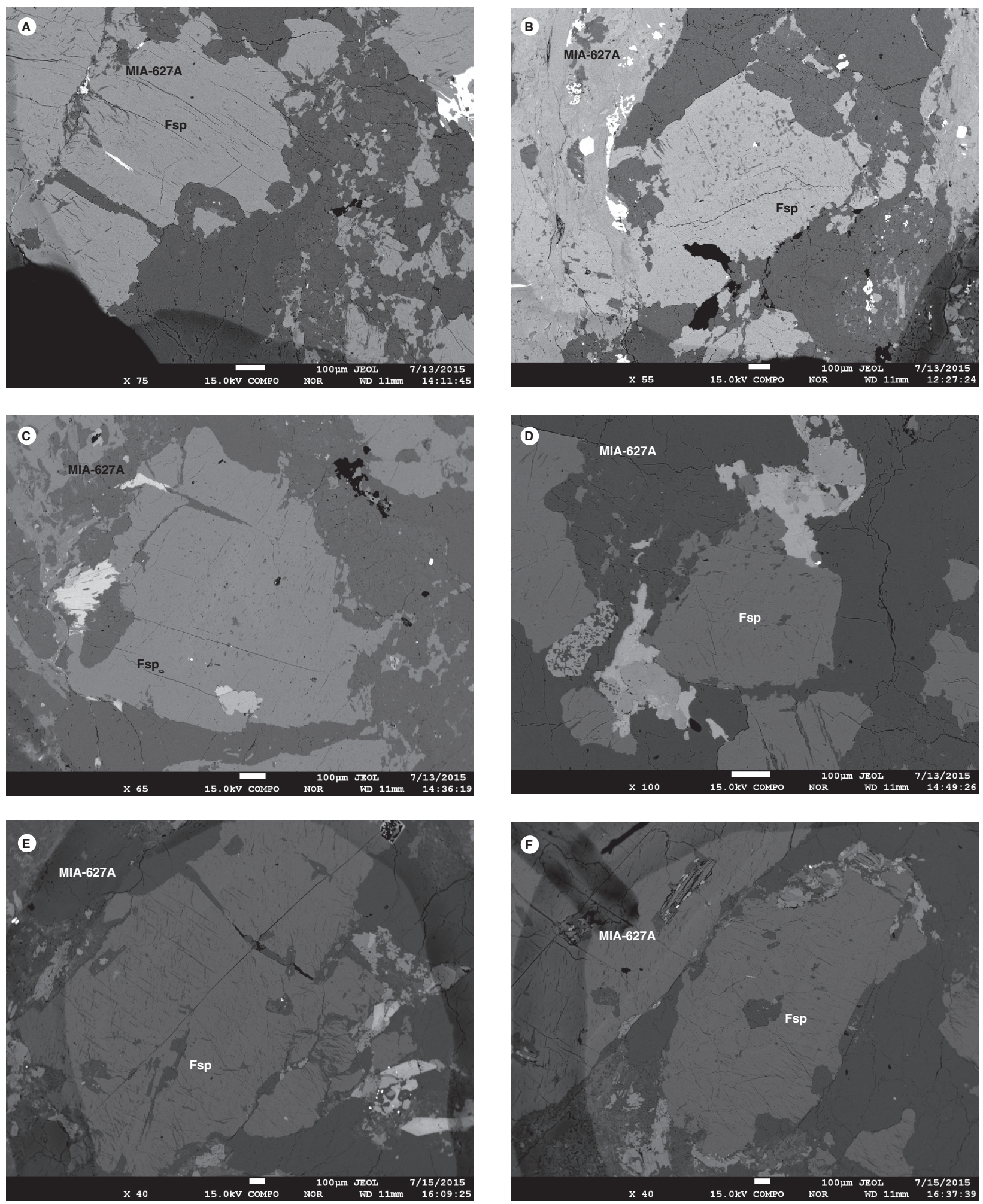

Figura 12. Imágenes de electrones retrodispersados de cristales de feldespato potásico (Fsp) en las muestras MIA-627A y MIA 631. Se observan micropertitas en filoncillos y parches 
Tabla 5. Análisis de cristales de feldespato alcalino de la muestra MIA-627A

\begin{tabular}{|c|c|c|c|c|c|c|c|c|c|c|}
\hline & $\begin{array}{c}\text { MIA-627A-C2- } \\
\text { Kfs-1 }\end{array}$ & $\begin{array}{c}\text { MIA-627A-C2- } \\
\text { Kfs-2 }\end{array}$ & $\begin{array}{c}\text { MIA-627A-C2- } \\
\text { Kfs-3 }\end{array}$ & $\begin{array}{c}\text { MIA-627A-C2- } \\
\text { Kfs-4 }\end{array}$ & $\begin{array}{c}\text { MIA-627A-C5- } \\
\text { Kfs-1 }\end{array}$ & $\begin{array}{c}\text { MIA-627A-C5- } \\
\text { Kfs-2 }\end{array}$ & $\begin{array}{c}\text { MIA-627A-C5- } \\
\text { Kfs-3 }\end{array}$ & $\begin{array}{c}\text { MIA-627A-C5- } \\
\text { Kfs-4 }\end{array}$ & $\begin{array}{c}\text { MIA-627A-C6- } \\
\text { Kfs-1 }\end{array}$ & $\begin{array}{c}\text { MIA-627A-C6- } \\
\text { Kfs-2 }\end{array}$ \\
\hline $\mathrm{SiO}_{2}$ & 64,82 & 64,93 & 64,78 & 65,36 & 65,04 & 65,01 & 64,83 & 65,19 & 64,29 & 64,94 \\
\hline $\mathrm{TiO}_{2}$ & 0,01 & 0,01 & 0,00 & 0,01 & 0,00 & 0,01 & 0,00 & 0,00 & 0,00 & 0,02 \\
\hline $\mathrm{Al}_{2} \mathrm{O}_{3}$ & 18,57 & 18,55 & 18,35 & 18,47 & 18,48 & 18,44 & 18,25 & 18,43 & 18,22 & 18,23 \\
\hline $\mathrm{FeO}$ & 0,00 & 0,00 & 0,00 & 0,04 & 0,01 & 0,00 & 0,00 & 0,03 & 0,00 & 0,00 \\
\hline $\mathrm{MgO}$ & 0,00 & 0,00 & 0,00 & 0,00 & 0,00 & 0,01 & 0,00 & 0,00 & 0,00 & 0,00 \\
\hline $\mathrm{CaO}$ & 0,02 & 0,05 & 0,00 & 0,01 & 0,03 & 0,00 & 0,00 & 0,00 & 0,00 & 0,02 \\
\hline $\mathrm{Na}_{2} \mathrm{O}$ & 0,72 & 0,56 & 0,60 & 0,83 & 0,52 & 0,43 & 0,33 & 0,51 & 0,40 & 0,56 \\
\hline $\mathrm{K}_{2} \mathrm{O}$ & 15,78 & 15,89 & 16,25 & 15,70 & 16,16 & 16,32 & 16,44 & 16,12 & 16,09 & 16,20 \\
\hline Total & 99,90 & 99,99 & 99,98 & 100,41 & 100,24 & 100,22 & 99,84 & 100,26 & 98,99 & 99,97 \\
\hline $\mathrm{Si}$ & 11,97 & 11,98 & 11,99 & 12,00 & 11,99 & 11,99 & 12,01 & 12,01 & 12,00 & 12,01 \\
\hline $\mathrm{Al}$ & 4,04 & 4,03 & 4,00 & 4,00 & 4,01 & 4,01 & 3,98 & 4,00 & 4,01 & 3,97 \\
\hline $\mathrm{Ti}$ & 0,00 & 0,00 & 0,00 & 0,00 & 0,00 & 0,00 & 0,00 & 0,00 & 0,00 & 0,00 \\
\hline $\mathrm{Fe}^{2+}$ & 0,00 & 0,00 & 0,00 & 0,00 & 0,00 & 0,00 & 0,00 & 0,00 & 0,00 & 0,00 \\
\hline $\mathrm{Mg}$ & 0,00 & 0,00 & 0,00 & 0,00 & 0,00 & 0,00 & 0,00 & 0,00 & 0,00 & 0,00 \\
\hline $\mathrm{Na}$ & 0,26 & 0,20 & 0,22 & 0,29 & 0,19 & 0,16 & 0,12 & 0,18 & 0,14 & 0,20 \\
\hline $\mathrm{Ca}$ & 0,00 & 0,01 & 0,00 & 0,00 & 0,01 & 0,00 & 0,00 & 0,00 & 0,00 & 0,00 \\
\hline $\mathrm{K}$ & 3,72 & 3,74 & 3,84 & 3,68 & 3,80 & 3,84 & 3,89 & 3,79 & 3,83 & 3,82 \\
\hline Total & 19,99 & 19,97 & 20,04 & 19,98 & 20,00 & 20,00 & 20,00 & 19,98 & 19,98 & 20,01 \\
\hline z & 16,02 & 16,02 & 15,99 & 16,00 & 16,00 & 16,00 & 15,99 & 16,01 & 16,01 & 15,99 \\
\hline $\mathrm{x}$ & 3,98 & 3,95 & 4,05 & 3,98 & 3,99 & 4,00 & 4,00 & 3,97 & 3,98 & 4,03 \\
\hline Or & 93,48 & 94,68 & 94,67 & 92,51 & 95,19 & 96,10 & 97,07 & 95,44 & 96,36 & 94,91 \\
\hline$A b$ & 6,44 & 5,08 & 5,33 & 7,42 & 4,67 & 3,88 & 2,93 & 4,56 & 3,62 & 4,98 \\
\hline An & 0,08 & 0,25 & 0,00 & 0,07 & 0,14 & 0,01 & 0,00 & 0,00 & 0,02 & 0,11 \\
\hline Total & 100,00 & 100,00 & 100,00 & 100,00 & 100,00 & 100,00 & 100,00 & 100,00 & 100,00 & 100,00 \\
\hline
\end{tabular}

Tabla 6. Análisis de cristales de feldespato alcalino de la muestra MIA-631

\begin{tabular}{|c|c|c|c|c|c|c|c|c|c|c|c|c|}
\hline & $\begin{array}{l}\text { MIA-627A- } \\
\text { C7-Kfs-1 }\end{array}$ & $\begin{array}{l}\text { MIA-627A- } \\
\text { C7-Kfs-2 }\end{array}$ & $\begin{array}{l}\text { MIA-627A- } \\
\text { C7-KfS-3 }\end{array}$ & $\begin{array}{l}\text { MIA-627A- } \\
\text { C7-Kfs-4 }\end{array}$ & $\begin{array}{l}\text { MIA-627A- } \\
\text { C7-Kfs-5 }\end{array}$ & & $\begin{array}{l}\text { MIA-631- } \\
\text { C4-KfS-1 }\end{array}$ & $\begin{array}{l}\text { MIA-631- } \\
\text { C4-KfS-2 }\end{array}$ & $\begin{array}{l}\text { MIA-631- } \\
\text { C4-KfS-3 }\end{array}$ & $\begin{array}{l}\text { MIA-631- } \\
\text { C5-Kfs-1 }\end{array}$ & $\begin{array}{l}\text { MIA-631- } \\
\text { C5-Kfs-2 }\end{array}$ & $\begin{array}{l}\text { MIA-631- } \\
\text { C5-Kfs-3 }\end{array}$ \\
\hline $\mathrm{SiO}_{2}$ & 64,77 & 64,88 & 65,08 & 64,62 & 64,74 & $\mathrm{SiO}_{2}$ & 64,79 & 65,11 & 64,80 & 64,41 & 64,74 & 65,02 \\
\hline $\mathrm{TiO}_{2}$ & 0,00 & 0,01 & 0,00 & 0,00 & 0,01 & $\mathrm{TiO}_{2}$ & 0,03 & 0,01 & 0,03 & 0,00 & 0,01 & 0,00 \\
\hline $\mathrm{Al}_{2} \mathrm{O}_{3}$ & 18,63 & 18,35 & 18,25 & 18,52 & 18,10 & $\mathrm{Al}_{2} \mathrm{O}_{3}$ & 18,33 & 18,65 & 18,42 & 18,45 & 18,66 & 18,31 \\
\hline $\mathrm{FeO}$ & 0,04 & 0,04 & 0,00 & 0,00 & 0,00 & $\mathrm{FeO}$ & 0,04 & 0,05 & 0,10 & 0,03 & 0,02 & 0,04 \\
\hline $\mathrm{MgO}$ & 0,00 & 0,00 & 0,01 & 0,00 & 0,00 & $\mathrm{MgO}$ & 0,00 & 0,00 & 0,00 & 0,00 & 0,00 & 0,00 \\
\hline $\mathrm{CaO}$ & 0,01 & 0,03 & 0,05 & 0,01 & 0,00 & $\mathrm{CaO}$ & 0,03 & 0,00 & 0,02 & 0,00 & 0,05 & 0,00 \\
\hline $\mathrm{Na}_{2} \mathrm{O}$ & 0,65 & 0,40 & 0,45 & 0,80 & 0,46 & $\mathrm{Na}_{2} \mathrm{O}$ & 0,57 & 0,62 & 0,67 & 0,69 & 1,13 & 0,48 \\
\hline $\mathrm{K}_{2} \mathrm{O}$ & 15,97 & 16,33 & 16,10 & 15,70 & 16,15 & $\mathrm{~K}_{2} \mathrm{O}$ & 15,92 & 15,97 & 15,75 & 15,75 & 14,94 & 16,02 \\
\hline Total & 100,07 & 100,03 & 99,94 & 99,64 & 99,46 & Total & 99,70 & 100,40 & 99,79 & 99,33 & 99,56 & 99,87 \\
\hline $\mathrm{Si}$ & 11,96 & 12,00 & 12,02 & 11,97 & 12,03 & $\mathrm{Si}$ & 12,00 & 11,97 & 11,99 & 11,97 & 11,96 & 12,02 \\
\hline $\mathrm{Al}$ & 4,05 & 4,00 & 3,97 & 4,04 & 3,96 & $\mathrm{Al}$ & 4,00 & 4,04 & 4,02 & 4,04 & 4,06 & 3,99 \\
\hline $\mathrm{Ti}$ & 0,00 & 0,00 & 0,00 & 0,00 & 0,00 & $\mathrm{Ti}$ & 0,00 & 0,00 & 0,00 & 0,00 & 0,00 & 0,00 \\
\hline $\mathrm{Fe}^{2+}$ & 0,00 & 0,00 & 0,00 & 0,00 & 0,00 & $\mathrm{Fe}^{2+}$ & 0,00 & 0,01 & 0,01 & 0,00 & 0,00 & 0,00 \\
\hline $\mathrm{Mg}$ & 0,00 & 0,00 & 0,00 & 0,00 & 0,00 & $\mathrm{Mg}$ & 0,00 & 0,00 & 0,00 & 0,00 & 0,00 & 0,00 \\
\hline $\mathrm{Na}$ & 0,23 & 0,14 & 0,16 & 0,29 & 0,16 & $\mathrm{Na}$ & 0,20 & 0,22 & 0,24 & 0,25 & 0,41 & 0,17 \\
\hline $\mathrm{Ca}$ & 0,00 & 0,00 & 0,01 & 0,00 & 0,00 & $\mathrm{Ca}$ & 0,01 & 0,00 & 0,00 & 0,00 & 0,01 & 0,00 \\
\hline $\mathrm{K}$ & 3,76 & 3,85 & 3,79 & 3,71 & 3,83 & $\mathrm{~K}$ & 3,76 & 3,75 & 3,72 & 3,73 & 3,52 & 3,78 \\
\hline Total & 20,01 & 20,00 & 19,97 & 20,01 & 19,98 & Total & 19,98 & 19,99 & 19,98 & 20,00 & 19,97 & 19,96 \\
\hline$z$ & 16,01 & 16,00 & 16,00 & 16,01 & 15,99 & $z$ & 16,00 & 16,01 & 16,01 & 16,01 & 16,03 & 16,01 \\
\hline$x$ & 4,00 & 4,00 & 3,97 & 4,00 & 3,99 & $x$ & 3,98 & 3,97 & 3,97 & 3,99 & 3,94 & 3,95 \\
\hline Or & 94,15 & 96,26 & 95,66 & 92,80 & 95,88 & Or & 94,69 & 94,42 & 93,85 & 93,72 & 89,43 & 95,64 \\
\hline $\mathrm{Ab}$ & 5,79 & 3,62 & 4,10 & 7,16 & 4,12 & $A b$ & 5,14 & 5,58 & 6,07 & 6,28 & 10,32 & 4,36 \\
\hline An & 0,06 & 0,12 & 0,24 & 0,04 & 0,00 & $\mathrm{An}$ & 0,16 & 0,00 & 0,09 & 0,00 & 0,25 & 0,00 \\
\hline Total & 100,00 & 100,00 & 100,00 & 100,00 & 100,00 & Total & 100,00 & 100,00 & 100,00 & 100,00 & 100,00 & 100,00 \\
\hline
\end{tabular}


En la muestra LMC-078 se analizaron dos cristales de feldespato. Los cristales de este mineral exhiben micropertitas en parches que se aprecian en las imágenes, e inclusiones de criales de plagioclasa (figura 13); corresponden a ortosa o microclina pertítica $\left(\mathrm{Or}_{86,5-98,02} \mathrm{Ab}_{1,5-}\right.$ $13,05)$.

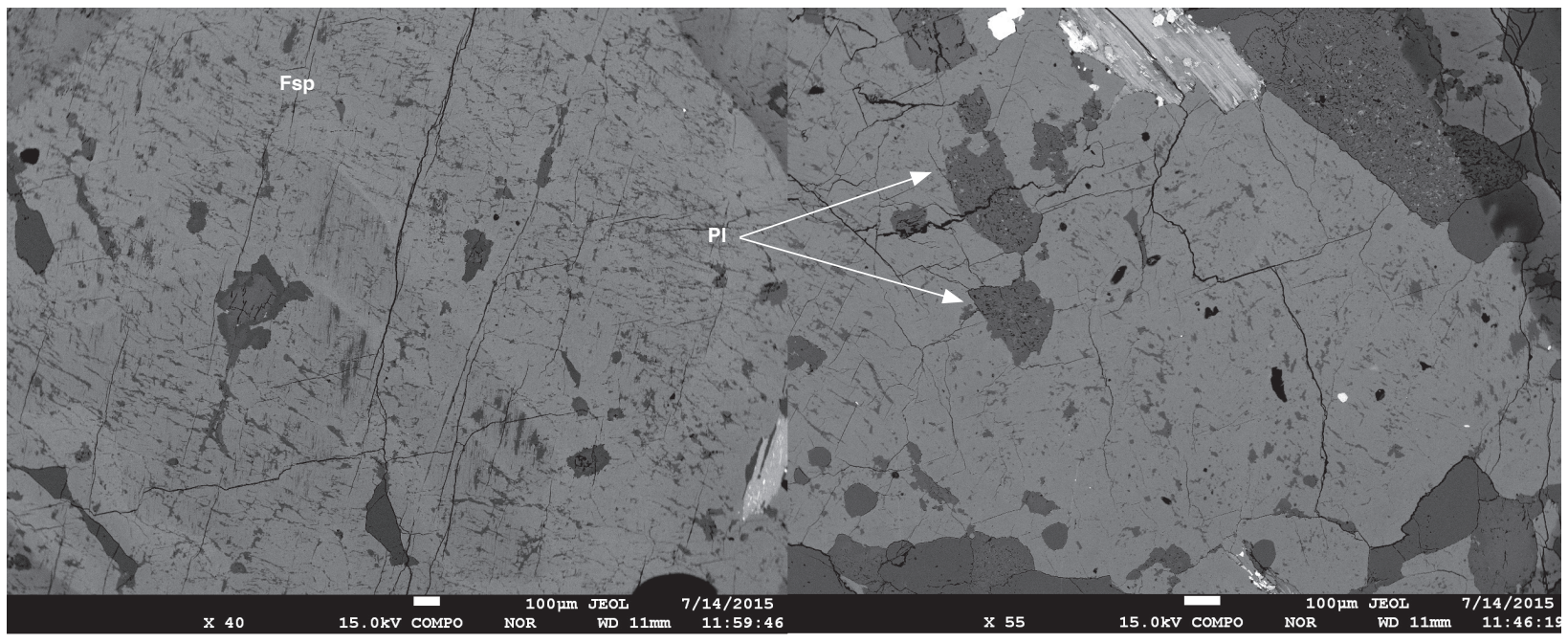

Figura 13. Imágenes de electrones retrodispersados de cristales de feldespato potásico (Fsp) en la muestra LMC-078. Los mencionados cristales presentan textura pertítica con parches y filoncillos de plagioclasa (PI)

Tabla 7. Análisis de cristales de feldespato alcalino de la muestra LMC-078

\begin{tabular}{|c|c|c|c|c|}
\hline & LMC-078-C8-Kfs-1 & LMC-078-C8-Kfs-3 & LMC-078-C9-Kfs-1 & LMC-078-C9-Kfs-2 \\
\hline $\mathrm{SiO}_{2}$ & 65,2 & 64,92 & 64,48 & 65,04 \\
\hline $\mathrm{TiO}_{2}$ & 0 & 0 & 0,02 & 0,03 \\
\hline $\mathrm{Al}_{2} \mathrm{O}_{3}$ & 18,36 & 18,64 & 18,74 & 18,74 \\
\hline $\mathrm{FeO}$ & 0,09 & 0,02 & 0,06 & 0,04 \\
\hline $\mathrm{MgO}$ & 0 & 0 & 0 & 0 \\
\hline $\mathrm{CaO}$ & 0,02 & 0,08 & 0,09 & 0,04 \\
\hline $\mathrm{Na}_{2} \mathrm{O}$ & 0,47 & 1,43 & 0,58 & 1,31 \\
\hline $\mathrm{K}_{2} \mathrm{O}$ & 15,98 & 14,36 & 15,81 & 14,9 \\
\hline Total & 100,12 & 99,45 & 99,77 & 100,09 \\
\hline $\mathrm{Si}$ & 12,02 & 11,98 & 11,93 & 11,96 \\
\hline $\mathrm{Al}$ & 3,99 & 4,05 & 4,09 & 4,06 \\
\hline $\mathrm{Ti}$ & 0 & 0 & 0 & 0 \\
\hline $\mathrm{Fe}^{2+}$ & 0,01 & 0 & 0,01 & 0 \\
\hline $\mathrm{Mg}$ & 0 & 0 & 0 & 0 \\
\hline $\mathrm{Na}$ & 0,17 & 0,51 & 0,21 & 0,47 \\
\hline $\mathrm{Ca}$ & 0 & 0,02 & 0,02 & 0,01 \\
\hline K & 3,76 & 3,38 & 3,73 & 3,49 \\
\hline Total & 19,95 & 19,94 & 19,99 & 19,99 \\
\hline$z$ & 16,0 & 16,0 & 16,0 & 16,0 \\
\hline$x$ & 3,9 & 3,9 & 4,0 & 4,0 \\
\hline Or & 95,6 & 86,5 & 94,3 & 88,1 \\
\hline$A b$ & 4,31 & 13,05 & 5,26 & 11,73 \\
\hline $\mathrm{An}$ & 0,12 & 0,42 & 0,44 & 0,17 \\
\hline
\end{tabular}




\subsection{Plagioclasa}

La plagioclasa se analizó en dos cristales de la muestra AMC-0131 y en un cristal de la muestra LMC-078 (figuras 14 y 15). Se analizaron los núcleos y bordes, que en el caso del cristal C10 (AMC-0131) muestran una variación composicional oscilatoria (figura 11) correspondiente a oligoclasa $\left(\mathrm{Ab}_{72,7-82,5} \mathrm{An}_{13,8-25,5} \mathrm{Or}_{1,3-2,5}\right)$. La plagioclasa C1 2 (muestra AMC-131) presenta variaciones composicionales menores y corresponde también a oligoclasa $\left(\mathrm{Ab}_{75,4-79,7} \mathrm{An}_{18,8-25,8} \mathrm{Or}_{1,5-2,8}\right)$, como se puede observar en la tabla 8 y en la figura 11 .
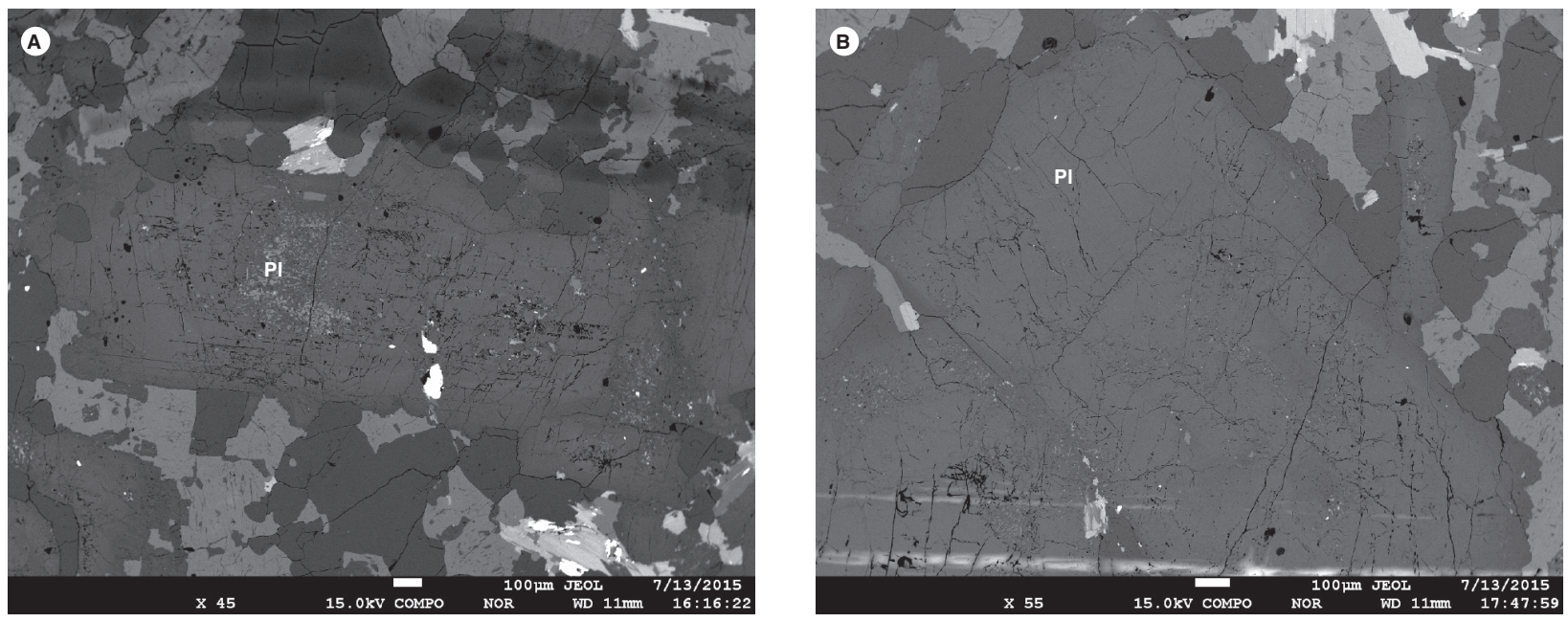

Figura 14. Cristales de plagioclasa (PI) en los campos $\mathrm{C} 10$ y $\mathrm{C} 12$ de la muestra AMC-0131. Imagen de electrones retrodispersados
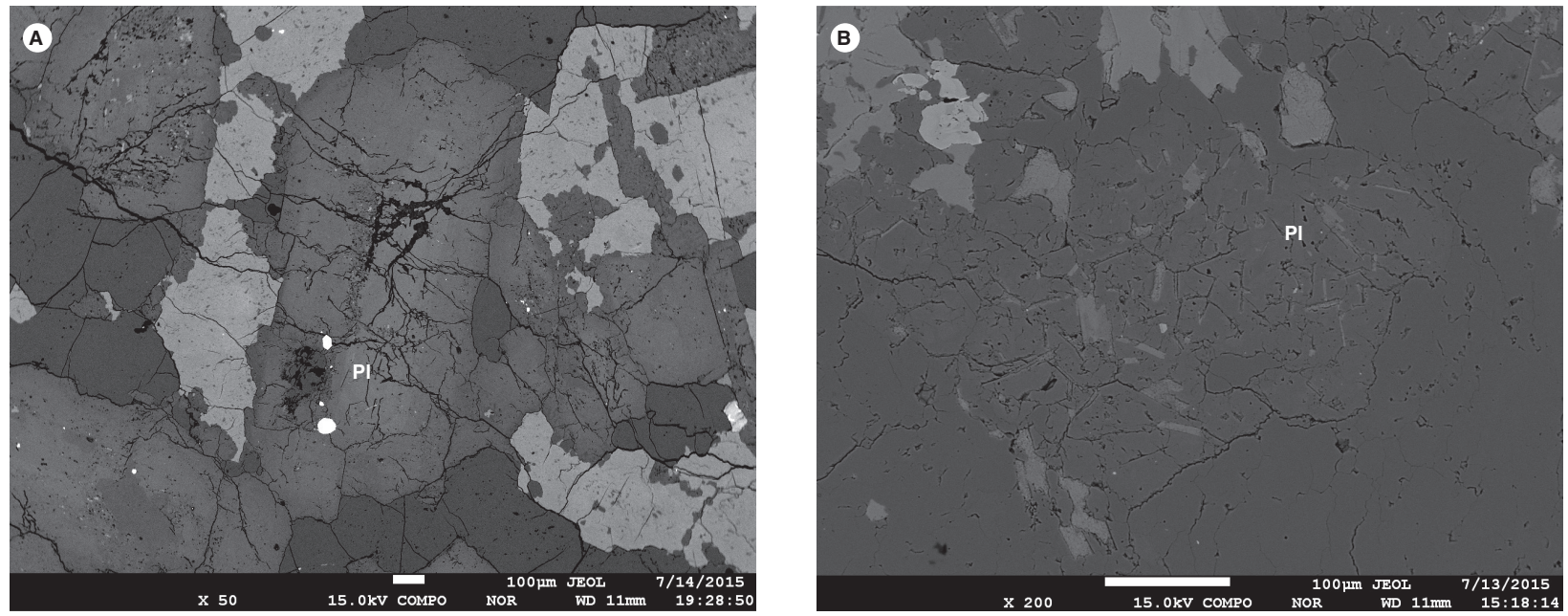

Figura 15. Cristales de plagioclasa de las muestras LMC-078 y MIA-627A en campos C7. Imagen de electrones retrodispersados. El núcleo de los cristales es más claro que los bordes 
Tabla 8. Análisis de cristales de plagioclasa de las muestras AMC-0131 y LMC-078

\begin{tabular}{|c|c|c|c|c|c|c|c|c|c|c|c|c|c|c|c|}
\hline & $\begin{array}{c}\text { AMC- } \\
0131- \\
\text { C10-Pl-1 }\end{array}$ & $\begin{array}{c}\text { AMC- } \\
0131- \\
\text { C10-PI-2 }\end{array}$ & $\begin{array}{c}\text { AMC- } \\
0131- \\
\text { C10-PI-3 }\end{array}$ & $\begin{array}{l}\text { AMC- } \\
\text { 0131-C10- } \\
\text { Pl-4A }\end{array}$ & $\begin{array}{c}\text { AMC- } \\
0131-C 10 \\
\text {-Pl-5 }\end{array}$ & $\begin{array}{c}\text { AMC- } \\
\text { 0131- } \\
\text { C10- PI-6 }\end{array}$ & $\begin{array}{c}\text { AMC- } \\
0131- \\
\text { C10-PI-9 }\end{array}$ & $\begin{array}{c}\text { AMC- } \\
0131- \\
\text { C12-Pl-1 }\end{array}$ & $\begin{array}{c}\text { AMC- } \\
0131- \\
\text { C12-PI-2 }\end{array}$ & $\begin{array}{c}\text { AMC- } \\
0131- \\
\text { C12-PI-3 }\end{array}$ & $\begin{array}{c}\text { AMC- } \\
0131- \\
\text { C12-PI-4 }\end{array}$ & $\begin{array}{l}\text { AMC- } \\
0131- \\
\text { C12-PI }\end{array}$ & $\begin{array}{c}\text { LMC-078- } \\
\text { C3-PI-1 }\end{array}$ & $\begin{array}{c}\text { LMC-078- } \\
\text { C3-PI-2 }\end{array}$ & $\begin{array}{l}\text { LMC-078- } \\
\text { C3-PI-3 }\end{array}$ \\
\hline $\mathrm{SiO}_{2}$ & 63,96 & 61,77 & 60,68 & 59,86 & 60,38 & 63 & 63,63 & 61,81 & 61,41 & 61,77 & 62,17 & 60,4 & 61,15 & 59,79 & 61,36 \\
\hline $\mathrm{TiO}_{2}$ & 0 & 0 & 0,02 & 0 & 0,01 & 0,01 & 0 & 0 & 0 & 0 & 0 & 0 & 0,00 & 0,00 & 0,03 \\
\hline $\mathrm{Al}_{2} \mathrm{O}_{3}$ & 22,9 & 24,54 & 25,15 & 25,56 & 25,29 & 23,29 & 23,31 & 24,09 & 24,72 & 23,87 & 23,56 & 24,96 & 25,02 & 26,12 & 24,89 \\
\hline $\mathrm{FeO}$ & 0,03 & 0,1 & 0,13 & 0,1 & 0,03 & 0,01 & 0,01 & 0,08 & 0,07 & 0,09 & 0,05 & 0,11 & 0,11 & 0,13 & 0,06 \\
\hline $\mathrm{MgO}$ & 0 & 0 & 0 & 0 & 0,01 & 0 & 0,01 & 0 & 0 & 0 & 0 & 0 & 0,00 & 0,00 & 0,00 \\
\hline $\mathrm{CaO}$ & 2,93 & 4,19 & 4,94 & 5,13 & 4,96 & 3,31 & 3,16 & 4,28 & 4,51 & 4,19 & 3,98 & 5,54 & 5,75 & 6,78 & 5,36 \\
\hline $\mathrm{Na}_{2} \mathrm{O}$ & 9,81 & 8,54 & 7,94 & 8,05 & 8,22 & 9,74 & 9,68 & 8,6 & 8,44 & 8,91 & 9,32 & 8,49 & 8,40 & 7,81 & 8,48 \\
\hline $\mathrm{K}_{2} \mathrm{O}$ & 0,45 & 0,41 & 0,39 & 0,34 & 0,26 & 0,24 & 0,34 & 0,47 & 0,4 & 0,49 & 0,27 & 0,44 & 0,34 & 0,30 & 0,29 \\
\hline Total & 100,1 & 99,54 & 99,24 & 99,03 & 99,14 & 99,6 & 100,1 & 99,33 & 99,54 & 99,32 & 99,34 & 99,95 & 100,76 & 100,92 & 100,46 \\
\hline $\mathrm{Si}$ & 11,28 & 10,98 & 10,84 & 10,73 & 10,8 & 11,18 & 11,22 & 11,02 & 10,93 & 11,03 & 11,08 & 10,77 & 10,80 & 10,58 & 10,85 \\
\hline $\mathrm{Al}$ & 4,76 & 5,14 & 5,29 & 5,4 & 5,33 & 4,87 & 4,84 & 5,06 & 5,18 & 5,02 & 4,95 & 5,25 & 5,21 & 5,45 & 5,19 \\
\hline $\mathrm{Ti}$ & 0 & 0,01 & 0,01 & 0,01 & 0 & 0 & 0 & 0,01 & 0,01 & 0,01 & 0 & 0,01 & 0,01 & 0,01 & 0,01 \\
\hline $\mathrm{Fe}$ & 0 & 0 & 0 & 0 & 0 & 0 & 0 & 0 & 0 & 0 & 0 & 0 & 0,00 & 0,00 & 0,00 \\
\hline $\mathrm{Mg}$ & 0 & 0 & 0 & 0 & 0 & 0 & 0 & 0 & 0 & 0 & 0 & 0 & 0,00 & 0,00 & 0,00 \\
\hline $\mathrm{Na}$ & 3,36 & 2,94 & 2,75 & 2,8 & 2,85 & 3,35 & 3,31 & 2,97 & 2,91 & 3,08 & 3,22 & 2,94 & 2,88 & 2,68 & 2,91 \\
\hline $\mathrm{Ca}$ & 0,55 & 0,8 & 0,94 & 0,98 & 0,95 & 0,63 & 0,6 & 0,82 & 0,86 & 0,8 & 0,76 & 1,06 & 1,09 & 1,29 & 1,02 \\
\hline K & 0,1 & 0,09 & 0,09 & 0,08 & 0,06 & 0,05 & 0,08 & 0,11 & 0,09 & 0,11 & 0,06 & 0,1 & 0,08 & 0,07 & 0,06 \\
\hline Total & 20,06 & 19,96 & 19,93 & 20 & 19,99 & 20,09 & 20,05 & 19,98 & 19,98 & 20,06 & 20,08 & 20,12 & 20,12 & 20,12 & 20,12 \\
\hline$z$ & 16,05 & 16,13 & 16,15 & 16,14 & 16,13 & 16,05 & 16,07 & 16,09 & 16,12 & 16,06 & 16,04 & 16,03 & 16,02 & 16,04 & 16,05 \\
\hline$x$ & 4,01 & 3,83 & 3,78 & 3,86 & 3,86 & 4,04 & 3,98 & 3,9 & 3,86 & 4 & 4,04 & 4,1 & 4,04 & 4,03 & 3,99 \\
\hline$A b$ & 83,7 & 76,76 & 72,68 & 72,48 & 73,86 & 83,07 & 83,08 & 76,28 & 75,41 & 77,17 & 79,69 & 71,69 & 71,20 & 66,47 & 72,92 \\
\hline An & 13,81 & 20,84 & 24,98 & 25,53 & 24,62 & 15,59 & 14,99 & 20,97 & 22,25 & 20,03 & 18,81 & 25,84 & 26,93 & 31,88 & 25,47 \\
\hline Or & 2,5 & 2,4 & 2,33 & 2 & 1,51 & 1,34 & 1,93 & 2,75 & 2,33 & 2,8 & 1,51 & 2,47 & 1,87 & 1,66 & 1,61 \\
\hline Total & 100 & 100 & 100 & 100 & 100 & 100 & 100 & 100 & 100 & 100 & 100 & 100 & 100,00 & 100,00 & 100,00 \\
\hline
\end{tabular}

Tabla 9. Análisis de cristales de plagioclasa de la muestra MIA-627A

\begin{tabular}{|c|c|c|c|c|}
\hline & MIA-627A-C7-PI-1 & MIA-627A-C7-PI-2 & MIA-627A-C7-PI-3 & MIA-627A-C7-PI-4 \\
\hline $\mathrm{SiO}_{2}$ & 67,73 & 67,35 & 66,14 & 68,23 \\
\hline $\mathrm{TiO}_{2}$ & 0 & 0 & 0 & 0 \\
\hline $\mathrm{Al}_{2} \mathrm{O}_{3}$ & 20,34 & 20,38 & 21,26 & 19,63 \\
\hline $\mathrm{FeO}$ & 0,01 & 0 & 0,04 & 0,06 \\
\hline $\mathrm{MgO}$ & 0 & 0,01 & 0,01 & 0,01 \\
\hline $\mathrm{CaO}$ & 0,72 & 0,85 & 1,61 & 0,47 \\
\hline $\mathrm{Na}_{2} \mathrm{O}$ & 11,84 & 11,93 & 11,24 & 12,18 \\
\hline $\mathrm{K}_{2} \mathrm{O}$ & 0,11 & 0,09 & 0,09 & 0,1 \\
\hline Total & 100,75 & 100,61 & 100,37 & 100,68 \\
\hline $\mathrm{Si}$ & 11,8 & 11,76 & 11,59 & 11,89 \\
\hline $\mathrm{Al}$ & 4,18 & 4,19 & 4,39 & 4,03 \\
\hline $\mathrm{Ti}$ & 0 & 0 & 0 & 0,01 \\
\hline $\mathrm{Fe}$ & 0 & 0 & 0 & 0 \\
\hline $\mathrm{Mg}$ & 0 & 0 & 0 & 0 \\
\hline $\mathrm{Na}$ & 4 & 4,04 & 3,82 & 4,12 \\
\hline $\mathrm{Ca}$ & 0,13 & 0,16 & 0,3 & 0,09 \\
\hline $\mathrm{K}$ & 0,03 & 0,02 & 0,02 & 0,02 \\
\hline Total & 20,12 & 20,12 & 20,12 & 20,12 \\
\hline$z$ & 15,97 & 15,95 & 15,99 & 15,93 \\
\hline$x$ & 4,16 & 4,22 & 4,14 & 4,23 \\
\hline$A b$ & 96,15 & 95,76 & 92,22 & 97,38 \\
\hline An & 3,24 & 3,75 & 7,28 & 2,08 \\
\hline Or & 0,6 & 0,49 & 0,5 & 0,54 \\
\hline Total & 100 & 100 & 100 & 100 \\
\hline
\end{tabular}




\subsection{Micas}

La biotita se analizó en cuatro cristales de la muestra AMC-0131 (figura 16) y en dos cristales de la muestra LMC-078 (figura 17). La localización de los puntos analizados se expone junto con las imágenes BSE. Las biotitas exhiben microfracturas que cortan el clivaje e inclusiones de opacos, algunos hexagonales (figuras 16 y 17 , tabla 10).

En la roca AMC-0131, la biotita tiene concentraciones de $\mathrm{SiO}_{2}$ entre 34,66 y 35,66\%; $\mathrm{FeO}$ entre 19,96 y 24,87\%; $\mathrm{Al}_{2} \mathrm{O}_{3}$ entre 15,94 y 17,26\%, y MgO entre 6,54 y $8,48 \%$, como se muestra en la tabla 10 . Los cristales de biotita presentan valores altos de aluminio tetraédrico $\left(\mathrm{Al}^{\mathrm{IV}}\right)$ (2,3 a 2,8 atom/unidad fórmula), característicos de granitos peraluminosos, como se observa en el gráfico de Abdel Rahman (1994), lo que sugiere que la muestra AMC-131 podría corresponder a un granito tipo $\mathrm{S}$ (Whalen y Chappell, 1988).

El cristal AMC-0131-C11 presenta un contenido de $\mathrm{SiO}_{2}$, entre 32,84 y $35,75 \%$, que corresponde a un tipo especial de biotita, según el diagrama de Rieder et al. (1998), en el que se observan sus valores separados de los de las demás muestras, dado su contenido de $\mathrm{SiO}_{2}$; los demás cristales se agrupan juntos (figura 18A). Las biotitas de la muestra AMC-0131 presentan una composición intermedia entre biotita y annita; el cristal C1 1 presenta una composición entre biotita y siderofilita, y los resultados de todos los análisis se inscriben en la serie peraluminosa (figura 18B).
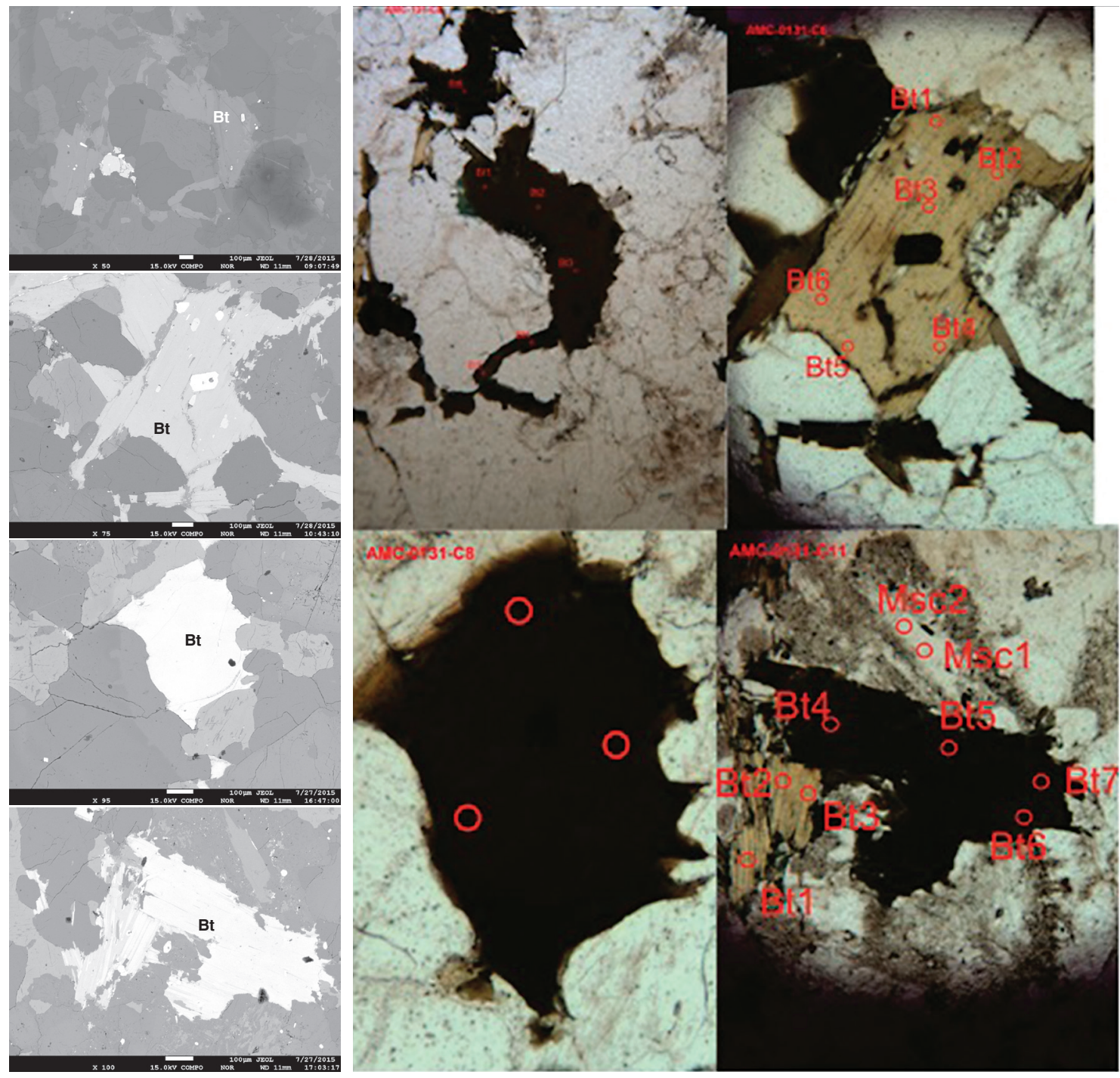

Figura 16. Imágenes de electrones secundarios retrodispersados (BSE) y puntos analizados de diferentes cristales de biotita de la muestra AMC-0131 

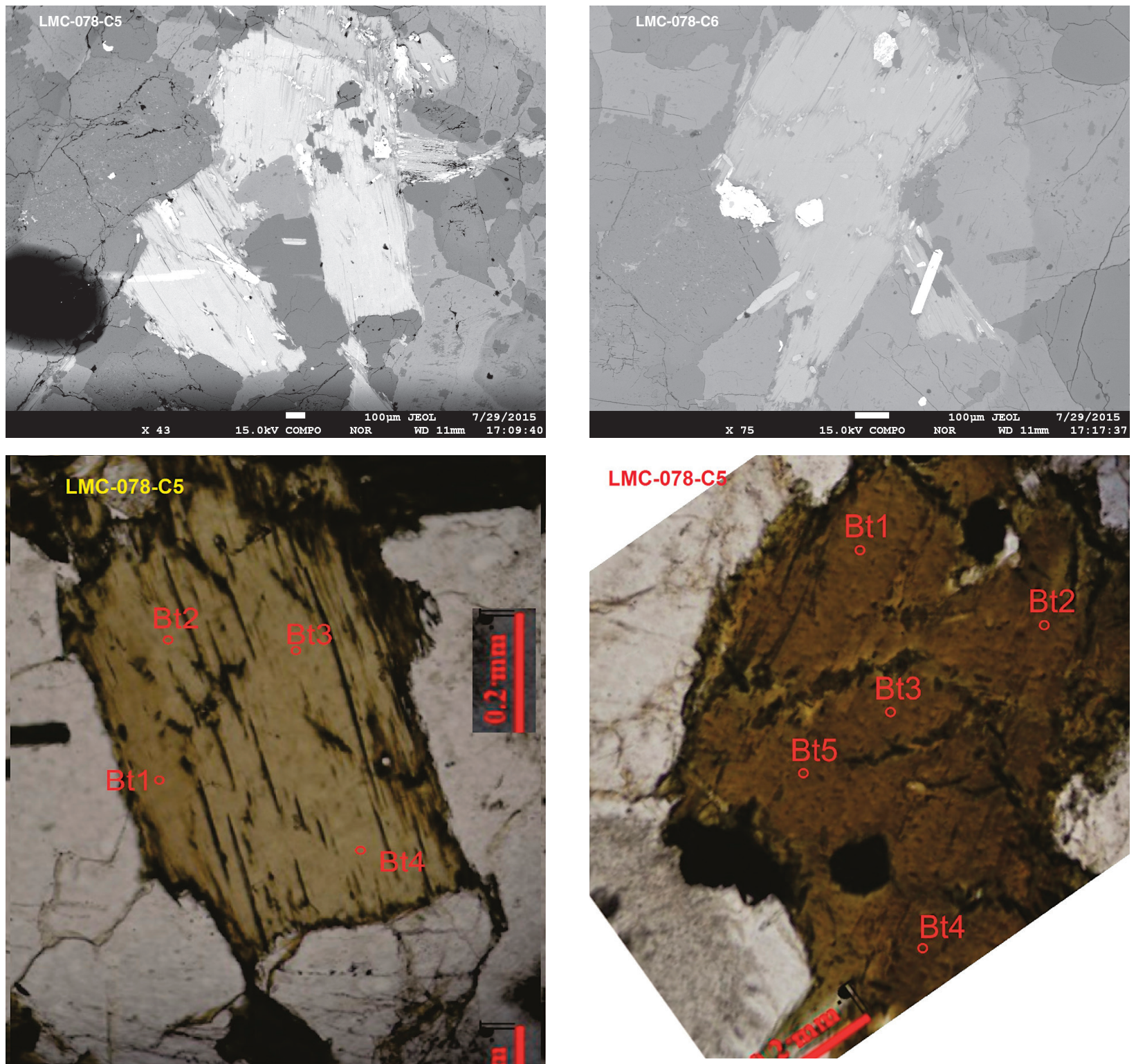

Figura 17. Imágenes de electrones secundarios retrodispersados (BSE) y puntos analizados de diferentes cristales de biotita de la muestra LMC-078 
Tabla 10. Composición química de biotitas en la roca AMC-0131

\begin{tabular}{|c|c|c|c|c|c|c|c|c|c|c|c|}
\hline $\begin{array}{c}\text { Punto } \\
\text { analizado }\end{array}$ & $\begin{array}{c}\text { AMC-0131- } \\
\text { C2-Bt-2 }\end{array}$ & $\begin{array}{c}\text { AMC-0131- } \\
\text { C2-Bt-3 }\end{array}$ & $\begin{array}{c}\text { AMC-0131- } \\
\text { C2-Bt-4 }\end{array}$ & $\begin{array}{c}\text { AMC-0131- } \\
\text { C2-Bt-5 }\end{array}$ & $\begin{array}{c}\text { AMC-0131- } \\
\text { C2-Bt-6 }\end{array}$ & $\begin{array}{c}\text { AMC-0131- } \\
\text { C6-Bt-1 }\end{array}$ & $\begin{array}{c}\text { AMC-0131- } \\
\text { C6-Bt-2 }\end{array}$ & $\begin{array}{c}\text { AMC-0131- } \\
\text { C6-Bt-3 }\end{array}$ & $\begin{array}{c}\text { AMC-0131- } \\
\text { C6-Bt-4 }\end{array}$ & $\begin{array}{c}\text { AMC-0131- } \\
\text { C6-Bt-5 }\end{array}$ & $\begin{array}{c}\text { AMC-0131- } \\
\text { C6-Bt-6 }\end{array}$ \\
\hline $\mathrm{SiO}_{2}$ & 34,95 & 34,86 & 35,34 & 35,38 & 36 & 35,01 & 35,43 & 35,11 & 35,06 & 35,09 & 34,8 \\
\hline $\mathrm{TiO}_{2}$ & 2,43 & 2,62 & 2,34 & 2,53 & 2,61 & 2,49 & 2,51 & 1,93 & 2,80 & 2,70 & 1,95 \\
\hline $\mathrm{Al}_{2} \mathrm{O}_{3}$ & 16,47 & 16,48 & 16,91 & 16,78 & 16,08 & 16,57 & 16,79 & 16,98 & 17,07 & 16,98 & 16,60 \\
\hline $\mathrm{FeO}$ & 21,62 & 20,44 & 21,40 & 21,07 & 20,25 & 21,93 & 21,52 & 22,11 & 21,29 & 21,28 & 21,20 \\
\hline $\mathrm{MgO}$ & 7,49 & 6,74 & 7,07 & 7,02 & 7,44 & 6,94 & 7,04 & 7,25 & 6,74 & 6,94 & 7,76 \\
\hline $\mathrm{MnO}$ & 0,61 & 0,61 & 0,66 & 0,64 & 0,68 & 0,58 & 0,52 & 0,48 & 0,56 & 0,54 & 0,48 \\
\hline $\mathrm{CaO}$ & 0,00 & 0,01 & 0,00 & 0,00 & 0,00 & 0,00 & 0,02 & 0,00 & 0,00 & 0,00 & 0,01 \\
\hline $\mathrm{Na}_{2} \mathrm{O}$ & 0,12 & 0,12 & 0,12 & 0,08 & 0,06 & 0,07 & 0,07 & 0,07 & 0,06 & 0,10 & 0,05 \\
\hline $\mathrm{K}_{2} \mathrm{O}$ & 9,64 & 9,23 & 9,72 & 9,74 & 9,66 & 9,64 & 9,50 & 9,48 & 9,55 & 9,55 & 9,60 \\
\hline Total & 93,31 & 91,11 & 93,56 & 93,24 & 92,76 & 93,23 & 93,40 & 93,41 & 93,14 & 93,18 & 92,50 \\
\hline \multicolumn{12}{|c|}{ Fórmula basada en 220} \\
\hline $\mathrm{Si}$ & 5,54 & 5,62 & 5,58 & 5,59 & 5,69 & 5,56 & 5,59 & 5,56 & 5,55 & 5,55 & 5,56 \\
\hline Alv & 2,46 & 2,38 & 2,42 & 2,41 & 2,31 & 2,44 & 2,41 & 2,44 & 2,45 & 2,45 & 2,44 \\
\hline $\mathrm{Al}^{\mathrm{VI}}$ & 0,62 & 0,75 & 0,72 & 0,72 & 0,69 & 0,67 & 0,71 & 0,73 & 0,73 & 0,72 & 0,69 \\
\hline $\mathrm{Ti}$ & 0,29 & 0,32 & 0,28 & 0,30 & 0,31 & 0,30 & 0,30 & 0,23 & 0,33 & 0,32 & 0,23 \\
\hline $\mathrm{Mg}$ & 1,77 & 1,62 & 1,66 & 1,66 & 1,75 & 1,64 & 1,66 & 1,71 & 1,59 & 1,64 & 1,85 \\
\hline $\mathrm{Fe}^{2+}$ & 2,87 & 2,76 & 2,82 & 2,79 & 2,68 & 2,91 & 2,84 & 2,93 & 2,82 & 2,82 & 2,83 \\
\hline $\mathrm{Mn}$ & 0,08 & 0,08 & 0,09 & 0,09 & 0,09 & 0,08 & 0,07 & 0,07 & 0,08 & 0,07 & 0,06 \\
\hline $\mathrm{Ca}$ & 0,00 & 0,00 & 0,00 & 0,00 & 0,00 & 0,00 & 0,00 & 0,00 & 0,00 & 0,00 & 0,00 \\
\hline $\mathrm{Na}$ & 0,04 & 0,04 & 0,04 & 0,03 & 0,02 & 0,02 & 0,02 & 0,02 & 0,02 & 0,03 & 0,02 \\
\hline $\mathrm{K}$ & 1,95 & 1,90 & 1,96 & 1,96 & 1,95 & 1,96 & 1,91 & 1,92 & 1,93 & 1,93 & 1,96 \\
\hline Total & 15,62 & 15,46 & 15,57 & 15,54 & 15,48 & 15,57 & 15,52 & 15,60 & 15,50 & 15,52 & 15,60 \\
\hline $\mathrm{Fe} /(\mathrm{Fe}+\mathrm{Mg})$ & 0,62 & 0,63 & 0,63 & 0,63 & 0,60 & 0,64 & 0,63 & 0,63 & 0,64 & 0,63 & 0,60 \\
\hline $\begin{array}{c}\text { Punto } \\
\text { analizado }\end{array}$ & $\begin{array}{c}\text { AMC-0131- } \\
\text { C8-Bt-1 }\end{array}$ & $\begin{array}{c}\text { AMC-0131- } \\
\text { C8-Bt-2 }\end{array}$ & $\begin{array}{c}\text { AMC-0131- } \\
\text { C8-Bt-3 }\end{array}$ & $\begin{array}{c}\text { AMC-0131- } \\
\text { C11-Bt-3 }\end{array}$ & $\begin{array}{c}\text { AMC-0131- } \\
\text { C11-Bt-3 }\end{array}$ & $\begin{array}{c}\text { AMC-0131- } \\
\text { C11-Bt-4 }\end{array}$ & $\begin{array}{c}\text { AMC-0131- } \\
\text { C11-Bt-5 }\end{array}$ & $\begin{array}{c}\text { AMC-0131- } \\
\text { C11-Bt-6 }\end{array}$ & $\begin{array}{c}\text { AMC-0131- } \\
\text { C11-Bt-7 }\end{array}$ & $\begin{array}{c}\text { AMC-0131- } \\
\text { C11-Bt-7 }\end{array}$ & $\begin{array}{c}\text { AMC-0131- } \\
\text { C2-Bt-1 }\end{array}$ \\
\hline $\mathrm{SiO}_{2}$ & 35,76 & 35,02 & 35,97 & 32,84 & 32,17 & 34,26 & 35,75 & 35,74 & 35,11 & 35,11 & 34,57 \\
\hline $\mathrm{TiO}_{2}$ & 2,639 & 2,43 & 2,622 & 1,799 & 1,749 & 1,979 & 2,638 & 2,669 & 2,731 & 2,731 & 1,924 \\
\hline $\mathrm{Al}_{2} \mathrm{O}_{3}$ & 16,51 & 17,26 & 16,75 & 17,09 & 17,26 & 16,42 & 16,77 & 16,93 & 17,26 & 17,26 & 15,94 \\
\hline $\mathrm{FeO}$ & 20,08 & 20,54 & 19,96 & 24,87 & 24,78 & 23,37 & 21,58 & 21,47 & 21,91 & 21,91 & 21,5 \\
\hline $\mathrm{MgO}$ & 7,011 & 6,622 & 6,542 & 8,346 & 8,489 & 7,69 & 6,802 & 7,074 & 6,596 & 6,596 & 7,983 \\
\hline $\mathrm{MnO}$ & 0,622 & 0,745 & 0,728 & 0,68 & 0,722 & 0,658 & 0,682 & 0,74 & 0,651 & 0,651 & 0,571 \\
\hline $\mathrm{CaO}$ & 0,011 & 0 & 0 & 0 & 0,025 & 0,034 & 0 & 0 & 0 & 0 & 0,038 \\
\hline $\mathrm{Na}_{2} \mathrm{O}$ & 0,056 & 0,118 & 0,128 & 0,05 & 0,051 & 0,071 & 0,11 & 0,091 & 0,066 & 0,066 & 0,104 \\
\hline $\mathrm{K}_{2} \mathrm{O}$ & 9,613 & 9,421 & 9,356 & 7,124 & 6,795 & 8,732 & 9,637 & 9,615 & 9,623 & 9,623 & 9,638 \\
\hline Total & 92,31 & 92,15 & 92,06 & 92,81 & 92,04 & 93,22 & 93,97 & 94,33 & 93,95 & 93,95 & 92,27 \\
\hline \multicolumn{12}{|c|}{ Fórmula basada en 220} \\
\hline $\mathrm{Si}$ & 5,675 & 5,583 & 5,708 & 5,273 & 5,208 & 5,472 & 5,613 & 5,613 & 5,586 & 5,528 & 5,557 \\
\hline Alv & 2,325 & 2,417 & 2,292 & 2,727 & 2,792 & 2,528 & 2,387 & 2,387 & 2,414 & 2,472 & 2,443 \\
\hline $\mathrm{Al}^{\mathrm{VI}}$ & 0,762 & 0,825 & 0,84 & 0,508 & 0,501 & 0,562 & 0,716 & 0,716 & 0,704 & 0,729 & 0,577 \\
\hline $\mathrm{Ti}$ & 0,315 & 0,291 & 0,313 & 0,217 & 0,213 & 0,238 & 0,311 & 0,311 & 0,314 & 0,323 & 0,233 \\
\hline $\mathrm{Mg}$ & 1,658 & 1,574 & 1,548 & 1,998 & 2,049 & 1,831 & 1,592 & 1,592 & 1,648 & 1,548 & 1,913 \\
\hline $\mathrm{Fe}^{2+}$ & 2,664 & 2,738 & 2,648 & 3,339 & 3,356 & 3,12 & 2,833 & 2,833 & 2,805 & 2,885 & 2,89 \\
\hline $\mathrm{Mn}$ & 0,084 & 0,101 & 0,098 & 0,092 & 0,099 & 0,089 & 0,091 & 0,091 & 0,098 & 0,087 & 0,078 \\
\hline $\mathrm{Ca}$ & 0,002 & 0 & 0 & 0 & 0,004 & 0,006 & 0 & 0 & 0 & 0 & 0,007 \\
\hline $\mathrm{Na}$ & 0,017 & 0,036 & 0,039 & 0,016 & 0,016 & 0,022 & 0,033 & 0,033 & 0,028 & 0,02 & 0,032 \\
\hline $\mathrm{K}$ & 1,946 & 1,916 & 1,894 & 1,459 & 1,403 & 1,779 & 1,93 & 1,93 & 1,917 & 1,932 & 1,976 \\
\hline Total & 15,45 & 15,48 & 15,38 & 15,63 & 15,64 & 15,65 & 15,51 & 15,51 & 15,51 & 15,52 & 15,7 \\
\hline $\mathrm{Fe} /(\mathrm{Fe}+\mathrm{Mg})$ & 0,616 & 0,635 & 0,631 & 0,626 & 0,621 & 0,63 & 0,64 & 0,64 & 0,63 & 0,651 & 0,602 \\
\hline
\end{tabular}



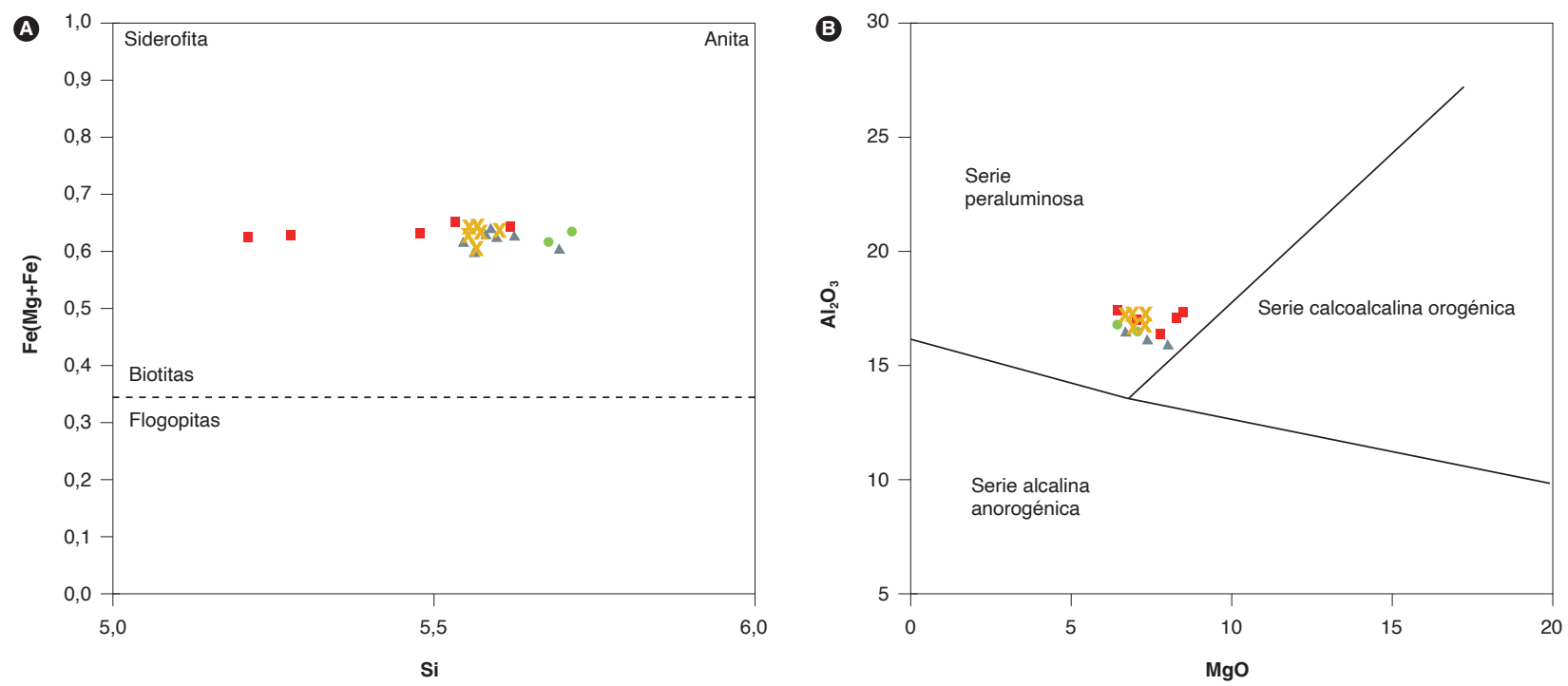

Figura 18. Biotitas de la muestra AMC-0131 de la facies porfídica del Monzogranito de La Corcova

Fuente: diagramas A de Rieder et al. (1998), B de Abdel Rahman (1994) y este trabajo

La biotita de la roca LMC-078 tiene concentraciones de $\mathrm{SiO}_{2}$ entre 35,49 y $36,25 \%$; $\mathrm{FeO}$ entre 17,79 y $20,38 \%$; $\mathrm{Al}_{2} \mathrm{O}_{3}$ entre 16,49 y 1 7,58\%, y MgO entre 9,41 y $10,01 \%$, como se muestra en la tabla 11. Los cristales de biotita presentan valores altos de aluminio tetraédrico $\left(\mathrm{Al}^{\mathrm{IV}}\right)$ (2,43 a 2,5 atom/unidad fórmula), que se ubican en el límite entre granitos peraluminosos y granitos calcoalcalinos orogénicos, como se observa en el gráfico de Abdel Rahman (1994) (figura 19B).

Las biotitas de la muestra LMC-078 tiene contenidos de $\mathrm{SiO}_{2}$ poco variables. Presentan una composición con valores intermedios de $\mathrm{Fe}(\mathrm{Mg}+\mathrm{Fe})$ entre 0,50 y 0,53 , y no muestran mucha dispersión en el diagrama de Rieder et al. (1998) (figura 19A).

Se analizaron cristales de mica blanca en las muestras AMC-0131, LMC-078 y MIA-627A (los resultados de los análisis se presentan en tabla 12), que tienen contenidos de Si entre 6,21 y 6,40, de Mg entre 0,12 y 0,47, de Fe entre 0,39 y 0,56, y un contenido medio de Al. Los cristales tienen bajo contenido de $\mathrm{Na}(0,09$ a 0,20).

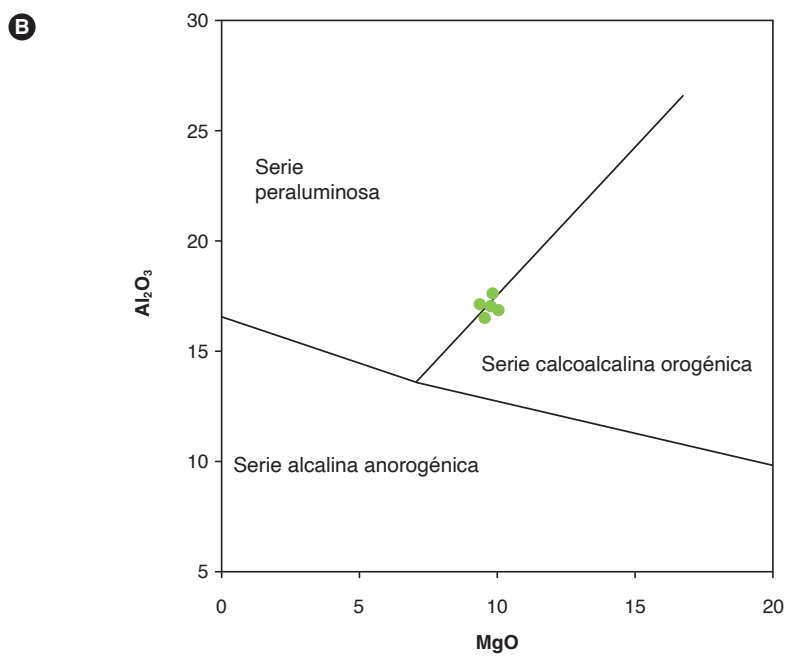

Figura 19. Biotitas de la muestra LMC-078 de la facies típica del Monzogranito de La Corcova Fuente: Rieder et al. (1998), Abdel Rahman (1994) y este trabajo 
Tabla 11. Composición química de biotitas de la roca LMC-078

\begin{tabular}{|c|c|c|c|c|c|c|c|}
\hline Punto analizado & LMC-078-C5-Bt-1 & LMC-078-C5-Bt-2 & LMC-078-C5-Bt-4 & LMC-078-C6-Bt-1 & LMC-078-C6-Bt-2 & LMC-078-C6-Bt-3 & LMC-078-C6-Bt-4 \\
\hline $\mathrm{SiO}_{2}$ & 35,67 & 35,63 & 35,49 & 36,25 & 36,02 & 36,04 & 35,51 \\
\hline $\mathrm{TiO}_{2}$ & 2,86 & 3 & 2,88 & 2,46 & 2,49 & 2,55 & 2,58 \\
\hline $\mathrm{Al}_{2} \mathrm{O}_{3}$ & 17,12 & 16,82 & 17,14 & 17,22 & 17,58 & 17,1 & 16,49 \\
\hline $\mathrm{FeO}$ & 18,68 & 18,07 & 17,83 & 18,06 & 17,79 & 19,09 & 20,38 \\
\hline $\mathrm{MgO}$ & 9,41 & 10,01 & 9,69 & 9,98 & 9,91 & 9,72 & 9,55 \\
\hline $\mathrm{MnO}$ & 0,58 & 0,63 & 0,53 & 0,52 & 0,49 & 0,47 & 0,52 \\
\hline $\mathrm{CaO}$ & 0 & 0 & 0 & 0,01 & 0,03 & 0 & 0,05 \\
\hline $\mathrm{Na}_{2} \mathrm{O}$ & 0,19 & 0,24 & 0,24 & 0,38 & 0,27 & 0,14 & 0,12 \\
\hline $\mathrm{K}_{2} \mathrm{O}$ & 9,68 & 9,62 & 9,61 & 9,41 & 9,58 & 9,34 & 8,77 \\
\hline Total & 94,2 & 94,02 & 93,41 & 94,29 & 94,16 & 94,44 & 93,98 \\
\hline \multicolumn{8}{|c|}{ Fórmula basada en 220} \\
\hline $\mathrm{Si}$ & 5,511 & 5,5 & 5,51 & 5,56 & 5,53 & 5,52 & 5,57 \\
\hline $\mathrm{All}^{\mathrm{IV}}$ & 2,489 & 2,5 & 2,49 & 2,44 & 2,47 & 2,48 & 2,43 \\
\hline $\mathrm{Al}^{\mathrm{VI}}$ & 0,627 & 0,57 & 0,64 & 0,67 & 0,71 & 0,54 & 0,66 \\
\hline $\mathrm{Ti}$ & 0,332 & 0,35 & 0,34 & 0,28 & 0,29 & 0,3 & 0,34 \\
\hline $\mathrm{Mg}$ & 2,167 & 2,3 & 2,24 & 2,28 & 2,27 & 2,21 & 2,24 \\
\hline $\mathrm{Fe}^{2+}$ & 2,413 & 2,33 & 2,31 & 2,32 & 2,28 & 2,65 & 2,3 \\
\hline $\mathrm{Mn}$ & 0,076 & 0,08 & 0,07 & 0,07 & 0,06 & 0,07 & 0,07 \\
\hline $\mathrm{Ca}$ & 0 & 0 & 0 & 0 & 0 & 0,01 & 0 \\
\hline $\mathrm{Na}$ & 0,058 & 0,07 & 0,07 & 0,11 & 0,08 & 0,04 & 0,07 \\
\hline $\mathrm{K}$ & 1,908 & 1,9 & 1,9 & 1,84 & 1,87 & 1,74 & 1,81 \\
\hline Total & 15,58 & 15,6 & 15,58 & 15,58 & 15,57 & 15,56 & 15,49 \\
\hline $\mathrm{Fe} /(\mathrm{Fe}+\mathrm{Mg})$ & 0,53 & 0,5 & 0,51 & 0,5 & 0,5 & 0,54 & 0,51 \\
\hline
\end{tabular}

Tabla 12. Composición química de las moscovitas de las muestras AMC-0131, LMC-078 y MIA-627A

\begin{tabular}{|c|c|c|c|c|c|c|c|c|c|c|}
\hline $\begin{array}{c}\text { Punto } \\
\text { analizado }\end{array}$ & $\begin{array}{l}\text { AMC-0131- } \\
\text { C11-Msc-1 }\end{array}$ & $\begin{array}{l}\text { AMC-0131- } \\
\text { C11-Msc-2 }\end{array}$ & $\begin{array}{c}\text { LMC-078-C2- } \\
\text { Ms-1 }\end{array}$ & $\begin{array}{c}\text { LMC-078-C2- } \\
\text { Ms-2 }\end{array}$ & $\begin{array}{c}\text { LMC-078-C2- } \\
\text { Ms-3 }\end{array}$ & $\begin{array}{c}\text { LMC-078-C2- } \\
\text { Ms-4 }\end{array}$ & $\begin{array}{c}\text { LMC-078-C7- } \\
\text { Ms-2 }\end{array}$ & $\begin{array}{c}\text { LMC-078-C7- } \\
\text { Ms-3 }\end{array}$ & $\begin{array}{c}\text { LMC-078-C7- } \\
\text { Ms-4 }\end{array}$ & $\begin{array}{c}\text { LMC-078-C7- } \\
\text { Ms-5 }\end{array}$ \\
\hline $\mathrm{SiO}_{2}$ & 46,14 & 46,19 & 45,66 & 45,63 & 46,16 & 45,57 & 45,75 & 45,65 & 45,26 & 46,13 \\
\hline $\mathrm{TiO}_{2}$ & 0,59 & 0,42 & 0,21 & 0,41 & 0,31 & 0,36 & 0,69 & 0,35 & 0,43 & 0,3 \\
\hline $\mathrm{Al}_{2} \mathrm{O}_{3}$ & 30,83 & 30,75 & 32,32 & 32,25 & 32,1 & 31,9 & 31,39 & 31,27 & 30,35 & 30,75 \\
\hline $\mathrm{FeO}$ & 3,39 & 3,46 & 3,65 & 3,61 & 3,76 & 3,76 & 3,75 & 3,84 & 4,85 & 4,09 \\
\hline $\mathrm{MgO}$ & 0,76 & 0,77 & 0,91 & 0,87 & 0,95 & 0,94 & 0,99 & 1,24 & 2,28 & 1,48 \\
\hline $\mathrm{MnO}$ & 0,02 & 0,03 & 0,03 & 0,02 & 0,06 & 0,06 & 0,05 & 0,04 & 0,07 & 0,01 \\
\hline $\mathrm{CaO}$ & & & 0,04 & 0 & 0,01 & 0,01 & 0,02 & & & 0,01 \\
\hline $\mathrm{Na}_{2} \mathrm{O}$ & 0,7 & 0,69 & 0,56 & 0,53 & 0,54 & 0,51 & 0,5 & 0,46 & 0,38 & 0,38 \\
\hline $\mathrm{K}_{2} \mathrm{O}$ & 10,61 & 10,62 & 10,63 & 10,54 & 10,59 & 10,59 & 10,67 & 10,81 & 10,8 & 10,68 \\
\hline Total & 93,02 & 92,92 & 94,01 & 93,86 & 94,47 & 93,71 & 93,81 & 93,65 & 94,41 & 93,82 \\
\hline \multicolumn{11}{|c|}{ Fórmula basada en 220} \\
\hline $\mathrm{Si}$ & 6,38 & 6,4 & 6,26 & 6,26 & 6,29 & 6,24 & 6,35 & 6,3 & 6,24 & 6,35 \\
\hline $\mathrm{All}^{\mathrm{IV}}$ & 1,62 & 1,6 & 1,74 & 1,74 & 1,71 & 1,76 & 1,65 & 1,7 & 1,76 & 1,65 \\
\hline $\mathrm{Al}^{\mathrm{VI}}$ & 3,4 & 3,41 & 3,47 & 3,47 & 3,45 & 3,17 & 3,33 & 3,38 & 3,17 & 3,33 \\
\hline $\mathrm{Ti}$ & 0,06 & 0,04 & 0,02 & 0,04 & 0,03 & 0,04 & 0,03 & 0,04 & 0,04 & 0,03 \\
\hline $\mathrm{Mg}$ & 0,16 & 0,16 & 0,19 & 0,18 & 0,19 & 0,47 & 0,3 & 0,25 & 0,47 & 0,3 \\
\hline $\mathrm{Fe}^{2+}$ & 0,39 & 0,4 & 0,42 & 0,41 & 0,43 & 0,56 & 0,47 & 0,44 & 0,56 & 0,47 \\
\hline $\mathrm{Mn}$ & 0 & 0 & 0 & 0 & 0,01 & 0,01 & 0 & 0 & 0,01 & 0 \\
\hline $\mathrm{Ca}$ & 0 & 0 & 0,01 & 0 & 0 & 0 & 0 & 0 & 0 & 0 \\
\hline $\mathrm{Na}$ & 0,19 & 0,19 & 0,15 & 0,14 & 0,14 & 0,1 & 0,1 & 0,12 & 0,1 & 0,1 \\
\hline $\mathrm{K}$ & 1,87 & 1,88 & 1,86 & 1,84 & 1,84 & 1,9 & 1,87 & 1,9 & 1,9 & 1,87 \\
\hline Total & 14,08 & 14,08 & 14,12 & 14,09 & 14,09 & 14,25 & 14,12 & 14,14 & 14,25 & 14,12 \\
\hline $\mathrm{Fe} /(\mathrm{Fe}+\mathrm{Mg})$ & 0,71 & 0,71 & 0,69 & 0,7 & 0,69 & 0,54 & 0,61 & 0,64 & 0,54 & 0,61 \\
\hline
\end{tabular}




\begin{tabular}{|c|c|c|c|c|c|c|c|c|}
\hline $\begin{array}{c}\text { Punto } \\
\text { analizado }\end{array}$ & $\begin{array}{c}\text { MIA-627A-C1- } \\
\text { Ms-1 }\end{array}$ & $\begin{array}{c}\text { MIA-627A-C1- } \\
\text { Ms-2 }\end{array}$ & $\begin{array}{c}\text { MIA-627A-C1- } \\
\text { Ms-4 }\end{array}$ & $\begin{array}{c}\text { MIA-627A-C4- } \\
\text { Ms-1 }\end{array}$ & $\begin{array}{c}\text { MIA-627A-C4- } \\
\text { Ms-3 }\end{array}$ & $\begin{array}{c}\text { MIA-627A-C4- } \\
\text { Ms-4 }\end{array}$ & $\begin{array}{c}\text { MIA-627A-C4- } \\
\text { Ms-5 }\end{array}$ & $\begin{array}{c}\text { MIA-627A-C4- } \\
\text { Ms-6 }\end{array}$ \\
\hline $\mathrm{SiO}_{2}$ & 45,43 & 45,29 & 45,13 & 46,57 & 45,57 & 45,11 & 45,53 & 45,58 \\
\hline $\mathrm{TiO}_{2}$ & 0,43 & 0,75 & 0,59 & 0,47 & 0,67 & 0,7 & 0,46 & 0,61 \\
\hline $\mathrm{Al}_{2} \mathrm{O}_{3}$ & 32,88 & 32,37 & 32,4 & 30,74 & 32,48 & 31,94 & 32,44 & 32,54 \\
\hline $\mathrm{FeO}$ & 3,59 & 3,39 & 3,55 & 4,11 & 3,49 & 3,55 & 3,62 & 3,44 \\
\hline $\mathrm{MgO}$ & 0,63 & 0,57 & 0,67 & 1,07 & 0,63 & 0,59 & 0,61 & 0,59 \\
\hline $\mathrm{MnO}$ & 0,06 & 0,07 & 0,05 & 0,07 & 0,03 & 0,06 & 0,03 & 0,03 \\
\hline $\mathrm{CaO}$ & & & & & 0 & & 0,04 & 0,01 \\
\hline $\mathrm{Na}_{2} \mathrm{O}$ & 0,65 & 0,61 & 0,75 & 0,36 & 0,55 & 0,57 & 0,46 & 0,33 \\
\hline $\mathrm{K}_{2} \mathrm{O}$ & 10,52 & 10,6 & 10,32 & 10,82 & 10,66 & 10,67 & 10,82 & 11,02 \\
\hline Total & 94,17 & 93,64 & 93,45 & 94,2 & 94,08 & 93,2 & 93,98 & 94,14 \\
\hline \multicolumn{9}{|c|}{ Fórmula basada en 220} \\
\hline $\mathrm{Si}$ & 6,21 & 6,23 & 6,22 & 6,38 & 6,24 & 6,24 & 6,24 & 6,24 \\
\hline $\mathrm{All}^{\mathrm{IV}}$ & 1,79 & 1,77 & 1,78 & 1,62 & 1,76 & 1,76 & 1,76 & 1,76 \\
\hline $\mathrm{Al}^{\mathrm{VI}}$ & 3,51 & 3,47 & 3,47 & 3,35 & 3,47 & 3,45 & 3,49 & 3,49 \\
\hline $\mathrm{Ti}$ & 0,04 & 0,08 & 0,06 & 0,05 & 0,07 & 0,07 & 0,05 & 0,06 \\
\hline $\mathrm{Mg}$ & 0,13 & 0,12 & 0,14 & 0,22 & 0,13 & 0,12 & 0,12 & 0,12 \\
\hline $\mathrm{Fe}^{2+}$ & 0,41 & 0,39 & 0,41 & 0,47 & 0,4 & 0,41 & 0,41 & 0,39 \\
\hline $\mathrm{Mn}$ & 0,01 & 0,01 & 0,01 & 0,01 & 0 & 0,01 & 0 & 0 \\
\hline $\mathrm{Ca}$ & 0 & 0 & 0 & 0 & 0 & 0 & 0,01 & 0 \\
\hline $\mathrm{Na}$ & 0,17 & 0,16 & 0,2 & 0,09 & 0,15 & 0,15 & 0,12 & 0,09 \\
\hline $\mathrm{K}$ & 1,83 & 1,86 & 1,81 & 1,89 & 1,86 & 1,88 & 1,89 & 1,92 \\
\hline Total & 14,1 & 14,08 & 14,1 & 14,08 & 14,08 & 14,1 & 14,09 & 14,08 \\
\hline
\end{tabular}

\subsection{Magnetita}

Se analizó un cristal de magnetita de la muestra AMC0131 (figura 20). Los resultados obtenidos se presentan en la tabla 13. El cálculo del $\mathrm{Fe}^{3+}$ se hizo usando la fórmula de Droop (1987).

La magnetita presenta coloración gris, con baja reflectancia, es homogénea y de aspecto liso, con inclusiones de pirita de color amarillo pálido, con buena reflec- tancia. La magnetita tiene valores altos de $\mathrm{Fe}_{2} \mathrm{O}_{3}$ (entre 53,58 y $53,64 \%$ ) y de $\mathrm{FeO}$ (entre 48,16 y $48,19 \%$ ); concentraciones menores de $\mathrm{MnO}$ (entre 0,04 y $0,08 \%$ ). El contenido de $\mathrm{TiO}_{2}$ es menor o igual a $0,02 \%$, y el de $\mathrm{Al}_{2} \mathrm{O}_{3}$ puede llegar hasta un $0,04 \%$. La pirita tiene una concentración de azufre (S) de 52,78\% y de hierro ( $\mathrm{Fe}$ ) de $45,57 \%$, así como bajas concentraciones de Co, $\mathrm{Cu}$ y Ni (tabla 13). 

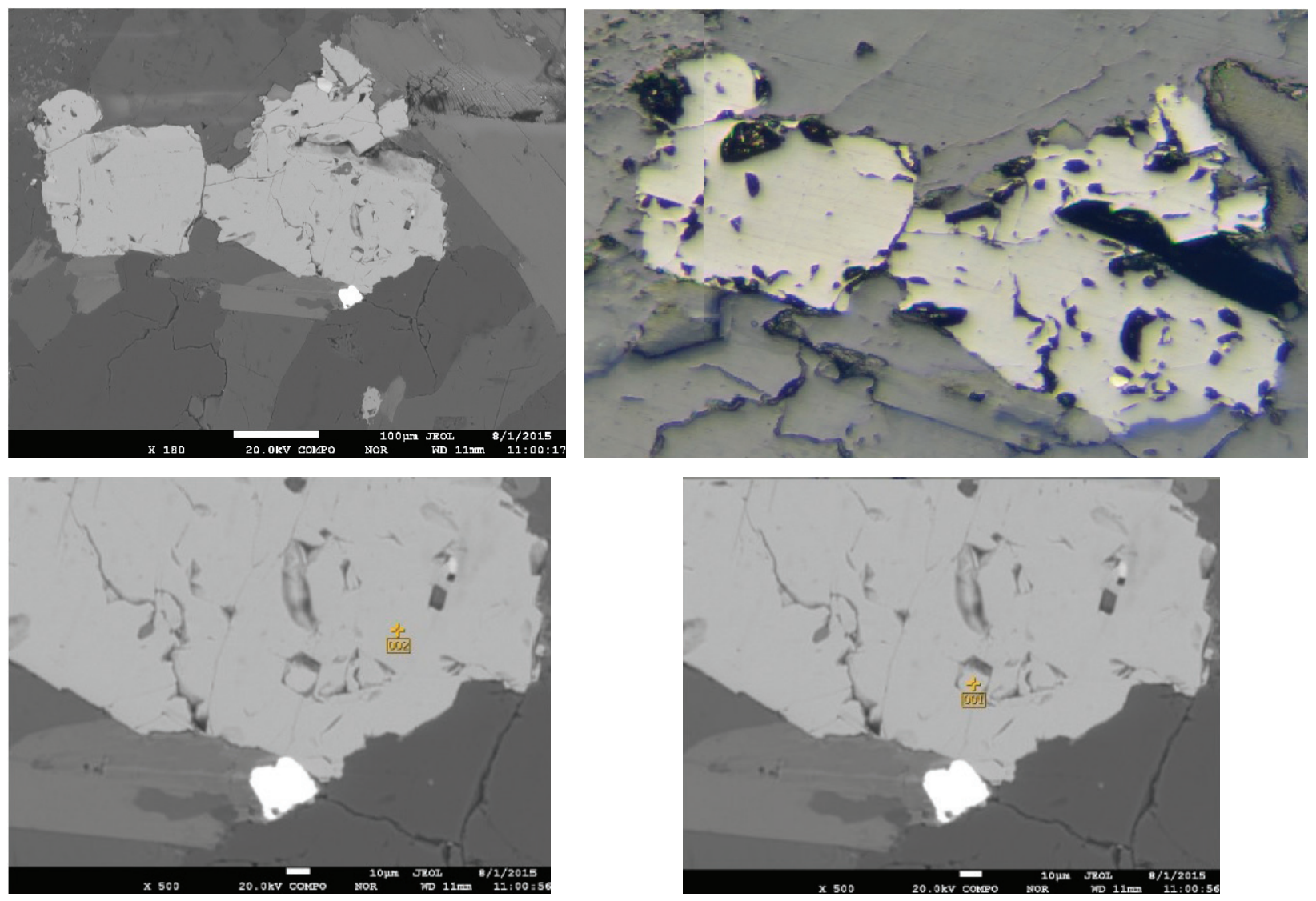

\begin{tabular}{lc}
\hline Volt & $20,00 \mathrm{kV}$ \\
\hline Mag & $\times 500$ \\
\hline Date & $2015 / 08 / 01$ \\
\hline Pixel & $1280 \times 960$ \\
\hline
\end{tabular}

Acquisition Condition

Pixel $1280 \times 960$
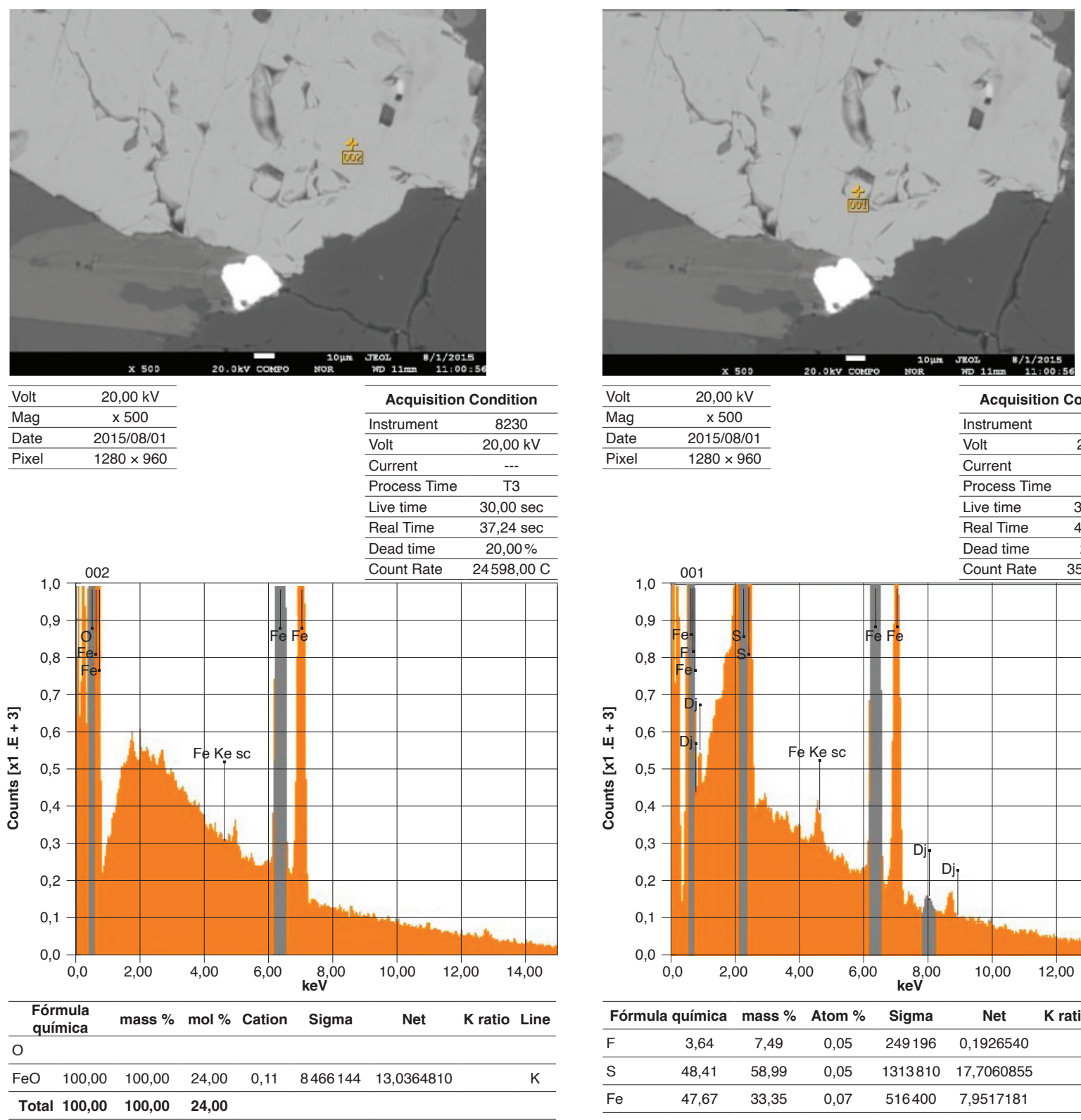

Acquisition Condition Instrument 8230

Volt $20,00 \mathrm{kV}$

Current ---

Pixel

$80 \times 960$

\begin{tabular}{lc} 
Instrument $\quad 8230$ \\
\hline Volt $\quad 20,00 \mathrm{kV}$
\end{tabular}

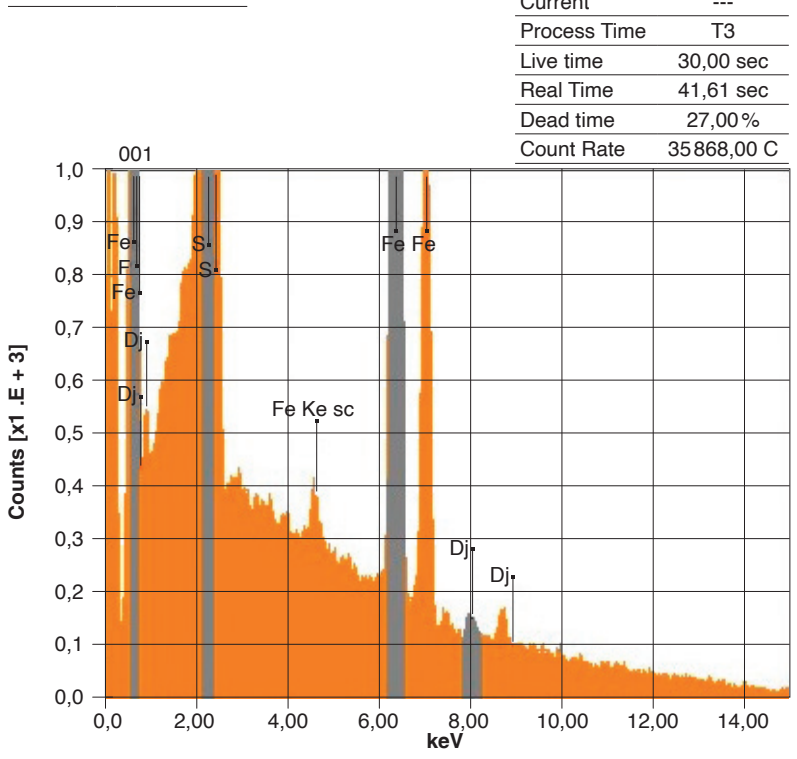

\begin{tabular}{lccccccc}
\hline \multicolumn{2}{l}{ Fórmula química } & mass $\%$ & Atom $\%$ & Sigma & Net & K ratio & Line \\
\hline $\mathrm{F}$ & 3,64 & 7,49 & 0,05 & 249196 & 0,1926540 & $\mathrm{~K}$ \\
\hline $\mathrm{S}$ & 48,41 & 58,99 & 0,05 & 1313810 & 17,7060855 & $\mathrm{~K}$ \\
\hline $\mathrm{Fe}$ & 47,67 & 33,35 & 0,07 & 516400 & 7,9517181 & $\mathrm{~K}$ \\
\hline $\mathrm{Cu}^{*}$ & 0,28 & 0,17 & 0,03 & 17270 & 0,0434175 & $\mathrm{~K}$ \\
\hline \multicolumn{2}{r}{ Total } & $\mathbf{1 0 0 , 0 0}$ & $\mathbf{1 0 0 , 0 0}$ & & & &
\end{tabular}

Figura 20. Imágenes de electrones secundarios retrodispersados (BSE) correspondientes a magnetita y pirita de la muestra AMC-0131 
Tabla 13. Composición química de magnetita y pirita de la muestra AMC-0131

\begin{tabular}{|c|c|c|c|c|c|}
\hline Punto analizado & AMC-0131-C1-Mt-1 & AMC-0131-C1-Mt-2 & AMC-0131-C1-Mt-3 & Elementos & AMC-0131-C1-Py-1 \\
\hline $\mathrm{SiO}_{2}$ & 0 & 0 & 0 & $\mathrm{Zn}$ & $-0,04$ \\
\hline $\mathrm{TiO}_{2}$ & 0 & 0 & 0,02 & As & 0,06 \\
\hline $\mathrm{Al}_{2} \mathrm{O}_{3}$ & 0 & 0,04 & 0 & $\mathrm{Ca}$ & ND \\
\hline $\mathrm{Cr}_{2} \mathrm{O}_{3}$ & 0,04 & 0,03 & 0,02 & $\mathrm{~s}$ & 52,79 \\
\hline $\mathrm{Fe}_{2} \mathrm{O}_{3}$ & 53,58 & 53,59 & 53,64 & $\mathrm{Fe}$ & 45,57 \\
\hline $\mathrm{FeO}$ & 48,19 & 48,16 & 48,17 & Co & 0,41 \\
\hline $\mathrm{MnO}$ & 0,04 & 0,06 & 0,08 & $\mathrm{Ni}$ & 0,11 \\
\hline $\mathrm{MgO}$ & 0 & 0,01 & 0,03 & Sb & $-0,02$ \\
\hline $\mathrm{ZnO}$ & 0 & 0 & 0 & $\mathrm{Cu}$ & 0,66 \\
\hline $\mathrm{CaO}$ & 0 & 0 & 0 & Total & 99,5 \\
\hline $\mathrm{V}_{2} \mathrm{O}_{3}$ & 0 & 0 & 0 & $\mathrm{Zn}$ & ND \\
\hline $\mathrm{NiO}$ & 0 & 0 & 0 & As & 0,03 \\
\hline Total & 101,84 & 101,9 & 101,96 & $\mathrm{Ca}$ & ND \\
\hline \multicolumn{2}{|c|}{ Fórmula basada en 320} & \multicolumn{2}{|c|}{$\mathbf{S}$} & \multicolumn{2}{|c|}{66,33} \\
\hline $\mathrm{Si}$ & 0 & 0 & 0 & $\mathrm{Fe}$ & 32,87 \\
\hline $\mathrm{Ti}$ & 0 & 0 & 0,004 & Co & 0,28 \\
\hline $\mathrm{Al}$ & 0 & 0,013 & 0 & $\mathrm{Ni}$ & 0,07 \\
\hline $\mathrm{Cr}$ & 0,01 & 0,008 & 0,006 & $\mathrm{Sb}$ & ND \\
\hline V & 0 & 0 & 0 & $\mathrm{Cu}$ & 0,42 \\
\hline $\mathrm{Fe} 3+$ & 11,995 & 11,99 & 11,993 & Total & 99,94 \\
\hline $\mathrm{Fe}^{2+}$ & 11,985 & 11,971 & 11,966 & & \\
\hline $\mathrm{Mg}$ & 0 & 0,004 & 0,011 & & \\
\hline $\mathrm{Mn}$ & 0,01 & 0,015 & 0,02 & & \\
\hline $\mathrm{Zn}$ & 0 & 0 & 0 & & \\
\hline $\mathrm{Ca}$ & 0 & 0 & 0 & & \\
\hline $\mathrm{Ni}$ & 0 & 0 & 0 & & \\
\hline Total & 24 & 24 & 24 & & \\
\hline $\mathrm{Mg} /\left(\mathrm{Mg}+\mathrm{Fe}^{2+}\right)$ & 0 & 0 & 0,001 & & \\
\hline $\mathrm{Cr} /(\mathrm{Cr}+\mathrm{Al})$ & 1 & 0,388 & 1 & & \\
\hline $\mathrm{Fe} 2+/\left(\mathrm{Fe}^{2+}+\mathrm{Mg}\right)$ & 1 & 1 & 0,999 & & \\
\hline
\end{tabular}

Se analizaron dos cristales de magnetita de la muestra LMC-078 (tabla 14). El mineral tiene un contenido de $\mathrm{FeO}_{\text {total }}$ entre 96,36 y $97,78 \%$ ( 11 ,96 y 11 , 99 a.p.f.u de $\mathrm{Fe}^{3+}$, y aproximadamente 12 a.p.f.u. $\mathrm{de} \mathrm{Fe}^{2+}$ ), es pobre en $\mathrm{TiO}_{2}$, con valores $<0,07 \%$. Presenta bajos contenidos de $\mathrm{Al}, \mathrm{Cr}$ y Mn.

\subsection{IImenita}

Las ilmenitas de las muestras LMC-07 8 y MIA-62 7A tienen superficies porosas e irregulares, muestran contenidos de $\mathrm{TiO}_{2}$ entre 46,6 y 53,6\%, de FeO entre 32,9 y
$38,4 \%$, de $\mathrm{Fe}_{2} \mathrm{O}_{3}$ muy variable y de $\mathrm{MnO}$ entre 7,8 y $11 \%$, y bajos contenidos de $\mathrm{MgO} \mathrm{y} \mathrm{V}_{2} \mathrm{O}_{3}$ (figuras 21 y 22).

Se realizó un análisis de EDS a la ilmenita de la muestra LMC-078-C11, con espectros fuertes de Ti, menor contenido de Fe, junto a un cristal de magnetita con superficie más lisa y homogénea, y sin inclusiones. En el espectro del cristal de ilmenita de la muestra MIA627A-C3 se observaron altos contenidos de Fe y Ti, y abundantes inclusiones en la imagen retrodispersada (figura 22), así como un borde más oscuro causado posiblemente por alteración. Los resultados se presentan en la tabla 15. 
Tabla 14. Composición química de magnetita en la muestra LMC-078

\begin{tabular}{|c|c|c|c|c|c|}
\hline Punto analizado & LMC-078-C10-Mt-1 & LMC-078-C10-Mt-2 & LMC-078-C10-Mt-3 & LMC-078-C11-Mt-1 & LMC-078-C11-Mt-2 \\
\hline $\mathrm{SiO}_{2}$ & 0,01 & ND & 0,02 & ND & $-0,03$ \\
\hline $\mathrm{TiO}_{2}$ & 0,07 & ND & ND & ND & 0,07 \\
\hline $\mathrm{Al}_{2} \mathrm{O}_{3}$ & 0,05 & 0,02 & 0,01 & 0,02 & 0,01 \\
\hline $\mathrm{Cr}_{2} \mathrm{O}_{3}$ & 0,07 & 0,05 & 0,03 & 0,03 & 0,03 \\
\hline $\mathrm{FeO}$ & 97,13 & 97,78 & 97,44 & 96,83 & 96,36 \\
\hline $\mathrm{MnO}$ & 0,04 & 0,06 & 0,07 & 0,03 & 0,02 \\
\hline $\mathrm{MgO}$ & 0,01 & $-N D$ & 0,01 & 0,03 & $-0,01$ \\
\hline Total & 97,2 & 97,68 & 97,37 & 96,72 & 96,28 \\
\hline $\mathrm{Si}$ & 0 & 0 & 0,01 & 0 & 0 \\
\hline $\mathrm{Ti}$ & 0,02 & 0 & 0 & 0 & 0,02 \\
\hline $\mathrm{Al}$ & 0,02 & 0,01 & 0 & 0,01 & 0 \\
\hline $\mathrm{Cr}$ & 0,02 & 0,01 & 0,01 & 0,01 & 0,01 \\
\hline $\mathrm{Fe}^{3+}$ & 11,96 & 11,99 & 11,99 & 11,99 & 11,98 \\
\hline $\mathrm{Fe}^{2+}$ & 11,97 & 11,98 & 11,97 & 11,97 & 11,98 \\
\hline $\mathrm{Mg}$ & 0 & 0 & 0 & 0,01 & 0,01 \\
\hline $\mathrm{Mn}$ & 0,01 & 0,01 & 0,02 & 0,01 & 0,01 \\
\hline Total & 24 & 24 & 24 & 24 & 24 \\
\hline
\end{tabular}

Tabla 15. Composición química de ilmenita en las rocas LMC-078 y MIA-627A

\begin{tabular}{|c|c|c|c|c|c|}
\hline Punto analizado & LMC-078-C11-IIm-1 & LMC-078-C11-IIm-2 & LMC-078-C11-IIm-3 & MIA-627A-C3-IIm-2 & MIA-627A-C3-IIm-3 \\
\hline $\mathrm{SiO}_{2}$ & & 0,01 & & & \\
\hline $\mathrm{TiO}_{2}$ & 53,58 & 46,60 & 51,87 & 52,05 & 51,57 \\
\hline $\mathrm{Cr}_{2} \mathrm{O}_{3}$ & 0,05 & & 0,00 & 0,00 & 0,01 \\
\hline $\mathrm{Al}_{2} \mathrm{O}_{3}$ & 0,01 & & 0,02 & & \\
\hline $\mathrm{Fe}_{2} \mathrm{O}_{3}$ & & 12,01 & 0,30 & 2,06 & 3,11 \\
\hline $\mathrm{FeO}$ & 34,25 & 32,97 & 35,45 & 38,33 & 38,42 \\
\hline $\mathrm{MnO}$ & 10,15 & 8,84 & 11,05 & 8,37 & 7,81 \\
\hline $\mathrm{MgO}$ & 0,02 & & 0,01 & 0,01 & 0,04 \\
\hline \multicolumn{6}{|l|}{$\mathrm{CaO}$} \\
\hline $\mathrm{V}_{2} \mathrm{O}_{3}$ & 0,39 & 0,34 & 0,33 & 0,34 & 0,34 \\
\hline Total & & 100,43 & 98,70 & 100,81 & 100,95 \\
\hline \multicolumn{6}{|c|}{ Cationes calculados a partir de $6(0)$} \\
\hline $\mathrm{Si}$ & 0,0001 & 0,0003 & 0,0000 & 0,0000 & 0,0000 \\
\hline $\mathrm{Ti}$ & 2,0771 & 1,7712 & 1,9936 & 1,9612 & 1,9411 \\
\hline $\mathrm{Fe}^{3+}$ & 0,0000 & 0,4568 & 0,0116 & 0,0776 & 0,1172 \\
\hline $\mathrm{Cr}$ & 0,0020 & 0,0000 & 0,0000 & 0,0000 & 0,0004 \\
\hline Al & 0,0004 & 0,0001 & 0,0011 & 0,0000 & 0,0001 \\
\hline $\mathrm{V}$ & 0,0161 & 0,0138 & 0,0136 & 0,0136 & 0,0136 \\
\hline $\mathrm{Fe}^{2+}$ & 1,4761 & 1,3932 & 1,5145 & 1,6058 & 1,6076 \\
\hline $\mathrm{Mg}$ & 0,0015 & 0,0000 & 0,0008 & 0,3550 & 0,0027 \\
\hline $\mathrm{Mn}$ & 0,4429 & 0,3784 & 0,4783 & 0,3552 & 0,3308 \\
\hline $\mathrm{Ca}$ & 0,0000 & 0,0000 & 0,0000 & 0,0000 & 0,0000 \\
\hline Total & 4,0000 & 4,0000 & 4,0000 & 4,0000 & 4,0000 \\
\hline
\end{tabular}




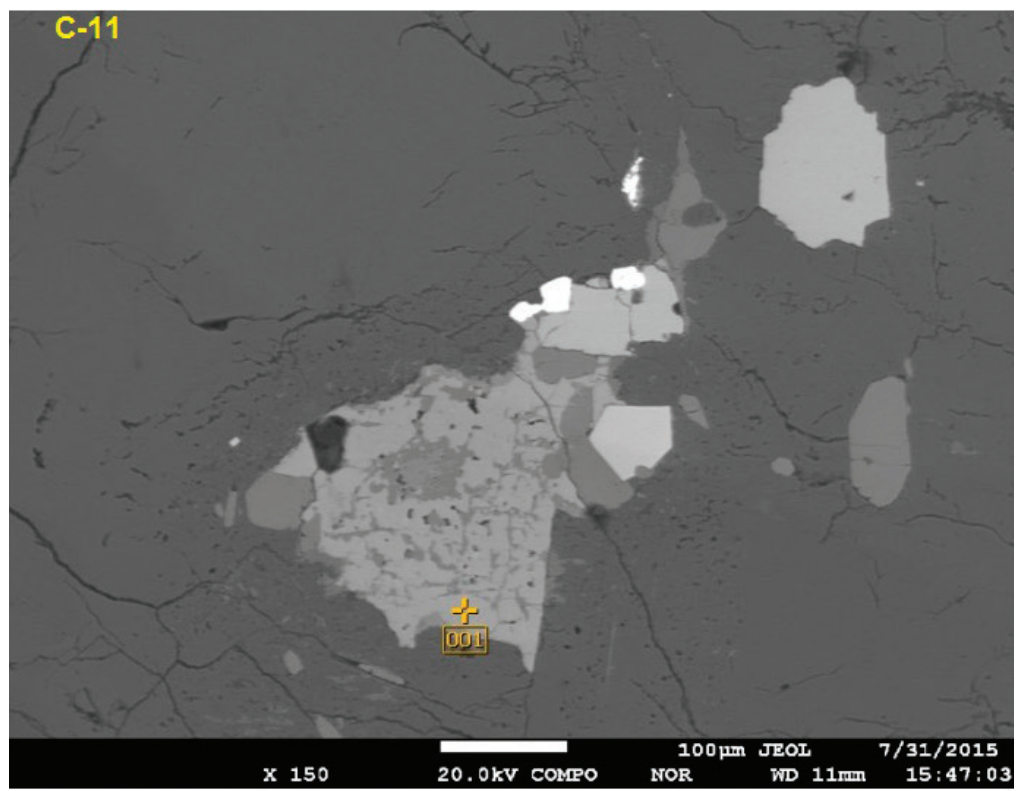

\begin{tabular}{lc}
\hline Volt & $20,00 \mathrm{kV}$ \\
\hline Mag & $\times 150$ \\
\hline Date & $2015 / 07 / 31$ \\
\hline Pixel & $1280 \times 960$ \\
\hline
\end{tabular}
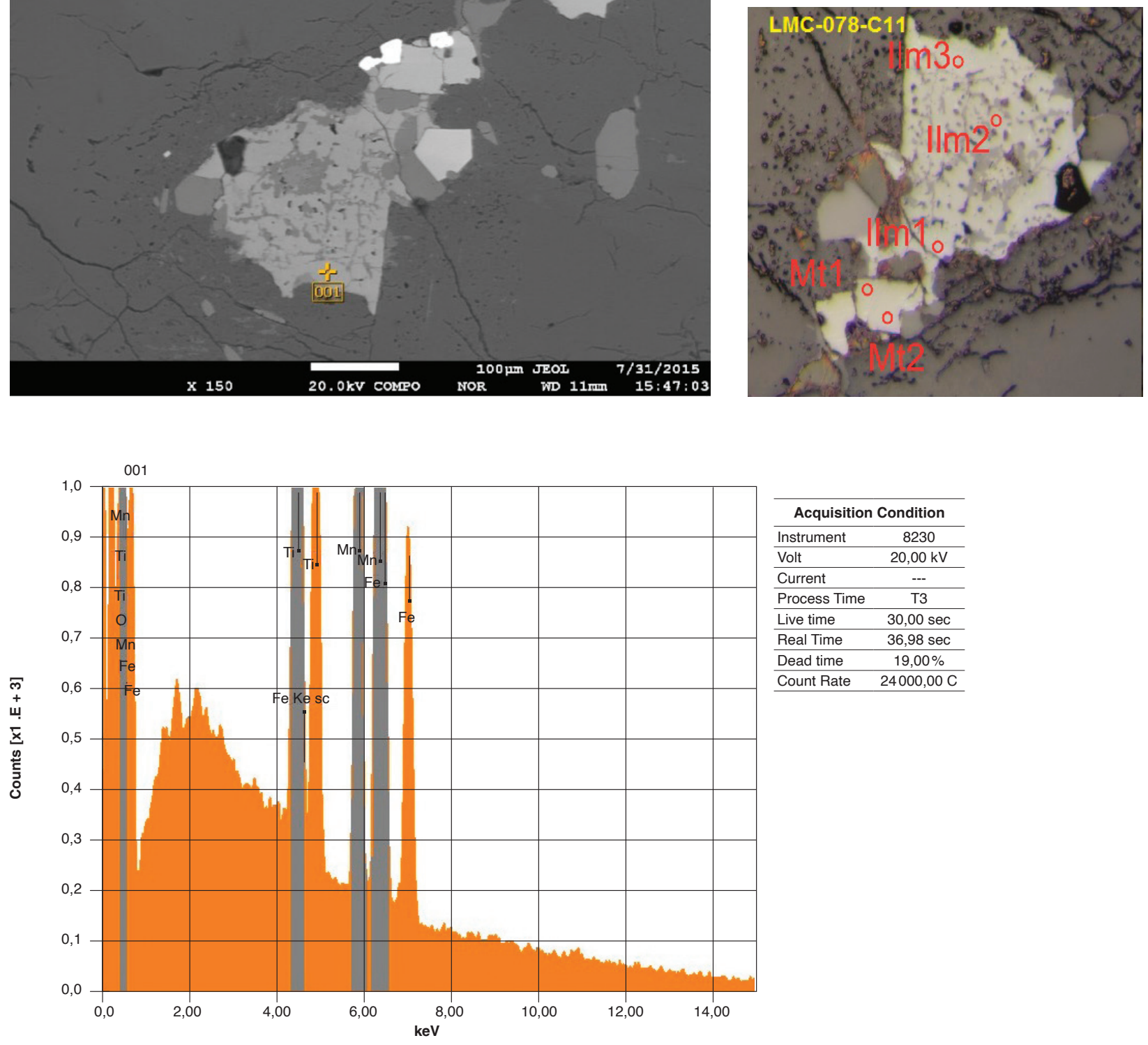

\begin{tabular}{lcccccccc}
\hline \multicolumn{1}{l}{ Fórmula química } & mass $\%$ & mol $\%$ & Cation & Sigma & Net & K ratio & Line \\
\hline $\mathrm{O}$ & & & & & & \\
\hline $\mathrm{TiO} 2$ & 48,06 & 45,36 & 7,49 & 0,07 & 5644104 & 5,1037606 & $\mathrm{~K}$ \\
\hline $\mathrm{MnO}$ & 10,01 & 10,64 & 1,76 & 0,05 & 937234 & 1,2679609 & $\mathrm{~K}$ \\
\hline $\mathrm{FeO}$ & 41,93 & 44,01 & 7,27 & 0,07 & 3575132 & 5,5051199 & $\mathrm{~K}$ \\
\hline Total & $\mathbf{1 0 0 , 0 0}$ & $\mathbf{1 0 0 , 0 0}$ & $\mathbf{1 6 , 5 1}$ & & & & \\
\hline
\end{tabular}

Figura 21. Imágenes de electrones secundarios retrodispersados (BSE) correspondientes a IImenitas de la muestra LMC-078-C11, resultados de EDS y localización de los puntos de análisis de microsonda 


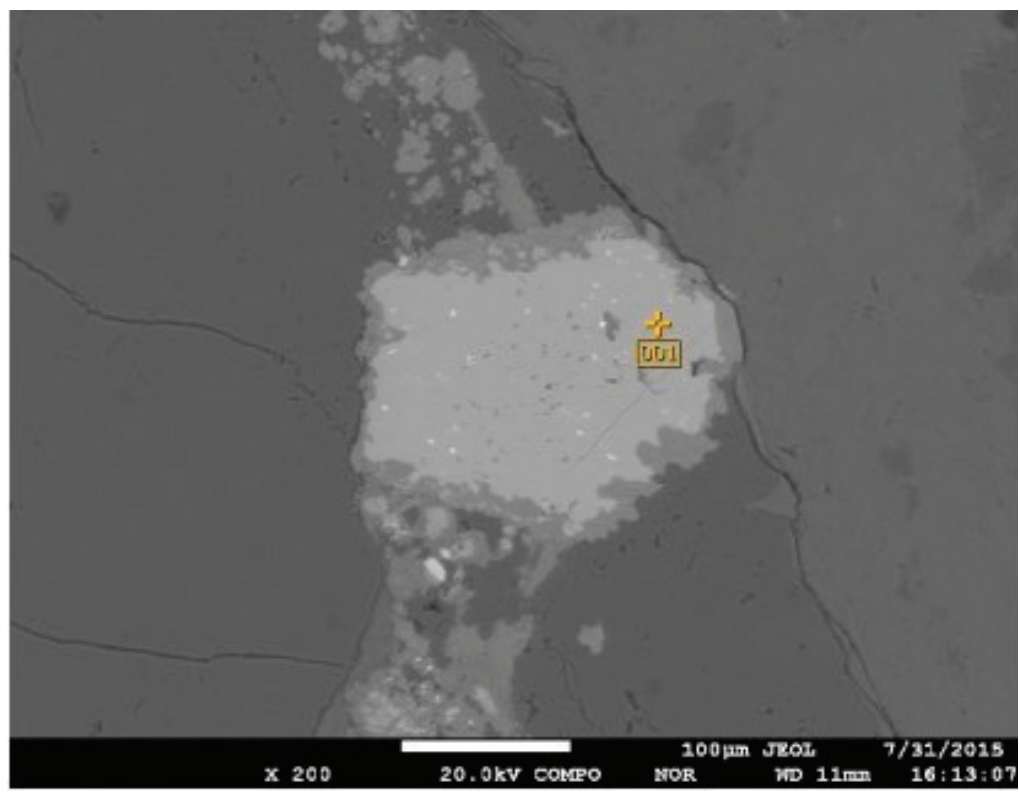

\begin{tabular}{lc}
\hline Volt & $20,00 \mathrm{kV}$ \\
\hline Mag & x 500 \\
\hline Date & $2015 / 07 / 31$ \\
\hline Pixel & $1280 \times 960$ \\
\hline
\end{tabular}
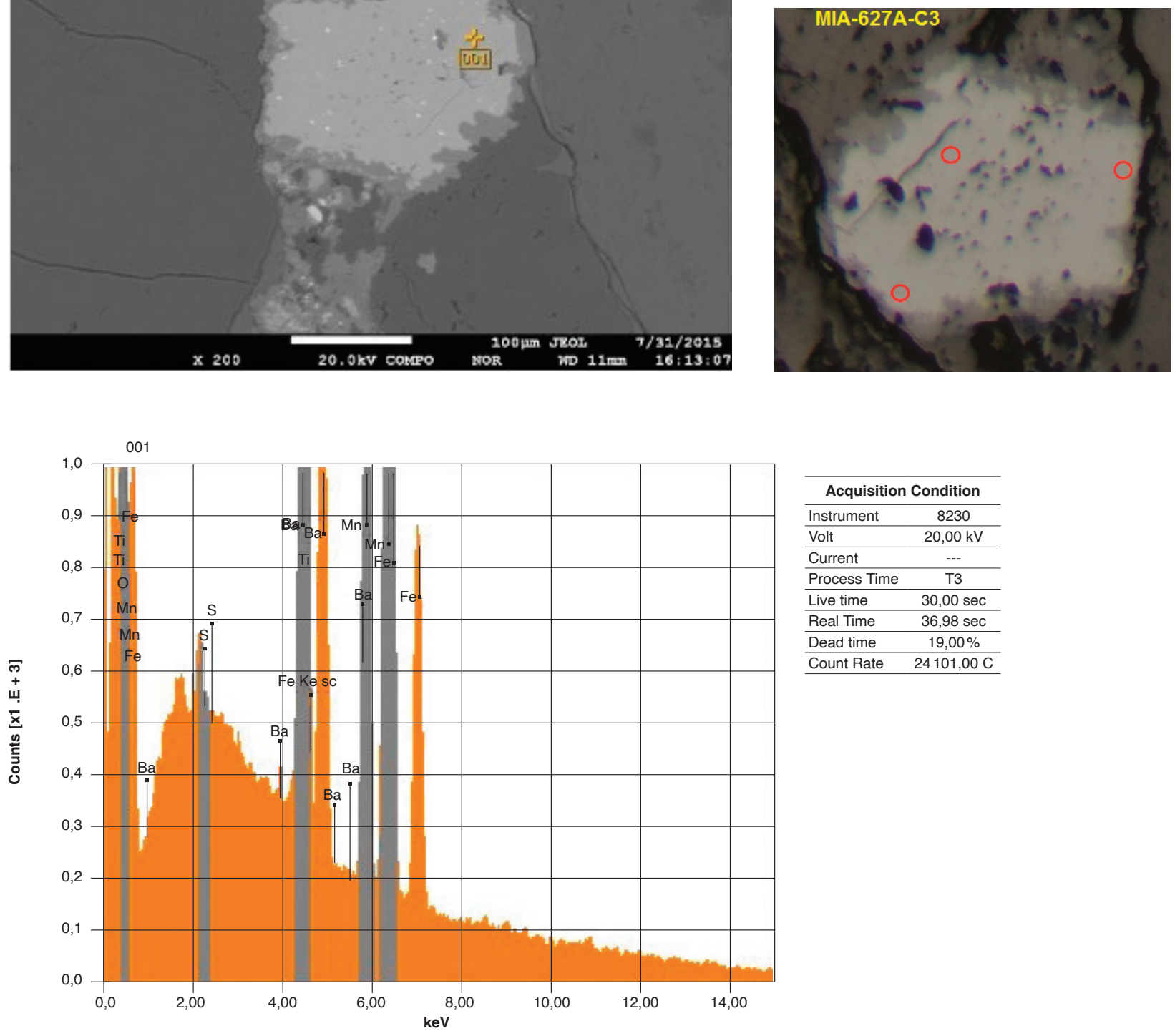

\begin{tabular}{|c|c|}
\hline \multicolumn{2}{|c|}{ Acquisition Condition } \\
\hline Instrument & 8230 \\
\hline Volt & $20,00 \mathrm{kV}$ \\
\hline Current & --- \\
\hline Process Time & T3 \\
\hline Live time & $30,00 \mathrm{sec}$ \\
\hline Real Time & $36,98 \mathrm{sec}$ \\
\hline Dead time & $19,00 \%$ \\
\hline Count Rate & $24101,00 \mathrm{C}$ \\
\hline
\end{tabular}

\begin{tabular}{lcccccccc}
\hline \multicolumn{1}{l}{ Fórmula química } & mass $\%$ & mol $\%$ & Cation & Sigma & Net & K ratio & Line \\
\hline $\mathrm{O}$ & & & & & & & \\
\hline $\mathrm{S}$ & $\mathrm{nd}$ & $\mathrm{nd}$ & & & & & $\mathrm{K}$ & \\
\hline $\mathrm{TiO} 2$ & 49,01 & 47,36 & 7,71 & 0,08 & 5973058 & 5,4012218 & & $\mathrm{~K}$ \\
\hline $\mathrm{MnO}$ & 8,41 & 9,16 & 1,49 & 0,04 & 815792 & 1,1036647 & & $\mathrm{~K}$ \\
\hline $\mathrm{FeO}$ & 38,59 & 41,47 & 6,75 & 0,07 & 3409003 & 5,2493085 & & $\mathrm{~K}$ \\
\hline $\mathrm{BaO}$ & 3,98 & 2,01 & 0,33 & 0,08 & 487928 & 0,6846878 & & $\mathrm{~L}$ \\
\hline Total & $\mathbf{1 0 0 , 0 0}$ & $\mathbf{1 0 0 , 0 0}$ & $\mathbf{1 6 , 2 9}$ & & & & & \\
\hline
\end{tabular}

Figura 22. Imágenes de electrones secundarios retrodispersados (BSE) correspondientes a IImenita de la muestra MIA-627A-C3, resultados de EDS y localización de los puntos analizados con la microsonda 


\section{Litogeoquímica}

La caracterización litogeoquímica del Monzogranito de La Corcova se realizó a partir de doce análisis realizados en diferentes muestras, a saber: de la facies normal y la facies porfídica (AMC-01 29, AMC-0131, AMC-0128 A, LMC-077, LMC-078), seis muestras: una de dique (JGB460A), una de monzogranito deformado (MIA-627A), una de cuarzodiorita de borde (MIA-630 B), una de anfibolita (MIA-62 7B-IGM-900932) y una de granofelsa de Qtz-Fsp (MIA-631-IGM-900937), una muestra tomada del trabajo de Van der Lelij (2013) (10VDL05), que corresponde a un dique granítico no deformado que corta el Neis de Bucaramanga y que podría estar relacionada con el Monzogranito de La Corcova, y una muestra que atraviesa el Neis de Bucaramanga cerca al contacto con el plutón LMC-065 (IGM-900921). A cada una de las muestras se le realizó análisis petrográfico, y a algunas de ellas, la datación $\mathrm{U} / \mathrm{Pb}$ en circón. Los análisis químicos se hicieron en el laboratorio del Servicio Geológico Colombiano, sede Bogotá. Para los óxidos mayores se utilizó el método de fluorescencia de rayos $\mathrm{X}$ incluyendo los elementos trazas V, Mo, Nb, Ta, W, Zr y Hf, y para el resto de elementos traza y tierras raras se utilizó el equipo de espectrometría de masas con plasma acoplado inductivamente (ICP-MS).

Los análisis de fluorescencia se realizaron con un espectrómetro de rayos X, FRX, Panalytical Axios Mineral para análisis elemental, configurado con un software especializado para materiales geológicos. La cuantificación de los óxidos mayores se realizó en muestra fundida con metaborato y tetraborato de litio, y la cuantificación de elementos menores se realizó en muestra prensada. El análisis de elementos traza de interés geoquímico en las rocas se realizó con un espectrómetro de masas con plasma inductivamente acoplado ICP-MS, Perkin Elmer Nexion. Para la disolución de la muestra se efectuó un ataque por pasos utilizando ácidos inorgánicos fuertes ( $\mathrm{HF}, \mathrm{HNO}_{3}, \mathrm{HClO}_{4} \mathrm{y} \mathrm{HCl}$ ). El proceso se realizó en sistema abierto, empleando distintas rampas de temperatura y tiempos de calentamiento. Gran parte de los diagramas geoquímicos se generaron con el uso del software GCD Kit version 4.0 (Janoušek et al., 2006).

Los contenidos de óxidos mayores se recalcularon teniendo en cuenta los valores de LOI (perdidas por ignición). Los resultados se muestran en la tabla 16, en la que las muestras se agruparon teniendo en cuenta los patrones que presentaron en el diagrama de REE vs. con- drito de Nakamura (1974). Se considera que diferentes patrones representan probablemente pulsos magmáticos de edad diferente, que pudieron originarse en fuentes distintas. Las variaciones en las relaciones entre las REE suelen ser características heredadas de la fuente, o debidas al fraccionamiento durante la evolución de los magmas.

\section{1. Óxidos de elementos mayores}

Los valores obtenidos de $\mathrm{SiO}_{2}$ en rocas granitoides del Monzogranito de La Corcova variaron entre 69,56 y $75,45 \%$, y solo las muestras 10 VDL05 y MIA-630B presentaron valores de $\mathrm{SiO}_{2}$ menores $(68,3 \%$ y 57,13 , respectivamente). Los valores obtenidos de $\mathrm{Al}_{2} \mathrm{O}_{3}, \mathrm{Fe}_{2} \mathrm{O}_{3}$, $\mathrm{MgO}, \mathrm{Na}_{2} \mathrm{O}$ y CaO disminuyen con el aumento del $\mathrm{SiO}_{2}$; el $\mathrm{K}_{2} \mathrm{O}$ varía entre 4,6 y 5,3\%; el CaO varía entre 0,7 y 2,5\%; el $\mathrm{MgO}$ presenta valores < $1 \% \mathrm{y} \mathrm{TiO}_{2}<0,6 \%$, y por otra parte las razones $\mathrm{K}_{2} \mathrm{O} / \mathrm{Na}_{2} \mathrm{O}$ son $>1$.

La roca MIA-630B, clasificada como cuarzodiorita, presenta valores bajos en $\mathrm{SiO}_{2}(57,1 \%)$, un contenido de $\mathrm{Al}_{2} \mathrm{O}_{3}$ de $16 \%$, de $\mathrm{MgO}$ de $4,11 \%$, y un contenido de álcalis $\left(\mathrm{Na}_{2} \mathrm{O}+\mathrm{K}_{2} \mathrm{O}\right)$ de $5,3 \%$, y de $\mathrm{TiO}_{2}$ alto $(>1,3 \%)$. La roca clasificada como anfibolita (MIA-627B) presenta los menores valores de $\mathrm{SiO}_{2}(49,6 \%)$, un alto contenido de $\mathrm{CaO}$ $(7,67 \%)$ y de $\mathrm{MgO}(4,8 \%)$. La roca clasificada como granofelsa (MIA-631) presenta contenidos de óxidos mayores similares a los de los monzogranitos y no muestra diferencias químicas notorias con respecto a estos.

Según los diagramas $\mathrm{K}_{2} \mathrm{O}$ versus $\mathrm{SiO}_{2}$ (Peccerillo y Taylor, 1976) y Hastie et al., (2007) (figura 23), las rocas granitoides analizadas de la facies normal y porfídica del Monzogranito de La Corcova pertenecen a las series calcoalcalina alta en K y shoshonítica. Las muestras MIA627B (IGM-900932), correspondiente a la anfibolita, y la muestra MIA-630B (IGM-900936), a cuarzodiorita, pertenecen al campo de la serie calcoalcalina alta en K. A diferencia de las demás muestras, corresponden a rocas con menores contenidos de $\mathrm{SiO}_{2}$ y mayores contenidos de Co (38 y 55 ppm). En el diagrama de discriminación de Th-Co de Hastie et al. (2007), la roca 10VDL05 analizada por Lelij (2013), a diferencia de las demás muestras, pertenece al campo de las rocas ácidas (D/R) y de la serie calcoalcalina alta en K y shoshonítica.

En el diagrama AFM de Irvine y Baragar (1971) (figura 24) se puede observar que las rocas analizadas hacen parte de las serie calcoalcalina: la muestra MIA6287B (IGM-900932), correspondiente a la anfibolita, 
que presenta un valor alto de $\mathrm{Fe}_{2} \mathrm{O}_{3}(13,97 \%)$ y valores altos de $\mathrm{MgO}(4,80 \%)$, pertenece a la serie toleítica, y probablemente corresponde a una roca menos diferenciada que las del Monzogranito de La Corcova, lo cual es cohe- rente con su menor contenido de $\mathrm{SiO}_{2}$ (tabla 16) y con los resultados de los análisis petrográficos. La muestra MIA630B, clasificada como cuarzodiorita, a diferencia de las demás muestras, pertenece a la serie calcoalcalina.

Tabla 16. Composición de óxidos mayores en rocas granitoides, diques y rocas de caja del Monzogranito de La Corcova

\begin{tabular}{ccccccccccccccc}
\hline IGM & N. Campo & $\mathbf{W}$ & $\mathbf{N}$ & $\mathrm{SiO}_{2}$ & $\mathrm{TiO}_{2}$ & $\mathrm{Al}_{2} \mathrm{O}_{3}$ & $\mathrm{Fe}_{2} \mathrm{O}_{3}$ & $\mathrm{MgO}$ & $\mathrm{CaO}$ & $\mathrm{Na}_{2} \mathrm{O}$ & $\mathrm{K}_{2} \mathrm{O}$ & $\mathrm{P}_{2} \mathrm{O}_{5}$ & $\mathrm{MnO}^{\mathrm{LOI}}$ \\
\hline 900862 & AMC-0129 & 1113420 & 1280055 & 69,56 & 0,62 & 16,59 & 1,66 & 0,24 & 1,74 & 3,17 & 5,29 & & 0,05 & 0,40 \\
\hline 900863 & AMC-0131 & 1114638 & 1284010 & 70,89 & 0,49 & 15,97 & 1,51 & 0,14 & 1,45 & 3,10 & 4,76 & & 0,07 & 0,32 \\
\hline 900861 & AMC-0128A & 1114798 & 1281084 & 73,2 & 0,3 & 13,9 & 2,05 & 0,39 & 1,54 & 2,52 & 5,27 & 0,1 & 0,05 & 0,58 \\
\hline 900929 & LMC-077 & 1112260 & 1283759 & 75,06 & 0,17 & 13,41 & 1,35 & 0,20 & 1,24 & 2,66 & 5,36 & 0,0 & 0,05 & 0,38 \\
\hline 900921 & LMC-065 & 1119186 & 1276101 & 75,45 & 0,13 & 13,65 & 1,26 & 0,09 & 0,72 & 2,20 & 5,23 & & 0,05 & 0,45 \\
\hline 900931 & MIA-627A & 1119356 & 1257497 & 74,23 & 0,07 & 15,23 & 0,86 & 0,09 & 0,71 & 3,03 & 4,62 & & 0,06 & 0,38 \\
\hline 900909 & JGB-460A & 1117564 & 1268142 & 77,36 & 0,03 & 11,90 & 0,79 & 0,05 & 0,57 & 2,86 & 4,95 & & 0,02 & 0,46 \\
\hline 10 & 1OVDL05 & 1117933 & 1277114 & 68,37 & 0,60 & 15,35 & 3,66 & 1,03 & 2,50 & 3,01 & 4,22 & 0,2 & 0,15 & 0,91 \\
\hline 900937 & MIA-631 & 1118186 & 1269536 & 71,18 & 0,42 & 14,18 & 2,49 & 0,67 & 2,27 & 2,54 & 5,01 & 0,1 & 0,06 & 0,93 \\
\hline 900930 & LMC-078 & 1115257 & 1286012 & 72,56 & 0,24 & 14,98 & 1,60 & 0,52 & 0,77 & 2,89 & 4,54 & 0,07 & 0,88 \\
\hline 900932 & MIA-627B & 1119356 & 1257497 & 49,62 & 3,00 & 15,26 & 13,97 & 4,80 & 7,67 & 1,95 & 1,47 & 0,4 & 0,21 & 1,54 \\
\hline 900936 & MIA-630B & 1114060 & 1270011 & 57,13 & 1,31 & 16,06 & 8,58 & 4,11 & 5,89 & 2,81 & 2,56 & 0,3 & 0,17 & 0,94 \\
\hline
\end{tabular}

Rojo: facies normal y porfirítica; verde: rocas de dique, negro: facies monzogranítica; azul: cuarzodioritas de borde y anfibolita. Los colores en la tabla indican la manera en que se agrupan las muestras y se relacionan con el color de las muestras en las figuras

A

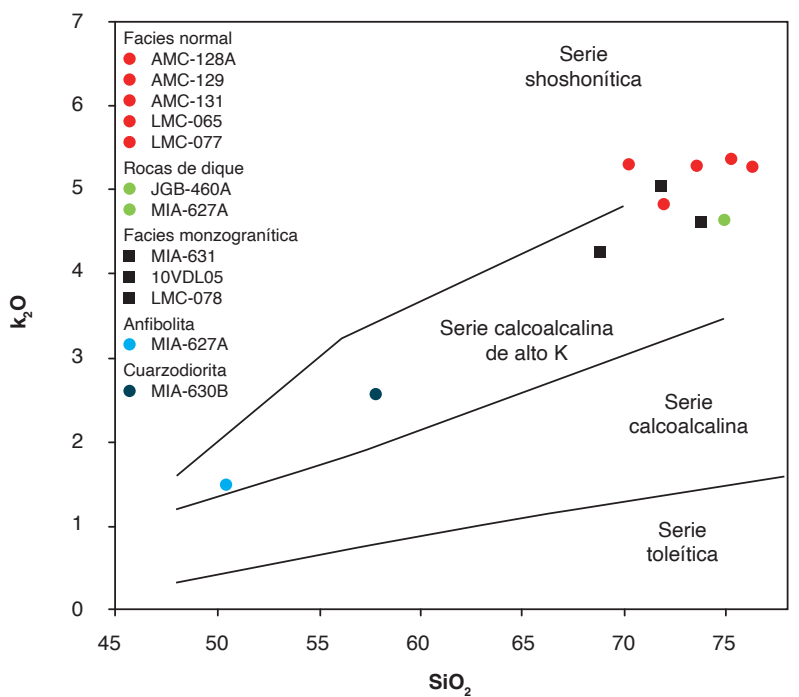

B

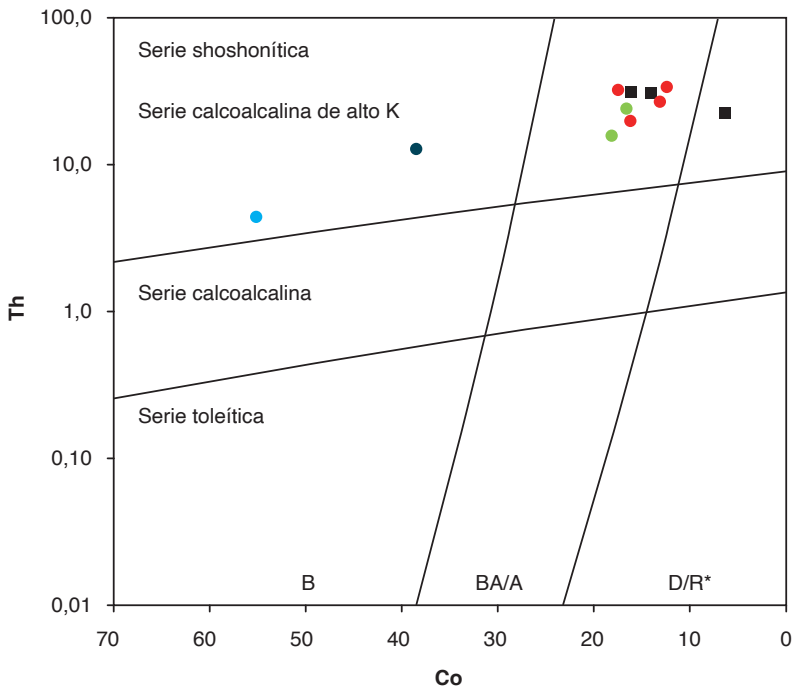

Figura 23. Clasificación de rocas del Monzogranito de La Corcova, diques y rocas metamorficas asociadas

Fuente: A) Diagrama $\mathrm{K}_{2} \mathrm{O}$ vs $\mathrm{SiO}_{2}$ (Peccerillo y Taylor, 1976) y B) Diagrama de clasificación Th-Co (Hastie et al., 2007), este trabajo 
En los diagramas TAS de Middlemost (1985, 1994) (figura 25 A y B), las rocas analizadas del Monzogranito de La Corcova, de acuerdo con su clasificación petrográfica, corresponden a rocas subalcalinas que pertenecen al campo de los granitos. La muestra (JGB460B-IGM-900909) forma parte del campo de los granitos de feldespato alcalino, y otras rocas, como la
10VDL05 y las cuarzomonzodioritas (MIA-630B- IGM900936), pertenecen al campo de las granodioritas. Los diques y cuerpos intrusivos químicamente menores hacen parte del campo de los granitos, y la anfibolita (MIA627B, IGM-900932), del campo de los gabros-cuarzodioritas.

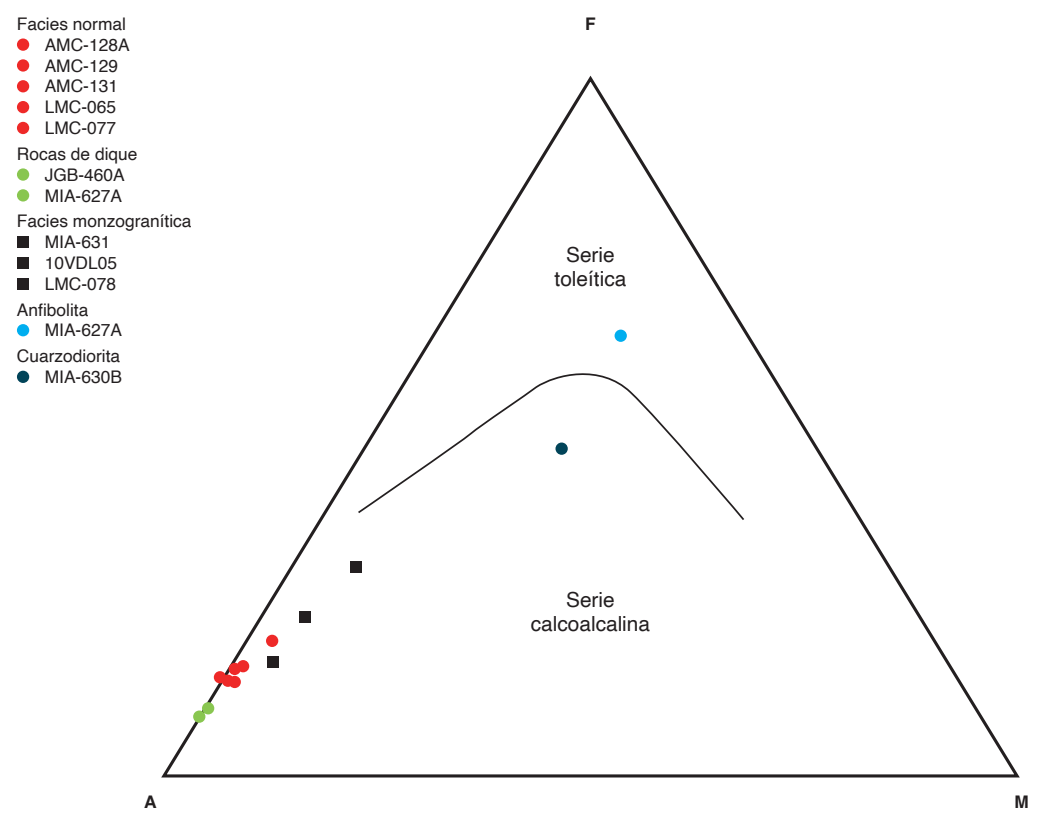

Figura 24. Diagrama AFM (Irvine y Baragar, 1971) correspondiente a las rocas del Monzogranito de La Corcova

A

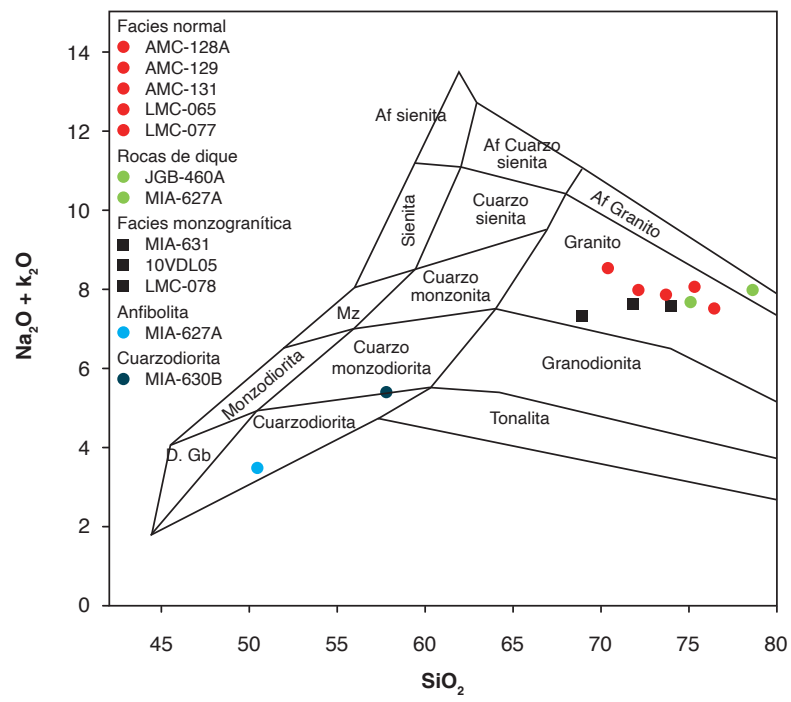

B

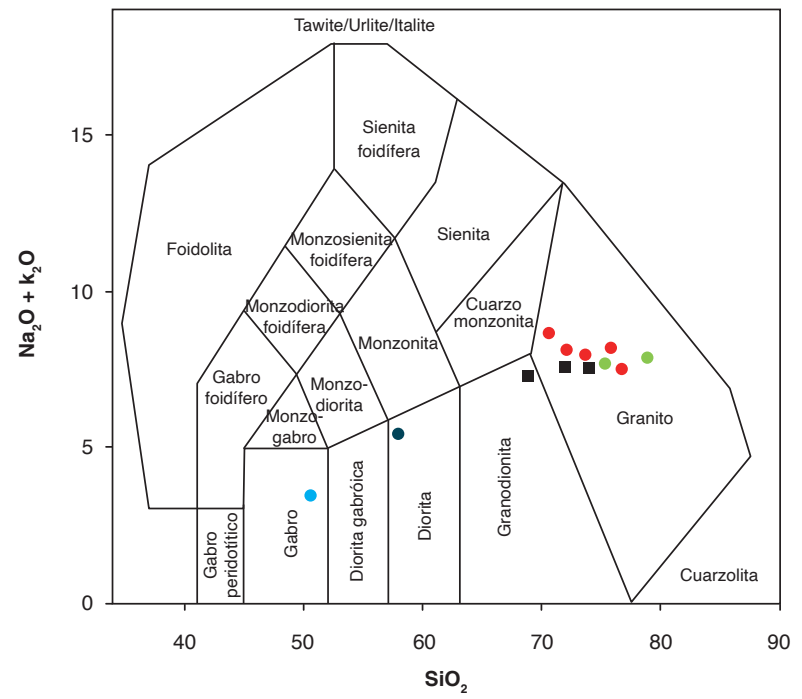

Figura 25. Diagramas de clasificación química de rocas del Monzogranito de La Corcova. A) Diagrama de Middlemost (1985). B) Diagrama de Middlemost (1994) 
En el gráfico de Shand (1943), los granitos que componen el Monzogranito de La Corcova hacen parte del campo peraluminoso, y presenta valores de $\left(\mathrm{Na}_{2} \mathrm{O}+\mathrm{K}_{2} \mathrm{O} /\right.$ $\left.\mathrm{Al}_{2} \mathrm{O}_{3}\right)_{\text {mol }}(\mathrm{A} / \mathrm{NK})>1$, y valores de $\left(\mathrm{Al}_{2} \mathrm{O}_{3} / \mathrm{Na}_{2} \mathrm{O}+\mathrm{K}_{2} \mathrm{O}+\mathrm{CaO}\right)$ mol $(\mathrm{A} / \mathrm{CNK})>1$, lo que podría sugerir aporte al magma de material de corteza continental, con valores altos de $\mathrm{SiO}_{2}(>68 \%$ ). Por otra parte, la cuarzodiorita (MIA-630BIGM-900936) y la anfibolita (MIA-62 7B, IGM-900932) pertenecen al campo metaluminoso (figura 26A).

En el diagrama de Debon y Le Fort (1983), modificado por Villaseca et al. (1998) (figura 26B), las rocas analizadas se agrupan en el campo peraluminoso, la mayoría de muestras en el campo de los granitos peraluminosos félsicos (f-P), algunas en el campo de los granitoides moderadamente peraluminosos (m-P), y solo la muestra 10VDL05 se diferencia de las demás analizadas.

En la mayoría de rocas, el índice de saturación de alúmina oscila entre 1 y 2 , y la relación $\mathrm{A} / \mathrm{CNK}$ es $>1$. Las muestras presentan valores de $\mathrm{A} / \mathrm{NK}$ entre 1 y 2 , sus relaciones $\mathrm{K}_{2} \mathrm{O} / \mathrm{Na}_{2} \mathrm{O}$ oscilan entre 1,5 y 2,3 , y el $\mathrm{Al}_{2} \mathrm{O}_{3}$ es mayor que $\mathrm{CaO}+\mathrm{Na}_{2} \mathrm{O}+\mathrm{K}_{2} \mathrm{O}$. Únicamente las muestras MIA-630B-IGM-900936 y MIA-627B，IGM-900932 presentan relación $\mathrm{A} / \mathrm{NK}>2$, relación $\mathrm{A} / \mathrm{CNK}<1$, relación $\mathrm{K}_{2} \mathrm{O} / \mathrm{Na}_{2} \mathrm{O}<1$ y Al $\mathrm{O}_{3}>\mathrm{CaO}+\mathrm{Na}_{2} \mathrm{O}+\mathrm{K}_{2} \mathrm{O}$.

A

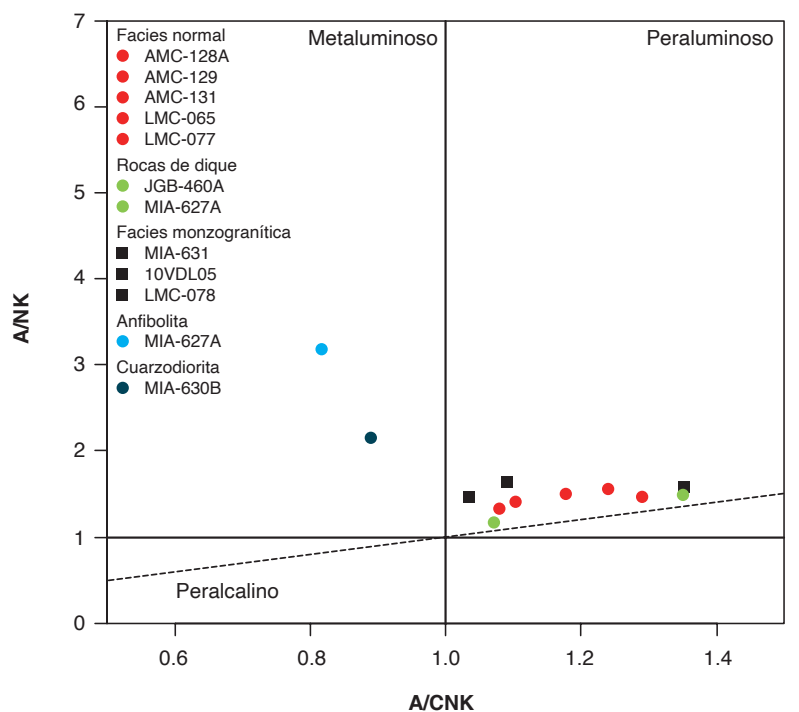

\subsection{Elementos traza y tierras raras}

En la tabla 17 se presentan los resultados de los análisis químicos de elementos traza y tierras raras correspondientes a rocas del Monzogranito de La Corcova, diques y rocas metamórficas.

Para la elaboración de los diagramas de elementos de las tierras raras (REE) normalizados con respecto al condrito según los valores de Nakamura (1974), las muestras analizadas del Monzogranito de La Corcova se agruparon teniendo en cuenta la facies que representan y el patrón geoquímico de REE. Se reconocieron cuatro patrones de REE, que podrían sugerir diferentes eventos o pulsos magmáticos dentro del plutón. El comportamiento general de los cuatro patrones es comparable con el de rocas generadas en ambientes de subducción por encima de la placa subducida, con enriquecimiento en tierras raras livianas (LREE) entre 10 y 300 veces el condrito y empobrecimiento hacia las tierras raras pesadas (HREE), además de anomalía negativa de Eu, que se incrementa con el aumento del contenido de $\mathrm{SiO}_{2}$ en las rocas, probablemente debida a fraccionamiento de la plagioclasa en el magma, que permitiría que $\mathrm{Eu}^{+3}$ cambie su estado de oxidación a $\mathrm{Eu}^{+2}$ (figura 27). Las relaciones $\mathrm{Eu} / \mathrm{Eu}^{*}<1 \mathrm{y}(\mathrm{La} / \mathrm{Sm})_{\mathrm{N}}>2$ evidencian un enriquecimiento de tierras raras ligeras con relación a las HREE en todas las muestras (tabla 18).

B

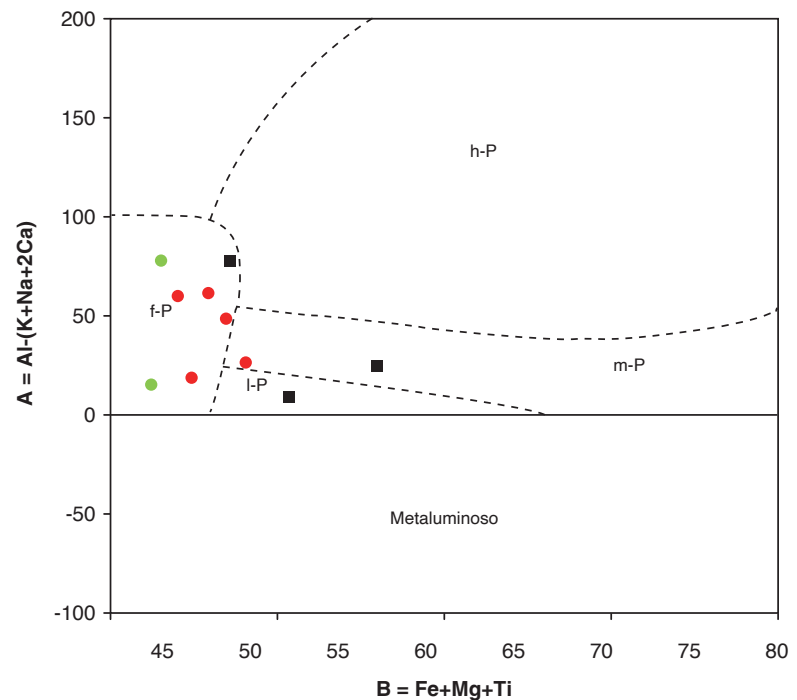

Figura 26. Diagramas de alcalinidad-aluminosidad correspondientes a rocas del Monzogranito de La Corcova. A) Diagrama de Shand (1943). B) Diagrama de Debon y Le Fort (1983) modificado por Villaseca et al. (1998).

Convenciones: f-P: granitoides peraluminosos félsicos; h-P: granitoides altamente peraluminosos; m-P: granitoides medianamente peraluminosos 
Tabla 17. Resultados de elementos traza y tierras raras en rocas del Monzogranito de La Corcova

\begin{tabular}{|c|c|c|c|c|c|c|c|c|c|c|c|c|c|c|}
\hline IGM & 900861 & 900862 & 900929 & 900863 & 900921 & 900931 & 900909 & 900937 & 900930 & & 900936 & 900932 & \multirow{2}{*}{\multicolumn{2}{|c|}{$\begin{array}{l}\text { Límites de } \\
\text { detección }\end{array}$}} \\
\hline $\begin{array}{c}\mathrm{N} . \\
\text { campo }\end{array}$ & $\begin{array}{l}\text { AMC- } \\
\text { 0128A }\end{array}$ & AMC-0129 & LMC-077 & AMC-0131 & LMC-065 & MIA-627A & JGB-460A & MIA-631 & LMC-078 & 10VDL05 & MIA-630B & MIA-627B & & \\
\hline Li & 31 & 32 & 40 & 51 & 5,9 & 9 & 3,8 & 24 & 16 & & 50 & 32 & $\mathrm{ppm}$ & 0,5 \\
\hline $\mathrm{Be}$ & 2,5 & 2,3 & 3,2 & 3 & 2,3 & 6,9 & 3,3 & 3,9 & 3,3 & 4,21 & 3,3 & 2,1 & $\mathrm{ppm}$ & 0,1 \\
\hline $\mathrm{Sc}$ & 4,6 & 4,7 & 5,3 & 5,5 & 19 & 5,3 & 4,8 & 10 & 11 & 11 & 34 & 59 & $\mathrm{ppm}$ & 0,1 \\
\hline v & 20 & 14 & 10 & 13 & 14 & 8,7 & 13 & 33 & 14 & 46 & 201 & 417 & $(\mathrm{mg} / \mathrm{Kg})$ & 0,2 \\
\hline $\mathrm{Cr}$ & 4,8 & 2 & 1,7 & 1,8 & 13 & 2,7 & 1,5 & 7,7 & 3,1 & 8 & 34 & 4,9 & $\mathrm{ppm}$ & 0,5 \\
\hline Co & 13 & 17 & 14 & 13 & 16 & 18 & 16 & 14 & 16 & 6,4 & 38 & 55 & $\mathrm{ppm}$ & 0,8 \\
\hline $\mathrm{Ni}$ & 4,3 & 3,3 & 2,7 & 2,7 & 17 & 7,4 & 2,2 & 7,9 & 32 & 6,4 & 42 & 13 & $\mathrm{ppm}$ & 0,5 \\
\hline $\mathrm{Cu}$ & 5,2 & 5,4 & 4,1 & 4,1 & 12 & 4,9 & 4,2 & 12 & 8,3 & 10,8 & 28 & 55 & ppm & 1 \\
\hline $\mathrm{Zn}$ & 35 & 26 & 17 & 26 & 49 & 16 & 6,5 & 44 & 40 & 65 & 93 & 147 & ppm & 4 \\
\hline $\mathrm{Ga}$ & 18 & 18 & 20 & 19 & 21 & 21 & 15 & 20 & 20 & 19,9 & 23 & 25 & ppm & 0,2 \\
\hline As & 2,6 & 1,9 & 1,9 & 1,7 & 3,7 & 1,3 & 1,1 & 3,4 & 2,6 & 3 & 2,5 & 2,5 & $\mathrm{ppm}$ & 0,4 \\
\hline $\mathbf{R b}$ & 210 & 231 & 273 & 268 & 126 & 291 & 173 & 229 & 221 & 144,6 & 177 & 126 & $\mathrm{ppm}$ & 0,2 \\
\hline $\mathrm{Sr}$ & 169,6 & 130,3 & 132,7 & 106,5 & 62,7 & 62,5 & 110,5 & 237,6 & 180,3 & 255,8 & 445,8 & 321,1 & $\mathrm{ppm}$ & 1 \\
\hline $\mathrm{Cd}$ & $<0,08$ & $<0,08$ & $<0,08$ & $<0,08$ & $<0,08$ & $<0,08$ & $<0,08$ & 0,08 & 0,1 & & 0,13 & 0,19 & $\mathrm{ppm}$ & 0,08 \\
\hline In & 0,03 & 0,02 & 0,02 & 0,03 & 0,14 & 0,05 & 0,02 & 0,04 & 0,04 & & 0,08 & 0,1 & & \\
\hline Cs & 2,7 & 2,5 & 3,2 & 4,3 & 1,1 & 2,6 & 1,3 & 2,2 & 2,6 & 2,1 & 3,5 & 2 & $\mathrm{ppm}$ & 0,1 \\
\hline $\mathrm{Ba}$ & 1627 & 1141,1 & 1008,8 & 776,4 & 1061,9 & 315,9 & 584 & 1184,5 & 1103,1 & 1058,5 & 627,6 & 375,7 & ppm & 1 \\
\hline La & 83,4 & 62 & 58,7 & 47,8 & 95 & 19,4 & 21 & 61,7 & 55,9 & 78,6 & 45 & 24,6 & $\mathrm{ppm}$ & 0,1 \\
\hline $\mathrm{Ce}$ & 158,8 & 120,3 & 111,1 & 93,1 & 190 & 38,9 & 38 & 120,7 & 113,7 & 138,3 & 94,2 & 56,8 & $\mathrm{ppm}$ & 0,1 \\
\hline $\mathrm{Pr}$ & 17,5 & 14,4 & 12,3 & 10,5 & 25 & 4,7 & 5,5 & 15,2 & 13,4 & 14,7 & 12,1 & 7,8 & ppm & 0,1 \\
\hline $\mathrm{Nd}$ & 64,7 & 44,9 & 37,1 & 30,6 & 91 & 17,6 & 18,1 & 50,7 & 37,4 & 54 & 47,3 & 32,7 & ppm & 0,1 \\
\hline Sm & 8,8 & 8,5 & 7,1 & 6,4 & 16 & 3,8 & 5,3 & 9,8 & 8,7 & 9,2 & 9,3 & 7,4 & $\mathrm{ppm}$ & 0,01 \\
\hline Eu & 1,22 & 0,91 & 1,04 & 0,75 & 1,9 & 0,48 & 0,66 & 1,41 & 1,44 & 1,8 & 1,43 & 1,54 & $\mathrm{ppm}$ & 0,01 \\
\hline Gd & 6,37 & 5,72 & 5,4 & 4,57 & 11 & 2,89 & 4,18 & 6,86 & 6,47 & 7 & 6,76 & 5,12 & $\mathrm{ppm}$ & 0,01 \\
\hline $\mathrm{Tb}$ & 0,94 & 0,85 & 0,98 & 0,74 & 1,9 & 0,89 & 1,12 & 1,48 & 1,18 & 1,1 & 1,73 & 1,23 & $\mathrm{ppm}$ & 0,01 \\
\hline Dy & 4,26 & 3,58 & 3,76 & 3,27 & 6,6 & 5,16 & 6,96 & 6,78 & 5,53 & 6,2 & 8,96 & 6,79 & ppm & 0,01 \\
\hline Ho & 0,72 & 0,54 & 0,66 & 0,51 & 1,1 & 1,07 & 1,5 & 1,38 & 1,04 & 1,3 & 1,93 & 1,38 & $\mathrm{ppm}$ & 0,01 \\
\hline Er & 2,15 & 1,48 & 1,78 & 1,42 & 2,8 & 3,26 & 4,58 & 4,11 & 2,95 & 3,5 & 5,72 & 3,99 & $\mathrm{ppm}$ & 0,01 \\
\hline $\mathrm{Tm}$ & 0,23 & 0,15 & 0,2 & 0,16 & 0,24 & 0,5 & 0,7 & 0,54 & 0,37 & 0,5 & 0,79 & 0,53 & $\mathrm{ppm}$ & 0,01 \\
\hline $\mathrm{Yb}$ & 1,36 & 0,91 & 1,27 & 1,04 & 1,5 & 3,44 & 4,86 & 3,49 & 2,36 & 3,3 & 5,1 & 3,31 & $\mathrm{ppm}$ & 0,01 \\
\hline Lu & 0,18 & 0,12 & 0,19 & 0,15 & 0,22 & 0,5 & 0,73 & 0,51 & 0,34 & 0,5 & 0,71 & 0,48 & $\mathrm{ppm}$ & 0,01 \\
\hline TI & 1,37 & 1,5 & 1,77 & 1,72 & 0,65 & 1,56 & 0,97 & 1,36 & 1,32 & & 1,05 & 0,91 & $\mathrm{ppm}$ & 0,01 \\
\hline $\mathrm{Pb}$ & 17,66 & 21,11 & 22,31 & 21,19 & 14 & 22,18 & 18,51 & 23,78 & 20,92 & 15,9 & 9,34 & 8,37 & ppm & 2 \\
\hline $\mathrm{Bi}$ & 0,07 & 0,07 & $<0,05$ & 0,08 & $<0,05$ & 0,11 & 0,09 & 0,06 & 0,06 & 0,1 & 0,09 & 0,14 & $\mathrm{ppm}$ & 0,1 \\
\hline Th & 32,9 & 31,4 & 31,2 & 28,2 & 20,9 & 16,2 & 24 & 29,8 & 30,8 & 22,7 & 12,7 & 4,5 & ppm & 0,1 \\
\hline U & 2,5 & 2 & 2 & 2,7 & 2,3 & 8,5 & 10,7 & 6,2 & 2,2 & 3,1 & 6,7 & 1 & $\mathrm{ppm}$ & 0 \\
\hline $\mathrm{Zr}$ & 205,5 & 185,2 & 132,5 & 126,7 & 193 & 60,6 & 51,8 & 214,3 & 205,7 & 340,5 & 175,2 & 153,4 & $(\mathrm{mg} / \mathrm{Kg})$ & 2 \\
\hline $\mathrm{Nb}$ & 10,5 & 12,6 & 13,6 & 14,9 & 11,1 & 15,1 & 15,8 & 14,4 & 14,2 & 16,4 & 16,4 & 13,1 & $(\mathrm{mg} / \mathrm{Kg})$ & 2 \\
\hline w & 37,3 & 58,5 & 44 & 51,6 & 50,8 & 66,1 & 58,9 & 36,5 & 42,8 & 0,2 & 31,4 & 23,3 & $(\mathrm{mg} / \mathrm{Kg})$ & 8 \\
\hline
\end{tabular}

Los colores en la tabla indican la manera en que se agrupan las muestras y se relacionan con el color de las muestras en las figuras

Al cruzar los datos de los diferentes patrones de REE con la edad obtenida por el método U/Pb en circones y la distribución espacial de las diferentes muestras (figura 27 ) se pudo observar que las rocas de composición monzogranítica a sienogranítica de las facies normal y porfídica presentan un patrón de REE paralelo (figura 27A, en rojo), con un empobrecimiento progresivo de las LREE hacia las HREE, pendiente negativa y anomalía negativa de Eu, patrón que se puede asociar con rocas generadas en un ambiente de arco. La distribución espacial de las muestra asociadas a este patrón de REE se restringe a la zona norte del plutón, y corresponde a la facies porfídica (AMC-0131) de Ward et al. (1973), a la facies normal del plutón (AMC-01 28 A, AMC-01 29 y LMC-077) y a diques y apófisis que intruyen el Neis de Bucaramanga (LMC065). Se ha obtenido una edad promedio ponderada en la roca AMC-0131 de 192,5 $\pm 2,6 \mathrm{Ma}$, que corresponde a la edad más joven, y una edad de 204,8 \pm 6,1 Ma para la roca LMC-077, que corresponde a la edad más antigua en el Monzogranito de La Corcova. Ambas rocas muestran patrones similares, aunque el patrón de la muestra LMC-077 cruza localmente las otras rocas. 

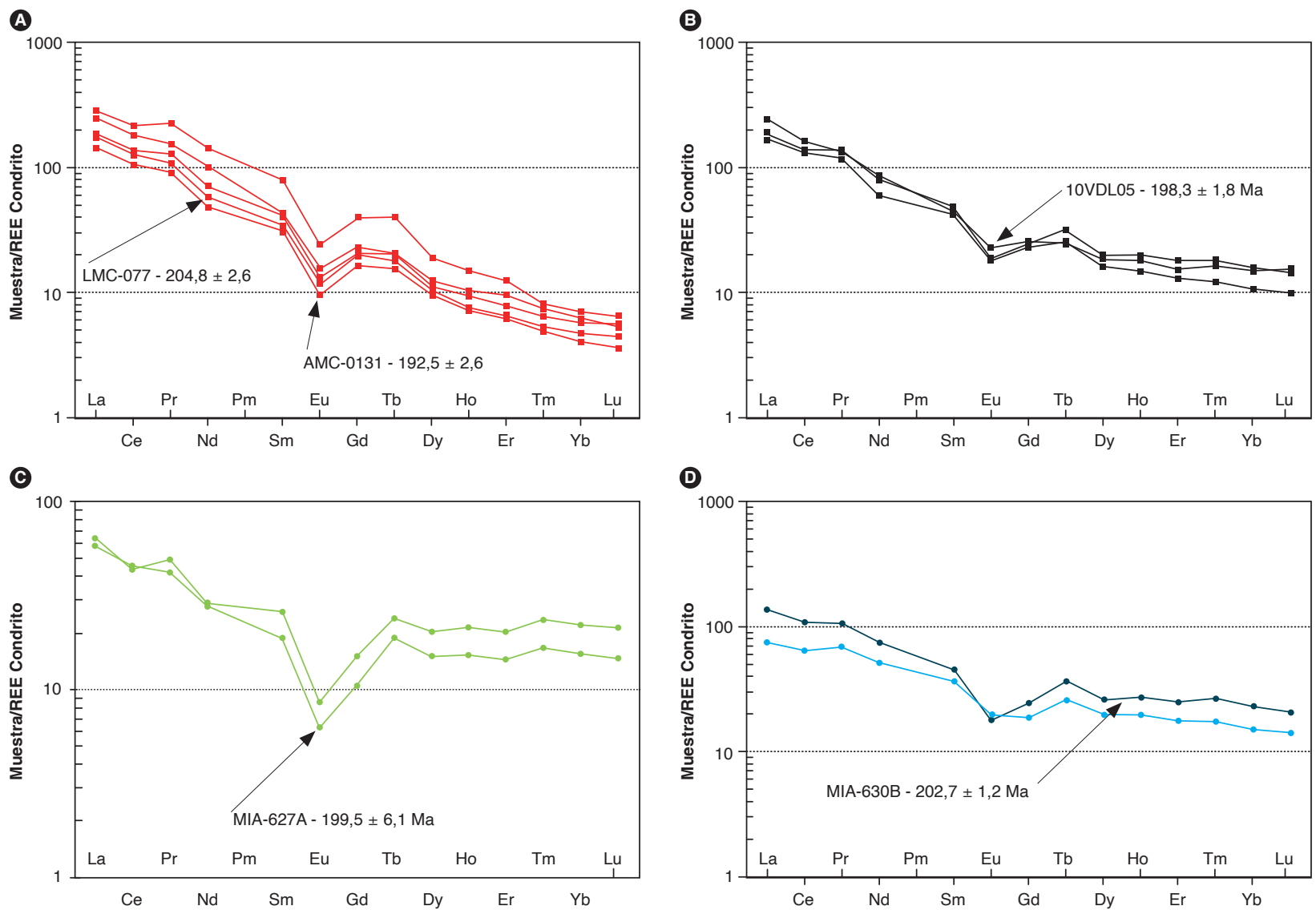

Figura 27. Diagramas de REE normalizados con respecto al condrito (Nakamura, 1974). Comparación de los patrones de las rocas del Monzogranito de La Corcova. A) Muestras de la facies normal y porfídica clasificadas como granitos. B) Muestras de la facies normal clasificadas como granitos y granodioritas (negro). C) Muestras de diques clasificadas como monzogranitos y sienogranitos (verde). D) Muestras de anfibolita y cuarzodiorita (azul)

El segundo patrón en los diagramas de elementos de las tierras raras (REE) normalizado con respecto al condrito según los valores de Nakamura (1974) (figura 27B) comprende una muestra de granodiorita (Van der Lelij, 2013, 10VDL05), una de granofelsa de Qtz-Fsp (MIA631), clasificada químicamente como un granito y un monzogranito (LMC-078). El patrón de REE (figura 27B) muestra empobrecimiento progresivo desde las LREE hacia las HREE (con valores mayores que los de las muestras del patrón anterior), pendiente negativa y anomalía negativa de Eu, lo que se puede asociar a rocas generadas en un ambiente de arco. Estas rocas se encuentran distribuidas en la parte central y norte del plutón y en un dique que atraviesa el Neis de Bucaramanga. La edad U/Pb obtenida en la muestra 10VDL05 es de 198,3 $\pm 1,8$ Ma, que en estas rocas sugiere un pulso magmático diferente, con una edad más antigua que la de las muestras agrupadas en la figura 27 A y en la tabla 17.
El tercer patrón en los diagramas de elementos de las tierras raras (REE) normalizado a condrito según los valores de Nakamura (1974) (figura 27C) comprende dos muestras de diques (MIA-627A y JGB-460-A) clasificadas químicamente como granitos y petrográficamente como un monzogranito y un sienogranito, respectivamente. El patrón de las REE normalizado con respecto al condrito de Nakamura (1974) muestra una notable diferencia respecto de los dos patrones anteriores: presenta empobrecimiento progresivo desde las LREE hacia las HREE, con una pronunciada anomalía negativa de Eu y un patrón plano de las HREE entre Tb y Lu, con valores de veinte a treinta veces el condrito, patrón que se podría asociar a rocas generadas en un ambiente de arco. De la muestra MIA-627-A se obtuvo una edad promedio ponderada $\mathrm{U} / \mathrm{Pb}$ de 199,5 \pm 4,6 Ma, que permite sugerir que estos diques intruyen rocas que superan los 199 Ma dentro del plutón. Estas rocas se encuentran localizadas hacia 
el centro y sur del cuerpo y representan un tercer pulso magmático de composición monzo-sienogranítico.

Por último, el cuarto patrón en los diagramas de elementos de las tierras raras (REE) normalizado con respecto al condrito según los valores de Nakamura (1974) (figura 27D) comprende una cuarzodiorita (MIA-630B) y una anfibolita con cuarzo (MIA-627B). El patrón de REE (figura 27D) de ambas rocas muestra un empobrecimiento progresivo desde las LREE hacia las HREE, una pendiente negativa y una anomalía negativa de Eu en la cuarzodiorita, mientras que la anfibolita no presenta la anomalía negativa de Eu. El patrón de ambas muestras se asocia a rocas generadas en un ambiente de arco, pero con diferente origen. La edad obtenida por el método $\mathrm{U} / \mathrm{Pb}$ en la muestra de cuarzodiorita (MIA-630B) es de $202,7 \pm 1,2 \mathrm{Ma}$, edad que corresponde a una de las más antiguas del Monzogranito de La Corcova.

En la tabla 18 se presentan las relaciones normalizadas con respecto al condrito de Nakamura (1974) correspondientes a algunas REE. Las rocas de dique presentan las menores sumatorias de REE $(102,71$ a 113,15), con unas relaciones $(\mathrm{Eu} / \mathrm{Yb})_{\mathrm{N}}$ de $0,4,(\mathrm{Cs} / \mathrm{Yb})_{\mathrm{N}}$ de 2,88 a 1,99 y $(\mathrm{La} / \mathrm{Yb})_{\mathrm{N}}$ de 3,77 a 2,88 más bajas que las de las demás rocas del monzogranito analizadas. Las rocas que representan la facies normal y porfídica muestran notable diferencia respecto de las demás rocas en la relación (La/
$\mathrm{Yb})_{\mathrm{N}}$, con valores muy altos (de 30,7 a 45,4) y la relación $(\mathrm{Ce} / \mathrm{Yb})$ entre 22,2 y 33,6. Las rocas del segundo patrón presentan valores de $(\mathrm{La} / \mathrm{Yb})_{\mathrm{N}}$ entre 11,8 y $15,8, \mathrm{y}(\mathrm{Ce} /$ $\mathrm{Yb}$ ) entre 2,9 y 3,5. Las rocas de dique del tercer patrón tienen valores de $(\mathrm{La} / \mathrm{Yb})_{\mathrm{N}}$ entre 2,88 y $3,77, \mathrm{y}(\mathrm{Ce} / \mathrm{Yb})$ entre 1,99 y 2,88 . La cuarzodiorita y la anfibolita presentan relaciones $(\mathrm{La} / \mathrm{Yb})_{\mathrm{N}}$ de 5,89 y 4,96, y $(\mathrm{Ce} / \mathrm{Yb})_{\mathrm{N}}$ entre 4,7 y 4,37 , respectivamente.

El Monzogranito de La Corcova presenta generalmente relaciones $(\mathrm{La} / \mathrm{Yb})_{\mathrm{N}}>2$, valores que se podrían asociar con rocas formadas en la corteza continental. Se presentan notables diferencias entre los cuatro patrones de REE con mayor o menor pendiente, lo que permite sugerir variaciones composicionales en los magmas, es decir, cambios en la fuente magmática en las rocas de cada patrón, con mayor o menor aporte del manto y de la corteza. Los valores altos de $(\mathrm{La} / \mathrm{Yb})_{\mathrm{N}}$, con patrones caracterizados por una pronunciada pendiente entre las LREE y las HREE, podrían representar mayores aportes de la corteza, periodos de mayor flujo magmático y/o corteza más gruesa. Los menores valores de $(\mathrm{La} / \mathrm{Yb})_{\mathrm{N}} \mathrm{po}-$ drían indicar mayores aportes al magma de material del manto y periodos de más bajo flujo magmático; menores pendientes en los patrones de REE podrían relacionarse con profundidades menores de génesis del magma (Girardi, 2008).

Tabla 18. Valores normalizados de REE según el condrito de Nakamura (1974) correspondientes a rocas del Monzogranito de La Corcova

\begin{tabular}{|c|c|c|c|c|c|c|c|}
\hline IGM & $\mathrm{Eu} / \mathrm{Eu}^{*}$ & $L a_{N} / Y_{b_{N}}$ & $\mathrm{La}_{\mathrm{N}} / \mathrm{Sm}_{\mathrm{N}}$ & $C e_{N} / \mathrm{Yb}_{\mathrm{N}}$ & $\mathrm{Ce}_{\mathrm{N}} / \mathrm{Sm}_{\mathrm{N}}$ & $\mathrm{Eu}_{\mathrm{N}} / \mathrm{Yb}_{\mathrm{N}}$ & Sum-REE \\
\hline 900862 & 0,4 & 45,44 & 4,5 & 33,62 & 3,33 & 2,86 & 264,4 \\
\hline 900861 & 0,5 & 40,78 & 5,8 & 29,62 & 4,21 & 2,55 & 350,7 \\
\hline 900863 & 0,42 & 30,69 & 4,59 & 22,79 & 3,41 & 2,05 & 201,05 \\
\hline 900929 & 0,52 & 30,73 & 5,09 & 22,21 & 3,68 & 2,35 & 241,55 \\
\hline 900921 & 0,43 & 40,84 & 3,56 & 31,2 & 2,72 & 3,48 & 445,1 \\
\hline 10 & 0,67 & 15,88 & 5,28 & 10,66 & 3,54 & 1,52 & 319,9 \\
\hline 900930 & 0,59 & 15,78 & 3,96 & 12,24 & 3,07 & 1,74 & 250,83 \\
\hline 900937 & 0,53 & 11,79 & 3,87 & 8,8 & 2,89 & 1,15 & 284,63 \\
\hline 900931 & 0,45 & 3,77 & 3,13 & 2,88 & 2,39 & 0,4 & 102,71 \\
\hline 900909 & 0,43 & 2,88 & 2,45 & 1,99 & 1,69 & 0,39 & 113,15 \\
\hline 900936 & 0,55 & 5,89 & 2,97 & 4,7 & 2,37 & 0,8 & 241 \\
\hline 900932 & 0,77 & 4,96 & 2,03 & 4,37 & 1,79 & 1,33 & 153,71 \\
\hline
\end{tabular}

Los colores en la tabla indican la manera en que se agrupan las muestras y se relacionan con el color de las muestras en las figuras 
En el diagrama multielemental de elementos trazas normalizado con respecto al NMORB (Sun y McDonough, 1989), las rocas del Monzogranito de La Corcova muestran un empobrecimiento en los elementos inmóviles $\mathrm{Nb}, \mathrm{Sr}, \mathrm{Zr}$, Ti y P, lo que podría corresponder a una separación de fases minerales accesorias tales como titanita, rutilo, circón y apatito, reflejo de la evolución magmática (Winter, 2001), donde el Nb presenta un comportamiento geoquímico similar al Ti (figura 28). Valores altos de los elementos litófilos de alto radio iónico (LILE) Cs, Ba y Th indican una afinidad con corteza continental (márgenes convergentes), donde abundan estos elementos altamente incompatibles. Valores altos de Sr, K, Ba y $\mathrm{Rb}$ pueden deberse a su movilización a partir de fluidos que interactúan en la zona de subducción con el magma (figura 28A). Las anomalías negativas de Nb, Ti y P son características de arcos magmáticos relacionados con ambientes de subducción, con empobrecimiento progresivo. Estas rocas también presentan una anomalía negativa de $\mathrm{Nb}$ con respecto al Th y Ce, signatura geoquímica típica de magmas originados en ambientes tectónicos relacionados con arcos, con un patrón subparalelo en la mayoría de las muestras en cada grupo de rocas.

Los elementos traza más móviles (LILE) presentan concentraciones mayores que el N-MORB, mientras que los elementos traza menos móviles, en los patrones de diques (figura 28C), cuarzodiorita y anfibolita (figura 28D), presentan concentraciones por encima del N-MORB, y en las rocas monzograníticas de la facies normal y porfiríticas (figura 28A y B), por debajo del N-MORB.
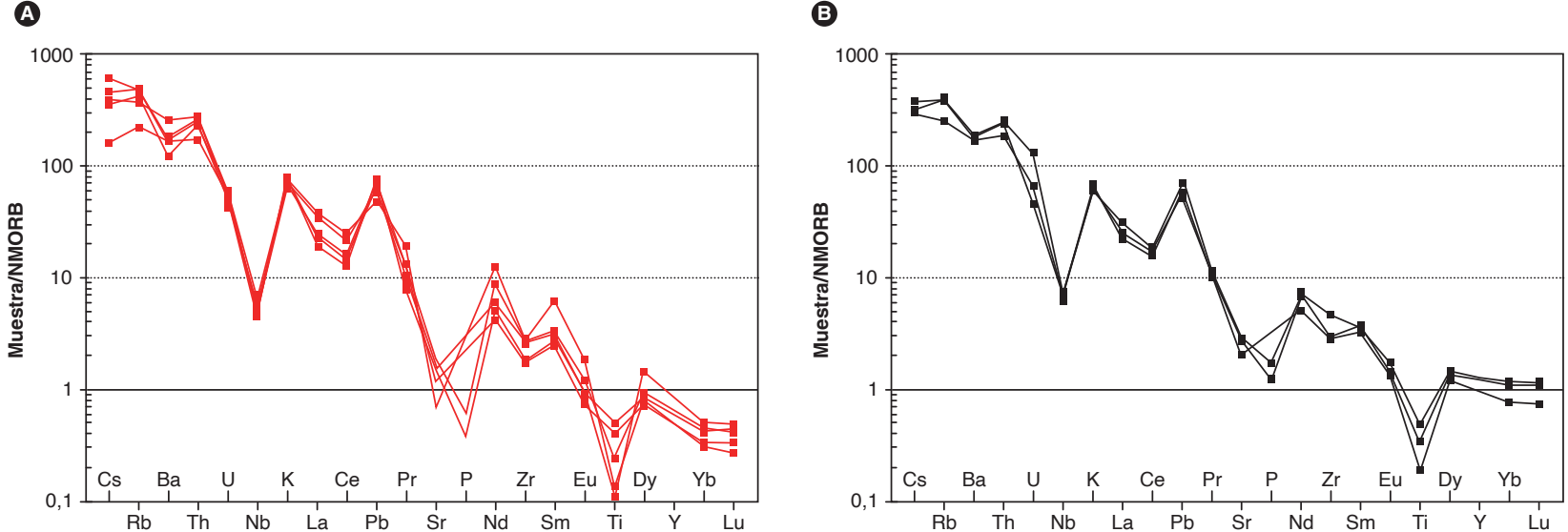

○

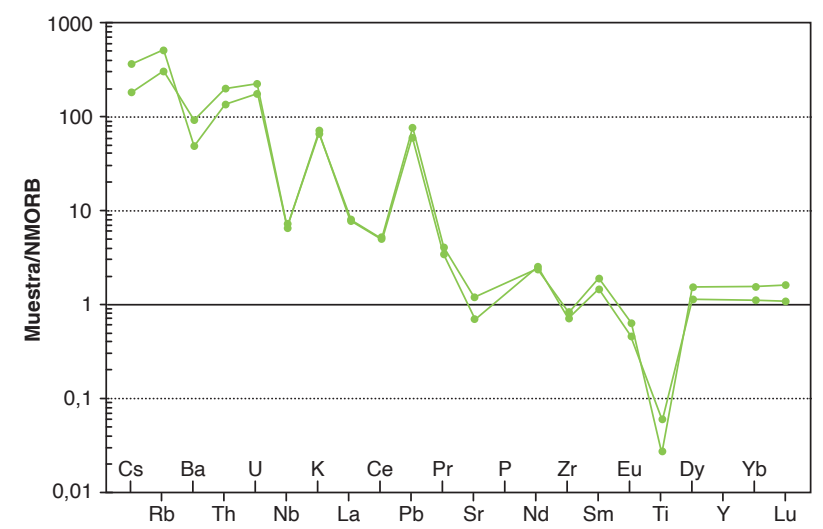

D

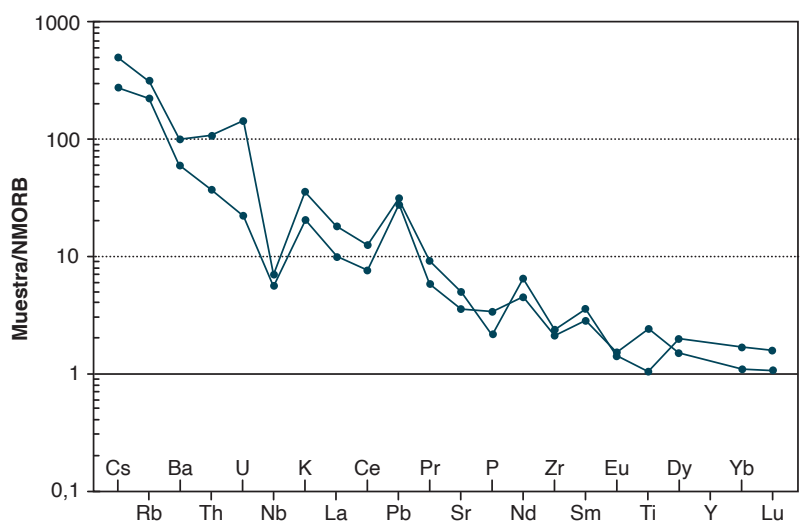

Figura 28. Diagrama multielemental normalizado con respecto a NMORB. Rojo: granitos de la facies normal y porfídica. Negro: granitos y granodioritas de facies normales del plutón. Verde: rocas de diques clasificadas como monzogranitos y sienogranitos. Azul: anfibolita y cuarzodiorita

Fuente: Sun y McDonough (1989) y este trabajo 
Al observar los grupos de rocas que sugieren diferentes pulsos magmáticos en el Monzogranito de La Corcova, en el diagrama multielemental de elementos incompatibles (Sun y McDonough, 1989) se presentan pequeñas diferencias en los trenes de los elementos traza. Se resalta que las rocas de la facies normal y porfídica presentan mayores anomalías de titanio y valores más bajos que el N-MORB de Dy, Y, Yb y Lu.

\subsection{Discriminación del ambiente tectónico}

En los diagramas de Whalen et al. (1987) y de Frost et al. (2001), las rocas del Monzogranito de La Corcova se clasifican en el campo de los granitos tipo I y tipo $\mathrm{S}$ (figura 29 A y B); según los diagramas Rb/Zr vs. Nb de Martin (1994) (figura 29C) corresponden a granitos de arco magmático. El diagrama Rb/Zr vs. Nb de Martin (1994) indica que las rocas del Monzogranito de La Corcova pertenecen a un arco magmático normal. Se puede interpretar que el magma parental de los granitoides es de zona de subducción y que habría tenido dos fuentes: por un lado, un componente relacionado con la placa oceánica más los sedimentos oceánicos subducidos, y por otra parte, un componente importante perteneciente a la corteza continental, y la mayoría de las rocas se clasi-

(A)

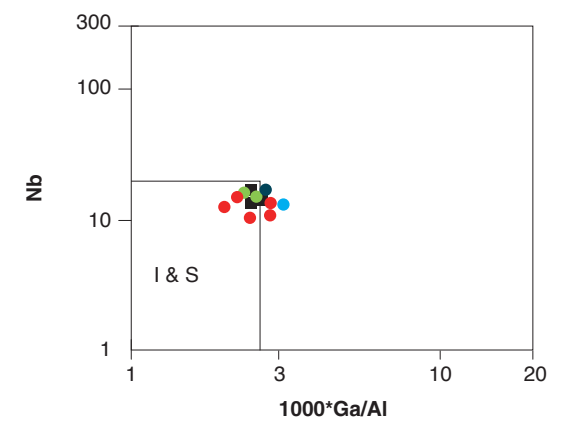

$\boldsymbol{C}$

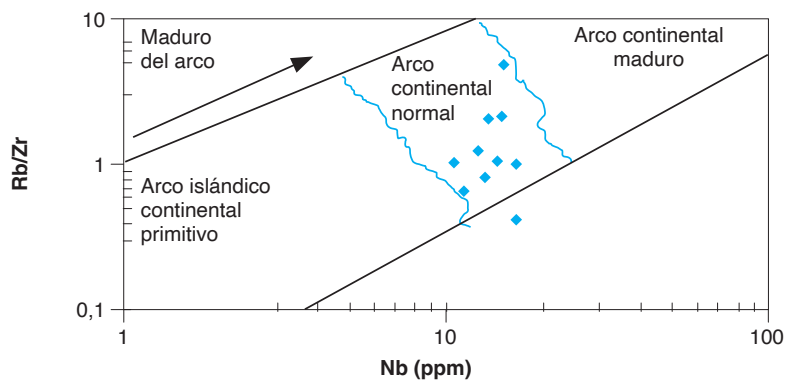

ficarían entre granitos tipo S e I. Mineralógicamente, algunas rocas analizadas del Monzogranito de La Corcova tienen hornblenda y carecen de moscovita, presentan facies intermedias tonalíticas con hornblenda y biotita. El feldespato potásico es blanco y la biotita, parda; estas características se asocian a granitos tipo I altamente diferenciados. En el diagrama de Frost et al. (2001), las rocas asociadas a la facies porfídica pertenecen al campo de los granitos ferrosos, junto con las rocas de dique, mientras que las rocas monzograníticas y cuarzodioríticas más antiguas hacen parte del campo de los granitos magnesianos frecuentes en ambientes poscolisionales y de arcos, y pueden haber heredado esta condición de la fusión parcial de la corteza continental (Frost y Frost, 2008) (figura 29D).

Van der Lelij (2013) considera que los granitoides de Santander del Triásico-Jurásico presentan valores en roca total de $\varepsilon \mathrm{Ndt}$, que se correlacionan bien con $\varepsilon \mathrm{Hft}$ del circón y hacen parte de los trenes de plutones formados por areniscas orogénicas recicladas y material de manto.

Los diques que intruyen el Monzogranito de La Corcova corresponden a granitos de arco magmático, según los diagramas Rb/Zr vs. Nb de Martin (1994) (figura 29C) y los aracnogramas de tierras raras.

B

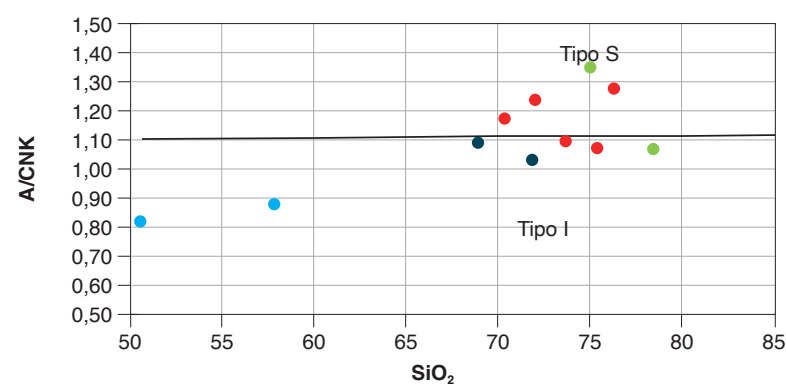

(D)

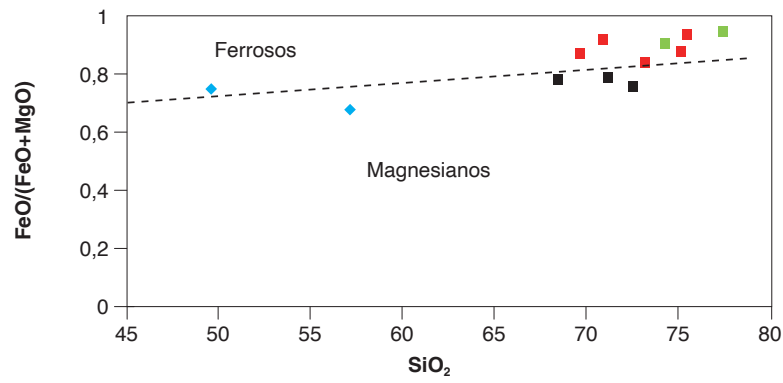

Figura 29. Diagramas discriminantes del ambiente tectónico de emplazamiento del Monzogranito de La Corcova. A) Diagrama de Whalen et al. (1987) de discriminación de granitos I, S, A. B) Diagrama de Frost et al. (2001) de discriminación de granitoides tipo I y S. C) Diagrama Rb/Zr vs. Nb de Martin (1994). D) Diagrama de Frost et al. (2001) 


\section{Posición estratigráfica y edad}

El Monzogranito de La Corcova intruye la formación Silgará, el Neis de Bucaramanga y, localmente, el Ortoneis de Berlín (Ward et al., 1973). Además, está atravesado por diques graníticos de edad Jurásica.

Los primeros resultados radiométricos de este cuerpo fueron presentados por Goldsmith et al. (1971), quienes obtuvieron edades utilizando el método K-Ar en moscovita y biotita; las edades obtenidas fueron de $195 \pm 7$ Ma en la moscovita y $111 \pm 4$ Ma en la biotita. El resultado en moscovita es interpretado como la edad del emplazamiento de los batolitos (Goldsmith et al., 1971) y da una edad semejante a las edades K/Ar en biotita de rocas de los batolitos principales del Macizo de Santander (Ward et al., 1973). La edad obtenida en la biotita fue interpretada por Goldsmith et al. (1971) como indicativa de un evento térmico local no identificado que afectó a la biotita; sin embargo, hay que considerar el estado de alteración de la biotita analizada, ya que el resultado pierde validez si la biotita se encontraba cloritizada.

Ward et al. (1973) sugirieren que el Monzogranito de La Corcova parecería ocupar una posición intermedia en el tiempo entre las rocas ígneas granodioríticas grises y las ígneas rosadas más graníticas.

Recientemente, Van der Lelij (2013) presentó una datación obtenida con el método U-Pb en circón, y reportó una edad de 198,3 $\pm 1,8$ Ma para una muestra de dique del Monzogranito de La Corcova (10VDL05) en el Neis de Bucaramanga. La muestra presenta paralelismo con las rocas de composición granítica que se localizan en el interior del plutón en los aracnogramas de REE normalizados con respecto a condrito de Nakamura (1974), lo que permite sugerir que hace parte de uno de los pulsos que dieron origen a este plutón (figura 27B).

Para este proyecto se dataron cinco muestras, cuatro de ellas tomadas en el interior del Monzogranito de La Corcova y una quinta correspondiente a un xenolito del Neis de Bucaramanga en el interior del plutón. Las dataciones se relacionaron con los patrones geoquímicos de los aracnogramas de tierras raras normalizados con respecto a condrito de Nakamura (1974), con el objeto de entender los pulsos magmáticos que dieron origen a todo el cuerpo y su distribución espacial y temporal, y regionalmente poder correlacionar estos eventos con otros presentes en cuerpos triásico-jurásicos del Macizo de Santander. Los resultados y la localización de las dataciones se presentan en la figura 1 y en la tabla 19.
La separación de los minerales densos se realizó en el Laboratorio químico del Servicio Geológico Colombiano, sede Medellín, mediante separación hidrodinámica y magnética, y también se realizó, allí mismo, el montaje de los circones. Las muestras AMC-031 y LMC077 se dataron por el método U-Pb en circones en el laboratorio de Ablación Laser del Servicio Geológico Colombiano utilizando un equipo de ablación laser Photon Machines, con un láser exímer de $193 \mathrm{~nm}$ y un espectrómetro ICP-Masas Element 2. Se utilizaron como patrones de referencia Plesovice, 91500 y M. Dromedry. Los puntos analizados fueron de 20 micrones, y la reducción de datos se realizó mediante el programa Iolite IGROpro. Se utilizaron tiempos de integración para la línea base de 0 s-38 s y para las muestras y patrones de referencia 32,5 $\mathrm{s}-8 \mathrm{~s}$, tiempos que concuerdan con el tiempo de corrida de los análisis. Los isótopos utilizados para la integración manual fueron ${ }^{238} \mathrm{U}, \mathrm{Pb}^{206} \mathrm{y} \mathrm{Pb}^{204}$. Los resultados finales corresponden a la media de los datos obtenidos luego de aplicar una discriminación de datos con dos desviaciones estándar. El procesamiento se llevó a cabo utilizando las rutinas de Isoplot V3.5, y la corrección por plomo común se realizó de acuerdo con el modelo de evolución de Stacey y Krammers (1975).

Las muestras MIA-630B, MIA-627A y AMC-01 28A fueron enviadas al Laboratorio de Estudios Isotópicos (LEI) del Centro de Geociencias de la Universidad Nacional Autónoma de México (UNAM), campus Juriquilla. La metodología utilizada fue la siguiente: las concentraciones de U y Th fueron calculadas empleando un circón estándar externo, de acuerdo con Paton et al. (2010). Las incertidumbres de sigma 2 propagadas se lograron según Paton et al. (2010). Las proporciones ${ }^{207} \mathrm{~Pb} /{ }^{206} \mathrm{~Pb}$, edades y errores se calcularon según Petrus y Kamber (2012). Los puntos analizados fueron de 23 micrómetros. Se utilizó el protocolo de análisis modificado de Solari et al. (2010). Los datos se midieron empleando un Thermo X series QICPMS acoplado a un resonetics, y una estación de trabajo láser excimer Resolución M050. Se realizó un análisis estadístico con el fin de mejorar el rango de confiabilidad de la edad proporcionada por el laboratorio, teniendo en cuenta la relación $\left[\left({ }^{207} \mathrm{~Pb} /{ }^{235} \mathrm{U}\right)-\left({ }^{206} \mathrm{~Pb} /{ }^{238} \mathrm{U}\right)\right]$ $\left./\left({ }^{207} \mathrm{~Pb} /{ }^{235} \mathrm{U}\right)\right] \mathrm{x} 100$, y se eliminaron los datos de circones con valores discordantes que estuvieran, en general, por encima del $15 \%$ y errores de más del $5 \%$. Los gráficos de concordia e histogramas se elaboraron en el software de Isoplot/Ex vers, 4,15 (Ludwig, 2012). 
Tabla 19. Resultados de geocronología en muestras del Monzogranito de La Corcova obtenidos por el método LA-MC-ICP-MS U-Pb en circones

\begin{tabular}{|c|c|c|c|c|c|c|c|}
\hline IGM-SD & N. campo & w & $\mathbf{N}$ & Plancha & Clasificación & Edad & $\mathrm{N} .{ }^{\circ} \mathrm{Zr}$ \\
\hline 900929 & LMC-077 & 1112260 & 1283759 & & Monzogranito & $204,8 \pm 6,1$ & 48 \\
\hline 900936 & MIA-630B & 1114060 & 1270011 & 120 & Cuarzodiorita & $202,7 \pm 1,2$ & 35 \\
\hline 900931 & MIA-627A & 1119356 & 1257497 & 120 & Monzogranito-dique & $199,5 \pm 4,6$ & 35 \\
\hline 900863 & AMC-0131 & 1114638 & 1284010 & 109 & Sienogranito & $192,5 \pm 2,6$ & 52 \\
\hline 900861 & AMC-0128A & 1114798 & 1281084 & 109 & $\begin{array}{c}\text { Xenolito-granofelsa } \\
\text { de Qtz-PI-Kfs }\end{array}$ & $462,7 \pm 3,1$ & 35 \\
\hline
\end{tabular}

De la facies monzogranítica se dató la muestra LMC077 (IGM-900929), localizada en la parte norte del cuerpo intrusivo, correspondiente a un monzogranito equigranular. Se obtuvieron circones prismáticos cortos achatados, algunos fracturados, de tamaños entre 50 y $100 \mu \mathrm{m}$. Las imágenes de catodoluminiscencia (CL) de estos circones evidenciaron zonación oscilatoria, con núcleo gris claro y algunos núcleos heredados.

Se filtraron los datos para descartar los circones con valores discordantes (discordancia > 10\%) y errores de edad corregida mayores de 5 , con el fin de mejorar el rango de confiabilidad de la edad, que presentaba un amplio rango entre 196 y 1426 Ma. Se tomó como grupo más coherente $n=8$ circones, que arrojaron una edad promedio ponderada de 204,8 $\pm 6,1 \mathrm{Ma}$, con MSWD = 5,3, edad que se interpretó como la de cristalización de la roca. Se presentó un segundo grupo de circones $(\mathrm{n}=11)$, concordantes, con edades entre 211 y $232 \mathrm{Ma}$, que arrojaron una edad promedio ponderada de 224,1 \pm 4,9 y MSWD $=5,2$, que se interpretó como una edad de cristalización heredada (figura 30). El diagrama de discordia presenta una amplia dispersión de edades concordantes entre 196 y 242 Ma, sin que se observe una agrupación de los datos definida.

En circones de la muestra LMC-077, las razones $\mathrm{Th} / \mathrm{U}$ varían entre 0,4 y 1 para el grupo de los ocho circones $(\mathrm{n}=$ 8) que se tomaron para definir la edad promedio ponderada, relación que sugiere una cristalización ígnea (Rubatto, 2002). La muestra LMC-077 presenta una edad de 230 Ma ( $\mathrm{n}=1)$, con una relación $\mathrm{Th} / \mathrm{U}<0,1$, que sugiere un circón metamorfo heredado; además, presenta núcleos con edades heredadas de 224,1 $\pm 4,9(n=11)$, del Paleozoico, entre 259 y $498 \mathrm{Ma}(\mathrm{n}=15)$, del Neoproterozoico $(\mathrm{n}=3)$ y del Mesoproterozoico $(n=1)$, que se resumen en el gráfico de densidad de probabilidad de la figura 30.

De las rocas intermedias de borde se dató la muestra MIA-630B, clasificada como cuarzodiorita, que aparece también como xenolitos dentro de la facies monzogranítica. De la muestra MIA-630B se obtuvieron circones prismáticos, cortos y achatados, de color púrpura tenue, algunos fracturados, de tamaños entre 50 y $100 \mu \mathrm{m}$. Las imágenes de catodoluminiscencia (CL) evidenciaron una zonación concéntrica.

Los análisis efectuados en la muestra MIA-630B fueron todos concordantes. Inicialmente se filtraron los datos para descartar los circones con valores discordantes (discordancia > 10\%) y errores de edad corregida mayores de 5, con el fin de mejorar el rango de confiabilidad de la edad. El grupo más consistente lo conformaron 28 circones $(\mathrm{n}=28)$, con una edad promedio ponderada de $202,7 \pm 1,2$ Ma y MSWD = 1,5, que se interpretó como la edad de cristalización de la roca. Se presentó un segundo grupo de circones con edades entre 207,3 Ma y 213 Ma, y edad promedio ponderada de $210,48 \pm 0,92 \mathrm{Ma}(\mathrm{n}=7)$ y MSWD $=0,79$, que se interpretó como una edad de cristalización heredada (figura 31 ).

Las razones $\mathrm{Th} / \mathrm{U}$ correspondientes a la muestra MIA-630B varían entre 1 y 4 en los circones, de los que se obtuvo la edad promedio ponderada y la edad heredada, relación que sugiere cristalización ígnea (Rubatto, 2002). Un circón arrojó una edad de 80 Ma, con una relación $\mathrm{Th} / \mathrm{U}=0,48$, menor que la del resto de circones, lo que podría indicar contaminación de la muestra por procesos naturales.

Se dató una tercera muestra correspondiente a diques que atraviesan el cuerpo intrusivo (muestra MIA627A). Los circones, que se separaron de un saprolito de la roca, se presentan fracturados, de tamaños gruesos y tonalidades púrpuras, en general corto-prismáticos, con tamaños de hasta $240 \mu \mathrm{m}$. En CL presentan zonamiento prevalentemente oscilatorio. Para interpretar los datos obtenidos de la muestra MIA-627A, fueron procesados en el software de Isoplot/Ex vers. 4,15 (Ludwig, 2012) (figura 31 ). 
A

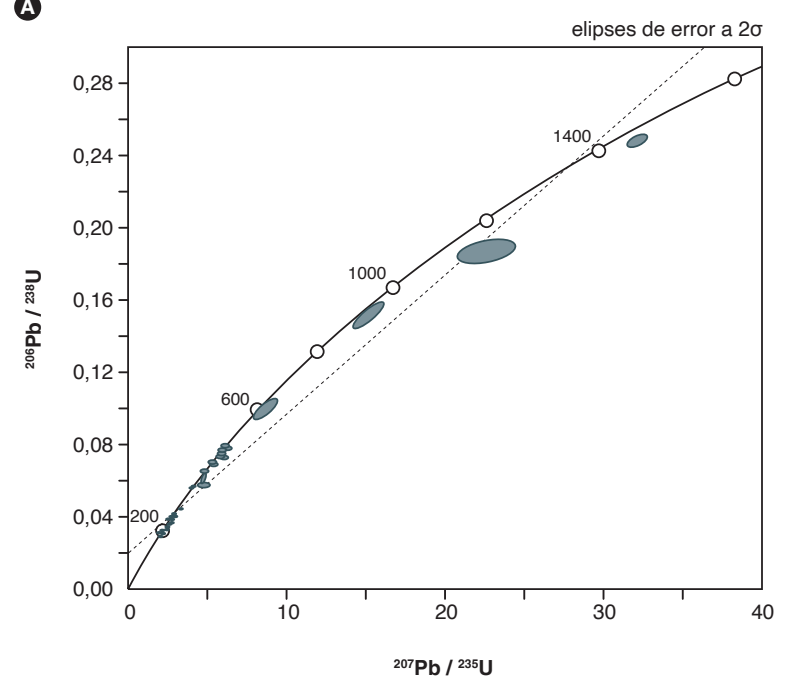

C

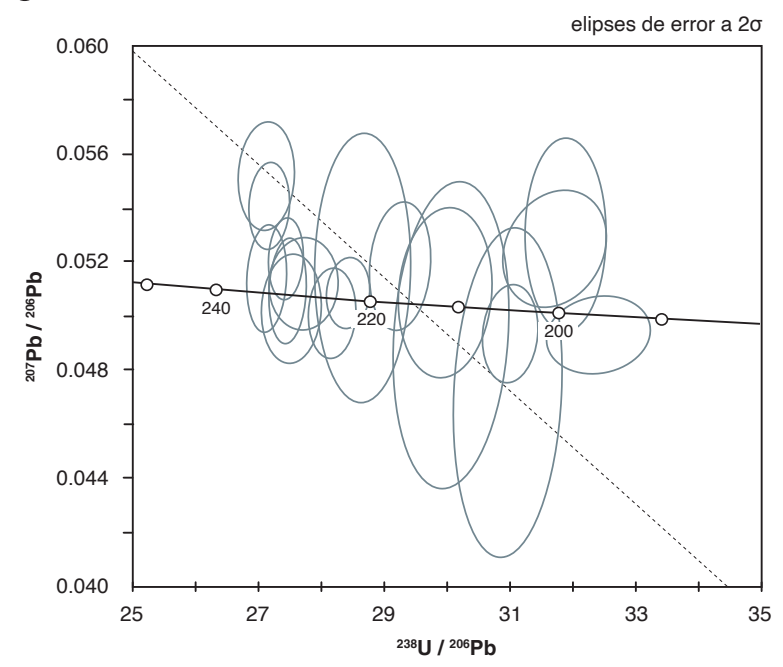

E

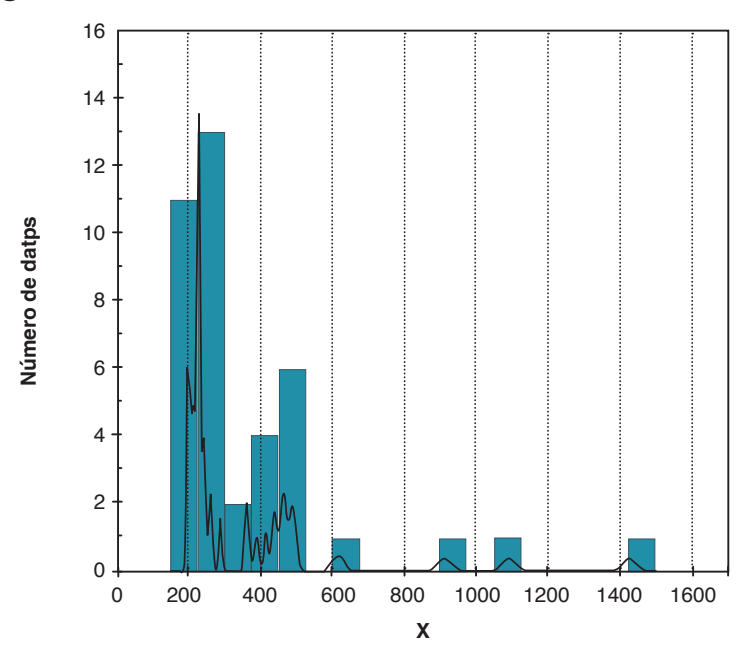

B

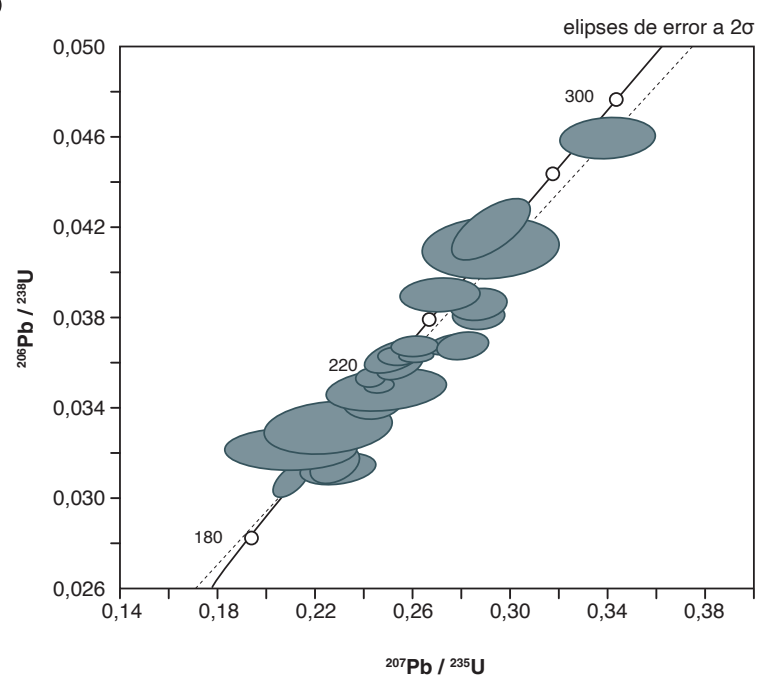

D

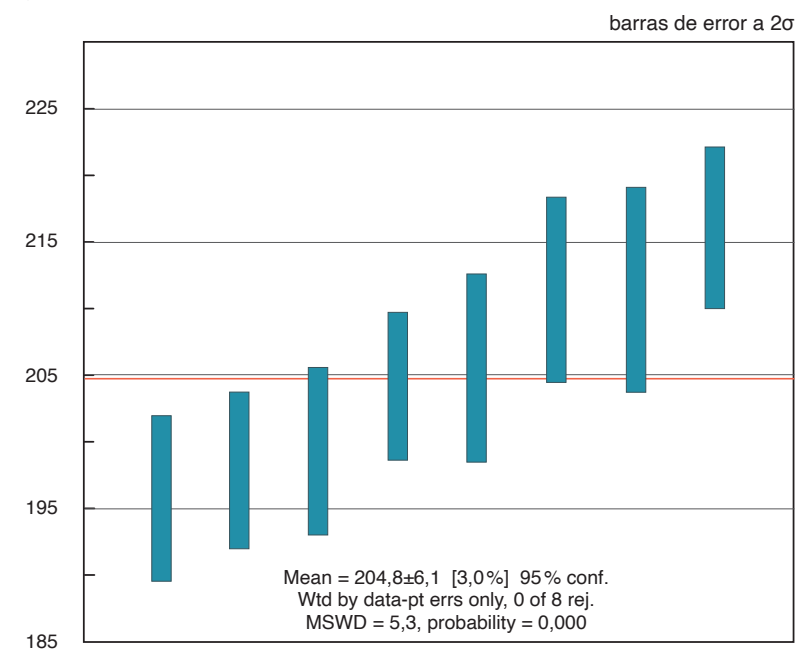

F

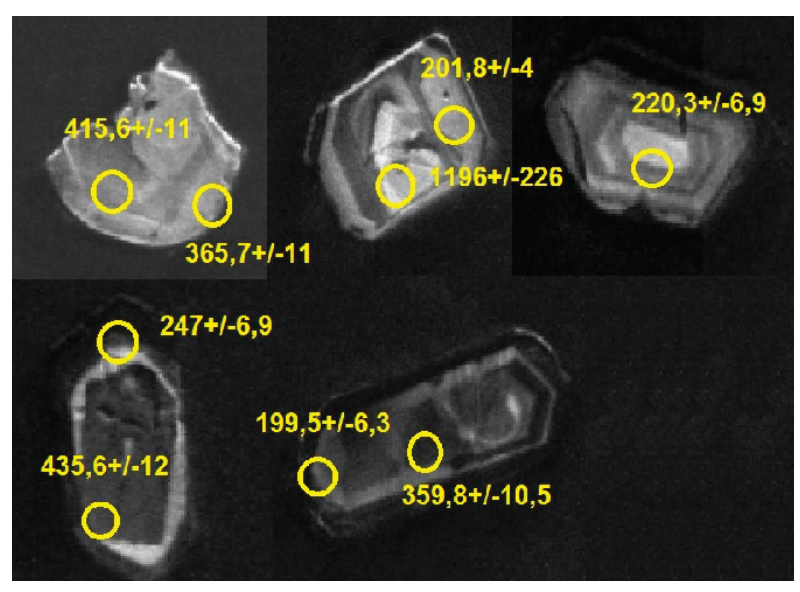

Figura 30. Muestra LMC-077. A) Diagrama de concordia. B) Detalle de edades concordantes entre 180 y 300 Ma. C) Diagrama de Tera-Wasserburg. D) Edad promedio ponderada. E) Diagrama de densidad de probabilidad. F) imágenes de catodoluminiscencia y edades U-Pb en circones 
A

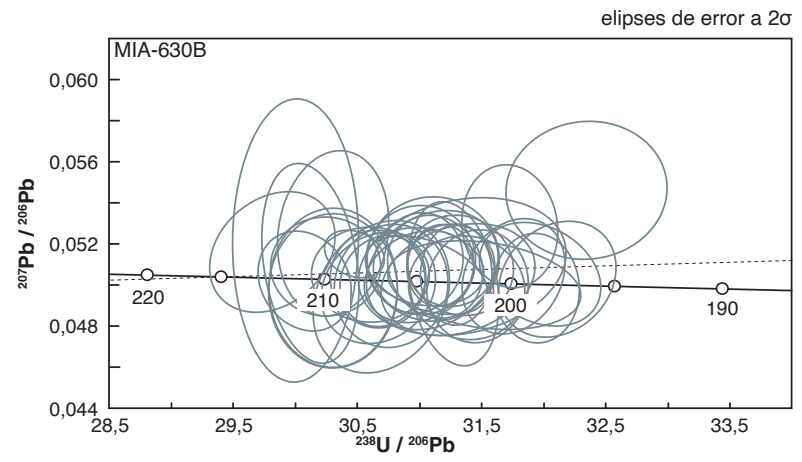

c

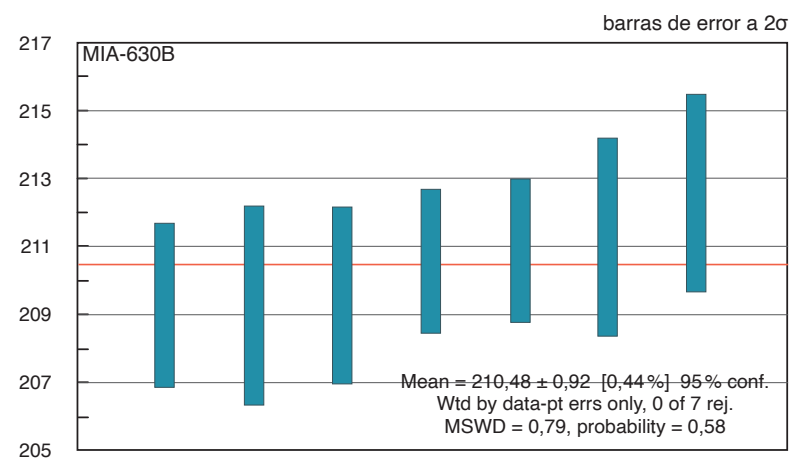

토

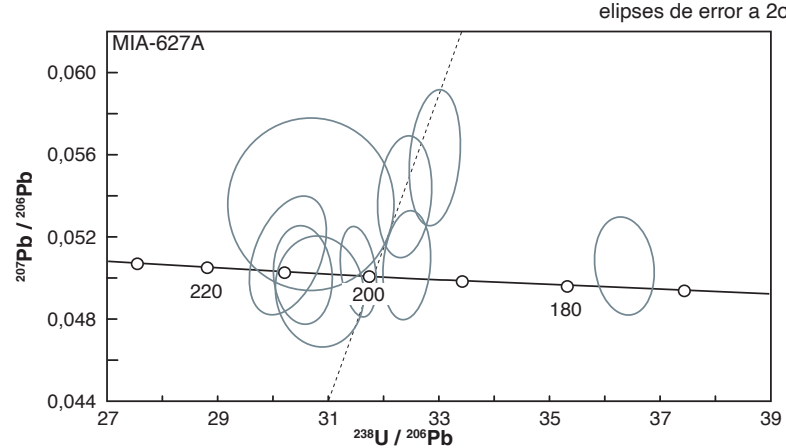

G

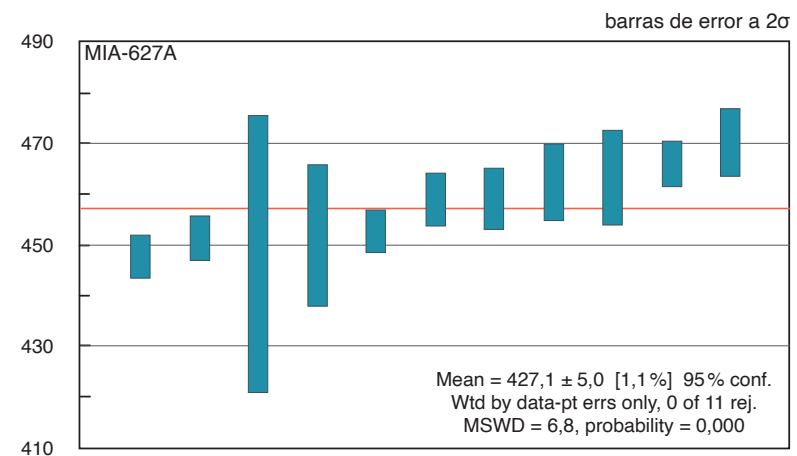

B

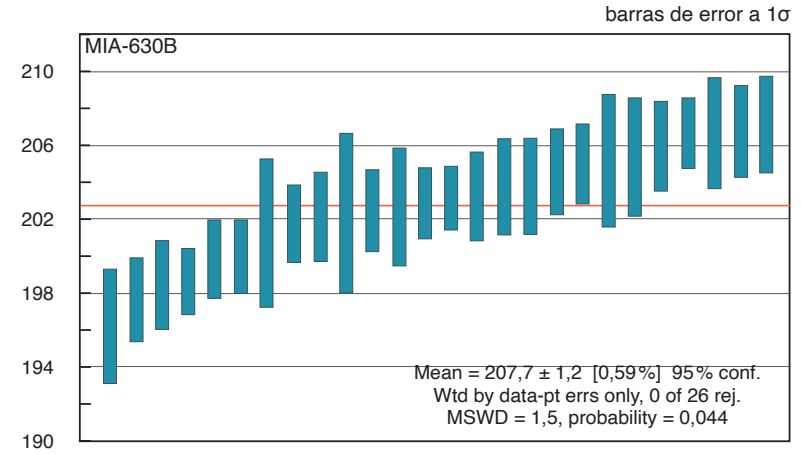

D

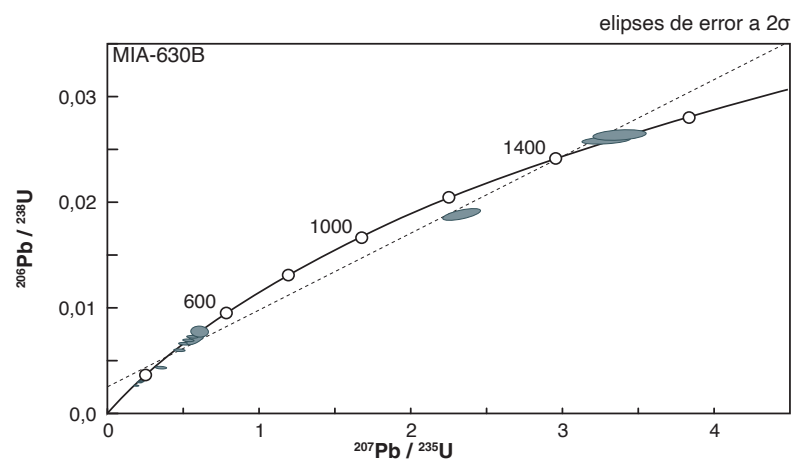

F

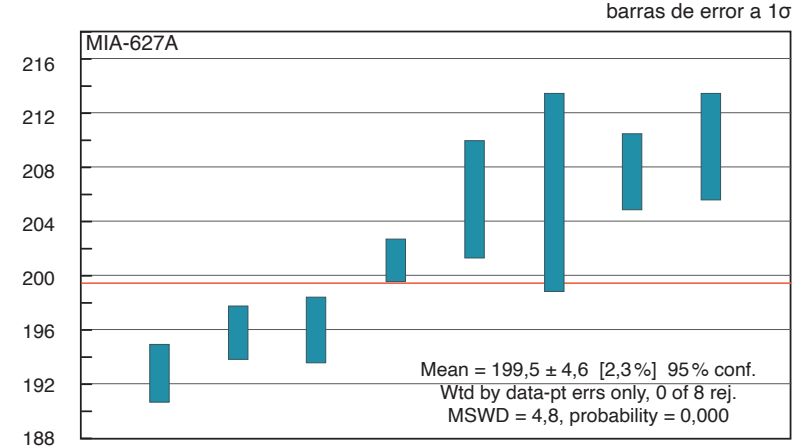

(十)

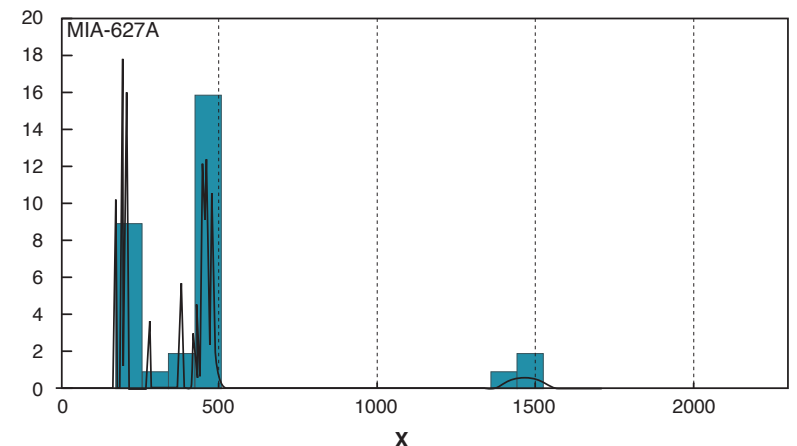

Figura 31. Muestra MIA-630B. A) Diagrama Tera-Wasserburg. B) Edad promedio ponderada. C) Edad promedio ponderada de circones heredados, muestra MIA-627A. D) Diagrama de concordia. E) Gráfico Tera-Wasserburg. F) Diagrama de densidad de probabilidad. G) Edad promedio ponderada de circones heredados. H) Histograma de densidad de probabilidad 
Inicialmente se filtraron los datos para descartar los circones con valores discordantes (discordancia > 10\%), de acuerdo con la relación $\left[\left({ }^{207} \mathrm{~Pb} /{ }^{235} \mathrm{U}\right)-\left({ }^{206} \mathrm{~Pb} /{ }^{238} \mathrm{U}\right)\right] /$ $\left.\left({ }^{207} \mathrm{~Pb} /{ }^{235} \mathrm{U}\right)\right] \mathrm{x} 100$, y errores de edad corregida mayores de 5 , con el fin de mejorar el rango de confiabilidad de la edad. Los resultados obtenidos presentaron una distribución concordante, pero bastante variada, desde ca. $175 \mathrm{Ma}$ (un cristal) hasta ca. $1500 \mathrm{Ma}$ (dos análisis concordantes) (figura 31).

El grupo más consistente lo conformaron ocho circones $(\mathrm{n}=8)$, con una edad promedio ponderada de 199,5 \pm 4,6 Ma (límite Triásico tardío-Jurásico temprano) y MSWD = 4,8, que se interpretó como la edad de cristalización de la roca. Además, se obtuvieron edades heredadas del Pérmico (281 Ma, $\mathrm{n}=1$ ), Devónico (382 Ma, $\mathrm{n}=1$ ), Silúrico (419 y $430 \mathrm{Ma}, \mathrm{n}=2$ ), Ordovícico, con una edad promedio ponderada de 457,1 $\pm 5, \mathrm{n}=11$ y MWSD = 6,8; edades entre 481 Ma y 484 Ma $(n=3)$, Cámbrico (495 Ma, $\mathrm{n}=1$ ) y edades mezoproterozoicas (1418 Ma a 1498 Ma, $\mathrm{n}=3$ ) obtenidas en núcleos de circones y en xenocristales. La edad promedio ordovícica de 457,1 \pm 5 Ma es similar a las edades obtenidas en rocas del Neis de Bucaramanga y en un xenolito de esta unidad perteneciente al Monzogranito de La Corcova.

En el gráfico de Th/U vs. Edad (figura 32) correspondiente a circones de la muestra MIA-627A se observa un conjunto de datos con edades de alrededor de $200 \mathrm{Ma}$, con relaciones $\mathrm{Th} / \mathrm{U}$ que varían entre 0,01 y 1,2 , valores variables que no muestran un conjunto de datos defini- dos que sugieran un solo origen. Los circones heredados muestran relaciones $\mathrm{Th} / \mathrm{U}$ diversas: circones paleozoicos entre 0,1 y 0,6, y escasos alrededor de 1, sugieren un origen ígneo, y los mesoproterozoicos con relaciones Th/U entre 0,4 y 0,5 también sugieren un origen ígneo.

Se dató la muestra AMC-0131 mediante el estudio de circones que se obtuvieron a partir de una roca clasificada petrográficamente como sienogranito, que se asocia con la facies porfirítica del Monzogranito de La Corcova. Se obtuvieron circones euhedrales, entre los que predominaban los prismáticos cortos y transparentes de tonalidad rosa, con pocas inclusiones fluidas, con un tamaño promedio de $200 \mu \mathrm{m}$ en la dimensión mayor y 100 a $150 \mu \mathrm{m}$ en la menor, algunos de 50 x $100 \mu \mathrm{m}$. Se obtuvo una segunda población de circones subesféricos euhedrales de color lila con tamaños entre $90 \times 100 \mu \mathrm{m}$ y 180 x $180 \mu \mathrm{m}$. Las imágenes de catodoluminiscencia (CL) evidenciaron una zonación concéntrica típica de circones ígneos, con núcleos más luminiscentes y algunos núcleos heredados.

Se filtraron los datos para descartar los circones con valores discordantes (discordancia > 10\%), de acuerdo con la relación $\left[\left({ }^{207} \mathrm{~Pb} /{ }^{235} \mathrm{U}\right)-\left({ }^{206} \mathrm{~Pb} /{ }^{238} \mathrm{U}\right)\right] /$ $\left.\left({ }^{207} \mathrm{~Pb} /{ }^{235} \mathrm{U}\right)\right] \mathrm{x} 100$, y errores de edad corregida mayores de 5 , con el fin de mejorar el rango de confiabilidad de la edad. Las edades obtenidas se distribuyeron a lo largo de la curva de concordia desde $183 \mathrm{Ma}$ hasta $1.333 \mathrm{Ma}$, lo que puso en evidencia un grupo coherente de edades entre 183 y $204 \mathrm{Ma}(\mathrm{n}=24)$, que arroja una edad prome-

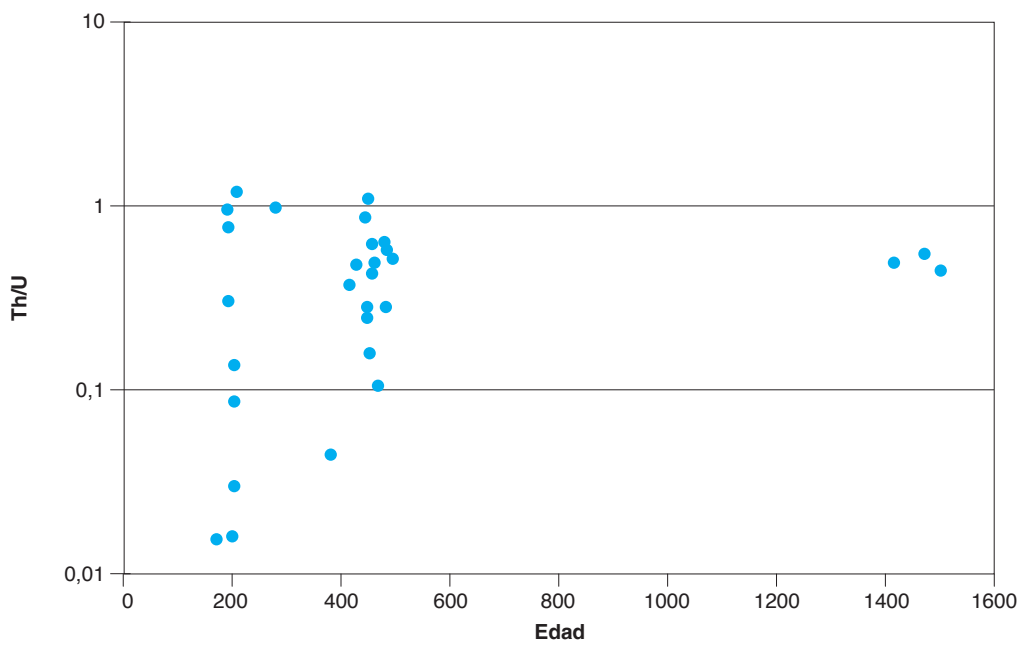

Figura 32. Gráfico de relación Th/U vs. edad en circones de la muestra MIA-627A 
dio ponderada de 192,5 $\pm 2,6 \mathrm{Ma}$ (sinemuriana), con un MSWD $=3,8$, que se interpreta como la edad de cristalización de la roca (figura 33). Igualmente, se presentaron circones heredados con edades del Carbonífero (338 Ma, $\mathrm{n}=1$ ); Devónico (405 a 413 Ma, $\mathrm{n}=3$ ); Ordovícico (445 a 476, $n=5$ ); Neoproterozoico (865 a 991, $n=4)$, Mesoproterozoico (1 006 a $1333, \mathrm{n}=8$ ) concordantes y discordantes (figura $33 \mathrm{C} \mathrm{y} \mathrm{D).}$

A

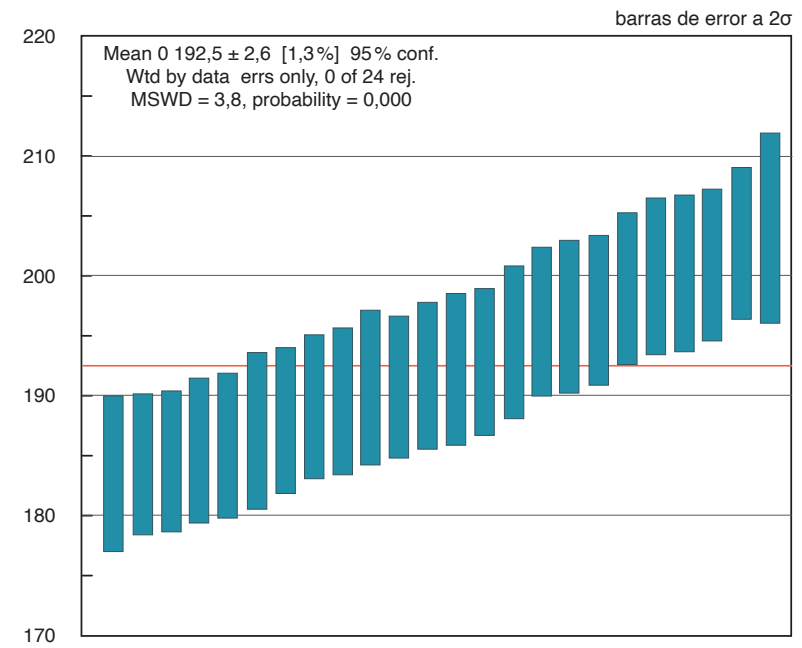

C

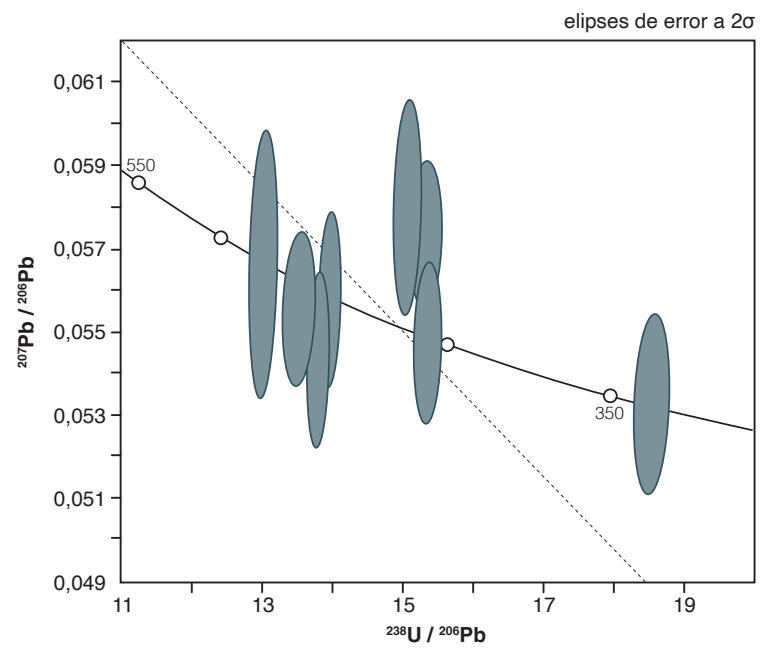

La muestra AMC-0131 presenta relaciones Th/U por encima de 0,1 y alrededor de 1 en los circones, que arrojaron la edad promedio ponderada Jurásica Inferior de $192,5 \pm 2,6 \mathrm{Ma}$, que sugiere un origen ígneo (figura 34). Las relaciones $\mathrm{Th} / \mathrm{U}$ en circones con edades del Paleozoico y del Precámbrico están entre 0,2 y 1, y son similares a las de circones de origen ígneo. Tres circones revelan valores inferiores a 0,1 , que podrían sugerir origen metamórfico.

B

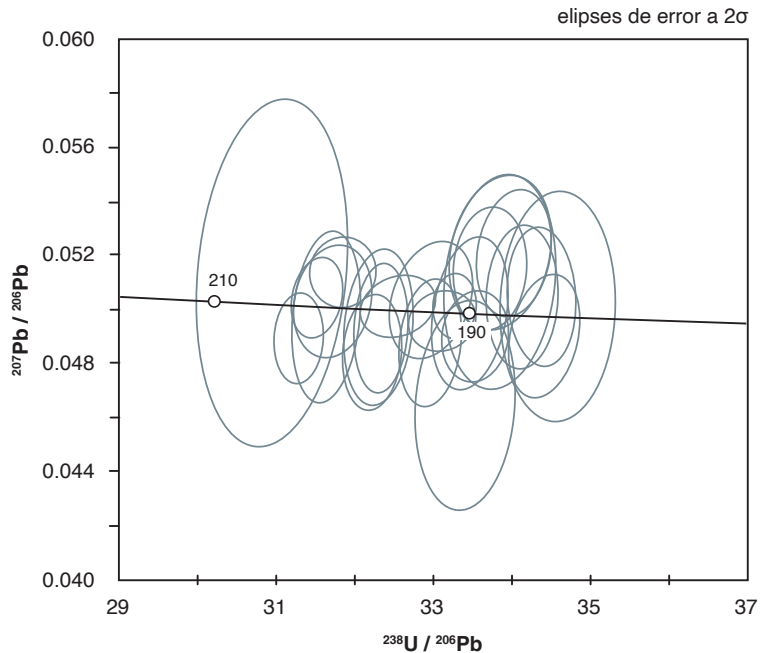

D

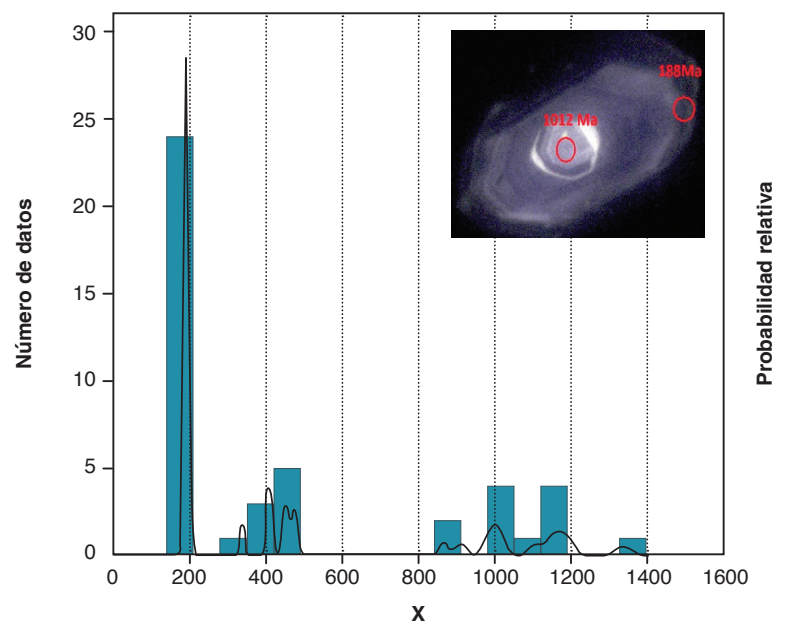

Figura 33. Muestra AMC-0131. A) Edad promedio ponderada en circones jurásicos. B) Diagrama Tera-Wasserburg correspondiente a circones jurásicos. C) Diagrama de concordia de circones paleozoicos. D) Histograma de densidad de probabilidad 


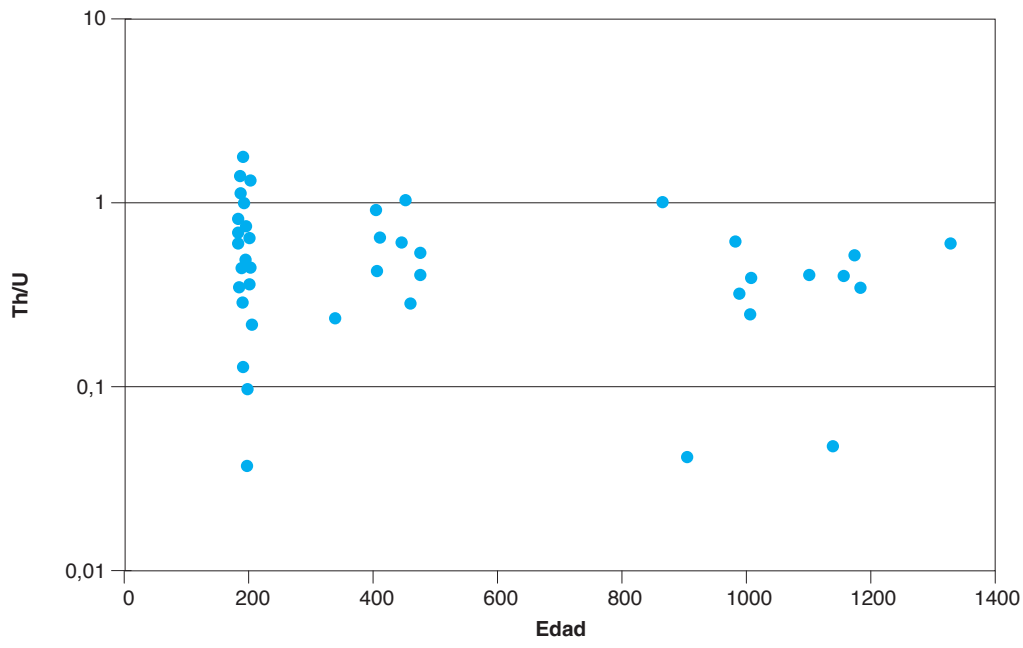

Figura 34. Diagrama de relación Th/U vs. edad en circones de la muestra AMC-0131

La muestra AMC-0128A corresponde a un xenolito de granofelsa de Qtz+fsp con Bt, que se correlaciona con el Neis de Bucaramanga y se encuentra en el interior del Monzogranito de La Corcova. Los circones obtenidos de esta muestra fueron prismas cortos euhedrales; las imágenes de CL muestran que estos circones presentan estructuras internas complicadas, con núcleos oscuros, zonamiento oscilatorio y sobrecrecimientos altamente luminiscentes. Los datos obtenidos de estos circones al graficarlos muestran en la concordia una posición que va desde 400 hasta unos 550 Ma, con una densidad máxima en el rango de ca. 460 hasta ca. 500 Ma. Un único circón sugiere una herencia neoproterozoica. Se interpretó, en este caso, que el rango entre 460 y 500 Ma indica una cristalización continua del magma. Se filtraron los datos para descartar los circones con valores discordantes (discordancia $>5 \%$ ), de acuerdo con la relación $\left.\left[\left({ }^{207} \mathrm{~Pb} /{ }^{235} \mathrm{U}\right)-\left({ }^{206} \mathrm{~Pb} /{ }^{238} \mathrm{U}\right)\right] /\left({ }^{207} \mathrm{~Pb} /{ }^{235} \mathrm{U}\right)\right] \mathrm{x} 100$, y errores de edad corregida mayores de 5 , con el fin de mejorar el rango de confiabilidad de la edad. La mejor aproximación a la edad de cristalización lo arrojó un grupo cohe- rente de nueve circones $(n=9)$, con una edad promedio ponderada de 462,7 \pm 3,1 con MSWD = 1,7 (figura 35). Un segundo grupo de edades coherentes, representado por diecinueve circones $(\mathrm{n}=19)$ arrojó una edad promedio ponderada de $482,4 \pm 3,3$ y MSWD $=4,6$, que se interpretó como una edad heredada dentro del mismo tren de cristalización (figura 35).

En la muestra AMC-0128A un único circón arrojó una edad de 382,3 Ma, que se encuentra sobre la curva de concordia, pero no es posible saber su significado geológico; además, el sitio de ablación se encuentra en el interior del cristal. Esta muestra presenta igualmente edades heredadas cámbricas ( 525 y 534 Ma, n = 2) y mesoproterozoicas (1029 Ma, $\mathrm{n}=1$ ), obtenidas en núcleos de circones más luminiscentes.

La muestra AMC-0128A presenta relaciones Th/U en los circones que arrojaron edades paleozoicas de alrededor de 1 , valor que sugiere origen ígneo, y en el caso de la edad Precámbrica arrojó una relación Th/U < 0,1 lo que sugiere un origen metamórfico. 
A

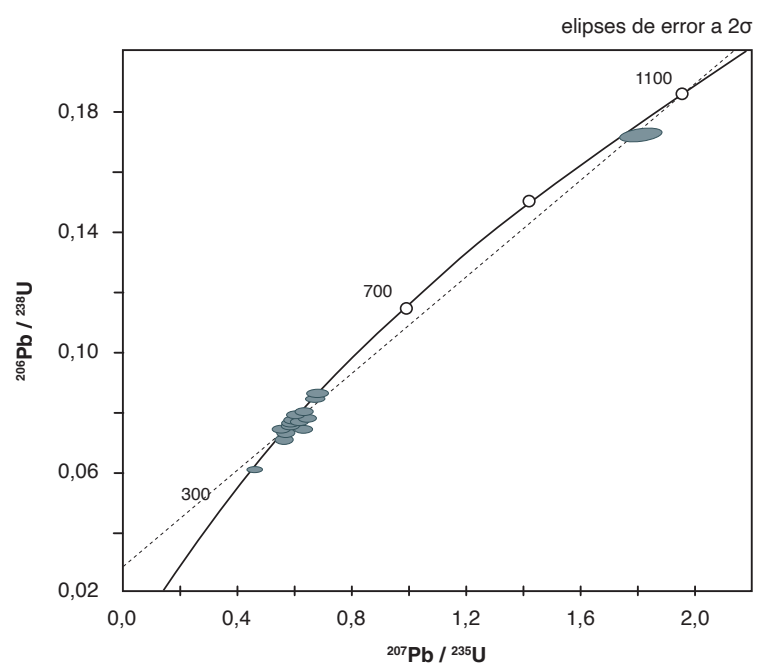

C

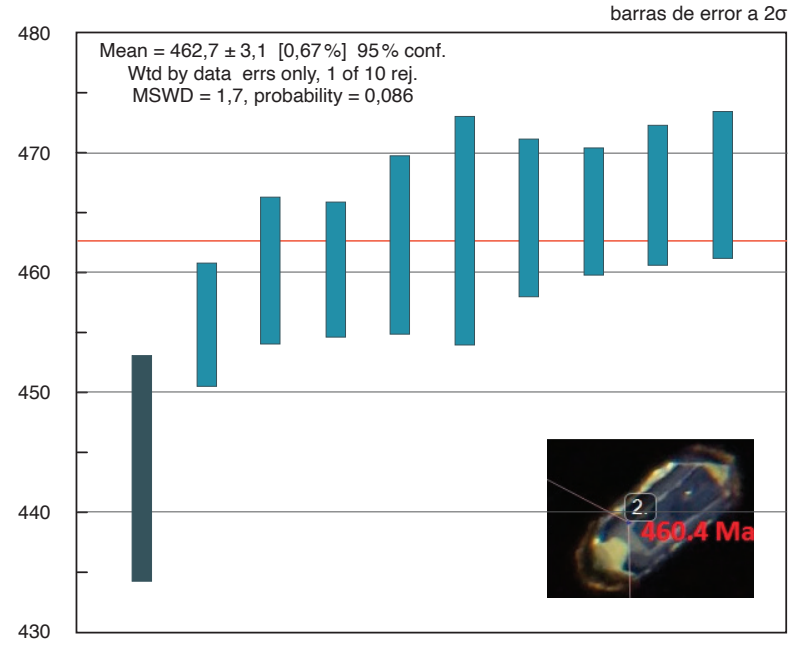

B

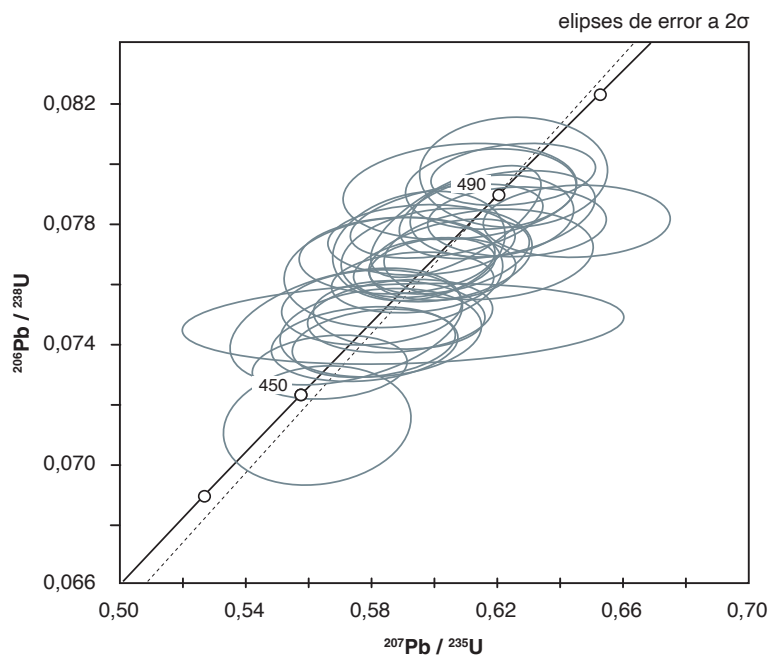

(D)

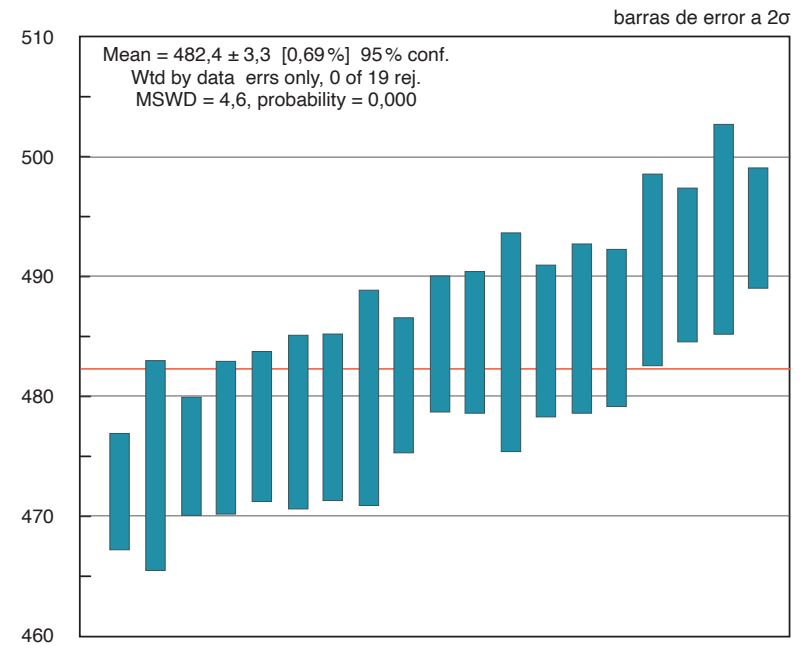

Figura 35. Muestra AMC-0128A. A) Gráfico de concordia. B) Gráfico de concordia correspondiente a circones con edades paleozoicas. C) Edad de cristalización promedio ponderada en circones ordovícicos. D) Edad promedio ponderada en circones ordovícicos heredados

Las edades obtenidas en el Monzogranito de La Corcova muestran una edad inicial de cristalización de 204,8 $\pm 6,1$ Ma en circones separados de un monzogranito (LMC-077), y 202,7 $\pm 1,2$ en diorita del borde del cuerpo intrusivo (MIA-630B), siendo estas las edades más antiguas obtenidas en el plutón, seguidas por edades de cristalización en rocas sienograníticas y monzograníticas de alrededor de 198,3 $\pm 1,8 \mathrm{Ma}$ (muestra 10VDL05). Probablemente un pulso posterior originó diques de sienogranito (que se emplazaron en las rocas monzograníticas y en unidades metamorficas encajantes, con edad promedio de 199,5 $\pm 4,6 \mathrm{Ma}$ (muestra MIA-
627 A). Por último, en el plutón se reconoce una facies porfídica monzogranítica tardía que intruye facies monzograníticas anteriores, con una edad de cristalización de 192,5 $\pm 2,6 \mathrm{Ma}$ (muestra AMC-0131), que representa el pulso más joven encontrado en rocas de este cuerpo intrusivo.

Al comparar la edad obtenida en circones de un xenolito de neis cuarzo-feldespático, probablemente del Neis de Bucaramanga, con las edades de núcleos heredados de los circones de muestras del Monzogranito de La Corcova, se encontró que coinciden las de los circones del xenolito y las de los circones heredados (figura 36). 
A
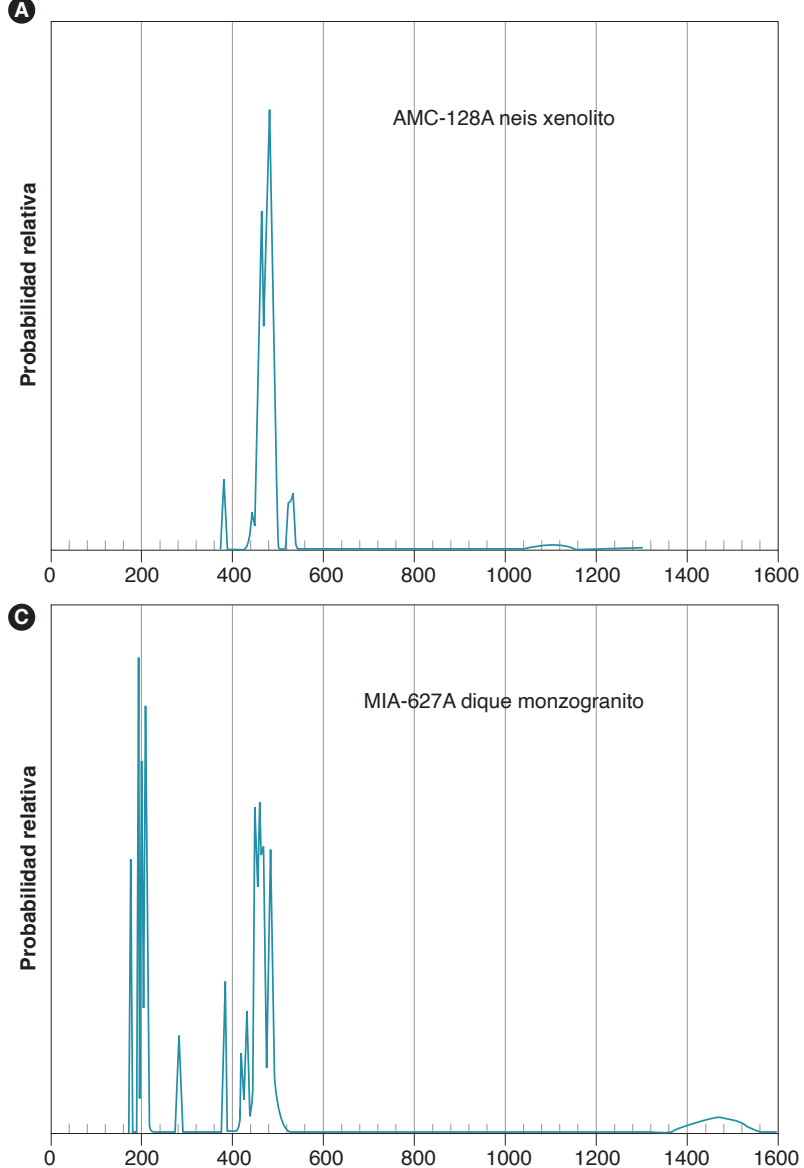
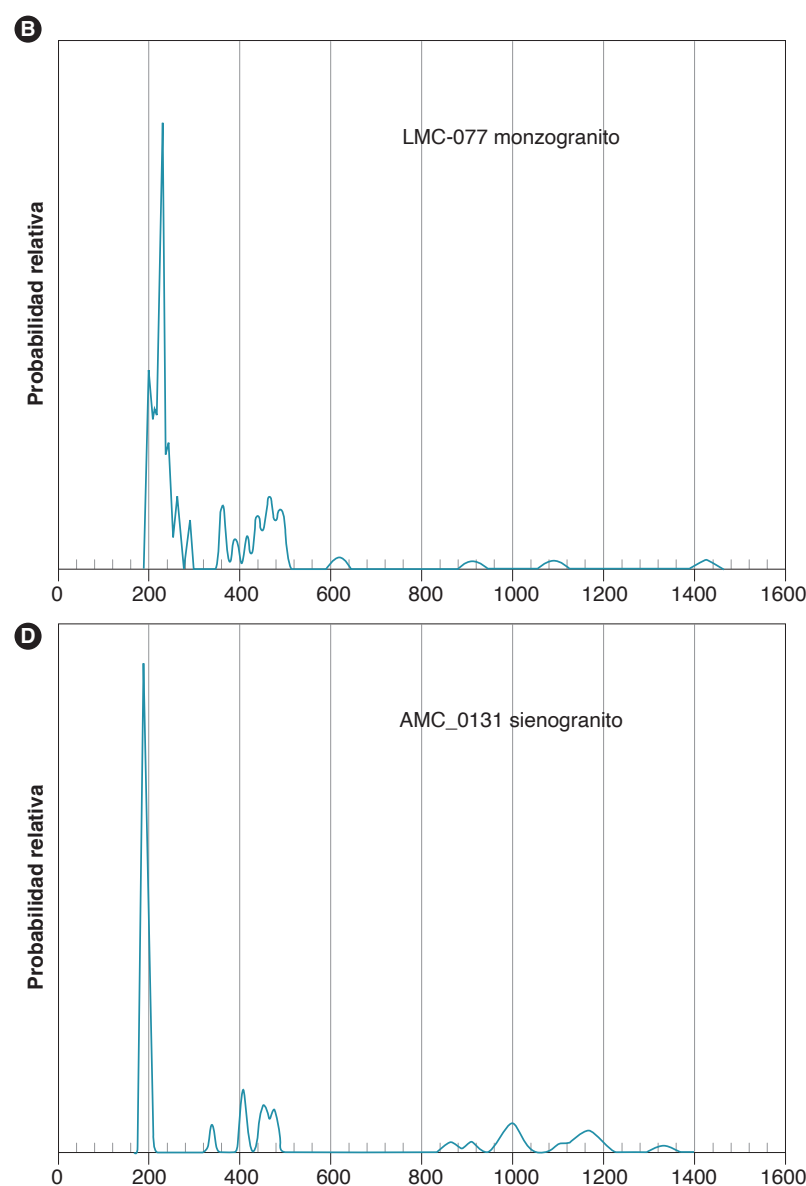

Figura 36. Diagramas de densidad de probabilidad en los que se comparan las edades de circones heredados de rocas y diques del Monzogranito de La Corcova con las edades obtenidas en un xenolito del neis de Bucaramanga

\subsection{Geoquímica de elementos traza en circones}

El análisis mediante ICP-MS permitió determinar la abundancia de los elementos traza de cada circón en las muestras MIA-630B, MIA-627 A y AMC-01 28A (anexo 2). Los valores de REE se normalizaron con respecto a condrito según McDonough y Sun (1995) y se calcularon las relaciones $\mathrm{Pm}^{*}$ y Tm* de cada uno de ellos. En el análisis de los elementos traza se tuvieron en cuenta las edades obtenidas en cada circón, y se agruparon por edades. En las muestras MIA-627A, MIA-630B y AMC0128A se observó un patrón de REE con anomalía positiva de Ce y negativa de Eu, característico de circones ígneos, sin tener en cuenta la edad arrojada por cada circón (figura 37). La muestra MIA-630B presenta una me- nor anomalía negativa de Eu que las otras dos muestras. Los circones que arrojaron edades del Proterozoico en la muestra MIA-627A presentaron una anomalía positiva de Ce y una anomalía negativa de Eu, con menores valores de Pr que el resto de circones. El circón Zr-138 de la muestra MIA-630B arrojo una edad de 80 Ma y presentó un patrón ígneo con mayor anomalía de Eu que los demás circones, que en su mayoría tienen patrones paralelos. El cristal Zr-1 72 no presenta anomalía de Eu y se cruza con el patrón del resto de circones. En la muestra AMC-01 28A, los circones Zr-037, Zr-0,39 y Zr-0.68 presentan un patrón horizontal entre La y $\mathrm{Sm}$, diferente del de los demás circones. 

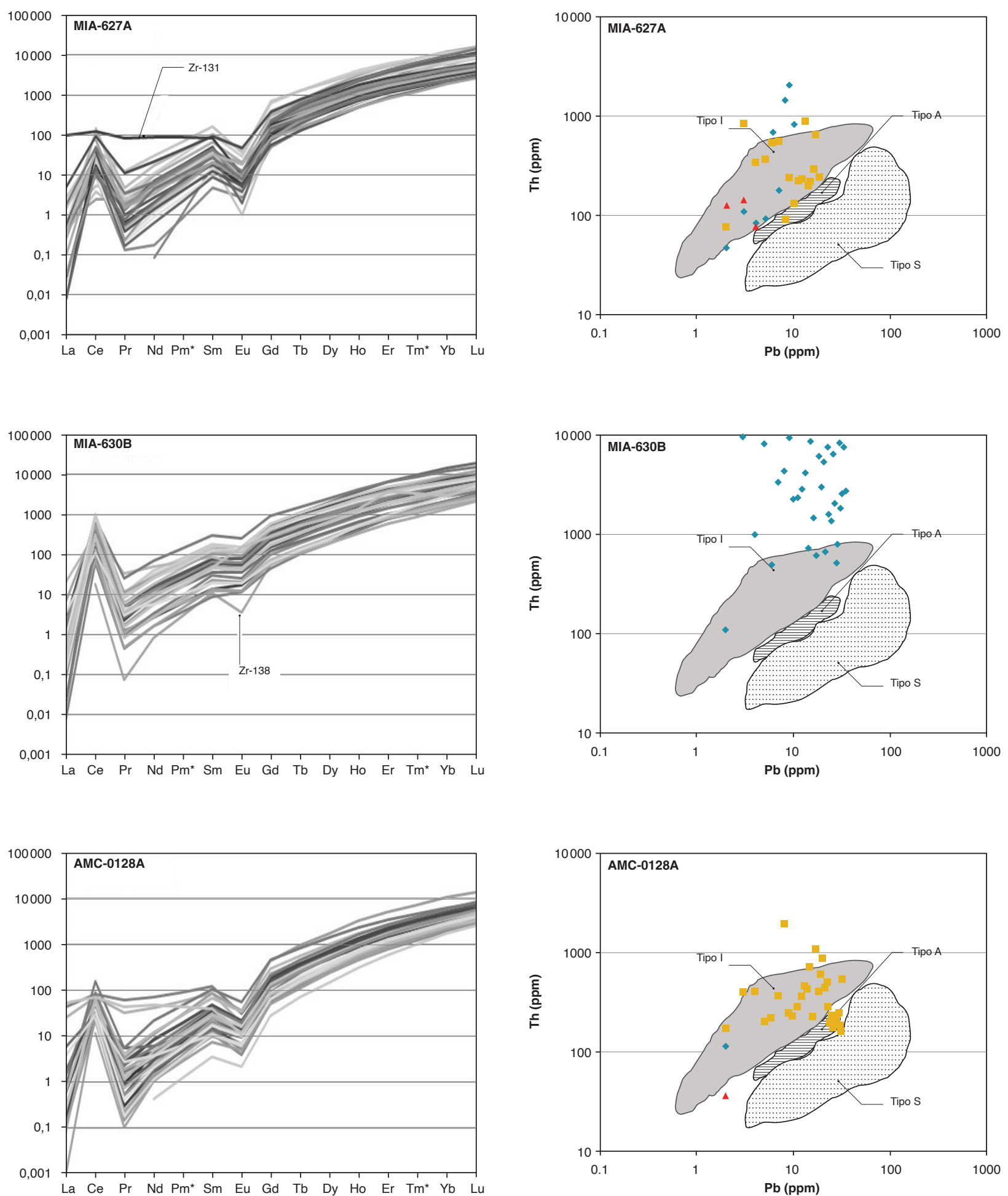

Figura 37. Patrones de los elementos de las tierras raras (REE) normalizados según el condrito de McDonough y Sun (1995), en circones de las muestras MIA-627A, MIA-630B y AMC-0128A, y tipo de magma según los valores de $\mathrm{Th}$ y Pb (diagrama de Wang et al., 2012), en muestras tomadas en el Monzogranito de La Corcova. En azul, circones con edades jurásicas a triásicas superiores, y en ocre, circones heredados del Paleozoico al Precámbrico 
En el diagrama de Th vs. Pb se observa que los circones de la muestra MIA-627A, con edades triásica-jurásicas, pertenecen al campo de los granitos tipo I, al igual que los circones con edades heredadas del Paleozoico al Mesoproterozoico (diagrama modificado de Wang et al., 2012 ) (figura 37). En su mayoría, los contenidos de Pb y Th en circones de la muestra MIA-630B, con edades entre 196 y 213 Ma, se sitúan por fuera del campo de los granitos tipo I, debido a sus altos valores en Th $>1000$ ppm. Los valores de los contenidos de $\mathrm{Pb}$ y Th en circones de la muestra AMC-0128A, correspondiente a un xenolito metamórfico con edades entre 382 y 1099 Ma, al ser graficados en el diagrama de Th vs. $\mathrm{Pb}$, permiten observar que la mayoría de los circones se localizan en el campo de los granitos tipo I, y algunos pocos alcanzan el campo de los granitos tipo A, lo que, de acuerdo a Wang et al. (2012), se puede presentar en granitos altamente evolucionados, de los que no hay una buena discriminación. Por lo tanto, se presenta una distribución similar entre los circones heredados en la muestra MIA-627A y los circones del xenolito de la muestra AMC-01 28A.

\section{Correlaciones}

El Monzogranito de La Corcova hace parte de los cuerpos ígneos producto del magmatismo triásico-jurásico, que se emplazaron en el basamento metamórfico del Macizo de Santander y cuya correlación se extiende tanto a los cuerpos subvolcánicos porfídicos como a los cuerpos plutónicos de composición granítica, entre los que se destacan la tonalita y granodiorita de páramo Rico (Ward et al., 1973), el Batolito de Mogotes (Ward et al., 1973, Correa Martínez et al., 2016), el Granito de Pescadero (Ward et al., 1973; Zapata et al., 2016), el Monzogranito de Rionegro (Arango et al., 2016) y pequeños plutones subvolcánicos, como las Riolitas de El Uvo (Zapata et al., 2018), la Riolita de San Joaquín (Rodríguez et al., 2018) y la Riolita del Alto Los Cacaos (Correa et al., 2018).

\section{Localidad tipo}

La sección tipo del Monzogranito de La Corcova se encuentra a lo largo de la carretera Bucaramanga-Páramo de Berlín, entre las coordenadas X: 1113267, 116656 y Y: 1280836,1281584 . Como sección tipo alternativa se presenta la vía terciaria Piedecuesta-sector La Nevera, y en la carretera que de Los Curos conduce a Guaca (cuadrángulo H-12), donde se puede observar el con- tacto intrusivo del Monzogranito de La Corcova con el Neis de Bucaramanga y afloran rocas miloníticas, neises y granofélsicos instruidos por rocas asociadas a este plutón.

\section{Génesis}

El Monzogranito de La Corcova presenta una mineralogía característica de granitoides tipo S e I, con presencia de feldespato potásico de color blanco, biotita parda, escasa hornblenda y magnetita e ilmenita, comunes en plutones altamente diferenciados, de acuerdo con Chappell y White (2001). Se presentan gabarros de rocas ígneas intermedias con presencia de hornblenda que son frecuentes en granitos tipo I. La química de las rocas permitió ubicarlas en el campo de los granitos tipo I, peraluminosos, y la geoquímica de los elementos traza en circones los situó igualmente en el campo de los granitos tipo I.

Las características macroscópicas y microscópicas de las rocas del Monzogranito de La Corcova, como texturas equigranulares, inequigranulares, aplíticas sacaroidales y porfídicas, son indicativas de un emplazamiento epizonal a subvolcánico del cuerpo, emplazamiento que ocurrió en un basamento metamórfico que sufrió fusión e incorporó xenocristales de circón y bloques a manera de xenolitos del Neis de Bucaramanga y de la formación Silgará.

Los monzogranitos presentan comúnmente ortosa pasando a microclina pertítica, característica de rocas plutónicas que se forman en ambientes de temperaturas intermedias.

La química mineral obtenida en cristales de biotita, en un monzogranito de la facies principal del plutón, permitió asociarlo a rocas de las series calcoalcalinas orogénicas y a rocas peraluminosas, de acuerdo con el diagrama de Abdel Rahman (1994). Este resultado es concordante con los de la química de óxidos de elementos mayores, que permitió clasificar las rocas como subalcalinas de la serie calcoalcalina alta en $\mathrm{K}$ y peraluminosas.

El Monzogranito de La Corcova presenta valores de $\mathrm{SiO}_{2}$ entre 69,56 y 75,45\%. Los valores de $\mathrm{Al}_{2} \mathrm{O}_{3}, \mathrm{Fe}_{2} \mathrm{O}_{3}$, $\mathrm{MgO}, \mathrm{Na}_{2} \mathrm{O}$ y CaO disminuyen con el aumento de $\mathrm{SiO}_{2}$; el $\mathrm{K}_{2} \mathrm{O}$ varía entre 4,6 y 5,3\%; el CaO varía entre 0,7 y $2,5 \%$; $\mathrm{MgO}<1$; las relaciones $\mathrm{K}_{2} \mathrm{O} / \mathrm{Na}_{2} \mathrm{O}>1$, con alto contenido de álcalis $\left(\mathrm{Na}_{2} \mathrm{O}+\mathrm{K}_{2} \mathrm{O}\right)$, y $\mathrm{Al}_{2} \mathrm{O}_{3}>\mathrm{CaO}+\mathrm{Na}_{2} \mathrm{O}+\mathrm{K}_{2} \mathrm{O}$. Se trata de granitos de la serie calcoalcalina alta en K. Las rocas también presentan un enriquecimiento en tierras 
raras livianas (LREE) de más de cien veces con respecto al valor del condrito, que se va empobreciendo progresivamente hacia las tierras raras pesadas (HREE), comportamiento normal en rocas generadas en ambientes de subducción (arco).

La presencia de xenocristales y núcleos de circones heredados del Paleozoico al Mesoproterozoico, en rocas monzograníticas y sienograníticas del Monzogranito de La Corcova, indica la fusión de rocas de la corteza continental en la que se emplazó, corteza que aportó material a los pulsos magmáticos que formaron el plutón. Las edades U/Pb ordovícicas obtenidas a partir de xenocristales y núcleos heredados en circones de rocas clasificadas como monzogranitos son comparables con edades U/Pb obtenidas en el Neis de Bucaramanga y en xenolitos del neis cuarzo-feldespático que se encuentran incluidos en el Monzogranito de La Corcova, con relaciones Th/U similares. Esto sugiere que el Neis de Bucaramanga fue una fuente importante en la formación del magma de los pulsos graníticos triásico-jurásicos, como se desprende de las edades heredadas en circones (figura 36).

Se puede interpretar que el magma parental se generó en una zona de subducción y que habría tenido dos fuentes: por un lado, la placa oceánica más los sedimentos oceánicos subducidos, y, por otra parte, la fusión de la corteza continental, que en algunos diagramas hace que las rocas se desplacen hacia el campo de los granitos tipo $\mathrm{S}$, aunque el ambiente de formación es típico de granitos de arco de margen continental tipo I.

El Monzogranito de La Corcova presenta relaciones $(\mathrm{La} / \mathrm{Yb})_{\mathrm{N}}>2$, valores que se asocian con rocas formadas en la corteza continental. Se presentan notables diferencias en la relación $(\mathrm{La} / \mathrm{Yb})_{\mathrm{N}}$ entre los cuatro patrones de REE, que a su vez presentan mayor o menor pendiente, lo que permite sugerir diferentes pulsos que representan variaciones composicionales en los magmas, diferencias que podrían explicarse con cambios en la fuente de los magmas de cada patrón, con mayor o menor aporte del manto y de corteza en cada uno de ellos. Así, los valores altos de $(\mathrm{La} / \mathrm{Yb})_{\mathrm{N}}$ representarían mayores aportes de corteza al magma, periodos de mayor flujo magmático y corteza más gruesa, y estarían caracterizados por patrones con pronunciada pendiente entre los LREE y los HREE, mientras los menores valores de $(\mathrm{La} / \mathrm{Yb})_{\mathrm{N}}$ indicarían mayores aportes al magma de material del manto, periodos de más bajo flujo magmático, origen del magma en profundidades menores, y presentarían menores pendientes en los patrones de REE, de acuerdo con el modelo propuesto por Girardi (2008).

\section{Recursos minerales}

Existen pequeñas explotaciones de arena a partir de saprolito del Monzogranito de La Corcova, sobre la vía Bucaramanga-Berlín.

\section{Conclusiones}

Este catálogo presenta nueva información acerca de las rocas del Monzogranito de La Corcova, mejora el conocimiento petrográfico, química mineral, litogeoquímico y geocronológico del cuerpo plutónico y define el cuerpo como un granito formado por varios pulsos magmáticos que incluye diques y cuerpos intrusivos menores de similar composición.

Composicionalmente, las rocas del Monzogranito de La Corcova varían entre monzogranitos y subordinadas granodioritas, sienogranitos y tonalitas. Se encuentra intruido por diques de riolitas y sienogranitos, con xenolitos de rocas metamorficas del Neis de Bucaramanga y de la Formación Silgará.

Se trata de rocas ácidas con contenidos de $\mathrm{SiO}_{2}$ entre 69,56 y 75,45\%, el $\mathrm{K}_{2} \mathrm{O}$ varía entre 4,6 y 5,3\%, el CaO varía entre 0,7 y 2,5\%, $\mathrm{MgO}<1 \%$, y $\mathrm{TiO}_{2}<0,6 \%$; la relación $\mathrm{K}_{2} \mathrm{O} / \mathrm{Na}_{2} \mathrm{O}>1$.

El Monzogranito de La Corcova es un plutón subalcalino de la serie calcoalcalina alta en $\mathrm{K}$, peraluminoso, con valores de $\mathrm{A} / \mathrm{NK}>1$ y valores de $\mathrm{A} / \mathrm{CNK}>1$, con valores de $\mathrm{Al}_{2} \mathrm{O}_{3}>\mathrm{CaO}+\mathrm{Na}_{2} \mathrm{O}+\mathrm{K}_{2} \mathrm{O}$.

En los diagramas multielementales se reconocen al menos cuatro patrones con edades de cristalización, U/ Pb en circón entre 192,5 $\pm 2,6$ y 204,8 \pm 6,1 Ma, que representan rocas de la facies principal, rocas de dique y cuerpos menores intrusivos, y sugieren que se trata de un cuerpo formado por varios pulsos magmáticos formados en un ambiente de arco continental.

Con base en la composición química de rocas y la química de circones, estas se clasifican como granitos tipo I.

En la rocas monzograníticas y sienograníticas, la presencia de xenocristales y núcleos de circones heredados del Paleozoico al Mesoproterozoico revela la contaminación con rocas de la corteza continental que aportaron material a los pulsos magmáticos que formaron este cuerpo intrusivo, y probablemente incidieron en el carácter peraluminoso de las rocas. Las edades $\mathrm{U} / \mathrm{Pb}$ ordo- 
vícicas obtenidas a partir de circones heredados en rocas clasificadas como monzogranitos son comparables con las edades $\mathrm{U} / \mathrm{Pb}$ obtenidas en rocas del Neis de Bucaramanga y en xenolitos de neis cuarzo-feldespático que se encuentran incluidos en el Monzogranito de La Corcova, con relaciones Th/U similares. Esto sugiere que el Neis de Bucaramanga fue una fuente importante en la formación del magma de los pulsos graníticos triásico-jurásicos, como se desprende de las edades heredadas en circones.

\section{Referencias}

Abdel Rahman, A. M. (1994). Nature of biotites from alkaline, calc-alkaline and peraluminous magmas. Journal of Petrology, 35 (2), 525-541. https://doi. org/10.1093/petrology/35.2.525.

Arango, M. I., Rodríguez, G., Zapata, G. y Correa M., A. M. (2016). Catálogo de Unidades Litoestratigráficas de Colombia. Monzogranito de Rionegro, Cordillera Oriental, Departamento Santander. Medellín: Servicio Geológico Colombiano.

Chappell, B. W. y White, A. J. R. (2001). Two contrasting granite types: 25 years later. Australian Journal of Earth Sciences, 48 (4), 489-499. https://doi.org/10.1046/j.1440-0952.2001.00882.x.

Clavijo, J. (1994). Mapa geológico generalizado del departamento de Norte de Santander. Memoria explicativa. Escala 1:250.000. Informe. Ingeominas.

Clavijo, J., Mantilla, F. L. C., Pinto, J., Bernal, L. y Pérez, A. (2008). Evolución geológica de la serranía de San Lucas, norte del valle medio del Magdalena y noroeste de la cordillera Oriental. Boletín de Geología, 30 (1), 45-62.

Cordani, U. G., Cardona, A., Jiménez, D. M., Liu, D. y Nutran, A. P. (2005). Geochronology of Proterozoic basement inliers from the Colombian Andes: Tectonic history of remnants from a fragmented Grenville belt. Special Publication 246. Londres: Geological Society.

Correa Martínez, A. M., Rodríguez, G., Arango, M. I., Zapata, G. y Bermúdez J. G. (2016). Catálogo de Unidades Litoestratigráficas de Colombia. Batolito de Mogotes. Medellín: Servicio Geológico Colombiano.

Correa Martínez., A. M., Rodríguez, G., Arango, M. I., Zapata, G. y Bermúdez, J. G. (201 8). Catálogo de unidades litoestratigráficas de Colombia. Riolitas del Alto Los Cacaos. Medellín: Servicio Geológico Colombiano.

Debon, F. y Le Fort, P. (1983). A chemical-mineralogical classification of common plutonic rocks and associa- tions. Earth and Environmental Science Transactions of The Royal Society of Edinburgh, 73 (3), 153-149. https://doi.org/10.1017/S0263593300010117.

Droop, G. (1987). A general equation for estimating $\mathrm{Fe}^{3+}$ concentrations in ferromagnesian silicates and oxides from microprobe analyses, using stoichiometric criteria. Mineralogical Magazine, 51 (361), 431-435. https://doi.org/1 0.11 80/minmag.1 987.051.361.10.

Etayo, F., Barrero, D., Lozano, H., Espinosa, A., González, H., Orrego, A. Ballesteros, I., Forero, H., Ramírez, C., Zambrano, F., Duque-Caro, H., Vargas., R., Núñez, A., Álvarez, J., Ropaín, C., Cardozo, E., Galvis, N. y Sarmiento, L. (1983). Mapa de terrenos geológicos de Colombia. Publicaciones Geológicas Especiales 14. Bogotá: Ingeominas.

Frost, B. R. y Frost, C. D. (2008). A geochemical classification for feldspathic igneous rocks. Journal of Petrology, 49 (11), 1955-1969. https://doi.org/10.1093/ petrology/egn054.

Frost, R. B., Barnes, C. G., Collins, W. J., Arculus, R. J., Ellis, D. J. y Frost, C. D. (2001). A geochemical classification for granitic rocks. Journal of Petrology, 42 (11), 2033-2048. https://doi.org/10.1093/petrology/42.11.2033.

García, C. y Ríos, C. (1999). Metamorfismo y metalogénia asociada del Macizo de Santander, cordillera Oriental, Colombia. Informe final Proyecto de Investigación 1102-05-083-95. Bucaramanga: Colciencias y Universidad Industrial de Santander.

Girardi, D. J. (2008). Evolution of magmas and magma sources to the Coast Mountains batholith, British Columbia, Canada, reflected by elemental and isotopic geochemistry (tesis). University of Arizona.

Goldsmith, R., Marvin, R. F. y Mehnert, H. H. (1971). Radiometric ages in the Santander Massif, Eastern Cordillera, Colombian Andes. U. S. Geological Survey Professional Paper (750): D44-D49.

Harris, N. W., Pearce, J. A. y Tindle, A. (1986). Geochemical characteristics of collision zone magmatism. En M. P. Coward y A. C. Ries (eds.), Collision tectonics. Special Publication, London: Geology Society.

Hastie, A. R., Kerr, A. C., Pearce, J. A. y Mitchell, S. F. (2007). Classification of altered volcanic island arc rocks using immobile trace elements: Development of the Th-Co discrimination diagram. Journal of Petrology, 48 (12), 2341-2357. https://doi.org/10.1093/ petrology/egm062. 
International Subcommision on Stratigraphic Classification (1987). Stratigraphic classification and nomenclature of igneous and metamorphic rock bodies. GSA Bulletin, 99 (3), 440-442. https://doi.org/ 10.1130/001 6-7606(1987)99<440:SCANOI>2.0.CO;2.

International Subcommision on Stratigraphic Classification (1994). International Stratigraphic Guide: A guide to stratigraphic classification, terminology and procedure, $2^{\text {a }}$ ed., Amos Salvador (ed.). Boulder: International Union of Geological Sciences, International Subcommission on Stratigraphic Classification y Geological Society of America.

Irvine, T. N. y Baragar, W. R. A. (1971). A guide to the chemical classification of the common volcanic rock. Canadian Journal of Earth Sciences, 8 (5), 523548. https://doi.org/10.1139/e71-055.

Janoušek, V., Farrow, C. M. y Erban, V. (2006). Interpretation of whole-rock geochemical data in igneous geochemistry: Introducing Geochemical Data Toolkit (GCDkit). Journal of Petrology, 47 (6), 1 255-1 259. https://doi.org/10.1093/petrology/egl013.

Le Bas, M. J., Le Maitre, R. N., Streckeisen, A. y Zanettin, B. (1986). A chemical classification of volcanic rock based on total silica diagram. Journal of Petrology, 27 (3), 745-750. https://doi.org/10.1093/petrology/27.3.745.

Leal Mejía, H. (2011). Phanerozoic gold metallogeny in the Colombian Andes: A tectono- magmatic approach (tesis Ph. D.). Universitat de Barcelona.

Ludwig, K. R. (2012). User's manual for Isoplot 3.7 5-4.15. A Geochronological Toolkit Microsoft Excel. Special Publication n. ${ }^{\circ}$. Berkeley: Berkeley Geochronology Center.

Mantilla, L. C., Bissig, T., Valencia, V. y Hart, C. (2013). The magmatic history of the Vetas-California mining district, Santander Massif Eastern Cordillera, Colombia. Journal of South American Earth Sciences, 45, 235-249. https://doi.org/10.1016/j.jsames.2013.03.006.

Martin, H. (1994). Archean grey gneisses and the genesis of the continental crust. En K. Codie (ed.), Archean crustal evolution (pp. 205-260). Netherland: Elsevier Scientific Publishers.

Mcdonough, W. F. y Sun, S. S. (1995). The composition of the Earth. Chemical Geology, 120 (3-4), 223-253. https://doi.org/10.1016/0009-2541(94)00140-4.
Middlemost, E. A. K. (1985). Magmas and magmatic rocks: An introduction to igneous petrology. London/New York: Longman.

Middlemost, E. A. K. (1994). Naming materials in magma-igneous rock system. Earth-Science Reviews, 37 (3-4), 215-224. https://doi.org/10.1016/00128252(94)90029-9.

Nakamura, N. (1 974). Determination of REE, Ba, Fe, Mg, $\mathrm{Na}$ and $\mathrm{K}$ in carbonaceous and ordinary chondrites. Geochimica et Cosmochimica Acta, 38 (5), 757-775. https://doi.org/10.1016/0016-7037(74)90149-5.

Ordóñez Cardona, O., Restrepo Álvarez, J. J. y Pimentel, M. M. (2006). Geochronological and isotopical review of pre-Devonian crustal basement of the Colombian Andes. Journal of South American Earth Sciences, 21 (4), 372-382. https://doi.org/10.1016/j. jsames.2006.07.005.

Paton, C., Woodhead, J. D., Hellstrom, J. C., Hergt, J. M., Greig, A. y Maas R. (2010). Improved laser ablation $\mathrm{U}-\mathrm{Pb}$ zircon geochronology through robust downhole fractionation correction. Geochemistry, Geophysics, Geosystems, 11 (3). https://doi.org/10.1029/ 2009GC002618.

Pearce, J. A. (2008). Geochemical fingerprinting of oceanic basalts with applications to ophiolite classification and the search for Archean oceanic crust. Lithos, 100 (1-4), 14-48. https://doi.org/10.1016/j. lithos.2007.06.016.

Peccerillo, A. y Taylor, T. S. (1976). Geochemistry of Eocene calc-alkaline volcanic rocks from Kastamonu area, Northern Turkey. Contributions to Mineralogy and Petrology, 58 (1), 63-81. https:/doi. org/10.1007/BF00384745.

Petrus, J. A. y Kamber, B. S. (2012). Vizual age: A novel approach to laser ablation ICP-MS U-Pb geochronology data reduction. Geostandards and Geoanalytical Research, 36 (3), 247-270. https://doi.org/10.1111/ j.1 751-908X.2012.00158.x.

Rieder, M., Cavazzini, G., D’yakonov, Y. U, S., Frank Kamenetskii, V. A., Gottardi, G., Guggenheim, S., Koval, P. V., Muller, G., Neiva, A. M. R. y Radoslovich, E. W. (1998). Nomenclature of the micas. Clays and Clay Minerals, 46 (5), 586-595. https://doi.org/10.1346/ CCMN.1998.0460513.

Restrepo, J. J., Ordóñez Carmona, O., Armstrong, R. y Pimentel, M. M. (2011). Triassic metamorphism in the 
northern part of the Tahamí Terrane of the Central Cordillera of Colombia. Journal of South American Earth Sciences (32), 497-507.

Restrepo, J. J. y Toussaint, J. F. (1988). Terranes and continental accretion in the Colombian Andes. Episodes, 11 (3), 189-193.

Restrepo-Pace, P. A., Ruiz, J., Gehrels, G. y Cosca, M. (1997). Geochronology and $\mathrm{Nd}$ isotopic data of Grenville-age rocks in the Colombian Andes: new constraints for Late Proterozoic-Early Paleozoic paleocontinental reconstructions of the Americas. Earth and Planetary Science Letters, 150 (3-4), 427-441. https://doi.org/1 0.1 016/S001 2-821 X(97)00091-5.

Ríos, C., García, C. y Takusa, A. (2003). Tectono-metamorphic evolution of the Silgara Formation metamorphic rocks in the Southwestern Santander Massif, Colombian Andes. Journal of South American Earth Sciences, 16 (2), 133-154. https://doi. org/10.1016/S0895-9811(03)00025-7.

Rodríguez, G., Arango, M. I., Correa, M., A. M. y Zapata, G. (2018). Catálogo de Unidades Litoestratigráficas de Colombia. Riolita de San Joaquín. Medellín: Servicio Geológico Colombiano.

Rubatto, D. (2002). Zircon trace element geochemistry: Partitioning with garnet and the link between $\mathrm{U}-\mathrm{Pb}$ ages and metamorphism. Chemical Geology, 184 (1-2), 123-138. https://doi.org/10.1016/S00092541(01)00355-2.

Shand, S. J. (1943). Eruptive rocks: Their genesis, composition, classification, and their relation to ore-deposits with a chapter on meteorite. New York: John Wiley \& Sons.

Smith, J. V. y Brown, W. L. (1988). Feldspar minerals. Vol. I: Crystal structures, physical, chemical and microtextural properties. Berlin: Springer-Verlag.

Solari, L., Gómez Tuena, A., Bernal, J., Pérez Arvizu, O. y Tanner, M. (201 0). U-Pb zircon geochronology with an integrated LA-ICP-MS microanalytical workstation: Achievements in precision and accuracy. Geostandards and Geoanalytical Research, 34 (1), 5-18. https://doi.org/10.1111/j.1 751-908X.2009.00027.x.

Stacey,J.S.yKramers,J.D.(1 975).Approximationofterrestrial lead isotope evolution by a 2-Stage Model. Earth and Planetary Science Letters, 26 (2), 207-221. https:// doi.org/10.1016/001 2-821X(75)90088-6.

Streckeisen, A. (1976). Classification and nomenclature of plutonic rocks: recommendations of the IUGS subcommission on the systematics of Igneous Rocks. Geologische Rundschau, 63 (2), 773-786. https:// doi.org/10.1007/BF01 820841.

Streckeisen, A. L. (1978). Classification and nomenclature of volcanic rocks, lamprophyres, carbonatites and melilite rocks. Recommendations and suggestions. Neues Jahrbuch für Mineralogie, 141, 1-14.

Sun, S. y McDonough, W. (1989). Chemical and isotopic systematics of oceanic basalts: Implications for mantle composition and processes. Special Publication 42, 313-345. London: Geological Society. https://doi. org/10.1144/GSL.SP.1 989.042.01.19.

Van der Lelij, R. (2013). Reconstructing North-Western Gondwana with implications for the evolution of the lapetus and Rheic Oceans: A geochronological, thermochronological and geochemical study (tesis de doctorado), Université de Genève.

Van der Lelij, R., Spikings, R. y Mora, A. (2016). Thermochronology and tectonics of the Mérida Andes and the Santander Massif, NW South America. Lithos, 248, 220-239. https://doi.org/10.1016/j.lithos.2016.01.006.

Villaseca, C., Barbero, L. y Herreros. V. (1998). A re-examination of the typology of peraluminous granite types in intracontinental orogenic belts. Earth and Environmental Science Transactions of The Royal Society of Edinburgh, 89 (2), 113-119. https://doi. org/10.1017/S0263593300007045.

Wang, Q., Zhu, D. C., Zhao, Z. D., Guan, Q., Zhang, X. Q., Sui, Q. L., Chu Hu, Z. y Mo, X. X. (2012). Magmatic zircons from I-, S- and A-type granitoids in Tibet: Trace element characteristics and their application to detrital zircon provenance study. Journal of Asian Earth Sciences, 53, 59-66. https://doi.org/10.1016/j. jseaes.2011.07.027.

Ward, D. E., Goldsmith, R., Cruz, B. J., Jaramillo, C. L. y Vargas, L. R. (1970). Mapa geológico del cuadrángulo H-13, Pamplona, Colombia. Bogotá: Ingeominas.

Ward, D., Goldsmith, R., Cruz, J. y Restrepo, H. (1973). Geología de los cuadrángulos H-1 2 Bucaramanga y H-13 Pamplona. Boletín Geológico, 21 (1-3), 132.

Ward, D. E., Goldsmith, R., Jimeno, A., Cruz, J., Restrepo, H. y Gómez, E. (1977a). Geología de la Plancha 109 Rionegro. Escala 1:100.000. Parte del cuadrángulo H-1 2. Versión digital 201 0. Bogotá: Ingeominas.

Ward, D. E., Goldsmith, R., Jimeno, A., Cruz, J., Restrepo, H. y Gómez, E. (1977b). Geología de la Plancha 120 
Bucaramanga. Escala 1:100.000. Parte del cuadrángulo H-12. Versión digital 2010 . Bogotá: Ingeominas.

Ward, D. E., Goldsmith, R., Cruz, J., Jaramillo, L. y Vargas, R. (1977c). Geología de la Plancha 121 Cerrito. Escala 1:100.000. Versión digital 2010. Bogotá: Ingeominas. Whalen, J. B., Currie, K. L. y Chappell, B. W. (1987). A-type granites: Geochemical characteristics, discrimination and petrogenesis. Contributions to $\mathrm{Mi}$ neralogy and Petrology, 95 (4), 407-419. https://doi. org/10.1007/BF00402202.

Whalen, J. B. y Chappell B. W. (1988). Opaque mineralogy and mafic mineral chemistry of I- and S-type granites of the Lachlan Fold Belt, Southeast Australia. American Mineralogist, 73 (3-4), 281-296.
Wilson, M. (1991). Igneous petrogenesis: A global tectonic approach. New York: Harper Collins Academic. https://doi.org/1 0.1007/978-1-4020-6788-4.

Winter, J. (2001). An introduction to igneous and metamorphic petrology. New Jersey: Prentice Hall.

Zapata, G., Correa M., A. M., Rodríguez, G. y Arango, M. I. (2016). Catálogo de Unidades Litoestratigráficas de Colombia. Granito de Pescadero. Medellín: Servicio Geológico Colombiano.

Zapata, G., Arango, M. I., Rodríguez, G., y Correa M, A. M. (201 8). Catálogo de Unidades Litoestratigráficas de Colombia. Riolitas El Uvo. Medellín: Servicio Geológico Colombiano. 


\section{ANEXOS}

Anexo A. Edades U-Pb del Monzogranito de La Corcova

Muestra LMC-077, Laboratorio del Servicio Geológico Colombiano

\begin{tabular}{|c|c|c|c|c|c|c|c|c|c|c|c|c|}
\hline $\begin{array}{l}\text { Identificación } \\
\text { Muestra }\end{array}$ & $\begin{array}{l}\text { Relación Final } \\
{ }^{207} \mathrm{~Pb}_{-}{ }^{235} \mathrm{U}\end{array}$ & $\begin{array}{c}\text { Error Interno } \\
\text { relación final } \\
{ }^{207} \mathrm{~Pb}_{-}{ }^{235} \mathrm{U} \text { a } \\
2 \mathrm{D}, \mathrm{E}\end{array}$ & $\begin{array}{l}\text { Relación Final } \\
{ }^{206} \mathrm{~Pb}_{-}{ }^{238} \mathrm{U}\end{array}$ & 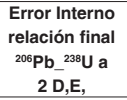 & $\begin{array}{l}\text { Ajuste error } \\
\text { de correlación } \\
\text { (Datos } \\
\text { negativos) }\end{array}$ & 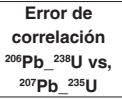 & $\begin{array}{c}\text { Edad corregida } \\
{ }^{206} \mathrm{~Pb}^{238} \mathrm{U} \\
(\mathrm{M}, \mathrm{A},)\end{array}$ & $\begin{array}{l}\mathrm{Edad}^{207} \mathrm{~Pb} \\
{ }^{235} \mathrm{U}(\mathrm{M}, \mathrm{A},)\end{array}$ & $\begin{array}{c}\% \\
\text { Discordia }\end{array}$ & $\begin{array}{c}\text { Edad } \\
\text { corregida } \\
{ }^{206} \mathrm{~Pb}^{238} \mathrm{U} \\
(\mathrm{M}, \mathrm{A},)\end{array}$ & $\pm 2 \sigma$ & $\begin{array}{l}\text { Relación } \\
\text { Final } \\
{ }^{238} \mathrm{U} /{ }^{232} \mathrm{Th}\end{array}$ \\
\hline LMC_077_24 & 1,01 & 0,051 & 0,076 & 0,001 & 0,253 & 0,253 & 452,127 & 711 & 57,257 & 452,127 & 13,28 & 2,695 \\
\hline LMC_077_55 & 0,235 & 0,013 & 0,026 & 0,001 & 0,35 & 0,35 & 167,332 & 213 & 27,292 & 167,332 & 31,91 & 2,121 \\
\hline LMC_077_53 & 0,233 & 0,017 & 0,026 & 0,001 & 0,31 & 0,31 & 166,866 & 212 & 27,048 & 166,866 & 31,93 & 26,65 \\
\hline LMC_077_56 & 0,202 & 0,008 & 0,024 & 0,001 & 0,597 & 0,597 & 151,304 & 186,3 & 23,129 & 151,304 & 29,44 & 5,468 \\
\hline LMC_077_54 & 0,555 & 0,019 & 0,058 & 0,002 & 0,682 & 0,682 & 363,592 & 447 & 22,94 & 363,592 & 68,66 & 1,482 \\
\hline LMC_077_57 & 0,45 & 0,021 & 0,049 & 0,002 & 0,799 & 0,799 & 308,933 & 376 & 21,709 & 308,933 & 60,24 & 1,601 \\
\hline LMC__077_3 & 0,338 & 0,03 & 0,038 & 0,001 & 0,401 & 0,401 & 238,219 & 283 & 18,798 & 238,219 & 8,20 & 1,495 \\
\hline LMC_077_52 & 0,428 & 0,028 & 0,049 & 0,001 & 0,288 & 0,288 & 307,356 & 361 & 17,453 & 307,356 & 57,90 & 0,487 \\
\hline LMC_077_45 & 0,233 & 0,023 & 0,032 & 0,002 & 0,779 & 0,779 & 201,891 & 206 & 2,035 & 201,891 & 39,42 & 1,55 \\
\hline LMC_077_48 & 0,221 & 0,008 & 0,032 & 0,001 & 0,805 & 0,805 & 202,306 & 202,7 & 0,195 & 202,306 & 38,22 & 8,091 \\
\hline LMC_077_58 & 0,233 & 0,009 & 0,032 & 0,001 & 0,659 & 0,659 & 202,316 & 211,4 & 4,49 & 202,316 & 39,46 & 1,484 \\
\hline LMC_077_51 & 0,369 & 0,022 & 0,045 & 0,002 & 0,761 & 0,761 & 286,375 & 314 & 9,646 & 286,375 & 55,49 & 1,443 \\
\hline LMC_077_43 & 0,597 & 0,02 & 0,079 & 0,003 & 0,855 & 0,855 & 488,387 & 474 & $-2,946$ & 488,387 & 92,38 & 1,491 \\
\hline LMC_077_47 & 0,348 & 0,02 & 0,052 & 0,003 & 0,826 & 0,826 & 329,211 & 301 & $-8,569$ & 329,211 & 62,81 & 3,342 \\
\hline LMC_077_59 & 0,565 & 0,023 & 0,072 & 0,003 & 0,829 & 0,829 & 450,048 & 452 & 0,434 & 450,048 & 86,72 & 19,084 \\
\hline LMC_077_50 & 0,205 & 0,007 & 0,027 & 0,001 & 0,719 & 0,719 & 172,317 & 189,1 & 9,74 & 172,317 & 32,57 & 0,64 \\
\hline LMC_077_49 & 0,201 & 0,008 & 0,027 & 0,001 & 0,778 & 0,778 & 173,454 & 185,1 & 6,714 & 173,454 & 33,20 & 1,043 \\
\hline LMC_077_46 & 2,139 & 0,079 & 0,204 & 0,006 & 0,507 & 0,507 & 1196,406 & 1151 & $-3,795$ & 1196,406 & 226,40 & 2,1 \\
\hline LMC_077_44 & 0,47 & 0,021 & 0,069 & 0,002 & 0,531 & 0,531 & 434,479 & 388 & $-10,698$ & 434,479 & 80,80 & 2,036 \\
\hline LMC___077_31 & 0,21 & 0,006 & 0,031 & 0,001 & 0,613 & 0,613 & 196,002 & 193 & $-1,532$ & 196,002 & 6,20 & 1,524 \\
\hline LMC__077_8 & 0,229 & 0,013 & 0,031 & 0,001 & 0,282 & 0,282 & 198,063 & 208 & 5,017 & 198,063 & 5,84 & 1,235 \\
\hline LMC__077_5 & 0,228 & 0,008 & 0,032 & 0,001 & 0,385 & 0,385 & 199,498 & 209,4 & 4,963 & 199,498 & 6,31 & 2,151 \\
\hline LMC__077_38 & 0,219 & 0,007 & 0,032 & 0 & 0,262 & 0,262 & 204,326 & 201,7 & $-1,285$ & 204,326 & 5,51 & 1,561 \\
\hline LMC___077_10 & 0,21 & 0,022 & 0,032 & 0,001 & 0,093 & 0,093 & 205,668 & 192 & $-6,646$ & 205,668 & 7,07 & 1,045 \\
\hline LMC__077_19 & 0,234 & 0,012 & 0,033 & 0,001 & 0,263 & 0,263 & 211,522 & 213 & 0,699 & 211,522 & 6,96 & 4,463 \\
\hline LMC___077_17 & 0,226 & 0,021 & 0,033 & 0,001 & 0,1 & $-0,038$ & 211,536 & 208 & $-1,672$ & 211,536 & 7,68 & 4,605 \\
\hline LMC__077_25 & 0,244 & 0,009 & 0,034 & 0 & 0,171 & 0,171 & 216,175 & 220,7 & 2,093 & 216,175 & 6,07 & 2,34 \\
\hline LMC__077_36 & 0,249 & 0,02 & 0,035 & 0,001 & 0,226 & 0,226 & 220,317 & 222 & 0,764 & 220,317 & 7,00 & 0,716 \\
\hline LMC__077_26 & 0,247 & 0,005 & 0,035 & 0 & 0,28 & 0,28 & 222,645 & 223,6 & 0,429 & 222,645 & 5,87 & 3,161 \\
\hline LMC__077_6 & 0,245 & 0,007 & 0,035 & 0 & 0,334 & 0,334 & 224,816 & 222,2 & $-1,164$ & 224,816 & 6,00 & 1,346 \\
\hline LMC__077_23 & 0,255 & 0,008 & 0,036 & 0,001 & 0,503 & 0,503 & 228,112 & 229,7 & 0,696 & 228,112 & 6,93 & 6,355 \\
\hline LMC__077_18 & 0,252 & 0,009 & 0,036 & 0,001 & 0,398 & 0,398 & 229,994 & 227,1 & $-1,258$ & 229,994 & 6,32 & 64,222 \\
\hline LMC__077_37 & 0,256 & 0,008 & 0,036 & 0 & 0,21 & 0,21 & 230,13 & 230,1 & $-0,013$ & 230,13 & 6,00 & 1,45 \\
\hline LMC__077_33 & 0,262 & 0,006 & 0,036 & 0 & 0,204 & 0,204 & 230,226 & 235,4 & 2,247 & 230,226 & 5,93 & 4,195 \\
\hline LMC__077_20 & 0,274 & 0,007 & 0,037 & 0 & 0,203 & 0,203 & 231,781 & 246,3 & 6,264 & 231,781 & 6,10 & 1,192 \\
\hline LMC__077_22 & 0,28 & 0,009 & 0,037 & 0 & 0,328 & 0,328 & 232,015 & 249,7 & 7,622 & 232,015 & 6,28 & 4,138 \\
\hline LMC__077_32 & 0,261 & 0,008 & 0,037 & 0 & 0,165 & 0,165 & 232,524 & 236,5 & 1,71 & 232,524 & 6,12 & 3,882 \\
\hline LMC__077_29 & 0,287 & 0,009 & 0,038 & 0 & 0,108 & 0,108 & 239,673 & 257,4 & 7,397 & 239,673 & 6,29 & 3,768 \\
\hline LMC__077_11 & 0,287 & 0,01 & 0,039 & 0,001 & 0,241 & 0,241 & 243,452 & 255,9 & 5,113 & 243,452 & 6,91 & 12,007 \\
\hline LMC__077_35 & 0,271 & 0,013 & 0,039 & 0,001 & 0,166 & 0,166 & 247,047 & 241 & $-2,448$ & 247,047 & 6,95 & 4,356 \\
\hline LMC__077_21 & 0,292 & 0,023 & 0,041 & 0,001 & 0,117 & 0,117 & 259,302 & 254 & $-2,045$ & 259,302 & 9,46 & 14,943 \\
\hline LMC__077_27 & 0,292 & 0,013 & 0,042 & 0,001 & 0,663 & 0,663 & 264,837 & 259,1 & $-2,166$ & 264,837 & 9,40 & 28,977 \\
\hline LMC__077_1 & 0,34 & 0,016 & 0,046 & 0,001 & 0,18 & 0,18 & 289,012 & 295 & 2,072 & 289,012 & 8,16 & 15,643 \\
\hline LMC__077_4 & 0,413 & 0,016 & 0,057 & 0,001 & 0,339 & 0,339 & 359,824 & 351 & $-2,452$ & 359,824 & 10,57 & 4,319 \\
\hline LMC___077_42 & 0,482 & 0,034 & 0,059 & 0,001 & 0,134 & 0,134 & 365,763 & 402 & 9,907 & 365,763 & 11,83 & 4,617 \\
\hline LMC__077_28 & 0,483 & 0,016 & 0,063 & 0,001 & 0,744 & 0,744 & 390,04 & 399 & 2,297 & 390,04 & 12,94 & 4,526 \\
\hline LMC__077_41 & 0,483 & 0,021 & 0,067 & 0,001 & 0,187 & 0,187 & 415,623 & 399 & -4 & 415,623 & 11,78 & 1,867 \\
\hline LMC__077_34 & 0,551 & 0,02 & 0,07 & 0,001 & 0,191 & 0,191 & 435,62 & 445 & 2,153 & 435,62 & 12,31 & 4,583 \\
\hline LMC__077_39 & 0,534 & 0,02 & 0,071 & 0,001 & 0,385 & 0,385 & 443,099 & 435 & $-1,828$ & 443,099 & 13,53 & 8,978 \\
\hline LMC__077_15 & 0,616 & 0,018 & 0,074 & 0,001 & 0,238 & 0,238 & 457,051 & 485 & 6,115 & 457,051 & 12,87 & 5,138 \\
\hline
\end{tabular}




\begin{tabular}{|c|c|c|c|c|c|c|c|c|c|c|c|c|}
\hline $\begin{array}{l}\text { Identificación } \\
\text { Muestra }\end{array}$ & $\begin{array}{l}\text { Relación Final } \\
{ }^{207} \mathrm{~Pb}_{-}{ }^{235} \mathrm{U}\end{array}$ & $\begin{array}{c}\text { Error Interno } \\
\text { relación final } \\
{ }^{207} \mathrm{~Pb}_{-2}{ }^{235} \mathrm{U} \text { a } \\
2 \mathrm{D}, \mathrm{E} \\
\end{array}$ & $\begin{array}{l}\text { Relación Final } \\
{ }^{206} \mathrm{~Pb}_{-}{ }^{238} \mathrm{U}\end{array}$ & 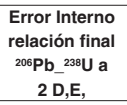 & $\begin{array}{c}\text { Ajuste error } \\
\text { de correlación } \\
\text { (Datos } \\
\text { negativos) }\end{array}$ & $\begin{array}{c}\text { Error de } \\
\text { correlación } \\
{ }^{206} \mathrm{~Pb}^{238} \mathrm{U} \text { vs, } \\
{ }^{207} \mathrm{~Pb}_{-}{ }^{235} \mathrm{U} \\
\end{array}$ & $\begin{array}{c}\text { Edad corregida } \\
{ }^{206} \mathrm{~Pb}_{-}^{238} \mathrm{U} \\
(\mathrm{M}, \mathrm{A},)\end{array}$ & $\begin{array}{l}\mathrm{Edad}^{207} \mathrm{~Pb} \\
{ }^{235} \mathrm{U}(\mathrm{M}, \mathrm{A},)\end{array}$ & $\begin{array}{c}\% \\
\text { Discordia }\end{array}$ & $\begin{array}{c}\text { Edad } \\
\text { corregida } \\
{ }^{206} \mathrm{~Pb}_{-}^{238} \mathrm{U} \\
(\mathrm{M}, \mathrm{A},)\end{array}$ & $\pm 2 \sigma$ & $\begin{array}{l}\text { Relación } \\
\text { Final } \\
{ }^{238} \mathrm{U} / \text { pl32 }^{23}\end{array}$ \\
\hline LMC__077_2 & 0,584 & 0,015 & 0,075 & 0,001 & 0,352 & 0,352 & 464,74 & 466,8 & 0,443 & 464,74 & 12,89 & 1,127 \\
\hline LMC__077_9 & 0,588 & 0,017 & 0,076 & 0,001 & 0,402 & 0,402 & 469,66 & 471 & 0,285 & 469,66 & 12,88 & 1,377 \\
\hline LMC__ $077 \_13$ & 0,6 & 0,023 & 0,078 & 0,001 & 0,242 & 0,242 & 481,984 & 474 & $-1,656$ & 481,984 & 13,51 & 1,869 \\
\hline LMC__077_7 & 0,637 & 0,022 & 0,079 & 0,001 & 0,327 & 0,327 & 489,776 & 497 & 1,475 & 489,776 & 13,48 & 4,17 \\
\hline LMC__077_14 & 0,613 & 0,021 & 0,08 & 0,001 & 0,146 & 0,146 & 498,184 & 487 & $-2,245$ & 498,184 & 13,50 & 1,979 \\
\hline LMC__ 077_12 & 0,868 & 0,065 & 0,101 & 0,005 & 0,777 & 0,777 & 618,317 & 633 & 2,375 & 618,317 & 30,57 & 7,312 \\
\hline LMC___077_40 & 1,519 & 0,081 & 0,153 & 0,006 & 0,848 & 0,848 & 911,641 & 943 & 3,44 & 911,641 & 40,00 & 5,459 \\
\hline LMC__077_30 & 2,26 & 0,15 & 0,188 & 0,005 & 0,433 & 0,433 & 1091,301 & 1190 & 9,044 & 1091,301 & 39,07 & 4,371 \\
\hline LMC__ $077 \_16$ & 3,215 & 0,053 & 0,249 & 0,003 & 0,583 & 0,583 & 1426,432 & 1460 & 2,353 & 1426,432 & 38,40 & 6,725 \\
\hline
\end{tabular}


MIA-630B, Laboratorio de la Universidad Nacional Autónoma de México

\begin{tabular}{|c|c|c|c|c|c|c|c|c|c|c|c|c|c|c|c|c|c|c|c|c|}
\hline & $\begin{array}{c}U \\
(\mathrm{ppm})^{1}\end{array}$ & $\begin{array}{c}\text { Th } \\
(\mathrm{ppm})^{1}\end{array}$ & Th/U & ${ }^{207} \mathrm{~Pb} /{ }^{206} \mathrm{~Pb}$ & $\pm 2 \mathrm{~s}$ abs & ${ }^{207} \mathrm{~Pb} /{ }^{235} \mathrm{U}$ & $\pm 2 \mathrm{~s}$ abs & ${ }^{206} \mathrm{~Pb} /{ }^{238} \mathrm{U}$ & $\pm 2 \mathrm{~s}$ abs & $\begin{array}{c}\text { Correlación } \\
\text { de errores }\end{array}$ & ${ }^{207} \mathrm{~Pb} /{ }^{235} \mathrm{U}$ & $\pm 2 \mathrm{~s}$ & ${ }^{207} \mathrm{~Pb} /{ }^{206} \mathrm{~Pb}$ & $\pm 2 \mathrm{~s}$ & $\begin{array}{c}\text { Mejor } \\
\text { edad (Ma) }\end{array}$ & $\pm 2 \mathrm{~s}$ & Disc\% & Error & ${ }^{206} \mathrm{~Pb} /{ }^{238} \mathrm{U}$ & $\pm 2 \mathrm{~s}$ \\
\hline Circón-162 & 3.030 & 10.330 & 3,41 & 0,0504 & 0,0019 & 0,2261 & 0,009 & 0,0326 & 0,0003 & 0,189 & 206,9 & 7,4 & 213 & 86 & 206,7 & 1,9 & 0,1 & $0,92 \%$ & 206,7 & 1,9 \\
\hline Circón-164 & 477 & 684 & 1,43 & 0,0503 & 0,0028 & 0,222 & 0,013 & 0,0326 & 0,0005 & 0,054 & 203 & 10 & 190 & 120 & 206,7 & 3 & $-1,82$ & $1,45 \%$ & 206,7 & 3 \\
\hline Circón-152 & 2.030 & 4.290 & 2,11 & 0,0498 & 0,002 & 0,2241 & 0,0095 & 0,0326 & 0,0004 & 0,102 & 205,3 & 7,9 & 180 & 90 & 206,8 & 2,5 & $-0,73$ & $1,21 \%$ & 206,8 & 2,5 \\
\hline Circón-166 & 2.580 & 7.610 & 2,95 & 0,0508 & 0,0018 & 0,2277 & 0,0092 & 0,0327 & 0,0004 & 0,387 & 208,2 & 7,6 & 224 & 84 & 207,2 & 2,6 & 0,48 & $1,25 \%$ & 207,2 & 2,6 \\
\hline Circón-163 & 1.000 & 1.890 & 1,89 & 0,0536 & 0,003 & 0,239 & 0,015 & 0,033 & 0,0004 & 0,052 & 217 & 12 & 340 & 120 & 209,3 & 2,4 & 3,55 & $1,15 \%$ & 209,3 & 2,4 \\
\hline Circón-141 & 404 & 530 & 1,31 & 0,0487 & 0,0029 & 0,227 & 0,015 & 0,033 & 0,0005 & 0,263 & 209 & 12 & 130 & 130 & 209,3 & 2,9 & $-0,14$ & $1,39 \%$ & 209,3 & 2,9 \\
\hline Circón-156 & 2.560 & 8.430 & 3,29 & 0,0513 & 0,002 & 0,2326 & 0,0093 & 0,0331 & 0,0004 & 0,257 & 212,3 & 7,9 & 244 & 87 & 209,6 & 2,6 & 1,27 & $1,24 \%$ & 209,6 & 2,6 \\
\hline $\begin{array}{l}\text { Circón-172- } \\
\text { MIA-630B }\end{array}$ & 2.050 & 2.790 & 1,36 & 0,0515 & 0,0037 & 0,234 & 0,019 & 0,0332 & 0,0003 & 0,344 & 214 & 15 & 250 & 130 & 210,6 & 2,1 & 1,59 & $1,00 \%$ & 210,6 & 2,1 \\
\hline Circón-171 & 2.510 & 7.860 & 3,13 & 0,0509 & 0,002 & 0,2305 & 0,0097 & 0,0333 & 0,0003 & 0,429 & 211,2 & 7,7 & 226 & 90 & 210,9 & 2,1 & 0,14 & $1,00 \%$ & 210,9 & 2,1 \\
\hline Circón-165 & 2.050 & 2.630 & 1,28 & 0,0523 & 0,0057 & 0,24 & 0,026 & 0,0333 & 0,0005 & 0,117 & 218 & 19 & 280 & 160 & 211,3 & 2,9 & 3,07 & $1,37 \%$ & 211,3 & 2,9 \\
\hline Circón-146 & 661 & 829 & 1,25 & 0,0511 & 0,0023 & 0,239 & 0,011 & 0,0335 & 0,0005 & 0,053 & 1053 & 20 & 230 & 100 & 212,6 & 2,9 & 2,07 & 2,07 & 217,1 & 8,7 \\
\hline
\end{tabular}


MIA-627A, Laboratorio de la Universidad Nacional Autónoma de México

\begin{tabular}{|c|c|c|c|c|c|c|c|c|c|c|c|c|c|c|c|c|c|c|c|c|c|}
\hline & & $\underset{(\mathrm{ppm})^{1}}{\mathrm{U}}$ & $\begin{array}{c}\text { Th } \\
(\mathrm{ppm})^{1}\end{array}$ & $\mathrm{Th} / \mathrm{U}$ & ${ }^{207} \mathrm{~Pb} /{ }^{206} \mathrm{~Pb}$ & $\pm 2 \mathrm{~s}$ abs & ${ }^{207} \mathrm{~Pb} /{ }^{235} \mathrm{U}$ & $\pm 2 \mathrm{~s}$ abs & ${ }^{206} \mathrm{~Pb} /{ }^{238} \mathrm{U}$ & $\pm 2 \mathrm{~s}$ abs & $\begin{array}{c}\text { Correlación } \\
\text { de errores }\end{array}$ & ${ }^{207} \mathrm{~Pb} /{ }^{235} \mathrm{U}$ & $\pm 2 \mathrm{~s}$ & ${ }^{207} \mathrm{~Pb} /{ }^{206} \mathrm{~Pb}$ & $\pm 2 \mathrm{~s}$ & $\begin{array}{l}\text { Mejor } \\
\text { edad } \\
(\mathrm{Ma})\end{array}$ & $\pm 2 \mathrm{~s}$ & Disc\% & Error & ${ }^{206} \mathrm{~Pb} /{ }^{238} \mathrm{U}$ & $\pm 2 \mathrm{~s}$ \\
\hline \multicolumn{2}{|c|}{ Circón-132 } & 1.590 & 69 & 0,043 & 0,075 & 0,007 & 0,404 & 0,090 & 0,039 & 0,003 & 0,880 & 344,000 & 52 & 1.050 & 130 & 246 & 20 & 28,4884 & 0,0813 & 246,0 & 20 \\
\hline \multicolumn{2}{|c|}{ Circón-110 } & 436 & 30,8 & 0,071 & 0,081 & 0,003 & 1,720 & 0,120 & 0,151 & 0,008 & 0,051 & $1.016,000$ & 55 & 1.218 & 83 & 1218 & 83 & 10,6299 & 0,0681 & 908,0 & 46 \\
\hline \multicolumn{2}{|c|}{ Circón-137-MIA-627A } & 2.790 & 81 & 0,029 & 0,055 & 0,003 & 0,203 & 0,043 & 0,027 & 0,004 & 0,427 & 188,000 & 32 & 400 & 97 & 169 & 25 & 10,1064 & 0,1479 & 169,0 & 25 \\
\hline \multicolumn{2}{|c|}{ Circón-127 } & 1.780 & 8 & 0,004 & 0,051 & 0,002 & 0,244 & 0,037 & 0,035 & 0,004 & 0,188 & 221,000 & 27 & 249 & 95 & 222 & 24 & $-0,4525$ & 0,1081 & 222,0 & 24 \\
\hline \multicolumn{2}{|c|}{ Circón-113 } & 5.870 & 93,8 & 0,016 & 0,050 & 0,002 & 0,192 & 0,008 & 0,028 & 0,000 & 0,427 & 178,400 & 6,6 & 210 & 87 & 175 & 2 & 1,9058 & 0,0114 & 175,0 & 2 \\
\hline \multicolumn{2}{|c|}{ Circón-119 } & 591 & 182 & 0,308 & 0,056 & 0,003 & 0,234 & 0,011 & 0,030 & 0,000 & 0,025 & 213,400 & 9,4 & 430 & 110 & 192,9 & 2,2 & 9,6064 & 0,0114 & 192,9 & 2,2 \\
\hline \multicolumn{2}{|c|}{ Circón-136 } & 2.570 & 2030 & 0,790 & 0,051 & 0,002 & 0,216 & 0,009 & 0,031 & 0,000 & 0,060 & 198,200 & 7,4 & 212 & 93 & 195,9 & 2 & 1,1604 & 0,0102 & 195,9 & 2 \\
\hline \multicolumn{2}{|c|}{ Circón-124 } & 881 & 840 & 0,953 & 0,055 & 0,002 & 0,230 & 0,010 & 0,031 & 0,000 & 0,059 & 210,900 & 8,6 & 381 & 97 & 196,1 & 2,4 & 7,0175 & 0,0122 & 196,1 & 2,4 \\
\hline \multicolumn{2}{|c|}{ Circón-112 } & 5.110 & 84 & 0,016 & 0,050 & 0,002 & 0,220 & 0,009 & 0,032 & 0,000 & 0,486 & 202,800 & 7 & 177 & 85 & 201,2 & 1,6 & 0,7890 & 0,0080 & 201,2 & 1,6 \\
\hline \multicolumn{2}{|c|}{ Circón-109 } & 539 & 46,8 & 0,087 & 0,048 & 0,002 & 0,221 & 0,011 & 0,032 & 0,001 & 0,493 & 202,700 & 9,3 & 96 & 98 & 205,7 & 4,3 & $-1,4800$ & 0,0209 & 205,7 & 4,3 \\
\hline \multicolumn{2}{|c|}{ Circón-111 } & 3.530 & 109 & 0,031 & 0,054 & 0,002 & 0,241 & 0,018 & 0,033 & 0,001 & 0,527 & 219,000 & 14 & 366 & 85 & 206,9 & 8 & 5,5251 & 0,0387 & 206,9 & 8 \\
\hline \multicolumn{2}{|c|}{ Circón-115 } & 5.010 & 692 & 0,138 & 0,050 & 0,002 & 0,227 & 0,010 & 0,033 & 0,000 & 0,451 & 207,400 & 8 & 192 & 84 & 207,7 & 2,8 & $-0,1446$ & 0,0135 & 207,7 & 2,8 \\
\hline \multicolumn{2}{|c|}{ Circón-130 } & 1.190 & 1440 & 1,210 & 0,052 & 0,002 & 0,233 & 0,010 & 0,033 & 0,001 & 0,040 & 212,800 & 8,3 & 255 & 93 & 209,6 & 3,9 & 1,5038 & 0,0186 & 209,6 & 3,9 \\
\hline \multicolumn{2}{|c|}{ Circón-104 } & 254 & 247 & 0,972 & 0,057 & 0,004 & 0,355 & 0,027 & 0,045 & 0,001 & 0,088 & 307,000 & 20 & 430 & 150 & 281,2 & 5,6 & 8,4039 & 0,0199 & 281,2 & 5,6 \\
\hline \multicolumn{2}{|c|}{ Circón-107 } & 1.810 & 82 & 0,045 & 0,056 & 0,002 & 0,472 & 0,020 & 0,061 & 0,001 & 0,523 & 394,000 & 13 & 455 & 81 & 382,4 & 3,6 & 2,9442 & 0,0094 & 382,4 & 3,6 \\
\hline \multicolumn{2}{|c|}{ Circón-118 } & 650 & 245 & 0,377 & 0,055 & 0,002 & 0,511 & 0,024 & 0,067 & 0,001 & 0,012 & 419,000 & 16 & 406 & 97 & 419,4 & 7 & $-0,0955$ & 0,0167 & 419,4 & 7 \\
\hline \multicolumn{2}{|c|}{ Circón-135 } & 503 & 243 & 0,483 & 0,056 & 0,002 & 0,532 & 0,023 & 0,069 & 0,001 & 0,169 & 433,000 & 16 & 448 & 92 & 430,5 & 4,7 & 0,5774 & 0,0109 & 430,5 & 4,7 \\
\hline \multicolumn{2}{|c|}{ Circón-126 } & 1.010 & 892 & 0,883 & 0,056 & 0,002 & 0,552 & 0,022 & 0,072 & 0,001 & 0,231 & 446,000 & 15 & 427 & 84 & 447,9 & 4,2 & $-0,4260$ & 0,0094 & 447,9 & 4,2 \\
\hline \multicolumn{2}{|c|}{ Circón-105 } & 744 & 830 & 1,116 & 0,056 & 0,002 & 0,568 & 0,024 & 0,073 & 0,001 & 0,172 & 456,000 & 15 & 435 & 90 & 451,5 & 4,4 & 0,9868 & 0,0097 & 451,5 & 4,4 \\
\hline \multicolumn{2}{|c|}{ Circón-134 } & 2.400 & 666 & 0,278 & 0,058 & 0,003 & 0,586 & 0,066 & 0,073 & 0,005 & 0,779 & 468,000 & 39 & 532 & 90 & 452 & 31 & 3,4188 & 0,0686 & 452,0 & 31 \\
\hline Circón & 129 & 890 & 223 & 0,251 & 0,055 & 0,003 & 0,554 & 0,034 & 0,073 & 0,002 & 0,630 & 446,000 & 23 & 410 & 100 & 452 & 14 & $-1,3453$ & 0,0310 & 452,0 & 14 \\
\hline Circón-121 & 1.420 & 227 & 0,160 & 0,056 & 0,002 & 0,558 & 0,023 & 0,073 & 0,001 & 0,289 & 450,000 & 15 & 426 & 84 & 452,9 & 4,3 & $-0,6444$ & 0,0095 & 452,9 & 4,3 & \\
\hline Circón-128 & 318 & 200 & 0,629 & 0,055 & 0,003 & 0,555 & 0,027 & 0,074 & 0,001 & 0,002 & 447,000 & 18 & 380 & 110 & 459,1 & 5,2 & $-2,7069$ & 0,0113 & 459,1 & 5,2 & \\
\hline Circón-106 & 808 & 348 & 0,431 & 0,055 & 0,002 & 0,572 & 0,024 & 0,074 & 0,001 & 0,425 & 459,000 & 15 & 419 & 85 & 459,3 & 6 & $-0,0654$ & 0,0131 & 459,3 & 6 & \\
\hline Circón-120 & 268 & 133 & 0,496 & 0,057 & 0,003 & 0,581 & 0,028 & 0,074 & 0,001 & 0,208 & 464,000 & 17 & 480 & 110 & 462,5 & 7,6 & 0,3233 & 0,0164 & 462,5 & 7,6 & \\
\hline Circón-116 & 906 & 564 & 0,623 & 0,057 & 0,002 & 0,576 & 0,026 & 0,075 & 0,002 & 0,401 & 463,000 & 16 & 471 & 88 & 463,5 & 9,4 & $-0,1080$ & 0,0203 & 463,5 & 9,4 & \\
\hline Circón-131 & 624 & 298 & 0,478 & 0,055 & 0,002 & 0,574 & 0,025 & 0,075 & 0,001 & 0,279 & 460,000 & 16 & 430 & 92 & 466,2 & 4,4 & $-1,3478$ & 0,0094 & 466,2 & 4,4 & \\
\hline Circón-114 & 5.130 & 543 & 0,106 & 0,056 & 0,002 & 0,590 & 0,022 & 0,076 & 0,001 & 0,881 & 471,000 & 14 & 461 & 76 & 470,4 & 6,7 & 0,1274 & 0,0142 & 470,4 & 6,7 & \\
\hline Circón-108 & 616 & 373 & 0,606 & 0,056 & 0,002 & 0,606 & 0,025 & 0,078 & 0,001 & 0,242 & 482,000 & 16 & 457 & 84 & 481,4 & 3,9 & 0,1245 & 0,0081 & 481,4 & 3,9 & \\
\hline $\begin{array}{c}\text { Circón- } \\
\text { 103-MIA- } \\
627 \mathrm{~A}\end{array}$ & 267 & 77,8 & 0,291 & 0,056 & 0,003 & 0,604 & 0,030 & 0,078 & 0,001 & $\begin{array}{c}\text { N30, } \\
19438\end{array}$ & 478,000 & 20 & 430 & 110 & 482,2 & 6,1 & $-0,8787$ & 0,0127 & 482,2 & 6,1 & \\
\hline Circón-125 & 364 & 233 & 0,640 & 0,059 & 0,003 & 0,612 & 0,036 & 0,078 & 0,002 & 0,402 & 484,000 & 21 & 562 & 96 & 484 & 12 & 0,0000 & 0,0248 & 484,0 & 12 & \\
\hline Circón-117 & 182 & 95 & 0,522 & 0,057 & 0,003 & 0,621 & 0,042 & 0,080 & 0,003 & 0,106 & 489,000 & 28 & 460 & 110 & 495 & 20 & $-1,2270$ & 0,0404 & 495,0 & 20 & \\
\hline Circón-122 & 252 & 127 & 0,504 & 0,090 & 0,003 & 2,334 & 0,099 & 0,189 & 0,004 & 0,704 & $1.221,000$ & 32 & 1418 & 69 & 1418 & 69 & 8,5995 & 0,0487 & 1116,0 & 22 & \\
\hline Circón-123 & 264 & 145 & 0,549 & 0,092 & 0,004 & 3,290 & 0,130 & 0,260 & 0,003 & 0,377 & $1.483,000$ & 34 & 1470 & 73 & 1470 & 73 & $-0,4046$ & 0,0497 & 1489,0 & 15 & \\
\hline Circón-133 & 174 & 78,2 & 0,449 & 0,094 & 0,004 & 3,380 & 0,140 & 0,264 & 0,003 & 0,235 & $1.499,000$ & 32 & 1498 & 74 & 1498 & 74 & $-0,6004$ & 0,0494 & 1508,0 & 14 & \\
\hline
\end{tabular}


AMC-128, Laboratorio de la Universidad Nacional Autónoma de México

\begin{tabular}{|c|c|c|c|c|c|c|c|c|c|c|c|c|c|c|c|c|c|c|c|c|}
\hline & $\begin{array}{c}\mathbf{U} \\
(\mathrm{ppm})^{1}\end{array}$ & $\begin{array}{c}\text { Th } \\
\text { (ppm) }\end{array}$ & $\mathrm{Th} / \mathrm{U}$ & ${ }^{207} \mathrm{~Pb} /{ }^{206} \mathrm{~Pb}$ & $\pm 2 \mathrm{~s}$ abs & ${ }^{207} \mathrm{~Pb} /{ }^{235} \mathrm{U}$ & $\pm 2 \mathrm{~s}$ abs & ${ }^{206} \mathrm{~Pb} /{ }^{238} \mathrm{U}$ & $\pm 2 s$ abs & $\begin{array}{c}\text { correlación } \\
\text { de errores }\end{array}$ & ${ }^{207} \mathrm{~Pb} /{ }^{235} \mathrm{U}$ & $\pm 2 \mathrm{~s}$ & ${ }^{207} \mathrm{~Pb} /{ }^{206} \mathrm{~Pb}$ & $\pm 2 s$ & $\begin{array}{c}\text { Mejor } \\
\text { edad (Ma) }\end{array}$ & $\pm 2 \mathrm{~s}$ & Disc\% & Error & ${ }^{206} \mathrm{~Pb} /{ }^{238} \mathrm{U}$ & $\pm 2 \mathrm{~s}$ \\
\hline Circón-044 & 410 & 150,1 & 0,37 & 0,0598 & 0,0029 & 0,5220 & 0,0210 & 0,0628 & 0,0012 & 0,3556 & 426,0 & 14,0 & 600,0 & 100,0 & 0,0 & 0,4 & 7,82 & $1,81 \%$ & 392,7 & 7,1 \\
\hline Circón-067 & 1.098 & 1120 & 1,02 & 0,06 & 0,00 & 0,59 & 0,02 & 0,07 & 0,00 & 0,72 & 470,00 & 15,0 & 624,0 & 89,0 & 0,0 & 0,7 & 6,00 & $2,11 \%$ & 441,8 & 9,3 \\
\hline Circón-045 & 346,8 & 122,7 & 0,35 & 0,05 & 0,00 & 0,46 & 0,02 & 0,06 & 0,00 & 0,22 & 384,00 & 14,0 & 380,0 & 100,0 & 0,0 & 0,2 & 0,44 & $1,36 \%$ & 382,3 & 5,2 \\
\hline Circón-065 & 566 & 191 & 0,34 & 0,06 & 0,00 & 0,56 & 0,02 & 0,07 & 0,00 & 0,12 & 454,00 & 15,0 & 512,0 & 91,0 & 0,0 & 0,1 & 2,25 & $2,12 \%$ & 443,8 & 9,4 \\
\hline Circón-052 & 1.440 & 751 & 0,52 & 0,06 & 0,00 & 0,57 & 0,02 & 0,07 & 0,00 & 0,18 & 458,00 & 13,0 & 467,0 & 89,0 & 0,0 & 0,2 & 0,48 & $1,14 \%$ & 455,8 & 5,2 \\
\hline Circón-062 & 383,9 & 212,9 & 0,55 & 0,06 & 0,00 & 0,58 & 0,02 & 0,07 & 0,00 & 0,19 & 464,00 & 15,0 & 500,0 & 100,0 & 0,0 & 0,2 & 0,80 & $1,35 \%$ & 460,3 & 6,2 \\
\hline Circón-037 & 613 & 431 & 0,70 & 0,06 & 0,00 & 0,58 & 0,02 & 0,07 & 0,00 & 0,23 & 465,00 & 13,0 & 502,0 & 92,0 & 0,0 & 0,2 & 0,99 & $1,19 \%$ & 460,4 & 5,5 \\
\hline Circón-046 & 288,8 & 265 & 0,92 & 0,06 & 0,00 & 0,58 & 0,03 & 0,07 & 0,00 & 0,13 & 465,00 & 17,0 & 520,0 & 110,0 & 0,0 & 0,1 & 0,54 & $1,60 \%$ & 462,5 & 7,4 \\
\hline Circón-054 & 636 & 1160 & 1,82 & 0,06 & 0,00 & 0,57 & 0,03 & 0,07 & 0,00 & 0,40 & 459,00 & 18,0 & 410,0 & 110,0 & 0,0 & 0,4 & $-1,00$ & $2,05 \%$ & 463,6 & 9,5 \\
\hline Circón-053 & 458,3 & 243 & 0,53 & 0,06 & 0,01 & 0,59 & 0,06 & 0,07 & 0,00 & 0,17 & 471,00 & 32,0 & 470,0 & 160,0 & 0,0 & 0,2 & 1,34 & $1,40 \%$ & 464,7 & 6,5 \\
\hline Circón-069 & 561,2 & 267,3 & 0,48 & 0,06 & 0,00 & 0,59 & 0,02 & 0,07 & 0,00 & 0,09 & 469,00 & 15,0 & 490,0 & 95,0 & 0,0 & 0,1 & 0,81 & $1,14 \%$ & 465,2 & 5,3 \\
\hline Circón-047 & 417,1 & 250 & 0,60 & 0,06 & 0,00 & 0,59 & 0,02 & 0,08 & 0,00 & 0,05 & 471,00 & 15,0 & 510,0 & 100,0 & 0,0 & 0,1 & 0,93 & $1,24 \%$ & 466,6 & 5,8 \\
\hline Circón-051 & 407 & 459 & 1,13 & 0,06 & 0,00 & 0,58 & 0,02 & 0,08 & 0,00 & 0,12 & 464,00 & 15,0 & 461,0 & 93,0 & 0,0 & 0,1 & $-0,73$ & $1,31 \%$ & 467,4 & 6,1 \\
\hline Circón-060 & 747,7 & 542 & 0,72 & 0,06 & 0,00 & 0,59 & 0,02 & 0,08 & 0,00 & 0,17 & 473,00 & 13,0 & 483,0 & 84,0 & 0,0 & 0,2 & 0,13 & $1,02 \%$ & 472,4 & 4,8 \\
\hline $\begin{array}{l}\text { Circón-070- } \\
\text { AMC-0128 }\end{array}$ & 193 & 185 & 0,96 & 0,06 & 0,00 & 0,59 & 0,03 & 0,08 & 0,00 & 0,14 & 470,00 & 18,0 & 470,0 & 120,0 & 0,0 & 0,1 & $-0,96$ & $1,83 \%$ & 474,5 & 8,7 \\
\hline Circón-038 & 902,9 & 432,7 & 0,48 & 0,06 & 0,00 & 0,60 & 0,02 & 0,08 & 0,00 & 0,11 & 477,00 & 13,0 & 491,0 & 88,0 & 0,0 & 0,1 & 0,42 & $1,05 \%$ & 475,0 & 5,0 \\
\hline Circón-061 & 484,5 & 302,4 & 0,62 & 0,06 & 0,00 & 0,61 & 0,02 & 0,08 & 0,00 & 0,28 & 483,00 & 12,0 & 495,0 & 87,0 & 0,0 & 0,3 & 1,28 & $1,32 \%$ & 476,8 & 6,3 \\
\hline Circón-041 & 386,8 & 389,9 & 1,01 & 0,06 & 0,00 & 0,59 & 0,03 & 0,08 & 0,00 & 0,02 & 471,00 & 15,0 & 470,0 & 110,0 & 0,0 & 0,0 & $-1,42$ & $1,30 \%$ & 477,7 & 6,2 \\
\hline Circón-039 & 398,5 & 217,4 & 0,55 & 0,06 & 0,00 & 0,62 & 0,03 & 0,08 & 0,00 & 0,15 & 487,00 & 17,0 & 537,0 & 96,0 & 0,0 & 0,1 & 1,83 & $1,51 \%$ & 478,1 & 7,2 \\
\hline Circón-059 & 539,8 & 473,9 & 0,88 & 0,06 & 0,00 & 0,60 & 0,02 & 0,08 & 0,00 & 0,25 & 478,00 & 15,0 & 484,0 & 93,0 & 0,0 & 0,2 & $-0,10$ & $1,44 \%$ & 478,5 & 6,9 \\
\hline Circón-050 & 1.181 & 489,6 & 0,41 & 0,06 & 0,00 & 0,60 & 0,02 & 0,08 & 0,00 & 0,26 & 474,00 & 14,0 & 445,0 & 85,0 & 0,0 & 0,3 & $-1,29$ & $1,85 \%$ & 480,1 & 8,9 \\
\hline Circón-049 & 509,3 & 378 & 0,74 & 0,06 & 0,00 & 0,60 & 0,02 & 0,08 & 0,00 & 0,12 & 476,00 & 16,0 & 470,0 & 110,0 & 0,0 & 0,1 & $-1,07$ & $1,16 \%$ & 481,1 & 5,6 \\
\hline Circón-063 & 553 & 246,7 & 0,45 & 0,06 & 0,00 & 0,63 & 0,02 & 0,08 & 0,00 & 0,07 & 493,00 & 14,0 & 548,0 & 91,0 & 0,0 & 0,1 & 1,70 & $1,16 \%$ & 484,6 & 5,6 \\
\hline Circón-064 & 411,7 & 188,7 & 0,46 & 0,06 & 0,00 & 0,65 & 0,02 & 0,08 & 0,00 & 0,05 & 505,00 & 15,0 & 593,0 & 88,0 & 0,0 & 0,0 & 4,02 & $1,22 \%$ & 484,7 & 5,9 \\
\hline Circón-043 & 2.940 & 2033 & 0,69 & 0,06 & 0,00 & 0,61 & 0,02 & 0,08 & 0,00 & 0,64 & 481,00 & 13,0 & 493,0 & 80,0 & 0,0 & 0,6 & $-0,77$ & $1,88 \%$ & 484,7 & 9,1 \\
\hline Circón-066 & 321,1 & 227,9 & 0,71 & 0,06 & 0,00 & 0,60 & 0,03 & 0,08 & 0,00 & 0,33 & 479,00 & 16,0 & 446,0 & 99,0 & 0,0 & 0,3 & $-1,21$ & $1,30 \%$ & 484,8 & 6,3 \\
\hline Circón-068 & 465 & 200 & 0,43 & 0,06 & 0,00 & 0,62 & 0,03 & 0,08 & 0,00 & 0,36 & 489,00 & 15,0 & 514,0 & 90,0 & 0,0 & 0,4 & 0,65 & $1,44 \%$ & 485,8 & 7,0 \\
\hline Circón-058 & 1.117 & 924 & 0,83 & 0,06 & 0,00 & 0,62 & 0,02 & 0,08 & 0,00 & 0,19 & 488,00 & 13,0 & 499,0 & 87,0 & 0,0 & 0,2 & 0,43 & $1,34 \%$ & 485,9 & 6,5 \\
\hline Circón-040 & 241,1 & 238,2 & 0,99 & 0,06 & 0,00 & 0,61 & 0,03 & 0,08 & 0,00 & 0,14 & 481,00 & 19,0 & 440,0 & 120,0 & 0,0 & 0,1 & $-2,02$ & $1,61 \%$ & 490,7 & 7,9 \\
\hline Circón-048 & 573,6 & 305,9 & 0,53 & 0,06 & 0,00 & 0,62 & 0,02 & 0,08 & 0,00 & 0,16 & 490,00 & 14,0 & 478,0 & 90,0 & 0,0 & 0,2 & $-0,22$ & $1,30 \%$ & 491,1 & 6,4 \\
\hline Circón-057 & 661 & 636 & 0,96 & 0,06 & 0,00 & 0,63 & 0,02 & 0,08 & 0,00 & 0,05 & 493,00 & 15,0 & 512,0 & 86,0 & 0,0 & 0,0 & $-0,22$ & $1,76 \%$ & 494,1 & 8,7 \\
\hline Circón-055 & 662 & 438 & 0,66 & 0,06 & 0,00 & 0,63 & 0,02 & 0,08 & 0,00 & 0,23 & 493,00 & 13,0 & 501,0 & 83,0 & 0,0 & 0,2 & $-0,24$ & $1,01 \%$ & 494,2 & 5,0 \\
\hline Circón-042 & 534 & 572 & 1,07 & 0,06 & 0,00 & 0,67 & 0,03 & 0,08 & 0,00 & 0,17 & 522,00 & 17,0 & 521,0 & 97,0 & 0,0 & 0,2 & $-0,59$ & $1,49 \%$ & 525,1 & 7,8 \\
\hline Circón-056 & 293 & 174 & 0,59 & 0,06 & 0,00 & 0,68 & 0,03 & 0,09 & 0,00 & 0,09 & 524,00 & 18,0 & 480,0 & 100,0 & 0,0 & 0,1 & $-1,87$ & $1,29 \%$ & 533,8 & 6,9 \\
\hline $\begin{array}{l}\text { Circón-036- } \\
\text { AMC-0128 }\end{array}$ & 652 & 39 & 0,06 & 0,08 & 0,00 & 1,81 & 0,06 & 0,17 & 0,00 & 0,39 & $1.053,00$ & 20,0 & $1.099,0$ & 74,0 & 0,0 & 0,4 & 2,65 & $6,73 \%$ & $1.025,1$ & 9,2 \\
\hline
\end{tabular}


Anexo B. Química de elementos traza en circones

\begin{tabular}{|c|c|c|c|c|c|c|c|c|c|c|c|c|c|c|c|c|c|c|c|c|c|}
\hline (ppm) & $\mathbf{P}$ & $\mathrm{Ti}$ & $\mathrm{Y}$ & $\mathrm{Nb}$ & La & $\mathrm{Ce}$ & $\mathrm{Pr}$ & Nd & $\mathrm{Sm}$ & Eu & Gd & Tb & Dy & Ho & Er & $\mathrm{Yb}$ & Lu & $\mathrm{Hf}$ & $\mathrm{Pb}$ & Th & u \\
\hline \multicolumn{22}{|c|}{ MIA-627A } \\
\hline Circón-103-MIA-627A & 580 & 5,92 & 924 & 2,45 & 0 & 5,69 & 0,02 & 0,41 & 1,43 & 0,18 & 11,1 & 4,86 & 67,5 & 30,8 & 164 & 368 & 81,4 & 11700 & 22,1 & 77,8 & 267 \\
\hline Circón-104 & 420 & 11,2 & 1.590 & 1,08 & 0,06 & 16,6 & 0,19 & 2,47 & 5,6 & 1,1 & 31,5 & 12,8 & 141 & 57,9 & 250 & 428 & 81 & 11.800 & 11,8 & 247 & 254 \\
\hline Circón-105 & 1.200 & 13,4 & 5.480 & 4,34 & 0,63 & 25,2 & 1,13 & 13,9 & 24,1 & 2,01 & 138 & 46,9 & 537 & 196 & 820 & 1.280 & 240 & 9.800 & 57 & 830 & 744 \\
\hline Circón-106 & 1.400 & 9,4 & 3.470 & 2,36 & 0,4 & 14,2 & 0,26 & 3,44 & 7,04 & 0,41 & 50,8 & 21,5 & 289 & 120 & 562 & 1.070 & 209 & 13.400 & 63,3 & 348 & 808 \\
\hline Circón-107 & 760 & 9,2 & 1.040 & 30 & 0,17 & 3,19 & 0,32 & 3,3 & 5,3 & 0,11 & 17,6 & 5,7 & 71 & 29,8 & 185 & 860 & 244 & 20.200 & 112 & 82 & 1.810 \\
\hline Circón-108 & 980 & 7,9 & 2.690 & 2,33 & 0 & 14,9 & 0,09 & 2,13 & 5,62 & 0,22 & 39,2 & 17,1 & 229 & 92,5 & 431 & 810 & 156 & 12.000 & 50 & 373 & 616 \\
\hline Circón-109 & 450 & 5,8 & 970 & 5,12 & 0 & 5,8 & 0,01 & 0,08 & 0,71 & 0,15 & 10,2 & 4,69 & 75 & 32,5 & 166 & 417 & 89 & 10.200 & 18,5 & 46,8 & 539 \\
\hline Circón-110 & 130 & 10,6 & 401 & 4,49 & 0,09 & 5,11 & 0,08 & 0,78 & 0,85 & 0,16 & 5,22 & 2,17 & 28,9 & 13 & 70,5 & 171 & 40,6 & 12.500 & 60,3 & 30,8 & 436 \\
\hline Circón-111 & 1.150 & 11,5 & 2.150 & 15,7 & 0,09 & 2,31 & 0,1 & 0,69 & 2,9 & 0,26 & 18,3 & 10,9 & 175 & 70 & 374 & 1.210 & 261 & 18.300 & 107 & 109 & 3.530 \\
\hline Circón-112 & 1.520 & 5,72 & 1.940 & 10,8 & 0,15 & 1,48 & 0,23 & 3,12 & 6,3 & 0,69 & 26,6 & 14,4 & 176 & 61 & 313 & 1.190 & 261 & 20.100 & 178 & 84 & 5110 \\
\hline Circón-113 & 1.370 & 5,86 & 2.410 & 18,3 & 0 & 1,52 & 0 & 0,04 & 2,42 & 0,18 & 21,8 & 16,1 & 222 & 72,6 & 376 & 1.750 & 379 & 25.400 & 172 & 93,8 & 5.870 \\
\hline Circón-114 & 460 & 34 & 1.990 & 34,8 & 0,35 & 18,6 & 0,23 & 1,84 & 2,88 & 0,06 & 15,3 & 7,25 & 110 & 54,2 & 328 & 1.170 & 265 & 23.100 & 425 & 543 & 5.130 \\
\hline Circón-115 & 2.060 & 7,2 & 5.190 & 37,7 & 0,02 & 16,7 & 0,05 & 0,82 & 4,93 & 0,63 & 50,2 & 27,2 & 391 & 177 & 890 & 1.920 & 391 & 15.000 & 165 & 692 & 5.010 \\
\hline Circón-116 & 605 & 7,43 & 2.710 & 5,28 & 0 & 25,2 & 0,13 & 3,13 & 7,49 & 0,28 & 46,1 & 19,3 & 240 & 95,8 & 429 & 765 & 150 & 11.300 & 71,3 & 564 & 906 \\
\hline Circón-117 & 910 & 12,9 & 2.060 & 0,9 & 0,1 & 5,86 & 0,12 & 3,08 & 6,6 & 0,65 & 39,9 & 14,8 & 181 & 71 & 317 & 580 & 114 & 10.100 & 15,6 & 95 & 182 \\
\hline Circón-118 & 340 & 6,7 & 1.550 & 9,2 & 0,13 & 22,2 & 0,09 & 1,23 & 2,73 & 0,33 & 21,2 & 8,9 & 124 & 52,6 & 258 & 619 & 137 & 12.300 & 47 & 245 & 650 \\
\hline Circón-119 & 710 & 6,7 & 1.400 & 4,28 & 0 & 9,17 & 0,02 & 0,52 & 2,17 & 0,31 & 17,3 & 7,1 & 106 & 46,7 & 235 & 549 & 119 & 11.440 & 18,8 & 182 & 591 \\
\hline Circón-120 & 490 & 7,15 & 1.143 & 2,22 & 0,01 & 10,6 & 0,06 & 0,95 & 3 & 0,3 & 19,9 & 7,17 & 95 & 39,2 & 181 & 368 & 75,9 & 9.270 & 20,4 & 133 & 268 \\
\hline Circón-121 & 380 & 6,65 & 1.350 & 13,2 & 0 & 9,42 & 0,02 & 0,29 & 1,29 & 0,22 & 14,4 & 7,02 & 103 & 46,8 & 239 & 591 & 129 & 13.800 & 107 & 227 & 1.420 \\
\hline Circón-122 & 180 & 8,7 & 822 & 3,62 & 0 & 23,3 & 0,04 & 0,65 & 1,87 & 0,3 & 11,3 & 4,71 & 62,5 & 27,4 & 137 & 327 & 70,9 & 11.500 & 49 & 127 & 252 \\
\hline Circón-123 & 222 & 10,5 & 795 & 5,78 & 0 & 44,6 & 0,14 & 1,95 & 2,98 & 0,56 & 16,4 & 5,67 & 70,6 & 27 & 130 & 299 & 65,2 & 12.500 & 65,5 & 145 & 264 \\
\hline Circón-124 & 730 & 10,2 & 3.510 & 14,4 & 0,09 & 80 & 0,44 & 7,7 & 15,2 & 2,44 & 79 & 27,8 & 327 & 124 & 543 & 1.010 & 196 & 9.600 & 28 & 840 & 881 \\
\hline Circón-125 & 490 & 8,5 & 1.310 & 5,6 & 0 & 24,4 & 0,02 & 0,89 & 3,06 & 0,43 & 16,8 & 8,1 & 108 & 45,2 & 217 & 447 & 94 & 13.500 & 27 & 233 & 364 \\
\hline Circón-126 & 1.880 & 11 & 4.070 & 10 & 1,21 & 56,7 & 1,03 & 9,9 & 14 & 2,68 & 75,9 & 27,5 & 352 & 140 & 659 & 1.350 & 276 & 11.200 & 71,5 & 892 & 1.010 \\
\hline Circón-127 & 290 & 4,66 & 480 & 11,3 & 0,01 & 0,39 & 0 & 0 & 0,08 & 0 & 1,28 & 1,09 & 19,8 & 13,4 & 99 & 453 & 133 & 13.400 & 57 & 8 & 1.780 \\
\hline Circón-128 & 1.010 & 14,6 & 2.510 & 1,23 & 0,01 & 6,77 & 0,16 & 2,59 & 6,3 & 0,43 & 44,3 & 16,8 & 212 & 83,2 & 370 & 700 & 138 & 9.400 & 23,4 & 200 & 318 \\
\hline Circón-129 & 1.590 & 8,7 & 3.400 & 2,63 & 0 & 6,6 & 0,05 & 0,92 & 4,51 & 0,11 & 40,2 & 18,6 & 284 & 124 & 610 & 1.240 & 246 & 14.800 & 67,5 & 223 & 890 \\
\hline Circón-130 & 630 & 7,5 & 2.560 & 16,7 & 0 & 89,2 & 0,22 & 4,54 & 9,9 & 1,14 & 63,7 & 20,7 & 245 & 85,4 & 384 & 668 & 128 & 10.480 & 41,3 & 1.440 & 1.190 \\
\hline Circón-131 & 1.550 & 13,1 & 1.570 & 4,65 & 23 & 75 & 7,8 & 41 & 12,3 & 0,54 & 35,2 & 11,1 & 138 & 54,5 & 247 & 473 & 94,5 & 11.600 & 47,5 & 298 & 624 \\
\hline Circón-132 & 500 & 9,4 & 1.080 & 8,7 & 0,3 & 8,66 & 0,22 & 3,07 & 2,57 & 0,88 & 16 & 6,72 & 87 & 34,7 & 181 & 515 & 112 & 14.300 & 58,8 & 69 & 1.590 \\
\hline Circón-133 & 70 & 11,8 & 1.270 & 1 & 0 & 6,26 & 0,07 & 2,1 & 4,02 & 0,44 & 28,5 & 9,25 & 111 & 42,7 & 192 & 368 & 73,7 & 10.600 & 48 & 78,2 & 174 \\
\hline Circón-134 & 960 & 10,5 & 3.960 & 32,8 & 0,44 & 31,4 & 0,32 & 3,1 & 6,7 & 0,66 & 46,3 & 22 & 307 & 133 & 680 & 1.600 & 344 & 15.600 & 170 & 666 & 2.400 \\
\hline Circón-135 & 470 & 9,8 & 1.670 & 4,4 & 0,09 & 23,6 & 0,14 & 1,52 & 4,8 & 1,03 & 30,2 & 11,1 & 143 & 58,7 & 267 & 526 & 106 & 14.100 & 35,3 & 243 & 503 \\
\hline Circón-136 & 2.080 & 7,8 & 6.510 & 21,2 & 0,14 & 79,9 & 0,31 & 5,16 & 15,7 & 1,58 & 121 & 46,1 & 583 & 224 & 1.007 & 1.800 & 350 & 12.200 & 79,3 & 2.030 & 2.570 \\
\hline Circón-137-MIA-627A & 820 & 7,7 & 2.100 & 17,8 & 0,05 & 3,87 & 0,01 & 0,23 & 1,24 & 0,15 & 14 & 9,1 & 150 & 66,9 & 375 & 1.220 & 270 & 16.100 & 68,5 & 81 & 2790 \\
\hline \multicolumn{22}{|c|}{ MIA-630B } \\
\hline Circón-138-MIA-630B & 349 & 8,83 & 765 & 1,24 & 0 & 11,2 & 0,01 & 0,39 & 1,67 & 0,2 & 11,3 & 4,56 & 59,3 & 25 & 123 & 257 & 55,1 & 12530 & 3,06 & 113,1 & 235 \\
\hline Circón-139 & 520 & 21,4 & 4.500 & 37,8 & 0,17 & 606 & 1,02 & 18 & 26,4 & 8,58 & 114 & 35,9 & 406 & 151 & 664 & 1.290 & 257 & 8.000 & 83 & 9.970 & 2.620 \\
\hline Circón-140 & 257 & 5,86 & 1.460 & 3,13 & 0,03 & 80,6 & 0,3 & 5,66 & 6,91 & 2,49 & 33 & 11 & 125 & 48,7 & 232 & 518 & 114 & 8.200 & 42 & 1.030 & 1.231 \\
\hline Circón-141 & 100 & 6,38 & 860 & 2,81 & 0 & 49,6 & 0,05 & 0,74 & 2,02 & 0,7 & 13 & 4,8 & 67 & 27,5 & 138 & 328 & 74,6 & 12.200 & 14 & 530 & 404 \\
\hline Circón-142 & 200 & 284 & 2.170 & 20,8 & 0,36 & 293 & 0,46 & 6,5 & 11,3 & 3,58 & 46,5 & 16,1 & 179 & 67,7 & 305 & 620 & 127 & 6.400 & 45,3 & 4.520 & 1.470 \\
\hline Circón-143 & 440 & 9,8 & 4.880 & 18,3 & 0,54 & 460 & 0,93 & 13,5 & 18,9 & 6,95 & 100 & 32,9 & 412 & 163 & 705 & 1.330 & 258 & 9.230 & 67,3 & 8.400 & 2.060 \\
\hline Circón-144 & 154 & 6,71 & 714 & 4,64 & 0 & 38 & 0,04 & 0,76 & 1,29 & 0,66 & 8,8 & 3,75 & 46 & 21,8 & 121 & 340 & 80 & 10.190 & 27,5 & 511 & 885 \\
\hline Circón-145 & 480 & 9 & 3.510 & 11 & 0,05 & 257 & 0,45 & 7,5 & 11,4 & 4,5 & 65,9 & 22 & 286 & 115 & 521 & 1.150 & 241 & 7.250 & 51,3 & 3.450 & 1.510 \\
\hline Circón-146 & 87 & 6,31 & 872 & 4,66 & 0 & 79,7 & 0,08 & 1,32 & 2,94 & 1,08 & 14,8 & 5,19 & 67,6 & 27,4 & 130 & 296 & 62,3 & 9.640 & 22,5 & 829 & 661 \\
\hline Circón-147 & 540 & 7,68 & 2.890 & 19,7 & 0,31 & 266 & 0,45 & 6,39 & 10,1 & 3,06 & 50,7 & 17 & 218 & 89,9 & 459 & 1.030 & 220 & 9.860 & 77 & 4.360 & 2.250 \\
\hline Circón-148 & 888 & 9,5 & 6.600 & 26 & 0,2 & 552 & 0,94 & 14,1 & 21,6 & 7,75 & 108 & 38,4 & 484 & 205 & 1.030 & 2.280 & 468 & 7.090 & 100 & 9.500 & 3.180 \\
\hline Circón-149 & 390 & 7,07 & 2.060 & 11,8 & 0,02 & 187 & 0,16 & 3,01 & 6,9 & 2,14 & 40,8 & 14,1 & 176 & 67,9 & 302 & 560 & 110 & 10.410 & 40,8 & 2.310 & 1.280 \\
\hline Circón-150 & 282 & 7,87 & 1.850 & 11,9 & 0,1 & 184 & 0,32 & 4,51 & 6,43 & 2,81 & 31 & 10,8 & 133 & 56,3 & 289 & 757 & 171 & 7.990 & 42 & 2.400 & 1.280 \\
\hline Circón-151 & 377 & 7,7 & 2.940 & 9,84 & 0 & 218 & 0,21 & 4,23 & 8,06 & 2,9 & 48,7 & 18,3 & 235 & 92,7 & 426 & 855 & 169 & 8.590 & 42 & 2.890 & 1.270 \\
\hline Circón-152 & 693 & 6,55 & 4.280 & 13,9 & 0,01 & 248 & 0,25 & 4,26 & 9 & 3,11 & 68,7 & 25,1 & 335 & 139 & 647 & 1.300 & 265 & 9.680 & 67,8 & 4.290 & 2.030 \\
\hline Circón-153 & 240 & 6,07 & 900 & 3,05 & 0,08 & 58,9 & 0,11 & 1,27 & 2,08 & 0,96 & 12,1 & 4,72 & 60,1 & 25,8 & 129 & 314 & 72,2 & 13.800 & 34,5 & 740 & 1.040 \\
\hline Circón-154 & 317 & 10,1 & 2.920 & 24,6 & 0,08 & 438 & 0,85 & 13 & 18,1 & 6,86 & 75,1 & 23,9 & 264 & 94 & 407 & 790 & 156 & 8.780 & 74,8 & 8.800 & 2.270 \\
\hline Circón-155 & 342 & 13,5 & 1.950 & 15,4 & 4,91 & 203 & 3,13 & 22,5 & 12,9 & 3,1 & 47,3 & 13,4 & 154 & 62,7 & 287 & 608 & 128 & 7.990 & 170 & 36.600 & 5.290 \\
\hline
\end{tabular}




\begin{tabular}{|c|c|c|c|c|c|c|c|c|c|c|c|c|c|c|c|c|c|c|c|c|c|}
\hline (ppm) & P & $\mathrm{Ti}$ & $Y$ & Nb & La & $\mathrm{Ce}$ & $\mathrm{Pr}$ & $\mathrm{Nd}$ & Sm & $\mathrm{Eu}$ & Gd & Tb & Dy & Ho & Er & Yb & Lu & $\mathrm{Hf}$ & $\mathrm{Pb}$ & Th & u \\
\hline Circón-156 & 311 & 12 & 3.590 & 32 & 0,2 & 540 & 0,76 & 11,4 & 19,5 & 7,61 & 89,5 & 28,1 & 323 & 119 & 505 & 957 & 188 & 7.670 & 89,5 & 8.430 & 2.560 \\
\hline Circón-157 & 250 & 32,8 & 2.280 & 5,63 & 0,1 & 136 & 0,42 & 6,5 & 9,5 & 3,1 & 43,9 & 14,4 & 183 & 72,7 & 332 & 65 & 162 & 8.850 & 23,2 & 1.520 & 759 \\
\hline Circón-158 & 50 & 7,13 & 606 & 2,11 & 0,06 & 42,9 & 0,11 & 1,45 & 1,78 & 0,71 & 11,9 & 4 & 47,6 & 18,8 & 92 & 218 & 52,1 & 13.100 & 27 & 630 & 840 \\
\hline Circón-159 & 550 & 6,94 & 7.090 & 16,9 & 0,31 & 496 & 2,4 & 32,6 & 43,3 & 14,6 & 181 & 55,6 & 632 & 231 & 1.020 & 1.920 & 375 & 8.430 & 60,3 & 6.190 & 1.810 \\
\hline Circón-160 & 620 & 29,8 & 4.140 & 15,6 & 0,05 & 286 & 0,21 & 4,61 & 9,5 & 3,39 & 67,5 & 25,5 & 319 & 128 & 585 & 1150 & 229 & 8.050 & 43 & 3.070 & 1.360 \\
\hline Circón-161 & 540 & 8,4 & 3.110 & 14,7 & 0,47 & 286 & 0,46 & 5,8 & 10 & 3,58 & 60,6 & 19,9 & 255 & 97 & 452 & 950 & 192 & 7.500 & 63,5 & 5.500 & 2.020 \\
\hline Circón-162 & 560 & 9,19 & 5.540 & 33,1 & 0,08 & 629 & 0,9 & 14,2 & 24,3 & 8,64 & 116 & 39 & 464 & 175 & 773 & 1470 & 284 & 8.210 & 103 & 10.330 & 3.030 \\
\hline Circón-163 & 400 & 9 & 2.170 & 8,02 & 0,08 & 167 & 0,15 & 2,56 & 6,8 & 2,52 & 34,3 & 12,4 & 163 & 66,9 & 318 & 674 & 145 & 8.400 & 33,8 & 1.890 & 1.000 \\
\hline Circón-164 & 31 & 6,89 & 1.560 & 5,9 & 0 & 94,2 & 0,09 & 1,55 & 4,35 & 1,41 & 24,7 & 9,81 & 127 & 50,4 & 224 & 458 & 91,7 & 10.580 & 16,1 & 684 & 477 \\
\hline Circón-165 & 130 & 7,6 & 1.010 & 8,3 & 0,81 & 66 & 0,41 & 2,54 & 2,89 & 1,09 & 12,5 & 4,63 & 59,7 & 28,7 & 159 & 458 & 120 & 8.400 & 72 & 2.630 & 2.050 \\
\hline Circón-166 & 412 & 9,6 & 3.620 & 27,6 & 0,02 & 531 & 0,58 & 8,44 & 17,1 & 6,57 & 84,2 & 27,7 & 320 & 121 & 517 & 977 & 186 & 8.990 & 86,5 & 7.610 & 2.580 \\
\hline Circón-167 & 105 & 6,21 & 1.060 & 6,48 & 0,02 & 94,5 & 0,08 & 1,24 & 3,29 & 1,15 & 19,7 & 6,95 & 85 & 34,8 & 160 & 341 & 75,4 & 9.500 & 47,3 & 1.600 & 1.440 \\
\hline Circón-168 & 197 & 6,64 & 1.110 & 4,82 & 0,04 & 92,6 & 0,26 & 3,5 & 5,25 & 1,96 & 23,7 & 7,82 & 93 & 36 & 162 & 346 & 78,5 & 9.400 & 63,5 & 1.420 & 1.900 \\
\hline Circón-169 & 1.060 & 11,3 & 4.230 & 14,6 & 1,61 & 317 & 1,09 & 12,3 & 15,6 & 5,34 & 79,5 & 27,6 & 340 & 137 & 639 & 1.390 & 291 & 6.800 & 65 & 6.620 & 1.970 \\
\hline Circón-170 & 193 & 6,66 & 1.930 & 8,21 & 0,03 & 162 & 0,28 & 3,66 & 6,62 & 2,42 & 37,7 & 13,1 & 159 & 63,9 & 300 & 659 & 143 & 9.290 & 46,5 & 2.070 & 1.420 \\
\hline Circón-171 & 366 & 13,7 & 3.950 & 40,8 & 0,05 & 562 & 0,79 & 11,4 & 20,3 & 6,98 & 95,2 & 30,7 & 353 & 132 & 565 & 1.075 & 209 & 8.650 & 87,3 & 7.860 & 2.510 \\
\hline rcón-172-MIA-630B & 248 & 7,64 & 1.480 & 12,9 & 0,15 & 199 & 0,33 & 4,4 & 6,02 & 2,73 & 29,9 & 10,4 & 126 & 45,4 & 214 & 470 & 107 & 9.360 & 66 & 2790 & 2050 \\
\hline \multicolumn{22}{|c|}{-128A } \\
\hline $\begin{array}{l}\text { Circón-036-AMC } \\
012 B\end{array}$ & 139 & 7,42 & 576 & 3,94 & 0 & 10,9 & 0 & 0,2 & 0,54 & 0,12 & 5,5 & 2,56 & 37,4 & 17,4 & 96,1 & 278 & 64,7 & 12670 & 115 & 39 & 652 \\
\hline Circón-037 & 4.120 & 31,8 & 2.221 & 6,35 & 6,13 & 44,8 & 3,03 & 19 & 12,7 & 1,1 & 46,6 & 16,1 & 196 & 75,2 & 345 & 714 & 147 & 12.030 & 48 & 431 & 513 \\
\hline Circón-038 & 433 & 6,76 & 2.094 & 13,2 & 0,14 & 20,3 & 0,13 & 1,07 & 3,77 & 0,63 & 27,5 & 12 & 166 & 71,4 & 344 & 748 & 153 & 12.540 & 72,2 & 432,7 & 903 \\
\hline Circón-039 & 10.200 & 75 & 1.300 & 3,76 & 10,6 & 50,9 & 5,7 & 32,1 & 18,5 & 1,72 & 41,2 & 13,1 & 129 & 42,5 & 183 & 373 & 78,9 & 12.400 & 31,1 & 217,4 & 399 \\
\hline Circón-040 & 544 & 9,43 & 1.758 & 2,8 & 0,43 & 24,4 & 0,27 & 3,87 & 7,17 & 1,11 & 37,8 & 13,6 & 157 & 60,8 & 274 & 523 & 106 & 11.170 & 19,1 & 238,2 & 241 \\
\hline Circón-041 & 394 & 8,42 & 1.470 & 6,27 & 0 & 33,6 & 0,09 & 1,8 & 3,9 & 0,64 & 24,4 & 9,53 & 122 & 49,4 & 230 & 462 & 92,5 & 11.180 & 31,2 & 389,9 & 387 \\
\hline Circón-042 & 328 & 7,44 & 1.604 & 9,17 & 0 & 34,2 & 0,08 & 1,38 & 3,86 & 0,7 & 27,2 & 10,4 & 133 & 53,2 & 254 & 535 & 110 & 11.220 & 47,9 & 572 & 534 \\
\hline Circón-043 & 782 & 10,5 & 4.980 & 52,8 & 0,03 & 55,9 & 0,31 & 5,21 & 12,7 & 1,99 & 86,9 & 34 & 427 & 175 & 806 & 1.728 & 337 & 11.370 & 220 & 2033 & 2940 \\
\hline Circón-044 & 230 & 16 & 1.108 & 5,61 & 0,1 & 11,5 & 0,04 & 0,53 & 1,84 & 0,44 & 13,7 & 5,7 & 82,1 & 35,2 & 183 & 452 & 98,1 & 12.370 & 26,9 & 150,1 & 410 \\
\hline Circón-045 & 148 & 5,81 & 807 & 3,24 & 0 & 7,14 & 0,01 & 0,49 & 1,65 & 0,24 & 11,5 & 4,6 & 59,8 & 26,2 & 133 & 319 & 70,5 & 13.840 & 21,6 & 122,7 & 347 \\
\hline Circón-046 & 464 & 9,6 & 1.911 & 3,21 & 0,04 & 20,7 & 0,22 & 3,93 & 7,05 & 1,23 & 37,9 & 13,4 & 165 & 65,1 & 301 & 614 & 126 & 11.130 & 22,3 & 265 & 289 \\
\hline Circón-047 & 187 & 6,91 & 960 & 4,41 & 0 & 16,4 & 0,03 & 0,9 & 1,75 & 0,32 & 12,4 & 5 & 71,6 & 30,4 & 154 & 385 & 85 & 11.760 & 32,8 & 250 & 417 \\
\hline Circón-048 & 345 & 7,5 & 1.053 & 5,6 & 1,38 & 18,7 & 0,51 & 2,89 & 2,11 & 0,38 & 13,1 & 5,69 & 77,6 & 34 & 176 & 440 & 93,1 & 12.690 & 46,1 & 305,9 & 574 \\
\hline Circón-049 & 190 & 6,87 & 1.051 & 4,76 & 0 & 18,9 & 0,03 & 0,77 & 2,29 & 0,34 & 13,6 & 5,86 & 77,2 & 34,1 & 170 & 396 & 84,3 & 12.230 & 41,2 & 378 & 509 \\
\hline Circón-050 & 410 & 7,18 & 1.722 & 16,2 & 0,35 & 19,4 & 0,16 & 1,41 & 2,07 & 0,3 & 18,6 & 8,92 & 125 & 55,7 & 285 & 691 & 147 & 13.490 & 91,1 & 489,6 & 1181 \\
\hline Circón-051 & 452 & 11,1 & 2.812 & 5,09 & 0,14 & 40,5 & 0,38 & 5,75 & 10,2 & 1,91 & 58,2 & 20,7 & 248 & 96,8 & 438 & 853 & 171 & 10.110 & 31,6 & 459 & 407 \\
\hline Circón-052 & 381 & 6,83 & 2.240 & 21,7 & 0 & 40,7 & 0,05 & 1,4 & 5,03 & 0,6 & 30,8 & 12,3 & 174 & 73,6 & 364 & 826 & 173 & 13.600 & 111 & 751 & 1440 \\
\hline Circón-053 & 260 & 176 & 1.680 & 10,6 & 0,07 & 21,8 & 0,18 & 2,04 & 3,73 & 0,81 & 25,1 & 9,59 & 129 & 55,8 & 273 & 609 & 132 & 11.030 & 37,3 & 243 & 458 \\
\hline Circón-054 & 550 & 25,4 & 3.730 & 10,5 & 0,21 & 95 & 0,52 & 10,1 & 15,6 & 3,14 & 91 & 29,6 & 349 & 129 & 565 & 1.000 & 193 & 10.240 & 54 & 1160 & 636 \\
\hline Circón-055 & 561 & 7,47 & 2.229 & 6,96 & 0,37 & 27,4 & 0,26 & 2,08 & 5,22 & 0,78 & 35,5 & 13,6 & 180 & 73,9 & 359 & 752 & 156 & 12.190 & 55,2 & 438 & 662 \\
\hline Circón-056 & 341 & 6,41 & 786 & 3 & 0 & 15 & 0,02 & 0, & 1,73 & 0,22 & 10,4 & 4,29 & 59,8 & 25,5 & 128 & 307 & 67,4 & 12.240 & 26,9 & 174 & 93 \\
\hline Circón-057 & 393 & 8,06 & 1.696 & 8,37 & 0,06 & 31,6 & 0,12 & 1,75 & 4,42 & 0,92 & 26,9 & 10,8 & 138 & 56,2 & 276 & 587 & 123 & 11.720 & 52,4 & 636 & 661 \\
\hline Circón-058 & 70 & 18,2 & 2.688 & 12,1 & 0,36 & 53,5 & 0,23 & 2,64 & 6,21 & 1,12 & 41,4 & 16,5 & 211 & 88,8 & 429 & 953 & 202 & 11.980 & 91,5 & 24 & 1117 \\
\hline Circón-059 & 409 & 7,01 & 1.635 & 6,72 & 0,02 & 41,5 & 0,11 & 2,2 & 4,61 & 0,68 & 25,3 & 9,75 & 127 & 52,7 & 260 & 571 & 122 & 11.440 & 42,8 & 473,9 & 540 \\
\hline Circón-060 & 212 & 6, & 1.653 & 8,08 & 0 & 26,3 & 0,05 & 0, & 3,14 & 0,59 & 22,9 & 9,15 & 124 & 53,3 & 270 & 625 & 135 & 12.590 & 59,4 & 542 & 748 \\
\hline Circón-061 & 251 & 6,74 & 1.188 & 5,82 & 0 & 19,2 & 0,02 & 0,83 & 2,12 & 0,54 & 15,3 & 6,27 & 84,9 & 37,7 & 193 & 475 & 104 & 12.230 & 39 & 302,4 & 485 \\
\hline Circón-062 & 192 & 6,79 & 969 & 4,78 & 0 & 17,4 & 0,02 & 0,68 & 1,48 & 0,36 & 13,2 & 5,18 & 69,4 & 31,4 & 160 & 388 & 86,3 & 12.500 & 29,6 & 212,9 & 384 \\
\hline Circón-063 & 398 & 7,25 & 1.075 & 5,11 & 0,88 & 18,2 & 0,26 & 1,71 & 1,63 & 0,35 & 13 & 5,79 & 78,6 & 34,7 & 180 & 440 & 96,4 & 12.800 & 44,7 & 246,7 & 553 \\
\hline Circón-064 & 182 & 6,03 & 832 & 3,41 & 0,03 & 13,4 & 0,01 & 0,51 & 1,14 & 0,29 & 9,91 & 3,99 & 59,2 & 25,7 & 136 & 349 & 78,3 & 12.600 & 33,7 & 188,7 & 412 \\
\hline Circón-065 & 196 & 6,93 & 1.060 & 5,13 & 0 & 16,6 & 0,07 & 1,12 & 2,67 & 0,63 & 16,6 & 6,15 & 79,1 & 34,3 & 172 & 388 & 81,4 & 13.600 & 42,3 & 191 & 566 \\
\hline Circón-066 & 391 & 7,49 & 1.266 & 5,48 & 0 & 23,4 & 0,04 & 0,94 & 2,5 & 0,56 & 17,3 & 7,34 & 97,1 & 41,1 & 205 & 463 & 101 & 11.210 & 26,6 & 227,9 & 321 \\
\hline Circón-067 & 338 & 8,7 & 3.062 & 8,63 & 0,13 & 34,2 & 0,27 & 4,84 & 10,5 & 1,58 & 50,2 & 19,4 & 241 & 99,7 & 480 & 1.093 & 238 & 10.560 & 76,2 & 1120 & 1098 \\
\hline Circón-068 & 2.090 & 15 & 1.158 & 5,49 & 12,4 & 45 & 4 & 22,3 & 5,8 & 0,62 & 16,6 & 5,98 & 83,3 & 36,8 & 195 & 488 & 110 & 12.640 & 38,7 & 200 & 465 \\
\hline Circón-069 & 220 & 6,44 & 1.172 & 7,21 & 0 & 14,9 & 0,02 & 0,54 & 1,68 & 0,39 & 12,9 & 5,82 & 83,9 & 37,7 & 195 & 464 & 99,6 & 12.680 & 43,6 & 267,3 & 561 \\
\hline :on- & 391 & 8,88 & 1.720 & 3,32 & 0 & 18,9 & 0,14 & 2,87 & 6,18 & 1,02 & 36,4 & 12,5 & 155 & 60,5 & 265 & 484 & 97,4 & 10.430 & 15,5 & 185 & 193 \\
\hline
\end{tabular}

